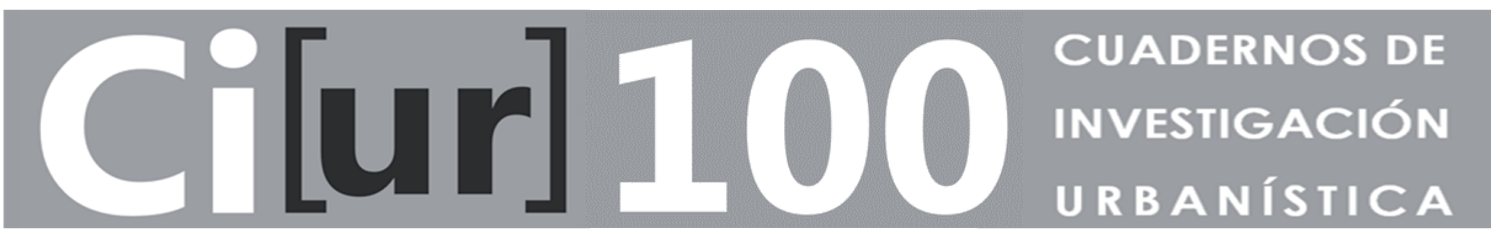

\title{
CIEN NÚMEROS DE CUADERNOS DE INVESTIGACIÓN URBANÍSTICA
}

\section{DEPARTAMENTO DE URBANÍSTICA Y ORDENACIÓN DEL TERRITORIO}

(ETSAM-UPM)

Mayo / Junio 2015 


\begin{tabular}{|c|c|}
\hline Director: & José Fariña Tojo \\
\hline \multicolumn{2}{|c|}{ Consejo de Redacción: } \\
\hline Director & Ester Higueras García \\
\hline Jefe de redacción & María Emilia Román López \\
\hline Vocales & $\begin{array}{l}\text { Julio Alguacil Gómez (Univ. Carlos III de Madrid), Pilar Chías Navarro (Univ. Alcalá } \\
\text { de Henares, Madrid), José Antonio Corraliza Rodríguez (Univ. Autónoma de } \\
\text { Madrid), Alberto Cuchí Burgos (Univ. Politécnica de Cataluña), José Fariña Tojo } \\
\text { (Univ. Politécnica de Madrid), Agustín Hernández Aja (Univ. Politécnica de Madrid), } \\
\text { Mariam Leboreiro Amaro (Univ. Politécnica de Madrid), Rafael Mata Olmo (Univ. } \\
\text { Autónoma de Madrid), Fernando Roch Peña (Univ. Politécnica de Madrid), Carlos } \\
\text { Manuel Valdés (Univ. Carlos III de Madrid) }\end{array}$ \\
\hline Consejo Asesor: & $\begin{array}{l}\text { Ma Teresa Arredondo (Directora de Relaciones con Latinoamérica, Univ. } \\
\text { Politécnica de Madrid), Luis Maldonado (Director de la Escuela Superior de } \\
\text { Arquitectura, Univ. Politécnica de Madrid), Antonio Elizalde, Julio García Lanza, } \\
\text { Josefina Gómez de Mendoza, José Manuel Naredo, Julián Salas, Fernando de Terán }\end{array}$ \\
\hline Comité Científico: & 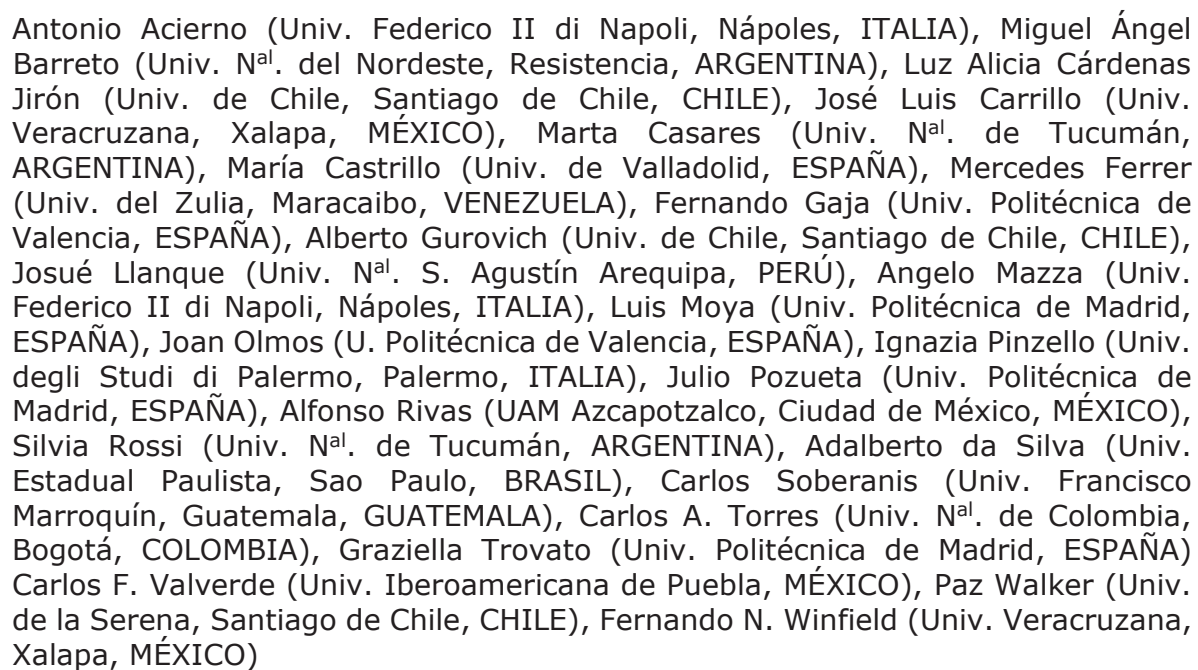 \\
\hline
\end{tabular}

Maquetación: Antonio Jesús Antequera Delgado: ciur.urbanismo.arquitectura@upm.es

Distribución: Mairea Libros: distribucion@mairea-libros.com

\section{COPYRIGHT 2015}

\section{DE LOS AUTORES DE LOS ARTÍCULOS}

I.S.S.N. (edición impresa): 1886-6654

I.S.S.N. (edición digital): 2174-5099

Año VIII, Núm. 100, mayo-junio 2015, 150 págs.

Edita: Instituto Juan de Herrera

Imprime: FASTER, San Francisco de Sales 1, Madrid 


\section{DESCRIPTORES:}

Edición especial / retrospectiva estudios urbanos / planeamiento y enseñananza / Urbanismo y crisis / sostenibilidad / enseñanza del urbanismo

\section{KEY WORDS:}

Special Issue / Urban Studies retrospective / Urban planning and teaching methodologies / Town Planning in time of crisis / sustainability / town planning teaching

\section{RESUMEN:}

El presente número supone una edición especial conmemorativa por los cien números alcanzados por los Cuadernos de Investigación Urbanística - Ci[ur]. A lo largo de las siguientes páginas se recogen una serie de breves artículos en los que diferentes profesores del Departamento de Urbanística y Ordenación del Territorio de la ETSAM, reflexionan sobre el estado actual de los estudios urbanos y pasan revista a algunos de los principales hechos que han tenido lugar en este campo en los últimos veinte años cuando se inició la serie Ci[ur]. Se trata pues de una retrospectiva, no enfocada desde la nostalgia sino desde la ilusión y el ánimo de que este número suponga el pistoletazo de salida de, como mínimo, otros cien números más.

\section{ABSTRACT:}

The present paper constitutes a special issue for the one hundred numbers reached by Cuadernos de Investigación Urbanística - Ci[ur]. Throughout the following pages, different professors from the Deparment of Regional and Town Planning of ETSAM, review the current situation of urban studies, as well as the main events that have taken place during the last twenty years, just when $\mathrm{Ci}[\mathrm{ur}]$, was published by the very first time. Therefore this is a restrospective, not made from nostalgia but from the enthusiasm and the hope of making this issue the kick-off for, at least, another onehundred issues to come. 


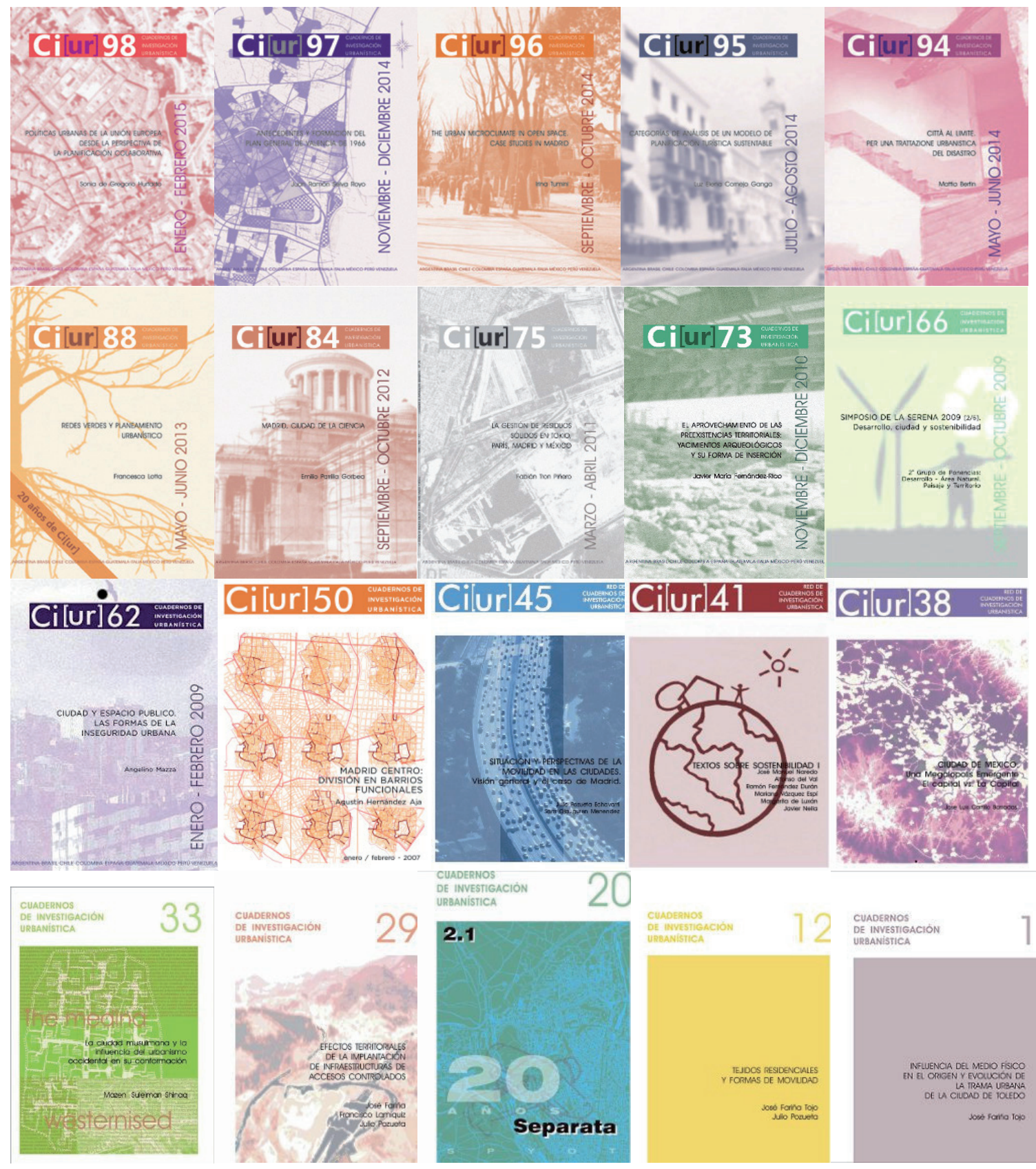

Figura 0. Una pequeña representación de los 100 números publicados entre 1993 y 2015 Fuente: Antonio Antequera

CONSULTA DE NÚMEROS ANTERIORES/ACCESS TO PREVIOUS WORKS:

La presente publicación se puede consultar en color en formato pdf en la dirección:

This document is available in pdf format and full colour in the following web page:

http://www2.aq.upm.es/Departamentos/Urbanismo/institucional/publicaciones/ciur/ 


\section{ÍNDICE}

Editorial...

La regulación jurídica de la transformación de la ciudad

Enrique Bardají Álvarez

Urbanismo, ciencia y evolución

Felipe Colavidas Espinosa

Nulidad parcial del PGOU 97. implicaciones de las sentencias del Tribunal

Superior de Justicia y del Tribunal Supremo para la ciudad de Madrid

Rafael Córdoba Hernández

Una reflexión crítica sobre la trasposición de la política urbana de la Unión

Europea al marco español

Sonia de Gregorio Hurtado..

Mecanismos urbanísticos y gestión pública en el ejercicio del derecho constitucional a una vivienda digna

Enrique de la Villa Polo.

Sobre la necesidad de armonizar las leyes urbanísticas de las CC. AA.

Abel Enguita Puebla.

Esplendor y ocaso de la sostenibilidad

José Fariña Tojo.

El futuro de los estudios de futuro en la planificación urbana y territorial

José Miguel Fernández Güell.

Migraciones globales y ciudad

Fernando Fernández

Ánimo y dedicación

Julio García Lanza

Habitabilidad básica en la enseñanza

Belén Gesto

Que treinta años no es nada... o sí: el abandono continuado de los barrios de la periferia histórica

Isabel González .

El planeamiento como imagen necesaria de la transformación social

Agustín Hernández Aja.....

Barrios saludables

Ester Higueras García

El planeamiento urbanístico, de la seguridad a la incertidumbre

Marian Leboreiro Amaro 
La ciudad fallida

Juan Miguel Morell y Fuentes.

Los antecedentes franquistas de la política de la vivienda social

Luis Moya González.

Un episodio relevante: burbuja especulativa y crisis inmobiliaria en perspectiva

José Manuel Naredo.

Cultura y políticas de rehabilitación y valorización de los centros históricos

Francisco Pol Méndez.

Rasgos urbanísticos del crecimiento residencial asociado a la burbuja inmobiliaria, 1995-2006

Julio Pozueta Echávarri

Expandirse cuando se encoge. La catastrófica paradoja del urbanismo madrileño Fernando Roch Peña. 95

Modelo urbano y litoral: una asignatura pendiente

Raquel Rodríguez Alonso

La evolución conceptual del planeamiento y la legislación urbanística actual Luis Rodríguez-Avial Llardent.

La torre de Babel

María José Rodríguez-Tarduchy

Paisajes de la crisis: problemas y oportunidades

Emilia Román López.

Elogio de la intuición:la Colonia Lukiškès en Vilnius, Lituania (1911-13)

Javier Ruiz Sánchez

A las puertas de Hábitat III

Julián Salas

Lo común y su desmantelamiento

Álvaro Sevilla Buitrago.

La consolidación del proceso de generación de desigualdad social en los sistemas urbanos contemporáneos. La ciudad negocio

Alejandro Tamayo Palacios..

El sueño de los pescadores de perlas

Lucila Urda Peña

Conocimiento ciudadano e investigación urbanística

Carlos Verdaguer Viana-Cárdenas 


\section{EDITORIAL: 100 números de Ci[ur]}

Cuadernos de Investigación Urbanística empezó su andadura en el año 1993. Ese año dos profesores del Departamento de Urbanística y Ordenación del Territorio, José Fariña y Julio Pozueta, propusieron al Consejo la publicación de los trabajos de investigación que en aquellos momentos se estaban realizando en dicho Departamento. La financiación con que se contaba era escasa y la edición modesta, pero se cumplían todos los requisitos legales de forma que se defendieron desde el principio los derechos de los autores, se hizo el depósito legal y se le asignó un ISBN. La organización de cada número era muy parecida a la actual con su correspondiente resumen en español e inglés, palabras clave, índice, bibliografía, etc.

Tres años después, en 1996 se empezaron a pasar a formato digital y se aprovechó también para digitalizar los primeros números de los que se hizo una segunda edición. La editorial pasó a ser el Instituto Juan de Herrera.

Desde aquellos comienzos en el año 1993 han transcurrido 22 años en los que el urbanismo y la ordenación del territorio han sufrido cambios muy importantes. La propia publicación también. No sólo en sus contenidos sino también en otras muchas cosas. Desde aspectos puramente formales hasta su conversión en revista, cambiando los primitivos ISBN por los actuales ISSN tanto en su edición electrónica como digital. Esta conversión se produjo en el año 2007 con ocasión de la aparición del número 48. A partir de ese momento se empezó a tratar como una revista científica adoptándose progresivamente todas las condiciones para que pudiera ser considerada como tal. Desde la revisión por pares hasta la indización. Actualmente está controlada por Latindex, Urbandoc, Inrecs, Resh, Dice, Isoc y Dialnet. Se ha optado, además, por el formato electrónico aunque se editan algunos ejemplares en papel destinados a los depósitos legales, bibliotecas y autores.

Al principio uno de los motivos por los que se decidió la publicación de Ci[ur] fue para intentar potenciar la difusión en español de la investigación de trabajos relacionados con el Urbanismo y la Ordenación del Territorio. Sobre todo tesis doctorales que se leían pero que no se difundían adecuadamente. De forma que, además de publicar trabajos realizados sobre todo en el Seminario del Departamento, se publicaban partes o resúmenes de las tesis doctorales leídas en el mismo. Poco a poco se fueron añadiendo universidades de habla hispana hasta constituir lo que hoy es la Red de Universidades Asociadas. De forma que, en el momento actual, hasta veinticuatro universidades de todo el mundo están asociadas a Ci[ur]. Y ya no solo se publica en español. De hecho, el Ci[ur]94 está en italiano y el Ci[ur]96 en inglés.

Casi todos los números están dedicados a un único trabajo lo que permite exponerlo con una extensión muy superior a la de la mayoría de las revistas de investigación. Esta ha sido una de las señas de identidad de Ci[ur] que sólo en algunos números se ha cambiado: el 20 (dedicado a los 20 años de actividad del Seminario de Investigación del departamento SPyOT), el 37 y el 47 (Informes anuales de las Universidades de la Red), los 41 y 42 (textos sobre sostenibilidad), y del 65 al 70 (Simposio de La Serena). A partir de este número correspondiente al año 2009 todos han sido monográficos dedicados a un único trabajo hasta llegar al último. 
Cuando en el Consejo de Redacción se planteó la necesidad de destacar el hecho de haber alcanzado el número 100 se pensó, de inmediato, que sería interesante establecer una visión panorámica de la situación actual y los problemas que preocupan hoy a profesionales e investigadores del Urbanismo y la Ordenación del Territorio. De forma que se decidió invitar a todos los profesores del Departamento para que escribieran con libertad de aquel tema que les apeteciera con un formato libre y con la única condición de la extensión. Y este es el resultado. Repasando ahora los títulos de los artículos y lo nombres de los autores parece que ha sido una buena idea. Ya sólo un repaso del índice da idea del interés de haberlo hecho. Existen temas recurrentes que aparecen no sólo en el título sino en los contenidos, otros emergentes, otros indicativos de lo mucho que se ha hecho mal y de la herencia recibida, también algunos sobre lo que nos espera y los problemas que vienen.

En cualquier caso, en estos veintidós años hemos comprendido que estamos en el límite de las posibilidades del planeta y que, a partir de ahora, nada será igual en la organización de nuestras ciudades y territorios. También que, probablemente, sea necesario replantear todas las bases en las que se apoyaba la relación entre ciudadanos, técnicos y políticos para conseguir que los lugares en los que vivimos los construyamos entre todos y no entre unos pocos.

Es de justicia un recuerdo para todos los compañeros de camino que nos han acompañado a lo largo de estos años y que ya no están. A los estudiantes y a los becarios que han ayudado a que se haya podido llegar a publicar este número cien, con la esperanza de que, si algo así puede llegar a repetirse en el número 200, la panorámica de la hipotética situación de entonces sea más positiva y optimista que la actual. 


\title{
LA REGULACIÓN JURÍDICA DE LA TRANSFORMACIÓN DE LA CIUDAD
}

\author{
Enrique Bardají Álvarez (Arquitecto - Profesor Ad Honorem DUyOT)
}

Tengo para mí que nuestra disciplina, o mejor su aplicación práctica, no pasa por momentos fáciles. La regulación de lo que deba ser la ciudad o la intervención física en ella, se perciben por el "pensamiento colectivo publicado dominante" como actividades envueltas con el oscuro velo de lo turbio.

No siempre fue así. El conjunto de determinaciones técnicas y artísticas que exigía el crecimiento de las ciudades del XIX, iniciaron el cuerpo teórico del urbanismo y aun respondiendo a corrientes de la historia más o menos generosas con unos grupos sociales u otros, no fueron consideradas en su época como actividades de inmorales cuando no delincuentes. El conjunto de conocimientos relativos a la planificación, desarrollo, reforma y ampliación de los edificios y espacios de las ciudades que conocemos como urbanismo, perseguía la mejora de la vida de los ciudadanos.

Tanto en los planes de ensanche como en los de reforma interior, el peso del trazado (el plano) y las sucintas normas jurídicas que lo acompañaban orientaban el peso de la intervención en la ciudad hacia la resolución de los problemas técnicos (abastecimientos de servicios, eliminación de residuos, organización de la movilidad, etc...) y de los artísticos (caracterización del espacio público y de los edificios). Sin duda que la importancia de la propiedad del suelo y de su transformación económica condicionaba los trazados, pero no con la contundencia que hoy lo hace. El objetivo reconocido del urbanismo era la organización del futuro de la ciudad para la mejor vida en ella de los ciudadanos. El planeamiento perdió ya hace unos años (me atrevo a decir que al menos, desde la Ley de 1977) el objetivo que lo engendró como disciplina. Cada vez de forma más intensa, parece que el urbanismo español se sustancia por, al menos, tres circunstancias que lo han hecho complejo e ineficaz.

El primer aspecto que configura el urbanismo en España es la fijación del contenido del derecho inmobiliario de la propiedad como valor primordial, quedando como valores accesorios la viabilidad técnica, la razonabilidad económica, los principios culturales a potenciar o proteger, la belleza de la ciudad o el bienestar de los ciudadanos. No es que las exposiciones de motivos de las Leyes del Suelo o las Memorias de los Planes no hagan referencia y persigan objetivos en relación con los valores expuestos, sino que los textos normativos concretos están dirigidos, fundamentalmente, a describir con prolijidad (en cualquiera de sus acepciones admitidas incluida la de "impertinente, pesado, molesto") todos los mecanismos que hagan del planeamiento un instrumento para determinar cómo se benefician (o perjudican) de la transformación y el crecimiento de la ciudad cada uno de los propietarios registrales de la misma.

A esta regulación garantista del derecho de la propiedad del suelo se le suma la voluntad de describir y reglamentar con Leyes y Normas los procesos que permiten hacer realidad construida lo proyectado (procedimientos tecnológicos, ambientales, económicos, jurídicos, patrimoniales, etc...). Sin embargo, cada uno de estos procesos 
contiene especificidades diversas que la norma ha regulado desde sí mismos, convirtiendo cada subproceso en un cuerpo "científico" completo que se autoalimenta permanentemente sin considerar, con suficiente énfasis, su interrelación con otros procesos igualmente presentes en la formación de la ciudad.

Y si todo ello no fuera suficiente, en España, una absurda deriva identitaria y cantonalista ha permitido que mucho de lo particularísimo haya sido entendido como sustantivo, dando lugar a diferentes y pequeñas variaciones sobre los principios comunes que no hacen sino complicar más el campo regulatorio de la intervención en la ciudad generando no solo 17 Leyes diferentes del Suelo en un único Estado sino innumerables interpretaciones, modificaciones y variaciones de cada una de dichas Leyes. Y lo más grave, en mi opinión, es que estas orientaciones han argumentado perseguir (positivando cada acción sobre la ciudad como imprescindible para su regulación) un principio básico e irrenunciable del Estado de Derecho que es la "seguridad jurídica" como expresión del "ius gentium", derecho que el progreso de la civilización ha obtenido para los ciudadanos, superando el "ius naturale".

Sin embargo, creo que la plasmación jurídica del urbanismo español ha conseguido, por dispersión, opacidad, incorrección en la técnica jurídica de la regulación de técnicas científicas y contradicción entre normas, una gran "inseguridad jurídica". Esta orientación de nuestra normativa urbanística ha hecho de ella un farragoso Corpus Legal inescrutable. El conjunto de protocolos que se deducen de las infinitas normas existentes es inmanejable y solo se materializa en actos físicos concretos de intervención en la ciudad cuando se conculcan (invito a que se me presente cualquier intervención física en la ciudad de la que no pueda señalar un pequeño o gran incumplimiento de alguna de las normas que la regulan). Por ello intervenir en el planeamiento (como instrumento del urbanismo) es hoy una actividad propia de "espeleólogos jurídicos" que se adentran en la procelosa caverna de la Norma Urbanística deduciendo de sus infinitos vericuetos interpretaciones discutibles (y discutidas), que dificultan extraordinariamente la pacífica intervención en la ciudad. Los procesos de inmersión en la Norma Urbanística han dado cuerpo a un mundo profesional que ha legitimado con sus "hallazgos normativos" verdaderas conculcaciones de la Razón y, sin duda, ha creado el caldo de cultivo adecuado para la corrupción.

Podría deducirse, erróneamente, de las frases anteriores que preconizo la desaparición de la regulación normativa en las actuaciones sobre la ciudad. Nada más alejado de mi posición que la vuelta a una inexistencia de regulación de carácter medieval. Sin embargo, la situación actual es la Ley de la Selva, escondida, eso sí, bajo una regulación positiva que parece conceder a la Normativa Urbanística una honorabilidad jurídica de la que, en su conjunto, carece.

La superación de esta situación solo puede caminar por las reformas legales que unifiquen, coordinen, simplifiquen y prioricen aquellos objetivos que desde sus inicios ha perseguido el Urbanismo y que, con mayor o menor éxito, enseñamos en nuestras Universidades. La claridad es un elemento imprescindible (bien que no el único) para alcanzar una auténtica "seguridad jurídica". La marea política regeneracionista de nuestras Instituciones que las circunstancias históricas han desencadenado en nuestro país, debe incluir en su agenda la regeneración del Corpus Legal Urbanístico. Es el momento. 


\title{
URBANISMO, CIENCIA Y EVOLUCIÓN
}

\author{
Felipe Colavidas Espinosa (Dr. Arquitecto - Profesor titular DUyOT)
}

Para Paco Alonso; desde luego, por lo que dice, pero, sobre todo, por lo que hace: por la materialización de lo dicho.

La piedra angular del método científico es el postulado de la objetividad de la Naturaleza. Es decir, la negativa sistemática a considerar capaz de conducir a un conocimiento "verdadero" toda interpretación de los fenómenos dada en términos de causas finales, es decir de "proyecto". Se puede datar exactamente el descubrimiento de este principio. La formulación, por Galileo y Descartes, del principio de inercia, no fundaba sólo la mecánica, sino la epistemología de la ciencia moderna, aboliendo la física y la cosmología de Aristóteles.

Jacques Monod

Tener ideología no es tener ideas. Estas no son como las cerezas, sino que vienen sueltas, hasta el punto de que una misma persona puede juntar varias que se hallan en conflicto unas con otras. Las ideologías son, en cambio, como paquetes de ideas preestablecidos, conjuntos de tics fisionómicamente coherentes, como rasgos clasificatorios que se copertenecen en una taxonomía o tipología personal socialmente congelada.

Rafael Sánchez Ferlosio

En la atenta invitación de José Fariña a participar en el número conmemorativo de $\mathrm{CI}[\mathrm{ur}$ ], se manifiesta la intención de que esta centésima entrega de la revista sea, "solo por una vez", un número de opinión. Se expresa así la convicción de que el hecho de opinar es excepcional en la larga trayectoria de este foro de investigación urbanística.

Sin entrar ahora a validar o rebatir esta opinión, es irrefutable que, desde una dimensión estrictamente científica, la contraposición entre hechos y opinión resulta determinante. Ciertamente, el enfrentamiento ciencia versus creencia dividió radicalmente en dos el conocimiento humano, que había tenido su origen genuino en Grecia. El esencial descubrimiento de esta confrontación se debe a la ciencia nueva barroca -con Galileo, Bacon, Descartes y Newton a la cabeza- y al posterior acento empirista de la Ilustración escocesa. Como no podía ser de otra manera, esta nueva epistemología determina también el devenir del urbanismo.

De esto es de lo que preferentemente quiero tratar aquí ${ }^{1}$, pues en clara

${ }^{1}$ El contenido esencial de este artículo surge de mi antiguo interés intelectual -el que, en cierta forma, impulsó la redacción de mi tesis doctoral La ciudad pensada, 1990- por la comprensión completa de la habitabilidad general como hecho central de nuestro linaje. Desde hace años, vengo realizando con Isabel Bravo (arquitecta, ETSAM, 1995) un Tratado de habitabilidad, en redacción, algunas de cuyas cuestiones cruciales (la habitabilidad como elemento exógeno clave de la constitución y progresivo desarrollo de la naturaleza humana; su reconocimiento como hecho sensible material determinante de 
confrontación con el auténtico conocimiento científico, tengo a la sobreabundancia de ideología y opinión por el rasgo negativo más sobresaliente del urbanismo: el que más lastra y debilita su capacidad de clarificar la habitabilidad humana y de enfrentarse con la máxima eficacia a la mejora del territorio construido ${ }^{2}$. Este asunto no solo afecta a los tres últimos decenios, que esta revista nos acota como ámbito temporal de análisis, sino al tiempo transcurrido desde que se intentó por primera vez fundamentar la autonomía disciplinar, con las primeras propuestas rigurosas de creación de nueva ciudad (Cerdá, 1859) y de reestructuración de la existente (Haussmann, 1856). Y es que fue entonces cuando se trató de esbozar de forma sistemática el paso de una habitabilidad espontánea a otra más ordenada que, al hilo de esta nueva epistemología científica, aspiraba a materializarse bajo el principio de objetividad y la metodología propiciada por la experiencia y la lógica.

La habitabilidad espontánea ha dominado tanto nuestro pasado prehistórico nómada como el proceso histórico de urbanización que, con origen en la ciudad de las primeras civilizaciones, se ha desplegado en un elenco fáctico de morfologías urbanas universales -construidas sustantivamente sin proyecto- ${ }^{3}$ hasta desembocar en este intento novecentista de planificar la urbanización. Pero este primer esbozo científico/disciplinar, en lugar de haberse consolidado, está aún pendiente de realización. También la habitabilidad está lejos de haberse afirmado como categoría científica autónoma: en un sentido global, es el objeto de estudio específico del urbanismo y de la ordenación del territorio ${ }^{4}$, en la doble vertiente de primera gran función y de estructuras físicas que constituyen su soporte material construido. Se define como el conjunto de cualidades que adquiere todo territorio natural al ser transformado en un lugar verdaderamente ordenado y lleno de significación, útil al desarrollo de las diversas funciones y actividades que, en torno a las dos esenciales de producción y residencia, precisa la vida humana para garantizar su reproducción saludable y el morar próspero.

Por pertenecer también al campo de las artes, el urbanismo se extiende más allá de la dimensión empírica y positiva; y, por tanto, los procedimientos lógicos y experimentales han de ser, en muchos casos, compartidos con el método analógico en la vertiente del urbanismo-arte. Pero la dimensión objetiva del urbanismo es de

su existencia, o la reivindicación de su rango y categoría científica) quedan apuntadas en el presente texto. Parte singular, sustantiva e indisoluble de esa habitabilidad general es la habitabilidad básica, que inicié como materia independiente de docencia en el año 92 en el DUyOT-ETSAM, a la que se incorporó unos años después Julián Salas, y en la que ahora ultiman sus trabajos específicos tres doctorandos (Carlos Galán, Belén Gesto y Luis Perea) y también sus diversos proyectos y actividades algunos otros miembros destacados de nuestro grupo de CD-HaB-ETSA-UPM.

${ }^{2}$ Tengo a este urbanismo-ideología, de carácter especulativo, por el dominante, pero no único, claro; obviamente hay también otras formas honrosas de hacer urbanismo, que priman fundamentar sus conclusiones en datos y que nunca han faltado en la disciplina, aunque a mi juicio hayan sido siempre corrientes minoritarias.

3 Sin menoscabo de que, a efectos de su universalidad, sea preciso matizar el sesgo occidental que manifiestan las etapas finales (precisamente, las que surgen a partir del Renacimiento y la ciencia barroca) de esta sucesión de formas urbanas históricas que se sucedieron hasta la inauguración de la disciplina en el XIX, se identifica el siguiente elenco: ciudad arcaica, clásica, medieval, gótica, renacentista, barroca, neoclásica e industrial. Estos modelos históricos hacen referencia tanto a ciudades completas como a tejidos parciales de ellas.

${ }^{4} \mathrm{Y}$ del conjunto de otras muchas disciplinas que, como la ingeniería o la arquitectura, conciernen a la totalidad del sector de la construcción mundial. 
tal envergadura que resulta prioritario su sometimiento al arsenal metodológico de todas las ciencias, caracterizado por ser fáctico, racional, sistemático, objetivo, analítico y empírico ${ }^{5}$. En este sentido, llama la atención que no exista siquiera un acuerdo universal sobre la analítica rigurosa del espacio urbano ni sobre el consecuente glosario básico de términos que habrían de constituir la base instrumental necesaria mediante la que poder abordar los dos diferentes cometidos que está obligado a desempeñar la disciplina: el conocimiento teórico, ajustado al principio de objetividad, y el profesional, de intervención práctica sujeta a dicho conocimiento.

En el ámbito de la compresión, la tarea pendiente es proporcionar una imagen mental completa de la habitabilidad y de su crucial importancia en el desarrollo de nuestro linaje. Este conocimiento teórico precisa también ser abordado en su vertiente pragmática. Al hilo de promover el trabajo empírico, planteo aquí instituir una categoría específica -dentro de la más amplia de condiciones generales de vida, vigente en las ciencias sociales y humanas- que, bajo la denominación índice de habitabilidad, sintetice numéricamente tales condiciones en cada país o territorio, de manera similar a como lo hacen, en sus respectivas materias, el índice de desarrollo humano y la renta per cápita.

Me parece oportuno recordar aquí una de las más trascendentales polémicas ocurridas en el mundo de la cultura y la ciencia: la suscitada por la conferencia que C.P. Snow pronunció en Cambridge en 1959. En ella, se denunciaba la división del pensamiento occidental en dos culturas: una literaria o humanística y otra científica, separadas ambas por una barrera de desconocimiento y prejuicios mutuos; barrera a la que Snow achacaba muchas de las dificultades que ralentizan el progreso fáctico. Se abría así camino a la tercera cultura, acuñada por J. Brockman en $1995^{6}$. Es a este territorio donde urge llevar al urbanismo desde la primera cultura en la que mayoritariamente aún sigue ubicado: una posición no empírica, plagada de ideología, que a menudo confunde el análisis de los hechos con la adhesión voluntarista a principios mítico-abstractos. Para tratar de instituir la habitabilidad como categoría científica, el reto está en lograr incardinar el urbanismo dentro de la teoría darwiniana de la evolución -más en concreto, dentro del neodarwinismo ${ }^{7}-$ : el modelo explicativo unificado más veraz que, quizá, ha existido nunca.

Es en dicha teoría explicativa donde la habitabilidad se constituye, en cuanto medio y entorno artificial, como un concepto exclusivo de nuestro linaje humano. Si el resto de las especies se adaptan sustantivamente sin proyecto al medio natural, la nuestra es la única que adapta, sustantiva y voluntariamente, el medio a sus propios intereses. Es en esta condición de entorno artificial donde la habitabilidad destaca

\footnotetext{
5 Tomo así distancia de otro tipo de propuestas especulativas que nunca han sido -al menos, en lo que yo conozco- mínimamente desarrolladas más allá de su nominación, como la de un posible método holístico.

6 También a los trabajos de A. Sokal y J. Bricmont sobre Imposturas intelectuales y a los de la institución Edge: un territorio en el que se reconoce a los científicos y los pensadores del mundo empírico su papel para explicar significados vitales profundos que antes se habían dejado exclusivamente en manos de los intelectuales tradicionales, de sesgo humanístico.

7 También denominada Síntesis Moderna de la Evolución, nacida en los años treinta del pasado siglo y afianzada con los avances actuales en genética.
} 
como el hecho más notorio de la producción tecnológico-cultural ${ }^{8}$ de nuestra especie.

Al efecto de poder llegar a entender este ajuste del medio natural al sujeto, habremos de situarnos en el clado que, hace unos siete millones de años, y al adoptar la postura erguida, nos distinguió del linaje filogenéticamente hermano. El bipedalismo, al dejar libres las manos, hizo posible el cambio alimenticio y propició la puesta en marcha del crecimiento estructural del cerebro, con todas sus consecuencias. Es en este marco conceptual donde la habitabilidad encuentra su base objetiva para poder alcanzar el mencionado rango científico. $Y$ es que, en cuanto entorno artificial, la habitabilidad constituye uno de los factores clave del éxito del Homo sapiens, pues resulta el elemento determinante tanto de la baja ininterrumpida de las tasas de mortalidad como, consecuentemente, del crecimiento demográfico.

Por otra parte, la habitabilidad constituye, en cuanto construcción del territorio, la columna vertebral económica del desarrollo material, y por ello, de la producción y el consumo de riqueza. Concierne a la reproducción de la propia fuerza de trabajo -a través de la residencia- y a la de las mercancías -en la producción propiamente dicha-, que, en cuanto es inversión en trabajo y capital fijo, viene transformando de forma sustantiva la superficie del planeta. Sin embargo, hay otra vertiente de la habitabilidad que trasciende lo material: es la capacidad de ese espacio construido para re-obrar sobre lo humano y hacernos, literalmente, a nosotros mismos. En cuanto constitutiva de civilización (ciudad) y cultura, la habitabilidad es capaz de transformar moral y físicamente a las personas. Ambos desarrollos quedan magistralmente recogidos en esta temprana intuición de Aristóteles: "La ciudad tiene su origen en la urgencia del vivir, pero persiste para el vivir bien, para la vida buena".

No quiero cerrar estas líneas sin reseñar un aspecto positivo del urbanismo en estas últimas décadas: con la revolución que ha supuesto el desarrollo de herramientas como Google Earth o Street View es posible disponer ya de información en tiempo real de planimetría de lugares remotos. En el ámbito de la enseñanza, especialmente en las asignaturas relacionadas con el desarrollo de habitabilidad básica, se ha hecho posible así el trabajo sobre territorios de los que hace tan solo unos lustros habría resultado muy costoso conseguir información. Esto supone una aportación crucial para realizar la elección adecuada del sitio de asentamiento: el primer y más importante de los cuatro pasos canónicos del proceso de urbanización expresado en la teoría de la habitabilidad ${ }^{9}$ que formalicé hace unos años, ampliando una vieja propuesta de Manuel Solá-Morales.

Más allá de su carácter operativo, cabe decir que este conjunto de herramientas nacidas de la revolución tecnológica ha transformado la médula de la disciplina, facilitando la consecución de una metodología propia de la ciencia: la primera aspiración de la que este escrito ha querido dejar constancia.

\footnotetext{
8 Agustín García Calvo definió el lenguaje como la Primera Gran Máquina que, en el ámbito mental, inmaterial, permite a la especie Homo sapiens construir el resto de máquinas. Al hilo, resulta fructífero considerar que la ciudad es la Segunda Gran Máquina, la más potente y determinante desde el punto de vista material, fáctico.

9 Las cuatro etapas canónicas de la teoría de la habitabilidad: 1) Elección del suelo adecuado, 2) Parcelación del primer orden que establece la división urbana en público y privado; 3) Urbanización del espacio público (RELP) y 4) Edificación de las parcelas residenciales y de dotaciones y equipamientos.
} 


\title{
NULIDAD PARCIAL DEL PGOU 97. IMPLICACIONES DE LAS SENTENCIAS DEL TRIBUNAL SUPERIOR DE JUSTICIA Y DEL TRIBUNAL SUPREMO PARA LA CIUDAD DE MADRID
}

\author{
Rafael Córdoba Hernández (Arquitecto - Profesor asociado DUyOT)
}

Si hay algo que, año tras año, no deja de sorprenderme es ver la cara de sorpresa que pone un alumno de planeamiento cuando se le explica que esa herramienta con la que llevan trabajando prácticamente todo el curso, que lleva un largo proceso de control, tanto ambiental como técnico y jurídico por parte de las distintas administraciones y que condiciona, de una u otra manera, el desarrollo y sostenibilidad del municipio estudiado, puede ser declarada nula. Y es que todavía hay inocencia en la futura profesión.

Y digo inocencia, porque todavía no han llegado a ese punto donde, como técnico, te ves presionado a buscar dobles (o triples) interpretaciones sobre una condición de una ordenanza, intentan que soslayes una evaluación ambiental, que te saltes a la torera una catalogación o que construyas más alturas de las que te permite la normativa, por encargo o demanda de terceros. Todavía confían que la ley tenga una única lectura.

Si ya de por si les resulta sorprenderte la anterior afirmación, cuando te piden un ejemplo y les comentas, desde la Escuela Técnica Superior de Arquitectura de Madrid, que la mayoría de ellos habitan sobre un ejemplo en sí mismo, las caras pasan de sorpresa a susto. $Y$ es que parece mentira que, no ya los estudiantes de urbanismo, sino los ciudadanos de esta gran urbe, desconozcan en su mayoría que teníamos (o tenemos) el planeamiento de nuestro municipio anulado en gran parte por varias sentencias judiciales.

El Plan General de Ordenación Urbana de Madrid (PGOUM 97) en breve cumplirá su mayoría de edad y hasta las elecciones pasadas de mayo de 2015 estaba en revisión con la intención de desembocar en un nuevo modelo, mucho más flexible, para la ciudad. Pero en esta ocasión no entraremos en la discusión de la flexibilidad de ese nuevo modelo y las desastrosas consecuencias que podría tener. Tan sólo nos disponemos a aclarar las cuestiones por las que fue anulado parcialmente para evitar caer en esos errores nuevamente.

En 1991, con la transformación del contexto socioeconómico y el cambio de orientación política del ayuntamiento, el PGOUM 85 sería desacreditado por limitar el crecimiento de la ciudad y con ello dificultar el acceso a la vivienda, por los problemas de movilidad y accesibilidad provocados por el aumento de actividad económica, por el deterioro del Casco Histórico, por la existencia de áreas industriales en ubicaciones centrales y por la pérdida de calidad urbana y ambiental de la capital.

Con la idea de subsanar esta serie de premisas nace un nuevo planteamiento bajo el paraguas de PGOUM 97. El Plan, entre otras actuaciones y propuestas planteaba una serie de desarrollos inmobiliarios que en su mayoría fueron los causantes de esa nulidad parcial que llegaría en 2003. Tienen ya nombres propios como los desarrollos del Este (Los Ahijones, Los Cerros o Los Berrocales), la Operación Campamento, la 
ampliación de la ciudad aeroportuaria de Barajas o algunos de los Programas de Actuación Urbanística ${ }^{10}$ (PAUs) diseñados por el equipo redactor. Una nulidad ocasionada porque muchos de estos desarrollos aprobados por la Comunidad de Madrid significaban la transformación de ámbitos de Suelo No Urbanizable de especial protección del planeamiento anterior, en Suelo Urbanizable. Algunas de las actuaciones puestas en entredicho afectaban a suelo protegido por especiales circunstancias en prácticamente la totalidad de su ámbito como eran los casos del Ensanche de San Fernando y Aravaca-La Escorzonera-Montes del Pilar, ambos con el $100 \%$ de su superficie afectada, o El Salobral-Nacional IV y Remate Suroeste Campamento, con más del $98 \%$ protegido.

El mismo año de su entrada en vigencia, se presentó un Recurso ContenciosoAdministrativo ante el Tribunal Superior de Justicia de Madrid impugnando la Aprobación Definitiva. En ella se alegaba la falta de justificación en la desaparición de la especial protección, en su mayoría ecológica, y el cambio de clasificación del suelo afectado. El 27 de febrero de 2003, el Tribunal Superior de Justicia de Madrid dictó Sentencia declarando nulas "aquellas determinaciones que suponían la desclasificación de terrenos clasificados en el Plan General de 1985 como Suelo No Urbanizable de Especial Protección". La falta de motivación que daban lugar a la eliminación de la protección de suelo no urbanizable y su reclasificación en suelo urbanizable quedaban claramente patentes.

La declaración apuntaba que los suelos que gozaban de alguna protección no se podían alterar mediante la determinación de nuevos espacios sin una justificación expresa y motivada de la desaparición de aquellos elementos o valores que fueron argumentados para plantear dicha protección. En este sentido, la nulidad afectaba a 28 ámbitos, incluyendo las iniciadas actuaciones de Montecarmelo, Las Tablas o Sanchinarro. Entre estos desarrollos se planteaban 34.300 viviendas en 1.010 Has.

El 3 de julio de 2007, el Tribunal Supremo dicta nueva Sentencia confirmando la del TSJ de Madrid pero excluyendo de la declaración de nulidad a varios Sectores, como el Camino de los Caleros, Montecarmelo, Sanchinarro, Las Tablas o el Cerros de los Gamos, dado que su clasificación como urbanizable procedía de modificaciones del PGOU 85 anteriores al objeto del Recurso Contencioso-Administrativo interpuesto.

Durante el año siguiente, tanto el Ayuntamiento como la Comunidad de Madrid elaborarán una Memoria justificativa intentando subsanar las deficiencias producidas en la reclasificación a efectos de regularizar la situación y dar de nuevo cobertura a la ordenación afectada por dichas Sentencias.

El acuerdo de 24 de enero de 2008 fue nuevamente impugnada por una doble vía, por una parte, a través del incidente de ejecución de sentencia que desembocó en los autos del TSJM de 10 de enero de 2011 y de 18 de febrero del mismo año recurridos en el recurso de casación no 2092/2011 en el que se ha dictado sentencia de 28 de septiembre de 2012, por la que se anula, entre otros, el acuerdo de Consejo de Gobierno y, por otra parte, por vía de recurso contencioso-administrativo indirecto contra el mismo acuerdo del Consejo de Gobierno de 24 de enero de 2008 que ha

10 Con estos instrumentos se buscaba ordenar y urbanizar completamente, suelos urbanizables que no se encontraban programados en el PGOUM. Con otras palabras, permitía poner en marcha desarrollos que no formaban parte del planeamiento aprobado y que estaban destinados a convertirse en complementarios del mismo. 
concluido con la sentencia dictada en el recurso de casación 1009/2011, de la misma fecha, igualmente anulatoria, entre otros, del acuerdo de 24 de enero de 2008.

El fundamento de ambas sentencias es la imposibilidad legal de la convalidación a posteriori de disposiciones declaradas nulas, carácter reconocido a los planes de ordenación. Así, el Tribunal Supremo dicta dos Sentencias en las que declara la nulidad del PGOU97 en los 22 ámbitos restantes, al entender que no cabe la subsanación de Instrumentos Urbanísticos declarados nulos y, por lo tanto no puede admitir la Memoria justificativa presentada 2008. Los ámbitos finalmente anulados serían los siguientes: UNP 4-04 Ensanche de Coslada, UZP 2-03 Los Ahijones, UNP 405 Ensanche de San Fernando, UZP 2-02 Los Cerros, UZP 2-04 Los Berrocales, UZP 3-01 Valdecarros, UZP 1.04 Vallecas-La Atalayuela, APR 17-01 El Salobral-Nacional IV, APE 09/03 Portillo de El Pardo, APE 09/20 Manzanares Norte, APE 08/06 Colonia Mingorrubio, UNP 4-08 Aravaca-La Escorzonera-Montes del Pilar, Equipamiento General de Valdegrulla, APR 19/04 La Dehesa, UZI 00-06 Arroyo del Fresno, UNP 407 Remate Suroeste Campamento, APE 10-08 Colonia Militar de Cuatro Vientos, APR 10-02 Instalaciones Militares Campamento, UNP 4-01 Ciudad Aeroportuaria-Parque de Valdebebas, UNP 4-10 Solana de Valdebebas, AOE 00-22 Sistema Aeroportuario de Barajas y UNP 4-11 Fuente Fría Norte.

Estas sentencias además planteaban efectos anulatorios "ex tunc", es decir, que los mismos se producen, no a partir de los fallos judiciales, sino que se retrotraen al momento mismo en que en que se aprobó el Plan General. Con ello quedaban afectadas 8.919 hectáreas del municipio, de las cuales 3.334 pasaban a ser nuevamente suelo rústico y el resto, se verían afectadas en cuanto a su ordenación y su desarrollo lógicamente.

La publicación de las Sentencias provocó una gran incertidumbre entre ciudadanos e inversores en su momento. Esta provenía sobre la situación final en la que quedaban esos suelos y el papel que iba a jugar ahora el Ayuntamiento. Muchos de estos desarrollos eran ámbitos en los que todos sus instrumentos urbanísticos tramitados en desarrollo del PGOU 97 habían sido aprobados (planes parciales, proyectos de urbanización y reparcelación) y que, gran parte de ellos tenían juntas de compensación constituidas y en funcionamiento, habiéndose ejecutado obras de urbanización, y otorgado licencias de construcción y de primera ocupación sobre terrenos que, al estar ahora regulados por el anterior planeamiento, pasaban a ser considerados Suelo No Urbanizable de Especial Protección. Sobre estos suelos, como es lógico y normal, no estaba permitida ni la construcción ni la urbanización prevista y/o desarrollada.

Ante este problema sólo cabe una solución y esta debería encauzarse por las Administraciones competentes, Comunidad y Ayuntamiento de Madrid, por un procedimiento de modificación de la clasificación y ordenación de los suelos en cuestión, con la dificultad añadida de tener que ajustarse a la Ley del Suelo vigente de la Comunidad Autónoma de Madrid. Entre tanto, quedan afectadas las actuaciones urbanísticas dado que la nulidad de las determinaciones afectadas del PGOU se extiende a los planes de desarrollo, especialmente, y actos de ejecución con las excepciones y matizaciones que procedan en cada caso.

Estas sentencias llegaban en un momento en el que el equipo de gobierno municipal había decidido revisar el planeamiento, y por lo tanto podía haber optado 
por tener en cuenta la sentencia y revisar o justificar las clasificaciones propuestas. Lejos de adoptar esta sentencia en el nuevo planteamiento del modelo territorial municipal, el consistorio determinó que no podía permitirse esperar a este proceso de Revisión para dar una solución al urbanismo de la ciudad por sus consecuencias económicas y sociales.

La solución planteada fue tramitar una Revisión Parcial de las determinaciones del PGOU 85 aún vigentes, a causa de las sentencias, culminando su proceso y devolviendo el marco jurídico y urbanístico completo al PGOU 97. Esta modificación del planeamiento, conocida popularmente como "Revisión Express" por su rápida concepción, tramitación y aprobación, en menos de unos meses, alcanzó acuerdo del Consejo de Gobierno de la Comunidad de Madrid de 2 de Agosto de 2013.

Una vez aprobada esta modificación, los ámbitos anulados pasaban de nuevo a ser clasificados como urbanos, urbanizables y no urbanizables, conforme a las características ambientales de ese momento y se reanudaba la actividad inmobiliaria en los mismos.

Este último movimiento a la desesperada del Ayuntamiento de Madrid por intentar salvar no sólo el discurso de los últimos años al respecto de su buena gestión del asunto sino el encarecimiento del proceso a causa de los juicios y la no paralización de las obras ha vuelto a ser recurrido por entender que ni acata ni ejecuta correctamente las sentencias de 2012.

Independientemente de este recurso, la situación no ha mejorado excesivamente ni para los vecinos de estos nuevos barrios ni para los inversores. Así, y debido a las sentencias se están resolviendo los recursos planteados, en relación a proyectos de urbanización y reparcelaciones aprobadas, siendo todos los fallos judiciales anulatorios de estos instrumentos. También se están recurriendo muchas de las licencias de obras y de primera ocupación concedidas.

En definitiva, a día de hoy muchos de los desarrollos urbanísticos de la ciudad de Madrid continúan parados porque hace casi veinte años las cosas no se hicieron bien ni se sometieron a los adecuados procesos de justificación o argumentación sobre los valores del territorio. En la actualidad contamos con herramientas de evaluación ambiental que deberían evitar que situaciones similares pudieran acontecer, pero no deberíamos olvidarnos que estas evaluaciones deben ser reales y responder a criterios medioambientales y de sostenibilidad que no deben dar réplica sólo a criterios inmobiliarios.

Si se nos podía hacer complicado explicar a los alumnos o ciudadanos que, un planeamiento tras los controles que lo acompañan en su tramitación puede ser anulado, prefiero no imaginarme lo que significaría explicarles que, el PGOU de una de las principales ciudades españolas jamás llegó a estar vigente en su totalidad durante su periodo de vigencia. Eso sí sería realmente difícil de justificar... 


\title{
UNA REFLEXIÓN CRÍTICA SOBRE LA TRASPOSICIÓN DE LA POLÍTICA URBANA DE LA UNIÓN EUROPEA AL MARCO ESPAÑOL
}

\author{
Sonia de Gregorio Hurtado (Dra. Arquitecta - Investigadora DUyOT)
}

En España al iniciar la década de los ochenta del siglo XX, se inicia la transferencia de competencias a las Comunidades Autónomas. Al finalizar los setenta se habían transferido a los Ayuntamientos. Ambos niveles de gobierno recibieron competencias en el ámbito del urbanismo y otras políticas urbanas, mientras que el Gobierno Central mantuvo muy pocas.

Esto dio lugar a una situación que rompía con la centralidad con la que la acción sobre la ciudad se había ejercido durante la dictadura. Se iniciaba una nueva etapa en la que Comunidades Autónomas y Ayuntamientos tuvieron que hacer frente a la difícil situación en la que se encontraban las ciudades después de un periodo caracterizado por la inacción para mejorar el medio urbano y la falta de reflexión sobre la ciudad. Los expertos y técnicos que estaban activos en el ámbito del urbanismo en ese periodo refieren la ilusión con la que los planificadores y las nuevas corporaciones municipales acometieron esta tarea, lo cual permitió la integración de la cultura urbanística en los nuevos instrumentos de planificación. También señalan el papel que jugó en la mejora urbana la participación ciudadana a través de los Movimientos Sociales Urbanos.

Así pues el inicio de la Transición conllevó la devolución de las competencias al nivel local, llevando la toma de decisiones a los niveles de gobierno que eran los directamente afectados por las políticas urbanas, y acercando el nivel de decisión a los ciudadanos, facilitando la integración de la participación en los procesos.

Desde el punto de vista de la gobernanza multi-nivel el momento se caracterizó a grandes rasgos por la colaboración entre los tres niveles de gobierno. En este sentido experiencias como la Remodelación de Barrios en Madrid (1979-1996) ejemplifican como fue posible la colaboración entre los mencionados tres niveles en un clima de cooperación y apoyo mutuo. También es un ejemplo de como la movilización ciudadana fue clave (dio inicio a la iniciativa), logrando introducir un problema urbano a resolver en la agenda de las nuevas instituciones.

Al finalizar la década de los ochenta y el inicio de los noventa el clima de colaboración multi-nivel perdió intensidad. Esta situación fue común también a otros ámbitos de política en los que las Comunidades y los Ayuntamientos empezaron a funcionar en base a una lógica de defensa de los ámbitos competenciales, dejando insuficientemente atendida la concertación entre los diferentes niveles de gobierno, y alejándose de la colaboración voluntaria entre administraciones que es parte esencial del Estado de las Autonomías. Este hecho explica en gran medida por qué España no abordó a lo largo de la Transición una reflexión a escala de país sobre la ciudad, ya que la falta de competencias del Gobierno Central sumada a las sentencias del Tribunal Constitucional, que declararon inconstitucionales algunos intentos del primero por actuar de manera concertada en ámbitos como la planificación territorial 
o el transporte, fueron "deslegitimando" la acción a escala nacional, de manera que, al contrario que muchos estados de la UE, España no logró dotarse de una política urbana a nivel de país y el Gobierno Central quedó desdibujado como actor en relación a este ámbito de acción política. El Plan Director de Infraestructuras de 1993 fue el intento más avanzado del Gobierno Central por actuar en el medio urbano en un clima de concertación con las Comunidades Autónomas y las ciudades, a través de la llamada Política de Ciudades. Sin embargo en 1996 la misma (que había empezado a dar lugar a resultados positivos) fue suprimida.

También en ese momento la participación empezó a perder vigor. Borja (2001) señala como uno de los factores que frenaron el desarrollo de la democracia local participativa las organizaciones partidarias que tienden al monopolio institucional de la vida política local. Urrutia señala la puesta en práctica de modelos de participación ciudadana con escasa voluntad política para incorporar a las organizaciones ciudadanas. Para él esa circunstancia dio lugar a dos actitudes frecuentes al inicio de la década de los noventa: el exclusivismo (acción de apoyo preferente por parte de las instituciones a determinadas organizaciones más cercanas a la línea política del gobierno); y el paternalismo institucional respecto a los ciudadanos y sus organizaciones "considerando como «favor» aquello que es «derecho» (Urrutia, 1992: 51). Ambas actitudes también describen el modo según el cual se ha venido entendiendo la participación hasta el momento presente en el ámbito del urbanismo en nuestro país, a pesar del desarrollo de valiosas excepciones.

En este contexto, muy simplificado en la exposición por una cuestión de extensión, al finalizar los años 80 e iniciar los años 90 la Comunidad Económica Europea (CEE) empieza a dirigir su atención a las ciudades, al entender que en estos ámbitos se habían concentrado a lo largo de las dos décadas anteriores problemas que limitaban el camino hacia la cohesión de los Estados Miembros (social y económica). A través de un camino complejo las instituciones comunitarias pusieron en marcha un proceso que derivó en la conformación de lo que hoy podemos llamar "política urbana de la Unión Europea (UE)", un ámbito en el que la UE no tiene competencias, formalizado poco a poco a través de un proceso complejo en el que ha tenido un papel importante el lanzamiento de instrumentos de política no vinculantes: comunicaciones de la Comisión Europea y documentos políticos de otros actores relevantes, líneas guía de actuación, instrumentos dotados de contenido económico para la regeneración urbana, intercambio de buenas prácticas, programas de construcción de capacidad y aprendizaje, etc. En 1989 la Comisión lanzó el primer instrumento específico de esta política (los Proyectos Piloto Urbanos -PPU-). Sobre la experiencia del mismo en 1994 se lanzó la Iniciativa Comunitaria URBAN para la regeneración urbana, el principal instrumento de la política urbana de la UE hasta el momento, cuyo desarrollo ha hecho una aportación de primer orden a la práctica de la regeneración en el contexto nacional (De Gregorio, 2012; De Gregorio, 2014). Este último ha asumido en gran medida la metodología de actuación de URBAN, aplicando el concepto de" regeneración urbana integrada" en barrios degradados (ibid.).

Volviendo al marco español, ya durante la segunda mitad de los ochenta y primeros noventa se pusieron de relieve una serie de cuestiones en relación a la actuación en el medio urbano que era importante atender, muchas de ellas eran fruto de la falta de acción del periodo dictatorial, mientras que otras empezaron a tener que ver con la nueva arquitectura institucional y con como empezaba a evolucionar 
la gobernanza asociada a la misma (en su dimensión multi-nivel, horizontal y de participación) y con el momento histórico (la globalización, la retirada del Estado como actor económico, el reto ambiental, la competitividad urbana). Otras, como el desafío demográfico, el cambio climático o la pobreza urbana, se han perfilado en los años siguientes en relación a nuevos problemas políticos, ambientales, sociales y económicos con importantes componentes inherentes a la realidad española: todas ellas cuestiones a abordar desde una reflexión que no se ha dado ni a escala de país, y salvo excepciones, tampoco a escala de las Comunidades Autónomas.

La falta de acción del Gobierno Central y de las Comunidades Autónomas contribuyó a que el primer plano de la reflexión sobre la actuación en la ciudad consolidada en el marco nacional fuera ocupado en gran parte desde el final de los años noventa por la política urbana de la UE. Esto se ha venido haciendo en una clave de trasposición directa de las metodologías y prioridades comunitarias al marco español, lo que ha conseguido desplazar la atención de la especificidad de nuestros temas pendientes y ha relegado la necesidad de abordar la acción en el medio urbano en base a una reflexión estratégica sobre los problemas a resolver, pero también sobre los muchos elementos positivos a preservar que son inherentes al modelo de ciudad en nuestro país. Mientras que la Iniciativa Comunitaria URBAN, y en general la política urbana de la UE, han hecho una aportación positiva a la práctica de la regeneración urbana en España (De Gregorio, 2012 y 2014), la observación de la evolución de su influencia sobre el marco español, una vez casi finalizados los proyectos de la Iniciativa Urbana ${ }^{11}$, empieza a poner de manifiesto que dicha aportación está contribuyendo a mantener en segundo plano nuestra reflexión pendiente (De Gregorio, 2015).

En el periodo 2004-2011 un esfuerzo del Gobierno Central, formalizado en el lanzamiento de documentos como el Libro Verde de Medioambiente Urbano (MARM, 2007 y 2009), la Estrategia Española de Medioambiente Urbano (MARM, 2008) o la Estrategia Española de Sostenibilidad Urbana y Local (MARM, 2011), junto con otras instrumentos de política entre los que cabe destacar el Plan Estratégico de Infraestructuras y Transporte (Ministerio de Fomento, 2005), parecían señalar el inicio de un camino que pretendía devolver al tema urbano atención por parte de las instituciones y de otros actores desde una visión de concertación (De Gregorio, 2012). Sin embargo, la observación del bajo impacto que dichos instrumentos han tenido en la acción de los gobiernos locales y su incapacidad de dar visibilidad al tema y provocar una reflexión sostenida sobre la ciudad, permite decir que se ha tratado de un esfuerzo que no ha llegado a dar resultados, o al menos los resultados esperados, y una vez más demuestra la incapacidad del país de poner esta cuestión en el centro de la atención y la acción política.

Como consecuencia, en el momento actual persisten una serie de cuestiones importantes que han quedado relegadas y desatendidas, invisibilizadas en gran medida por la política urbana de la UE. En este momento se están definiendo los

\footnotetext{
11 La iniciativa Comunitaria URBAN se desarrolló en dos fases: URBAN (1994-1999) y URBAN II (20002006). A partir de 2007 en el marco de la UE se inicia el mainstreaming de la política urbana. Desde ese enfoque países como España deciden dar continuidad a URBAN de manera explícita en su marco nacional a través de las ayudas del Fondo Europeo de Desarrollo Regional (FEDER) para el desarrollo urbano sostenible. En nuestro país esto se ha llevado a cabo a través de los proyectos de la Iniciativa Urbana (2008-2013).
} 
instrumentos que determinarán la implementación de dicha política en España en el periodo presente de la Política de Cohesión (2014-2020). Por esta razón, es clave recuperar esos temas pendientes e introducirlos en la acción en el medio urbano a través de los recursos del Fondo Europeo de Desarrollo Regional (FEDER), sin llevar a cabo una vez más una transposición directa de las directrices y metodologías comunitarias, sino una aplicación de las mismas adaptada y matizada por la realidad en la que actúan. Algunos de esos temas/acciones pendientes en relación a la actuación en el medio urbano que se proponen desde aquí son los siguientes:

- Una reflexión promovida por los Ayuntamientos, las Comunidades Autónomas y el Gobierno Central sobre la ciudad y, por tanto, también sobre el concepto/enfoque de la regeneración urbana que es necesario adoptar. Esta reflexión habría de incluir un debate sobre la gobernanza multi-nivel en relación a la actuación en el medio urbano.

- Abordar una reflexión sobre la sectorialidad desde la que se sigue actuando en la ciudad a través de proyectos de regeneración, a pesar de la creciente utilización del término "regeneración urbana integrada" para denotar muchas de esas actuaciones.

- En relación a lo anterior, dar lugar a una revisión del término de "regeneración urbana integrada", cuyo uso retórico en la trasposición del mismo al marco español desde el contexto comunitario parece haber derivado en un uso "acrítico"12 del mismo.

- Introducción en el concepto de regeneración urbana de temas poco integrados hasta el momento: la belleza urbana, el género, la mitigación y la adaptación al cambio climático, el desafío demográfico, la pobreza urbana, etc.

- Abordar la participación de la comunidad local desde una revisión de los instrumentos de participación previstos por la Ley 57/2003 de Medidas para la Modernización del Gobierno Local, al haberse mostrado estos ineficaces para canalizar la participación efectiva de los ciudadanos y sus organizaciones, así como de otros actores relevantes.

- Reflexionar sobre el insuficiente análisis, seguimiento y evaluación de políticas, ligado al bajo nivel de trasparencia y rendición de cuentas en relación a la actuación en la ciudad. En relación a esto, poner en marcha el Observatorio Urbano que se anunció en 2003 en el marco de la mencionada Ley 57/2003.

\footnotetext{
12 Uso aquí el adjetivo "acrítico" que utiliza José Manuel Naredo en relación al uso del término "desarrollo sostenible" en su texto Sobre el origen, el uso y el contenido del término sostenible, al considerar que existen similitudes en el uso retórico de este término y el de "regeneración urbana integrada". Disponible en: http://habitat.aq.upm.es/cs/p2/a004.html (última consulta 25 de junio de 2015).
} 


\section{REFERENCIAS BIBLIOGRÁFICAS:}

BORJA, J. (2001). "Participación, un desafío, una oportunidad, una cuestión política", en Proyecto Educativo de Ciudad. Gijón, Ayuntamiento de Gijón.

DE GREGORIO HURTADO, S. (2012). Políticas urbanas de la Unión Europea desde la perspectiva de la Planificación Colaborativa. Las Iniciativas Comunitarias URBAN y URBAN II en España. Tesis Doctoral. Escuela Técnica Superior de Arquitectura de la Universidad Politécnica de Madrid.

DE GREGORIO HURTADO, S. (2014). "La Iniciativa Comunitaria URBAN como factor de transformación de la práctica de la regeneración urbana: aproximación al caso español", en Ciudad y Territorio. Estudios Territoriales, volumen XLVI, número 180, pp. 253-276.

DE GREGORIO HURTADO, S. (2015). "La contribución de URBAN y URBAN II a la práctica de la regeneración urbana en España". Presentación en las Jornadas de Política de Regeneración Urbana en España: de las Enseñanzas a los Retos, Ayuntamiento de Lucena: Lucena, 28-29 Enero, 2015.

MARM (Ministerio de Medio Ambiente y Medios Rural y Marino) (2007). Libro Verde de medio ambiente urbano. Tomo I. MARM, Madrid.

MARM (Ministerio de Medio Ambiente y Medio Rural y Marino) (2008). Estrategia española de medio ambiente urbano. MARM, Madrid.

MARM (Ministerio de Medio Ambiente y Medio Rural y Marino) (2009). Libro verde de medio ambiente urbano. Tomo II. MARM, Madrid.

MARM (Ministerio de Medio Ambiente y Medio Rural y Marino) (2011). Estrategia española de sostenibilidad urbana y local. MARM, Madrid.

MINISTERIO DE FOMENTO (2005): Plan estratégico de infraestructuras y transporte. Ministerio de Fomento, Madrid.

URRUTIA, V. (1992): "Transformación y persistencia de los movimientos sociales urbanos, en Política y Sociedad, número 4, pp. 49-56. 


\title{
MECANISMOS URBANÍSTICOS Y GESTIÓN PÚBLICA EN EL EJERCICIO DEL DERECHO CONSTITUCIONAL A UNA VIVIENDA DIGNA.
}

\author{
Enrique de la Villa Polo (Arquitecto - Profesor asociado DUyOT)
}

Pese a la inexistencia de un desarrollo normativo específico del artículo 47 de la Constitución Española en el que se establece el derecho de todos los ciudadanos a una vivienda digna y adecuada, el fracaso en la ejecución efectiva de este derecho en los treinta y siete años transcurridos desde su aprobación, no es achacable a un erróneo diseño de los mecanismos legales para ello, sino a un deficiente manejo de estos mecanismos por los poderes públicos responsables de su aplicación.

El derecho de todo ciudadano disfrutar de una vivienda contenido en la el artículo 25 de la Declaración Universal de los Derechos Humanos, fue recogido en la Constitución Española de 1978, en su artículo 47. En él se establece que corresponde a los poderes públicos promover las condiciones necesarias y aprobar las normas pertinentes para hacerlo efectivo. A diferencia de otros derechos constitucionales, éste requiere de un desarrollo normativo para su aplicación.

Sin una norma legal que desarrolle el concepto constitucional de "vivienda digna y adecuada", la Oficina del Alto Comisionado de las Naciones Unidas para los Derechos Humanos en su Observación General no 4, considera que es aquella "donde los ciudadanos o las familias pueden vivir con seguridad, paz y dignidad". Parece claro que en esta definición la satisfacción del derecho a una vivienda va más allá de resolver el cobijo. Se trata de cubrir además otras necesidades. Como consecuencia, la regulación del derecho a la vivienda para el cumplimiento del mandato constitucional, además de abordarse desde su componente económica y edificatoria, es un aspecto que compete a la regulación sobre suelo y urbanismo, en la medida que afecta a otros aspectos de la vida colectiva.

Aproximándonos más al concepto, la Resolución 2012/2293(INI) del Parlamento Europeo, de 11 de junio de 2013, sobre la vivienda social en la Unión Europea identifica el derecho a una vivienda adecuada, como "la necesidad de promover el acceso de las personas con menos recursos a una vivienda segura y bien ubicada". Por tanto la regulación de este derecho, que por mandato constitucional deben garantizar los poderes públicos, debe incidir sobre a tres factores: Capacidad económica de los ciudadanos, seguridad de la edificación, y planificación de la estructura urbana.

Respecto a la seguridad, vinculada a las condiciones físicas de la edificación, la garantía queda cumplida con la aplicación de estándares mínimos de calidad idénticos en toda construcción independientemente de su destino. Algo que en el ordenamiento español regula el Código Técnico de la Edificación de 2007.

Respecto a la capacidad económica de los ciudadanos como factor de garantía de acceso a la vivienda, en un sistema inmobiliario regido exclusivamente por las reglas del libre mercado, el ejercicio de este derecho estaría directamente vinculado con la renta disponible de los ciudadanos. Las únicas medidas para garantizar este derecho, 
serán aquellas dirigidas a aumentar esta renta. No siendo así, corresponde a los poderes públicos intervenir en el sistema inmobiliario. Esta es la vía apuntada por la constitución española, cuando, el mismo artículo 47 en el que se establece el derecho a una vivienda digna, contiene el mandato de regular la utilización del suelo de acuerdo con el interés general, impedir la especulación, y la participación de la comunidad en las plusvalías que genere la acción urbanística de los entes públicos.

La actividad urbanística en España, tiene entre sus principios rectores el control de la especulación, y la reversión de las plusvalías. Los instrumentos de planeamiento en los que se recogen los modelos territoriales y locales de ordenación, tienen, entre otras, la función de propiciar la producción de viviendas de precio regulado que den cobertura a población con niveles de renta insuficientes para acceder al mercado libre, y destinar recursos para la creación de un parque inmobiliario público. Corresponde además a los Planes urbanísticos fijar las estrategias municipales para la ubicación concreta de estas viviendas, y la programación para su desarrollo.

Partiendo de la definición de la Resolución del Parlamento Europeo sobre la vivienda social en la Unión Europea, corresponden a la actividad urbanística dos de los tres aspectos sobre los que deben actuar los poderes públicos para facilitar el acceso a la vivienda: la previsión y programación de las viviendas dirigidas a población con niveles de renta más bajo, y la planificación de la estructura urbana. Por tanto, el camino hacia un ejercicio real del derecho constitucional a una vivienda digna y adecuada, pasa necesariamente por el planeamiento urbanístico.

De ello derivan algunos factores capitales que han condicionado la satisfacción del derecho a la vivienda. La distribución de competencias entre las administraciones del estado, comunidades y municipios, reparte la responsabilidad respecto al diseño de mecanismos legales e instrumentos estratégicos y tácticos que los desarrollen, y la implementación de los mismos. En este contexto, la ejecución de los instrumentos de ordenación municipal, los Planes General de Ordenación o equivalentes, es una competencia casi exclusivamente municipal. Como lo es la utilización de las plusvalías generadas por la actividad urbanística para la constitución de un Patrimonio Municipal de Suelo. Y es en esta escala de intervención en la que todo el proceso se ha mostrado más débil.

El concepto de Patrimonio Municipal de Suelo se incorporó a la legislación española en el Reglamento de Bienes de las Corporaciones Locales de 1955, como obligación de destinar un $5 \%$ del presupuesto del Ayuntamiento para su adquisición, pasando desde la Ley del Suelo de 1976 a generarse por cesión obligatoria de un porcentaje del aprovechamiento urbanístico. También la definición de su destino fue matizándose con el tiempo, y desde una finalidad genérica, pasó a vincularse con la intervención municipal en el mercado inmobiliario, de acuerdo con el interés general. Esta vinculación se produjo con la aprobación del TRLS de 1992, que preveía también la sustitución de la cesión de suelo por su equivalente económico, con obligación de destinarlo a la conservación y ampliación de este patrimonio.

La Sentencia del Tribunal Constitucional de 20 de marzo de 1997, reconoció la competencia del estado para la definición y destino del Patrimonio Municipal del Suelo, como patrimonio separado del resto de los bienes municipales. De este modo, el RDL 2/2008 por el que se aprueba la vigente Ley del Suelo del Estado, establece como destino de este suelo regular el mercado inmobiliario, bien mediante la construcción 
de viviendas sujetas a algún régimen de protección pública, bien enajenando terrenos a un precio no especulativo. En todo caso, los ingresos obtenidos mediante enajenación de terrenos o sustitución del aprovechamiento correspondiente a la Administración por su equivalente metálico deben necesariamente destinarse a la conservación y ampliación del Patrimonio Municipal de Suelo, y en ningún caso a la financiación de otras partidas de los presupuestos municipales. Una exigencia legal que sistemáticamente se ha incumplido en los municipios españoles.

Por tanto los mecanismos legales para permitir el derecho de todos a una vivienda digna, y los instrumentos para hacerlo efectivo, existen aún antes del mandato constitucional para ello. Y sin embargo, según datos de la oficina del Defensor del Pueblo, en 2013 había en torno a 276.000 viviendas públicas en España, 250.000 de las cuales están gestionadas por las comunidades autónomas y 26.000 por grandes municipios. El último censo oficial de población y vivienda de 2011 indica que España tiene 25,2 millones de viviendas. Por tanto, la vivienda social sería aproximadamente el $1,1 \%$ del sector de la vivienda en su conjunto. Este porcentaje es Ilamativamente bajo si se compara con países que han resuelto de forma razonablemente efectiva el ejercicio del derecho a la vivienda. En particular en Holanda el porcentaje alcanza el $32 \%$, y es del $23 \%$ en Austria, del $18 \%$ de Reino Unido y del $17 \%$ de Francia. De hecho, dentro del grupo de los 15 de la Unión Europea, sólo Grecia presenta un dato inferior a España.

A pesar de esta situación, el gasto público en vivienda desde el comienzo de la crisis económica en 2007 ha disminuido. La partida de vivienda de los Presupuestos Generales del Estado se redujo en más de la mitad entre 2008 y 2015 . Las ayudas a la vivienda descendieron de 40,95 euros por persona en 2008 a 27,79 en 2012, frente a los 134,65 euros de promedio de la Unión Europea en el 2012.

Incluso en este contexto, la Resolución 2012/2293(INI) del Parlamento Europeo, de 11 de junio de 2013, sobre la vivienda social en la Unión Europea, para la materialización del derecho a la vivienda proponía medidas que fácilmente podrían ponerse en práctica aun habiendo fallado las políticas públicas de suelo. Medidas tales como realizar auditorías de las viviendas y los edificios desocupados para definir estrategias al respecto, combatir la especulación y la infrautilización de las viviendas privadas, y regular las instituciones financieras y el mercado de financiación en relación con la vivienda, entre otras.

El número de viviendas vacías en España era de tres millones cuatrocientas cuarenta mil en 2011, según el último censo, lo que constituye un importante recurso potencialmente disponible que las autoridades públicas podían usar para garantizar el derecho a la vivienda. Sin embargo las autoridades públicas, salvo excepciones, desatendiendo las medidas propuestas por el Parlamento Europeo, no lo han puesto en valor. En algunos casos como en Cataluña y la Comunidad de Madrid incluso se ha retrocedido al respecto, disminuyendo los plazos para que una vivienda pública pueda pasar a manos privadas, o vendiendo las disponibles a sociedades de inversión, reduciendo así un parque ya limitado.

Por todo lo expuesto, existen los mecanismos legales para hacer efectivo el derecho de todos los ciudadanos a una vivienda digna y adecuada, si bien para ello las administraciones deben necesariamente ordenar su territorio incorporando esta necesidad, dando prioridad a la función social del suelo y las viviendas sobre los 
derechos de propiedad. Y este es un paso que a la vista de las cifras, las políticas municipales han dado insuficientemente. Analizar las razones para ello escapa del ámbito del urbanismo.

\section{REFERENCIAS BIBLIOGRÁFICAS:}

CIRIA PEREZ, F.J.: "Destino del Patrimonio Publico o Municipal del suelo" en Revista de Administración Local nº 17. (1998).

MARTÍN HERNÁNDEZ, P.: "El Patrimonio Municipal del Suelo: Su evolución normativa. (2006).

AMNISTÍA INTERNACIONAL. Informe. "El derecho a la Vivienda y los desalojos hipotecarios en España" (2015) 


\title{
SOBRE LA NECESIDAD DE ARMONIZAR LAS LEYES URBANÍSTICAS DE LAS COMUNIDADES AUTÓNOMAS
}

\author{
Abel Enguita Puebla (Dr. Arquitecto - Profesor Ad Honorem DUyOT)
}

\section{Introducción}

Como consecuencia de la aplicación del Art. 148.3 de la Constitución Española, que atribuye la competencia exclusiva en materia de "ordenación del territorio, urbanismo y vivienda" a las Comunidades Autónomas, éstas se han ido dotando de leyes específicas en esta materia, que han ido introduciendo -respecto de una legislación estatal común- numerosas disparidades, tanto en relación con los instrumentos de planeamiento y gestión del urbanismo y la ordenación del territorio, como en relación con las cargas y cesiones gratuitas impuestas a los propietarios.

En consecuencia, en materia de urbanismo y ordenación del territorio, no sólo se ha producido una ruptura de la unidad de mercado en los sectores afectados, sino una indirecta desigualdad en los derechos de la propiedad ligados al suelo. Por otra parte -a diferencia de otros países de la Unión Europea - en España el Estado ha ido perdiendo la visión y control global de las transformaciones_del territorio,con la consiguiente pérdida de eficacia en la planificación de las grandes infraestructuras nacionales, consumos de energía y aplicación de políticas de sostenibilidad diversas.

Así en efecto, en Dinamarca, en aplicación de su Ley del Planeamiento de 2002 después de cada Nueva elección al Folketing (Parlamento) el Ministro de Medio Ambiente debe presentar un informe sobre el planeamiento nacional al Comité para el Medio Ambiente y el Planeamiento Regional del Folketing ( Art.2). Adicionalmente el Ministro de Medio Ambiente "para asegurar la protección de los intereses nacionales, incluyendo asegurar la calidad del planeamiento...puede establecer normas reguladoras del uso de la autoridad garantizada por esta Ley y el contenido del planeamiento de acuerdo con esta Ley" ( Art.3 ).

En los Países Bajos, la Ley de Planeamiento Espacial de 2006 introduce un sistema de planeamiento espacial al nivel nacional, de carácter indicativo, mediante las denominadas Decisiones Clave de Planeamiento (Planologische Kernbeslissing). La primera, de las tres clases de Decisiones Clave de Planeamiento que diferencia la Ley, se denomina Esquemas de Estructura Nacional, y se refieren a desarrollos espaciales de escala nacional de medio y largo plazo. Un ejemplo es el Documento de Política Nacional sobre Planeamiento Espacial de 2004.

En Alemania, el sistema de planeamiento está descentralizado como en España, la Federación no cuenta con un instrumento de planeamiento espacial comprehensivo legalmente vinculante, pero en su lugar la Federación establece los principios de " Raumordnung", que son las líneas directrices fundamentales para todo el planeamiento y la política espaciales en Alemania. Mediante la nueva Ley Federal de Planeamiento Espacial (Raumordnunsgesetz) la Federación está autorizada para establecer los conceptos directores (Leitbilder) del desarrollo espacial en cooperación con los estados federados. 
Por otra parte la citada Ley Federal establece la obligatoriedad de elaborar un informe regular sobre el estado del planeamiento espacial, que se publica con intervalos regulares, generalmente cada cuatro años.

Finalmente, en el Reino Unido, en marzo de 2012 se publicaba el National Planning Policy Framework ( Marco para la Política Nacional de Planeamiento ) que establece las políticas del Gobierno en materia de planeamiento y como han de ser aplicadas. Proporciona un marco dentro del cual las autoridades locales pueden elaborar sus planes locales distintivos, que reflejen las necesidades y prioridades de sus respectivas comunidades.

En este contexto europeo, el texto refundido de la Ley del Suelo estatal de España de 2008 introducía en su Art.15.5 la siguiente norma:

"Las Administraciones competentes en materia de ordenación y ejecución urbanística deberán elevar al órgano que corresponda de entre sus órganos colegiados de gobierno, con la periodicidad mínima que fije la legislación en la materia, un informe de seguimiento de la actividad de ejecución urbanística de su competencia, que deberá considerar al menos la sostenibilidad ambiental y económica a que se refiere este artículo. Los Municipios estarán obligados al informe a que se refiere el párrafo anterior cuando lo disponga la legislación en la materia y, al menos, cuando deban tener una Junta de Gobierno Local "

De este texto se deduce que se impone a las Administraciones Autonómicas la obligación de controlar y coordinar el desarrollo urbanístico de sus municipios, mediante un seguimiento de este que garantice su sostenibilidad ambiental y económica, pero dichas Administraciones Autonómicas no asumen la obligación equivalente de trasladar a la Administración del Estado ningún tipo de informe regular equivalente que permita garantizar dicha sostenibilidad ambiental y económica a la escala del territorio nacional.

El Art. 150.3 de la Constitución establece sin embargo que:

"El Estado podrá dictar Leyes que establezcan los principios necesarios para armonizar las disposiciones normativas de las Comunidades Autónomas aún en el caso de materias atribuídas a la competencia de éstas, cuando así lo exija el interés general. Corresponde a las Cortes Generales, por mayoría absoluta de cada Cámara, la apreciación de esta necesidad".

Dado que actualmente se dan la motivación y condiciones necesarias para la armonización de las leyes urbanísticas de las Comunidades Autónomas, se considera necesario que dicha armonización sea abordada, abarcando al menos el contenido que se propone a continuación.

\section{Propuestas para la armonización de las leyes urbanísticas de las Comunidades Autónomas}

1) Presentación obligatoria por el Gobierno de un informe regular (cuatrienal) a las Cortes, sobre estado de la ordenación urbanística y territorial en el país.

Esta práctica asentada ya hace tiempo en países como Alemania o los Países Bajos -en los que dichos informes se presentan al Parlamento cada cuatro años- 
permite el seguimiento continuado de los procesos de transformación del territorio que derivan de la dinámica de las áreas urbanas y su valoración desde una perspectiva global. A partir de la misma, el Gobierno puede establecer políticas o líneas directrices de escala nacional, que orienten los planeamientos regionales a la consecución de una ordenación territorial y urbanística del país, más racional y sostenible. Adicionalmente, dicha perspectiva constituye una base fundamental de referencia al efecto de la planificación más eficiente de las grandes infraestructuras de escala nacional, directamente ligadas a las demandas generadas en las áreas urbanas. En consecuencia de todo lo anterior y con base en la obligatoriedad para las administraciones competentes de informar periódicamente del seguimiento de la actividad urbanística, que introduce la Ley del Suelo Estatal de 2008 citada, se abre la posibilidad de regular un proceso informativo de abajo-arriba, que permita la elaboración del informe regular con gran facilidad, con la frecuencia cuatrienal considerada.

2) Coordinación del planeamiento regional:

En aras a garantizar la coherencia a escala nacional de la ordenación del territorio, llevada a cabo a través de planeamientos de escala regional, se hace necesario armonizar tanto su contenido normativo, como documental. Asímismo deben establecerse procedimientos que aseguren la coordinación de planeamientos entre regiones adyacentes que prevengan la solución de continuidades naturales y favorezcan la obtención de economías de escala o la mayor funcionalidad y reducción de costes en el proyecto de infraestructuras suprarregionales.

2.1) Contenido normativo básico, común en los planes de ámbito regional.

Los planes de ámbito regional deberían hacer diferenciación entre dos tipos de determinaciones:

a) Determinaciones con repercusión suprarregional. Estas determinaciones deberían desarrollar/aplicar las políticas o líneas directrices de escala nacional en vigor. Adicionalmente deberá asegurarse su compatibilidad y coherencia con las determinaciones correspondientes de las regiones limítrofes.

b) Determinaciones de carácter interno regional. Desarrollarían aquellas políticas específicas, propias de cada ámbito regional, cuyo contenido carece de repercusión externa.

2.2) Delimitación de ámbitos subregionales de planeamiento y ámbitos transfronterizos.

Con el fin de fomentar la consecución de lógicas y necesarias economías de escala -en la implantación y posterior mantenimiento de infraestructuras- y una mayor racionalidad en la administración territorial, se debería inducir la agrupación de municipios, a efectos de planeamiento, en ámbitos subregionales.Tales agrupaciones podrían establecerse: 
a) Por iniciativa de municipios colindantes, integrados en áreas territoriales homogéneas que compartan los mismos intereses. En base a esta consideración, podrán establecerse agrupaciones "transfronterizas" de municipios, que afecten a comunidades autónomas adyacentes.

b) Mediante el establecimiento, por la administración autonómica correspondiente, de umbrales mínimos de población para la delimitación de los ámbitos de planeamiento urbanístico general.

El papel del Estado en este proceso se concretaría en el establecimiento de los criterios generales a aplicar para las agrupaciones, en coherencia con las políticas de escala nacional establecidas para la orientación de los planeamientos regionales.

\section{Armonización básica de los planes generales municipales y parciales:}

A partir del reestablecimiento de una misma tipología de clasificación del suelo común para todas las CC.AA - se debería armonizar el contenido básico o esencial de dichos instrumentos de planeamiento. Asímismo se debería establecer, con carácter general, cuáles han de considerarse, en los planes generales, las determinaciones de carácter estructurante.

\section{Armonización básica de las cesiones obligatorias y gratuitas:}

Cesiones para reservas dotacionales: Las diferentes leyes urbanísticas autonómicas actualmente vigentes, fijan -empleando diferentes criterios para establecer la base de referencia para los cálculos- categorías y estándares distintos para cuantificar las cesiones obligatorias y gratuitas. El resultado es que -según la autonomía de que se trate- la carga económica que suponen dichas cesiones para el promotor de una misma actuación varía, sin que haya una razón lógica fundamentada. Parece más lógico por el contrario que con carácter general, y con base en las características de la población beneficiaria, se estableciesen los tipos de dotaciones para las que se puede reclamar una cesión gratuita de suelo (o superficie construída, en aplicación del concepto de complejo inmobiliario establecido en el art. 17.4 del RDL 2/2008 de la Ley del Suelo Estatal T.R.) y se fijasen los estándares a aplicar para cuantificar la magnitud de la cesión.

\section{Armonización de los sistemas de ejecución:}

Complementariamente a la armonización de los instrumentos de planeamiento, se considera necesario armonizar los sistemas de ejecución en cuanto se refiere tanto a las clases aplicables, como a los procedimientos y requisitos regulados para su aplicación. 


\section{Unificación de la documentación requerida en los diversos instrumentos de planeamiento y sistemas de ejecución:}

Una de las tendencias más recientes en Europa relativas al urbanismo es la orientada a la digitalización generalizada de la información de los documentos de planeamiento y gestión urbanísticos, con el fin de facilitar el acceso a los mismos de los usuarios y ciudadanos en general y reducción de costes. El caso paradigmático es el de los Países Bajos, con la puesta en práctica desde el 2010, tras la aprobación de la nueva Ley de Planeamiento Espacial, de un plan global que requiere la normalización y aplicación generalizada a todo el país, tanto de los contenidos, como de los soportes gráficos, códigos representativos y en suma todos los elementos integrantes de los documentos de planeamiento y gestión. Con esta referencia, extrema, se considera necesario abordar en España, al menos, la unificación al nivel nacional, de los documentos exigibles en la tramitación de los planes y los sistemas de ejecución. 


\title{
ESPLENDOR Y OCASO DE LA SOSTENIBILIDAD
}

\author{
José Fariña Tojo (Dr. Arquitecto - Catedrático DUyOT)
}

En el año 1987 una comisión de la ONU coordinada por la primera ministra noruega Gro Harlem Brundtland elabora un informe que, en principio, llevaba el nombre de Nuestro Futuro Común. Este informe (también llamado informe Brundtland) pienso que, probablemente sea el texto más citado cuando se habla de sostenibilidad. $Y$, en concreto, el párrafo que se incluye en el capítulo 2 titulado "Hacia un desarrollo duradero" que dice: "El desarrollo duradero es el desarrollo que satisface las necesidades de la generación presente sin comprometer la capacidad de las generaciones futuras para satisfacer sus propias necesidades." Pero también me temo que es el texto menos leído en su totalidad a pesar de que todos lo citan (si exceptuamos El Quijote, claro, también muy citado pero escasamente leído en su totalidad).

Y es que en ese texto se decían cosas muy duras bajo un manto ciertamente optimista. Se podría resumir su espíritu diciendo que la salud del planeta está muy mal pero, entre todos, conseguiremos que esté muy bien. Lo que no se decía es cómo conseguirlo. En el punto 25 de la Introducción (An Overview by the World Commission on Environment and Development) se podía leer que: "Muchos de los actuales esfuerzos por conservar y mantener el progreso humano, satisfacer las necesidades humanas y realizar las ambiciones humanas son simplemente insostenibles - tanto en las naciones ricas como en las pobres -. Retiran en demasiada cantidad y con demasiada rapidez de las cuentas ya en exceso explotadas de los recursos del medio ambiente, para que sea posible continuar en el futuro sin caer en la bancarrota. Es posible que aparezcan beneficios en los balances de nuestra generación, pero nuestros hijos heredarán las pérdidas. Estamos tomando prestado capital del medio ambiente de las futuras generaciones sin intención ni perspectivas de reembolso. Es posible que nos condenen por nuestra manera de actuar dispendiosa, pero no podrán cobrar la deuda que estamos contrayendo con ellos. Actuamos como si eso no importara: las generaciones futuras no votan, no tienen poder político ni financiero, no pueden oponerse a nuestras decisiones".

Desde entonces han transcurrido casi treinta años. Casi treinta años en los cuales han pasado muchas cosas, pero pocas avalan el optimismo que tiñe el informe. El punto 29 de la Introducción decía que "el desarrollo duradero a nivel mundial exige que quienes son más ricos adopten medidas acordes con medios que respeten la ecología del planeta, en el uso de la energía, por ejemplo. Además, la rapidez del crecimiento de la población puede intensificar la presión sobre los recursos y retardar el progreso del nivel de vida. Se puede, pues, proseguir el desarrollo duradero únicamente si el tamaño y el crecimiento de la población están acordes con las cambiantes posibilidades de producción del ecosistema". Nada de esto se ha tenido en cuenta. Los países más poderosos, los grupos de presión que ostentan el poder de forma directa o indirecta han actuado de forma que, no sólo han tenido en cuenta a las generaciones futuras, sino que la distancia entre ricos y pobres (territorios, clases sociales, grupos) se ha ido incrementando en lugar de disminuir y el "debe" se ha ido incrementando de forma progresiva. 
Y esto se refleja como una metáfora en la propia evolución del término. Diez años después de publicarse el informe Brundtland José Manuel Naredo publica un artículo que puede leerse en $\mathrm{CF}+\mathrm{S}$ titulado "Sobre el origen, el uso y el contenido del término sostenible" cuya lectura aconsejo a todos aquellos que quieran entender como el sistema es capaz de asimilar, deglutir y convertir en otra cosa cualquier concepto que le resulte incómodo. Explica José Manuel como se vetó el término ecodesarrollo (ya antes de publicarse Nuestro Futuro Común) por sus implicaciones ecológicas, y luego se adaptó la expresión "desarrollo sostenible" como una especie de tierra de nadie entre desarrollistas y ambientalistas. Y se hizo así debido a su ambigüedad que permitía continuar con el sistema económico tradicional de crecimiento sin límites siempre que se atendiera de forma cosmética a la sostenibilidad de un sistema que, por supuesto, se sobreentendía no sostenible sin crecimiento económico. La expresión hizo fortuna y el término "desarrollo sostenible" pasó del acervo de la economía a la política.

Este paso se hizo ignorando, de una forma descarada, la sostenibilidad global y centrándose en la local. De forma que el "desarrollo sostenible" se entendió como aquel que miraba exclusivamente la posibilidad de mantener el desarrollo de "mi trocito" (territorial, empresarial, social) presuponiendo que todo el capital natural que yo consumiera "alguien" en "algún sitio" iba a dejar de consumirlo. Fue la época dorada de la planificación estratégica que trataba de conseguir la mayor cuota de riqueza, empleos y desarrollo, en un mundo competitivo y limitado. Por supuesto a costa de otros. Pronto se vio que esto era "insostenible" cuando determinados "trocitos" (por ejemplo, Brasil) se negaron a dejar de consumir su cuota para que otros se beneficiaran. Se empezó entonces a hablar de "sostenibilidad" como concepto más ecológico y global ya que era la única forma de que los que estaban por debajo de la media de consumo de planeta siguieran como estaban (o empeoraran) para que los que consumían por encima pudieran seguir haciéndolo. Ahora la sostenibilidad debía de ser global siempre y cuando los países ricos siguieran consumiendo como antes y los más pobres también. Todos los territorios, todos los grupos, todas las clases sociales, deberían entrar en la contabilidad global mundial y los consumos se equilibraban mediante unas limosnas en forma de cuotas.

Se empezó a hablar (todavía se habla) de sostenibilidad fuerte y débil. Como si fuera posible otro tipo de sostenibilidad más que la derivada de una justicia intergeneracional, interterritorial y social, que es la que está en el fondo del concepto. Así que todo empezó a ser "sostenible" (eso sí, "débilmente sostenible"). Se hacían juguetes sostenibles, leyes sostenibles, hasta los equipos de fútbol eran sostenibles (no es un eufemismo). Pero lo peor de todo es que los políticos adoptaron el adjetivo sostenible como una muletilla aplicable a cualquier cosa. Sobre todo a los temas ambientales locales cuya solución pasaba por desplazar el problema a otros sitios sin poder económico, político o militar. Así muchos países africanos empezaron a llenarse de chatarra tecnológica procedente de los países más ricos que se desprendían de ella a muy bajo costo y resolvían su problema local en pro de la sostenibilidad de Berlín, Oslo, Madrid o Nueva York. De tal forma que los políticos proponían resolver el problema de la contaminación de "su" ciudad utilizando, por ejemplo, coches eléctricos. Dado que la electricidad se produce de forma mayoritaria en centrales térmicas lo que se hacía era desplazar el problema de Madrid a Os Pontes. Eso sí, los 
madrileños podían respirar tranquilos y seguir consumiendo energía y contribuyendo al cambio climático, aunque no se enteraran de nada.

De forma que el paso del "desarrollo sostenible" (ya con muy mala prensa) a la "sostenibilidad" se produjo casi sin traumas. Pero la palabra se llenó de connotaciones espurias y la consiguiente polisemia tanto del sustantivo como del adjetivo la fue devaluando de forma progresiva. En el momento actual ya empieza a existir un cierto reparo a utilizarla incluso entre los políticos. Personalmente ya hace tiempo que he decidido no utilizarla en la medida de lo posible. O si lo hago tengo que dedicar un buen rato a explicar cuál es el sentido que le doy que no es más que el reflejo de un compromiso con la justicia intergeneracional, interterritorial y social. Después de unos comienzos prometedores en los que parecía que todos eran solidarios, comprometidos y ecológicos las cosas se fueron degradando.

En el año 1988, sólo un año después de publicarse Nuestro Futuro Común, se crea el Grupo Intergubernamental sobre Cambio Climático (GIEC-IPCC) con el sano propósito de seguir de forma científica el calentamiento climático. En 1992 se celebra la Cumbre de la Tierra en Río de Janeiro en la cual 173 jefes de estado adoptan el programa "Acción 21" que tendrá una enorme importancia en los momentos de esplendor de la "sostenibilidad" como praxis a favor de la justicia. Tres años después se celebra en Copenhague la cumbre mundial sobre desarrollo social en la que 128 jefes de estado y gobierno se plantean abordar de forma prioritaria la pobreza, el desempleo y la desintegración social. En la Cumbre de las ciudades de Estambul de 1996 los estados abordan el tema de la vivienda digna y unas ciudades respetuosas con el medio ambiente. Ya el lobo empezaba a sacar su patita en forma de un entendimiento del medio ambiente como "nuestro medio ambiente" pero, en general, el optimismo y la ilusión eran todavía generalizados. Es optimismo sigue presente en la Cumbre del Milenio celebrada en Nueva York en el año 2000, cumbre en la que se fijas los llamados "objetivos del milenio". Estamos en los momentos de esplendor.

Pero a partir de este momento las cosas empiezan a ponerse cuesta arriba: la cumbre del 2002 celebrada en Johannesburgo es el inicio del sálvese quien pueda. Todavía de forma tímida pero al lobo ya se le veía, no sólo la patita, sino también el hocico. Es la cumbre que podríamos llamar de los partenariados porque ya las empresas empiezan a ver las posibilidades de negocio. En el 2005 entra en vigor el protocolo de Kioto firmado con gran entusiasmo en 1997 (en la época esplendorosa de la sostenibilidad) y luego ratificado en 2010 por 168 estados para conseguir llegar a un compromiso por parte de un conjunto de países que representaran el $55 \%$ de las emisiones de gases con efecto invernadero. Es bien sabido que, por ejemplo, USA, el principal emisor de este tipo de gases no lo ratificó. A pesar del incumplimiento generalizado se propuso una prórroga que abarca desde el 2013 hasta el 2020 pero esta prórroga ni tan siquiera ha sido firmada por países tan importantes como Rusia, Estados Unidos o Japón. El último fiasco ha sido la cumbre de Rio+20 celebrada en el 2012 en la que los países no han conseguido llegar a ningún acuerdo operativo. De la última cumbre del clima auspiciada por la ONU mejor no hablar y eso que a finales de 2014 Estados Unidos y China han firmado un acuerdo para controlarse un poco.

El problema es que los países más ricos han empezado a comprobar que lo que decían algunos "catastrofistas" hace unos años parece que era cierto. Que estamos consumiendo más que lo que la biocapacidad de la Tierra es capaz de producir. Y que 
el planeta es una tarta limitada de la que tienen que comer 7000 millones de seres humanos. Y que si los 6000 millones que ahora consumen menos consumieran lo que les corresponde, los 1000 millones que consumen más tendrían que disminuirlo. El cambio tremendo que se ha producido desde mediados de los años ochenta es que, cuando en cualquier parte del planeta se superaba el nivel de consumo de las regiones urbanas o de los países no había problema, se expandían estos ámbitos ya que todavía teníamos suficiente planeta para hacerlo. Esta expansión se podía conseguir en forma de guerras, acuerdos comerciales o conquistas financieras. Pero eso se ha terminado. La huella ecológica producida por el consumo humano ha superado la superficie de la Tierra. Y lo que es peor, estamos consumiendo las reservas a las que, además, se les ve el fin.

La llamada sostenibilidad ya solo es posible de dos formas. O bien, de acuerdo con la justicia repartiendo la tarta. O bien, si queremos que los que más tienen tengan todavía más, quitándoselo a los que menos tienen. El problema es que un sistema económico basado en el crecimiento no puede funcionar si esa pequeña parte que lo domina no consume cada vez más. Los que me conocen ya saben lo que voy a decir a continuación. El sistema tiene una gran resiliencia en sí mismo. Ha dado pruebas a lo largo de la historia humana de tener la suficiente capacidad como para mantenerse a pesar de las mayores dificultades. No tengo ninguna duda de que el sistema encontrará por sí mismo la forma de perpetuarse. Es decir, no soy un catastrofista que piensa que todo se va a hundir y que la especie humana va a desaparecer de la faz de la Tierra. De lo que tampoco tengo dudas es de que, o controlamos el proceso, o mucha gente va a sufrir mucho. Mejor dicho, los que ya ahora sufren van a sufrir todavía más. Y muchos de los que se creían a salvo de tales sufrimientos (las llamadas clases medias) van a entrar en este grupo. La sostenibilidad entrará, por tanto, en una nueva fase.

Nota: he preferido no incluir citas ni bibliografía, excepto las directas que aparecen en el texto. Todas las referencias son de notorio conocimiento, y no harían más que enturbiar la lectura del artículo y la construcción del discurso ya de por sí bastante complejo. 


\title{
EL FUTURO DE LOS ESTUDIOS DE FUTURO EN LA PLANIFICACIÓN URBANA Y TERRITORIAL
}

\author{
José Miguel Fernández Güell (Dr. Arquitecto - Profesor titular DUyOT)
}

En los 25 años de existencia de nuestra revista CIUR, diversos cambios sociales, económicos, tecnológicos, ambientales y de gobierno han afectado con mayor o menor intensidad a la práctica de la planificación urbana y territorial. En estos años han surgido nuevas formas de hacer urbanismo como respuesta a nuevas demandas, se han consolidado otras tradicionales por su demostrada utilidad social y se han cuestionado otras obsoletas por su ineficacia para afrontar los retos de las ciudades contemporáneas. Sin ánimo de efectuar un recorrido exhaustivo sobre las vicisitudes que ha experimentado el Urbanismo en el último cuarto de siglo, en este breve artículo me centraré en describir la evolución que han seguido los estudios del futuro en nuestro campo profesional.

Históricamente, uno de los objetivos fundamentales de los urbanistas ha sido tomar decisiones en el presente para guiar desarrollo las actividades urbanas en el futuro y así mejorar las condiciones de vida. En otras palabras, los urbanistas han tratado de prever la evolución futura de las ciudades con el fin de anticipar y corregir los posibles impactos que pudieran afectarlas. Sin embargo, en la actualidad los planificadores urbanos no parecen perseguir con mucho convencimiento ese objetivo. A principios del siglo XX, visionarios como Daniel H. Burnham, Antonio Sant'Elia o Le Corbusier se esforzaron en escenificar con dibujos y palabras cómo serían las ciudades del futuro. Detrás de estas visiones de futuro no había reflexiones y análisis muy rigurosos que fundamentaran sus propuestas urbanas, más bien el sustento procedía de la intuición e imaginación del propio arquitecto-urbanista. A pesar de todo, esas visiones urbanas, cargadas de fuertes dosis de utopía, eran capaces de estimular e ilusionar a una amplia audiencia ciudadana.

A partir de los años 50 los urbanistas se volcaron en el desarrollo de modelos cuantitativos como la opción más rigurosa y precisa para prever el futuro, pero al mismo tiempo la menos amigable para comunicarse con los ciudadanos (HALL, 1996; TERÁN, 1996). Pronto estos modelos generaron un profundo desencanto debido a la magnitud de los errores cometidos en las predicciones, poniendo así de manifiesto las limitaciones del urbanismo científico y tecnocrático. Al descrédito sufrido por los modelos de simulación se sumó la incertidumbre producida por las turbulencias acaecidas en los años 70 --crisis energética, agotamiento de los sistemas políticos, crecientes impactos ambientales y cambios demográficos- que dejaron obsoletos los paradigmas anteriores. Bajo estas circunstancias, el planificador perdió sus marcos de referencia tradicionales y terminó reconociendo su impotencia para realizar previsiones fiables y explicar fenómenos urbanos complejos mediante leyes científicas y patrones regulares. De este modo, los urbanistas se fueron distanciando de las técnicas de previsión y pasaron a practicar una planificación más contingente, pragmática y cortoplacista.

A mitad de los años noventa, en determinados campos de conocimiento renació el interés hacia los estudios del futuro. Avances notables en las técnicas de previsión 
de carácter cualitativo, tales como el Método Delphi y el Diseño de Escenarios, atrajeron la atención de tecnólogos, sociólogos y empresarios. En poco tiempo, este interés se vio refrendado por la aparición de numerosas publicaciones científicas y profesionales, así como por la proliferación de consultores especializados en esta materia. Durante estos años surgieron en los países más desarrollados observatorios nacionales de prospectiva bajo el amparo de entidades estatales y regionales con el propósito de prever los cambios a largo plazo y así guiar las estrategias para el desarrollo socioeconómico y tecnológico de sus territorios. Sin embargo, el mundo del urbanismo, salvo excepciones contadas, permaneció ajeno a la utilización de las nuevas herramientas de prospectiva. De hecho, llamaba la atención cómo un colectivo de profesionales dedicados aparentemente a la planificación a largo plazo mostrara ignorancia y reticencia hacia estas herramientas.

Apoyado en las opiniones de expertos que han reflexionado sobre esta cuestión y en mi propia experiencia (COLE, 2001; FERNÁNDEZ GÜELL, 2011; ISSERMAN, 1985; WACHS, 2001), me atrevo a identificar cinco razones que explican este divorcio entre urbanistas y estudios del futuro.

Una primera razón, ya insinuada anteriormente, se refiere a la evolución que han experimentado los enfoques profesionales que dominan la planificación urbana. Tras la Segunda Guerra Mundial el control de la planificación urbana pasó de las manos de los arquitectos y diseñadores espaciales a los científicos sociales e ingenieros, que fundamentaron su labor en el pensamiento analítico. En este contexto, el futuro ya no era configurado mediante visiones espaciales, sino que se empleaban predicciones cuantitativas a partir de bases de datos, modelos matemáticos y algoritmos. Por tanto, una predicción no constituía una visión del futuro, sino que más bien se convertía en una simple proyección de tendencias históricas que daba lugar a una imagen tecnocrática del futuro.

La segunda razón radica en que los planes urbanísticos han pasado de centrarse en productos finales a focalizarse en procesos operativos de tipo continuo. Concretamente, los modernos enfoques de planificación colaborativa entre agentes públicos y privados han sustituido al antiguo paradigma de los planes basados en visiones y predicciones técnicas. Así, hoy en día la participación ciudadana y la colaboración con agentes locales se han convertido en elementos clave de un urbanismo concertado y orientado a la acción a corto y medio plazo. En este contexto, prevalece la preocupación por establecer la legitimidad del proceso de planificación mediante la formulación de múltiples visiones en lugar de perseguir con decisión alguna de ellas en particular. En suma, la necesidad de consenso y compromiso ha dejado a un lado la visualización del futuro.

La tercera razón se centra en argumentos ideológicos. El modelo neoliberal imperante desde finales de los años 1970 ha restringido la intervención pública en muchas esferas de la vida social y económica, propiciando recortes presupuestarios de los organismos públicos que han debilitado el proceso de planificación. Esta situación ha supuesto el aumento de la presión de las necesidades de corto plazo sobre las visiones a largo plazo, lo que ha cercenado la reflexión de futuro entre los planificadores urbanos. Evidentemente, la intensa recesión económica que sufrimos desde el año 2008 no ha hecho más que agravar esta situación en virtud de las políticas de austeridad auspiciadas por los organismos internacionales. 
En cuarto lugar, persiste una falta de confianza generalizada en las herramientas de prospectiva y en los planificadores para reflexionar de forma plausible sobre el futuro. Para el mundo urbanístico contemporáneo, una predicción es correcta siempre y cuando incorpore modelos matemáticos sencillos y comprensibles, que contengan verdades empíricas, en lugar de valores e ideales subjetivos sobre el futuro. Este pragmatismo tecnocrático se ha visto reforzado por los avances producidos en los sistemas de información geográfica, en los modelos de ordenador y en los métodos estadísticos. A pesar de que la sofisticación de las técnicas cuantitativas es más aparente que real, la opinión predominante es que estas técnicas aportan valor añadido al analista urbano, proporcionan un aura de complejidad científica a las predicciones y otorgan autoridad a las decisiones políticas.

Existe una quinta razón, propia del contexto español donde el marco jurídico es rígido y excesivamente regulador, los agentes inmobiliarios especulan descaradamente y muchos políticos toman decisiones de forma opaca y arbitraria. Obviamente, en este contexto resulta complicado generar visiones de futuro con el concurso de un amplio número de agentes locales y de la base ciudadana. En consecuencia, la situación española actual no es propicia para desplegar una planificación territorial comprometida y reflexiva que haga uso de los estudios del futuro.

Aunque de naturaleza muy diversa, estas razones explican la poca atención que los urbanistas han prestado en los últimos años a revisar y reinventar los métodos para prever el futuro. Todo parece indicar que la complejidad, la incertidumbre y el debate social inherentes al urbanismo contemporáneo han dificultado la puesta en práctica de métodos efectivos de previsión de futuro. Ahora bien, también parece que la planificación urbana ha sacrificado voluntariamente su rol visionario e idealista, y ha abandonado su responsabilidad de ser la fuente de inspiración e ideas acerca de lo que puede y debe hacerse en la ciudad.

Llegados a este punto, como investigadores podemos plantearnos una serie de cuestiones. ¿Merece la pena anticipar y controlar todos los aspectos de la vida urbana? ¿Si lo hiciéramos, perderíamos algo? ¿No son el caos, la espontaneidad y la imprevisibilidad sinónimos de la vitalidad urbana? ¿No limitan los sistemas complejos urbanos la certeza y predictibilidad de nuestras previsiones? ¿No es más inteligente aquella ciudad que facilita la combinación por azar y necesidad de gente diversa en muchos espacios de encuentro, fundamentalmente públicos? ¿No es el propósito del urbanismo contemporáneo reducir las dinámicas que tienden a generar lugares especializados y a segregar socialmente la población? ¿Serán capaces la ciencia y la tecnología de proporcionarnos los medios para lograr anticipaciones con elevado grado de fiabilidad? Todas estas inquietudes las podemos sintetizar en una doble pregunta: ¿sería conveniente, por un lado, y viable, por otro, recuperar los estudios del futuro en el urbanismo?

En mi opinión, no creo acertado hurtar a las ciudades y a los ciudadanos los avances en los estudios de futuro. Dudo mucho que estos avances supongan una amenaza para la vitalidad de nuestras ciudades y menos aun para los procesos de planificación; al contrario, pueden contribuir a resolver algunos de los retos a los que nos enfrentamos. De hecho, nuestras sociedades urbanas afrontan transformaciones en las estructuras demográficas, avances en el proceso de globalización, amenazas 
del cambio climático, aparición de tecnologías disruptivas y nuevos modelos de gobernanza. Adicionalmente, los citados cambios están ocurriendo con gran rapidez y comportamientos no lineales de difícil asimilación por la Sociedad. Razones todas ellas de peso para defender la conveniencia de reflexionar sobre el futuro.

En cuanto a su viabilidad, considero que sí es factible la recuperación de los estudios del futuro para el ámbito de la planificación urbana y territorial. Un primer argumento de apoyo es que se han producido progresos significativos en las herramientas de prospectiva, aumentando su catálogo, sus prestaciones y su fiabilidad (MYERS \& KITSUSE, 2000). Un segundo argumento se refiere al potencial de las nuevas tecnologías para explotar los enormes volúmenes de datos (big data) que se van a acumular en la nube computacional (cloud computing) y que previsiblemente podremos cruzar para entender mejor el comportamiento de las ciudades (BATTY et al., 2012). Un último argumento destaca la utilidad ya contrastada de los instrumentos de prospectiva para involucrar a los agentes locales (stakeholders) en los procesos de reflexión estratégica (FERNÁNDEZ GÜELL, 2006).

En suma, los estudios del futuro no nos garantizan el acierto de las previsiones, pero sí nos pueden aportar ideas frescas, sugerencias creativas y políticas renovadoras que funcionen como un contrapeso a la práctica excesivamente tecnocrática y jurídica que domina actualmente el urbanismo en nuestro país. Estimo que un ejercicio de prospectiva bien realizado nunca será una pérdida de tiempo, incluso si las previsiones no resultan acertadas. El mero hecho de enseñar a los agentes urbanos a pensar sobre el futuro de forma colectiva ya será un logro muy valioso.

\section{REFERENCIAS BIBLIOGRÁFICAS:}

BATTY, M. et al. (2012). "Smart cities in the future", UCL Working Papers Series, No 188, October 2012. UCL Centre for Advanced Spatial Analysis, London.

COLE, S. (2001). "Dare to dream: bringing futures into planning", American Planning Association Journal, 67 (4), pp. 372-383.

FERNÁNDEZ GÜELL, J. M. (2011). "Recuperación de los estudios del futuro a través de la prospectiva territorial", Ciudad y Territorio, No. 167, pp. 11-32.

FERNÁNDEZ GÜELL, J. M. (2006). Planificación estratégica de ciudades: Nuevos instrumentos y procesos, Editorial Reverté, Barcelona.

HALL, P. (1996). Cities of Tomorrow, Blackwell, London.

ISSERMAN, A. M. (1985). "Dare to plan: An essay on the role of the future in planning practice and education", Town Planning Review, No. 56 (4), pp. 483-491.

MYERS, D., \& KITSUSE, A. (2000), "Constructing the future in planning: a survey of theories and tools", Journal of Planning Education and Research, 19, pp. 221-231.

TERÁN, F. de (1996). "Evolución del planeamiento urbanístico (1846-1996)", Ciudad y Territorio - Estudios Territoriales, No. 107-108, pp. 167-184.

WACHS, M. (2001). "Forecasting versus Envisioning: A new window on the future", Journal of American Planning Association Journal, Vol. 67 No. 4, pp. 367-372. 


\title{
MIGRACIONES GLOBALES Y CIUDAD
}

\author{
Fernando Fernández Alonso (Arquitecto - Profesor asociado DUyOT)
}

\section{Inmigración internacional desde los años 90}

En los últimos 20 años se han incorporado a nuestra población un número de emigrantes internacionales como nunca se había producido anteriormente. Los cambios que en las ciudades ha implicado este flujo están relacionados con su capacidad de atracción y adaptación, pero tienen que ser considerados también como factores de revitalización o indicadores de decadencia.

Si en 1998 se produjo una entrada de 80.000 inmigrantes, en 2007, el año de mayor afluencia a nivel estatal, la entrada es de 1 millón de inmigrantes, lo que constituía en un solo año el $2 \%$ de la población nacional. El incremento de población empadronada en España en el mismo periodo es de de 5.264.244 individuos, de los que 3.845.483 ha sido de población extranjera, el $73 \%$. Desde entonces y como consecuencia de la crisis, se produce un descenso paulatino, con 500.000 entradas en 2009 y 342.000 en 2013. En este último periodo se produce además un fenómeno inverso, la salida de emigrantes, 300.000 en 2009 y 450.000 en $2013^{13}$. La pérdida de población extranjera no se ha producido por igual en todas las comunidades autónomas. Así, en la Comunidad de Madrid, en el 2007 sigue aumentado la población extranjera (1.001.058 a 1.118.991), hasta el año 2010, cuando se produce un punto de inflexión negativo (868.233 en 2015).

Como resultado de estas avenidas y flujos, nos encontramos con que la población extranjera en el periodo de 1996 a 2010 ha oscilado en esta comunidad del $2 \%$ al $17 \%$ y actualmente está en el $14 \%{ }^{14}$. Las nacionalidades mayoritarias son de Europa (364.527, 41\% total), y América del Sur, Central y del Caribe (301.160, 34\%). Marruecos representa el 9,26\% y China el 6,09\%. Si en 1998 la población rumana en Madrid, el grupo inmigrante mayoritario, eran 717 personas, en 2010 llegó a 210.822 y en 2014, a 199.141 personas. Como la población inmigrante se distribuye en el territorio de la Comunidad de Madrid, en un porcentaje significativo, por nacionalidades, el peso de estas comunidades mayoritarias es todavía mayor.

\section{Una nueva población urbana}

La emigración es fundamentalmente urbana, joven-adulta y familiar: el 44,05\% de los inmigrantes están en el municipio de Madrid, y el $41,46 \%$ en municipios de las coronas metropolitanas, es decir, en espacios urbanos ${ }^{15}$. Hay barrios en los que la

13 LOS FLUJOS MIGRATORIOS EN ESPAÑA DURANTE LA CRISIS. Mario Izquierdo, Juan Francisco Jimeno y Aitor Lacuesta, Dirección General del Servicio de Estudios del Banco de España. Boletín económico, Sep 2014. INMIGRACIÓN EXTRANJERA EN LA COMUNIDAD DE MADRID, Miguel Ángel de Prada, Colectivo Ioé.

14 Datos del Instituto de Estadística de la Comunidad de Madrid.

15 Madrid, Móstoles, Alcalá de Henares y Fuenlabrada son las cuatro primeras ciudades en número de población extranjera, pero son Parla, Coslada y Collado Villalba, entre los municipios con mayor población de derecho, los tres con mayor porcentajes de población extranjera. 
población extranjera llega hoy hasta el 20 y $25 \%$ y municipios en los que lo supera. Los grupos de edad ${ }^{16}$ tienen un gran contraste con la población española en el perfil de 25 a 39 años, con el $40 \%$ de la población extranjera en ese grupo frente al $20 \%$ de la población española, mientras que el porcentaje de la población menor de 20 años respecto al total es casi equivalente en los dos. Si como señala el informe del Banco de España el rápido incremento de ciudadanos extranjeros constituye un importante cambio en la fuerza laboral por edad y nivel educativo, las consecuencias en la ciudad no son menos significativas, más aún cuando la población inmigrante urbana se ha mantenido más resistente a la vuelta a su lugar de origen, pero los ciclos y fluctuaciones dependen de factores exógenos y globales. La inmigración supone en muchos barrios un relevo importantísimo de la población característica, de grupos de edad y sociales completos, pero no sabemos con seguridad cuántos de ellos están en los barrios para quedarse a largo plazo.

\section{Asentamiento de la inmigración en la ciudad consolidada}

Los inmigrantes se han asentado en todo tipo de barrios de la ciudad, excluyendo zonas de alto nivel económico con tipologías muy homogéneas, concentrándose en base a tres circunstancias: la disponibilidad de vivienda en alquiler o alojamiento barato, variado y rápido; la agrupación familiar o de colectivos y nacionalidades en un entorno muy cercano; y la cercanía al lugar de trabajo, por la reducción de costes de desplazamiento y en relación con algunas actividades, por el incremento de productividad y oportunidades. Muchas de las actividades económicas en las que se ocupan los emigrantes (servicios de hostelería, mantenimiento y limpieza, transporte, asistencia a hogares y cuidado de enfermos y ancianos, construcción) se realizan de forma independiente y ocasional, y con frecuencia a partir de redes familiares o de amigos, lo que requiere de proximidad.

Al contrario de la inmigración rural que dio lugar al crecimiento de la periferia madrileña en procesos ordenados e informales, la inmigración internacional se asienta en la ciudad consolidada. Los inmigrantes han ocupado una parte específica de las ciudades que en muchos casos acusaba problemas de obsolescencia, aportando a cambio vitalidad, actividad, negocios y cambios culturales. Esta población mantiene fuertes vínculos con sus barrios por cuestiones económicas, de proximidad, familiares, de grupo e identidad, incluso de seguridad, lo que ha favorecido la recuperación de estructuras de barrio y cercanía ajenas a las dinámicas de dispersión comercial y de ocio en la periferia. La baja cultura española de reocupación o recuperación de tejidos consolidados se ha visto compensada por la inmigración.

Los migrantes llegaron cuando las expectativas económicas eran muy altas, la ciudad se estaba expandiendo, y la población local buscaba nuevos lugares y tipologías para desarrollar programas vitales distintos. Se ha producido un intercambio de rentas que permitió a la población local la salida de sus barrios tradicionales y a la población emigrante la adquisición o alquiler de una vivienda, con distintos grados de habitabilidad, dignidad e integración urbana, muy precaria en muchos casos. La segura permanencia de gran parte de la segunda generación en su

\footnotetext{
${ }^{16}$ Informe de la población de origen extranjero empadronada en la Comunidad de Madrid. Observatorio
} de Inmigración del Centro de Estudios y Datos de la Comunidad de Madrid. Enero de 2015. 
nuevo país y la gran capacidad de ahorro de las familias inmigrantes, auguran que la población inmigrante no permanecerá en estas zonas, y que se trasladarán (y dispersarán) por la ciudad y el área metropolitana.

La ciudad y sus barrios han ganado a cambio la renovación y el mantenimiento de la edificación y la actividad local por vía de la nueva población, pero no es menos importante que los conflictos de integración sean puntuales, y que, en mi opinión, la inmigración contribuya a crear un nuevo acervo multicultural, disolviendo la homogeneidad de las visiones autóctonas familiares, colectivas y políticas. Los emigrantes ocupan la calle, parques y espacios públicos de una forma activa, organizada y respetuosa. La calle es, para ellos, un lugar de integración y celebración colectiva, mediante el deporte en grupo, la comida, el encuentro; que sea evidentemente barata refuerza la disponibilidad para este uso.

\section{Integración e inestabilidad}

En los periodos señalados la inmigración ha introducido en la ciudad unos tipos de diversidad e inestabilidad diferentes a los habituales, de carácter global y fuertemente percibidos por sus habitantes; la resistencia y adaptabilidad de los tejidos urbanos a nuevos escenarios cuantitativos y emocionales ha definido y definirá la vida de numerosos espacios de nuestras ciudades.

La integración de la diversidad está avanzada en los programas sociales y económicos con distintos modelos y grados de avance, y está desgraciadamente condicionada por los problemas de gestión de la creciente precarización social y del empleo. La conservación de la ciudad tradicional y la rehabilitación de barrios forma parte de la planificación urbanística; pero es necesaria una reflexión profunda sobre quiénes son los nuevos habitantes que la han ocupado y actualmente la utilizan, sufriendo gran parte de sus peores condiciones de habitabilidad.

Como actores de la ciudad, y hemos visto que en gran número y proporciones muy altas sobre la población tradicional, los colectivos inmigrantes van a participar en su futuro en la medida en que se consolide su permanencia. Y lo harán imponiendo quizás nuevas formas de entender la conservación y rehabilitación, el papel de los equipamientos, el espacio público y la movilidad.

Con escenarios y evoluciones ligados a cambios globales, o simplemente por el deseo de retorno a la nación de origen, la inestabilidad del número y carácter de la nueva población inmigrante es un nuevo factor de planificación. Los barrios pueden pasar a formar parte de las piezas de juego de una economía global, como lo es el suelo de actividades económicas. Los barrios y viviendas en los que los inmigrantes se han asentado, que eran frágiles ya antes de su llegada, pueden estar sometidos a dinámicas de abandono, deterioro, reocupación o incluso gentrificación para las cuales será necesario establecer estrategias de resistencia y adaptabilidad. 


\title{
ÁNIMO Y DEDICACIÓN
}

\author{
Julio García Lanza (Dr. Arquitecto -Profesor emérito DUyOT)
}

Quiero empezar este pequeño escrito, dando las gracias a $\mathrm{Ci}(U r)$ y, en especial a su director José Fariña, por haberse acordado de mí, para colaborar en el numero 100 de la revista $\mathrm{Ci}(U r)$. a pesar de llevar catorce años jubilado por la ETSAM como profesor titular, aunque algunos menos por el Departamento de Urbanismo, que tuvo a bien confiarme algunas clases como profesor emérito o "ad honorem",

Mis labores relacionadas con el urbanismo siempre han estado orientadas al planeamiento urbanístico, tanto teórica como prácticamente. Cuando al principio de los años sesenta del siglo pasado, los que empezábamos a estudiar urbanismo desde un punto de vista profesional, enseguida nos dimos cuenta de que el planeamiento urbanístico no podía ser únicamente un diseño más o menos ingenioso, reflejando en un plano la forma que en el futuro tendría la ciudad que se estuviese estudiando.

En aquellos años, los profesionales que nos interesábamos por el urbanismo íbamos a hacer los cursos del Instituto de Estudios de Administración Local para obtener el diploma de Técnico Urbanista. Es decir te hacías "técnico en urbanismo". Enseguida muchos descubrimos que el urbanismo era un quehacer muy complejo, apoyado en muchas ciencias: geográficas, económicas, sociales, estadísticas, biológicas, legales, demográficas, ambientales, etc. y pensamos que los estudios urbanos deberían tener un carácter científico multidisciplinar pero con su propia identidad.

En Mayo de 1956 salió la primera Ley del Suelo, regulando la actividad urbanística en el territorio nacional de España, que nos sirvió a los profesionales de la época como guía indiscutible para el desarrollo de los estudios urbanísticos que en su desarrollo había que hacer. Su preámbulo o declaración de intenciones es un autentico tratado de urbanismo moderno, en el que se explicitan las acciones a realizar para conseguir que el crecimiento de las ciudades españolas, que en aquel momento se producía de una manera acelerada, como consecuencia de la emigración de los habitantes de las zonas agrícolas a las ciudades industriales.

Si el espíritu que contenía aquella declaración de intenciones se hubiera mantenido a lo largo de los años en los desarrollos urbanísticos de las ciudades españolas, se habría conseguido un nivel de habitabilidad urbana mucho más alto que el que actualmente tienen.

Al principio, la Dirección General de Urbanismo recién creada dentro del Ministerio de la Vivienda, promovió la redacción de muchos Planes Generales de algunas capitales de provincia y los urbanistas, incipientes en la nueva labor, nos dedicamos con gran animo y entusiasmo al estudio de las necesidades de cada ciudad a través de equipos de abogados, estadísticos, economistas, sociólogos, ingenieros, arquitectos, etc. con objeto de redactar el Plan General de cada ciudad, que se consideraba más adecuado a cada caso, apoyados y animados por la Ley del Suelo recientemente aprobada. 
Por parte de las administraciones locales se respondió favorablemente, convocando concursos nacionales e internacionales de planeamiento urbanístico, para resolver los problemas aparecidos en sus territorios.

Esto animaba a los equipos de urbanistas a seguir estudiando y trabajando al mismo tiempo, para mejorar las soluciones de los problemas urbanos y territoriales de cada lugar.

En el año 1975 la Ley del Suelo se complemento con los reglamentos de la ley, que daban normas para el desarrollo detallado del territorio a través de Planes Parciales, Proyectos de Urbanización etc... y esto abre nuevos campos, a los arquitectos e ingenieros fundamentalmente, para la materialización formal de los nuevos barrios de la ciudad.

A la hora de la ejecución de los planes urbanísticos, surge el mayor enemigo del planeamiento urbano, la especulación del suelo, elemento, que a pesar de los contenidos que la propia Ley del Suelo tenía previsto contra ella, contando con el Patrimonio Municipal del Suelo, distorsiona, ensucia y prostituye las justas previsiones contenidas en los planes. La practican tanto los particulares como las administraciones, considerando que el aumento del valor del suelo al pasar de rustico a urbano no es un valor urbanístico-social sino monetario.

Con la crisis financiera y la llamada burbuja inmobiliaria, el efecto especulativo se multiplica y nos lleva a la situación en la que nos encontramos ahora, en la que el planeamiento urbanístico no tiene relevancia.

La situación postindustrial en la que se encuentra la sociedad actual, parece que tiene tintes universales, aunque cada territorio tenga sus propias peculiaridades, y la dinámica poblacional, tanto en cantidad como en localización. afecta a todo el mundo, por lo tanto las soluciones que se han de proponer para resolver los problemas de asentamientos urbanos han de ser consideradas globalmente.

El Planeamiento Urbano (organización del territorio para conseguir que los asentamientos humanos se produzcan de la forma más favorable para las actividades humanas y el mejor desarrollo del medio natural) que tocara hacer a las actuales y futuras generaciones de urbanistas, ha de tener en consideración las nuevas condiciones de vida que las sociedades del siglo XXI están empezando a vivir, igual que hicimos los que nos toco vivir la época industrial, tomándolo con entusiasmo y dedicación, porque merece la pena. 


\title{
HABITABILIDAD BÁSICA EN LA ENSEÑANZA
}

\author{
Belén Gesto (Arquitecta - Profesora asociada del DUyOT)
}

Tomé la decisión de estudiar arquitectura hace ya veinte años después de leer La ciudad de la Alegría, de Dominique Lapierre, y descubrir lo que podía ser la vida en un slum (tugurio) -que hasta entonces desconocía-. Y me aventuré en la carrera dispuesta a aprender a "hacer casas buenas, bonitas y baratas" -como me decía con palabras ingenuas y juveniles-, que fuesen capaces de dar dignidad a aquellos que poco tenían, que vivían en la miseria, hacinados en pequeños cuartos, en condiciones insalubres, compartiendo letrinas cada mañana y un sólo grifo de agua y que, conscientes de que por todo ello su esperanza de vida era menor, luchaban por lograr unas condiciones mínimas de habitabilidad.

En los seis años de carrera no encontré el espacio académico en la ETSAM que respondiese a las inquietudes con las que había comenzado y que me ayudase a formarme para ser capaz de dar respuesta, como arquitecta , a aquello a lo que me sentía llamada. Fue en sexto curso cuando por primera vez un profesor, Luis Felipe Teixidor, puso en clase una imagen de un tugurio, con la que se nos mostraba esa otra realidad -precaria- que se podía encontrar en algunas ciudades del planeta. Y fue gracias a él que supe de la existencia de un Curso de Posgrado ${ }^{17}$ y conocí a los dos profesores a los que a día de hoy, más de mil alumnos les debemos nuestros conocimientos en lo que ellos denominaban Habitabilidad Básica (HaB, en adelante). Esos profesores, a los que personalmente debo parte de lo que hoy soy, son Felipe Colavidas y Julián Salas, profesores del DUyOT ${ }^{18}$. Era el año 2000.

Hacía cuatro años -después de Hábitat $\mathrm{II}^{19}{ }_{-}$, habían iniciado una trayectoria académica juntos con la que cubrir un vacío en la enseñanza universitaria, en el campo de la Cooperación al Desarrollo y de los Asentamientos Humanos en países en desarrollo -en aquel momento denominados 'Tercer Mundo'-. Y durante casi veinte años -primero juntos, y luego por separado-, se han esforzado por intentar aportar instrumentos de ordenación territorial, planeamiento, urbanización y alojamiento a profesionales que deseaban trabajar para dar respuesta al hambre de vivienda20. Fundaron el ICHaB (Instituto de Cooperación en Habitabilidad Básica, uno de los primeros Grupos de Cooperación creados en la UPM) y en 2007 lograron el reconocimiento de Cátedra UNESCO de Habitabilidad Básica.

Incorporaron así la $\mathrm{HaB}$ en el ámbito académico, en la enseñanza universitaria. Primero, con la formación en posgrado que comenzaron con una asignatura de doctorado y el Curso de Especialización. Para luego, con el apoyo del DUyOT, ofertar

17 Curso de "Cooperación para el Desarrollo de Asentamientos Humanos en el Tercer Mundo" que, en 2016 iniciará su XIX edición. Comenzó siendo Curso de Especialización. En la actualidad es un Título de Experto.

18 Felipe Colavidas Espinosa, Dr. Arquitecto, profesor titular del DUyOT y Julián Salas Serrano, Dr. Ingeniero Industrial, investigador del CSIC y profesor ad honorem del DUyOT.

19 La Segunda Conferencia Mundial sobre Asentamientos Humanos que había tenido lugar en Estambul en 1996.

20 El libro de Julián Salas, Contra el hambre de vivienda, publicado en 1998 (editorial Escala, Colombia), se convirtió en referente dentro y fuera de España, especialmente en América Latina. 
en los estudios de Arquitectura del Plan 96 de la ETSAM, la asignatura optativa 715 Habitabilidad Básica que ha dado la oportunidad, a aquellos que tenían la inquietud, de poder formarse en ello durante sus estudios de grado ${ }^{21}$. Oportunidad que, hace veinte años, no tuve, y que sinceramente considero un gran aporte -aunque sea modesto- en y de nuestra Universidad.

HaB es, en palabras del profesor Colavidas, "la que colma las necesidades esenciales de cobijo que tenemos todas las personas. Su satisfacción supone que se cubran las urgencias residenciales del vivir, pero no sólo las que se refieren al mero cobijo, sino también a los espacios públicos, infraestructuras y servicios elementales que constituyen, en conjunto, un asentamiento propicio para la reproducción vital. Una $\mathrm{HaB}$ que atiende además de las necesidades de alojamiento y residencia -del estar-, las de producción -del ser material activo-". La HaB comprende, por tanto, abastecimiento de agua potable, saneamiento, eliminación de desechos, asistencia social básica, servicios de transporte y comunicaciones, caminos de bajo coste, suministro de energía, servicios de salud, escuelas, seguridad ciudadana, espacios para el ocio, viviendas semilla,... mediante construcciones e infraestructuras de bajo coste que deben ser capaces de mejorar paulatinamente.

En el ámbito internacional, las reflexiones que tuvieron lugar en la Conferencia sobre Asentamientos Humanos en 1976 (Hábitat I), supusieron una enorme sorpresa para muchos gobiernos -en particular, de América Latina-. Esta conferencia significó una apertura de miras ante una realidad que no se quería atender y el primer paso a la incorporación de nuevas estrategias y nuevas concepciones de la problemática de la habitabilidad precaria, así como de las posibles soluciones. Prueba de la nueva conciencia mundial fue la creación en 1978 del primer Centro de las Naciones Unidas para los Asentamientos Humanos (UNCHS). Este centro en 2001, tras la cumbre de los Objetivos de Desarrollo del Milenio, (ODM), se transformó en el Programa de las Naciones Unidas para los Asentamientos Humanos ONU-Habitat (UN-Habitat).

Fue precisamente a raíz de los ODM, en concreto de su meta 11 (conocida como "Cities without slums") dentro del objetivo 7 de "Garantizar la sostenibilidad del medio ambiente", cuando se hizo preciso definir tugurio y establecer los parámetros que permitiesen medir el cumplimiento de la meta que se había fijado "Haber mejorado considerablemente, para el año 2020, la vida de por lo menos 100 millones de habitantes de tugurios".

El informe de UN-HABITAT "Slums of the world: The face of urban poverty in the new millennium?", de 2003, recoge esos indicadores y determina que el grado de precariedad de un asentamiento urbano puede medirse en función del acceso de los hogares a cinco parámetros: acceso a agua potable, acceso a saneamiento básico, área suficiente para vivir, durabilidad de la vivienda y tenencia segura ${ }^{22}$. Se considera

21 En el nuevo Plan 2010, se imparte el Taller Experimental Habitabilidad Básica

22 Acceso al agua potable: Se considera que un hogar tiene acceso al suministro de agua potable si dispone de al menos 20 litros de agua por persona y día, a un precio inferior del $10 \%$ del total de los ingresos del hogar, sin que los miembros del hogar deban someterse a un esfuerzo extremo, especialmente las mujeres y los niños (menos de 1 hora al día). Acceso a saneamiento básico: Se considera que un hogar tiene acceso adecuado al saneamiento básico si sus miembros disponen de un sistema de eliminación de los excrementos, ya sea en forma de letrina privada o pública compartida por un número razonable de personas. Área suficiente para vivir, sin hacinamiento: Se considera que una vivienda proporciona un área suficiente para que sus miembros vivan si hay menos de tres personas por 
tugurio ('slum') un área de una ciudad en la que la mitad o más de su población carece de alguno de esos cinco parámetros (UN-HABITAT, 2003).

La cifra de personas viviendo en tugurios en las regiones en desarrollo en el 2012 era de 862,5 millones. Si bien se ha alcanzado la meta del Objetivo referida a la población de los tugurios, la cantidad de habitantes de estos barrios sigue aumentando en términos absolutos, debido en parte al ritmo vertiginoso del proceso de urbanización. Este proceso sigue siendo más rápido que las mejoras en los tugurios (UN-HABITAT, 2013). En 2012, los 862,5 millones de habitantes urbanos de las regiones en desarrollo que vivían en tugurios suponían un $33 \%$ de su población total urbana. En África subsahariana ese porcentaje era el más alto del planeta, del 62\%, siendo la región que además, según las estimaciones de Naciones Unidas, tendrá los mayores crecimientos demográficos y de tasas de urbanización de los próximos treinta años (UN, 2013).

En lo que al acceso a infraestructuras y servicios se refiere, cabría añadir dos datos relevantes: en 2012 había 748 millones de personas que seguían utilizando agua de fuentes no mejoradas y más de 2.500 millones no tenían acceso a saneamiento mejorado, un $10 \%$ y un $35 \%$ del total de población mundial respectivamente (UN, 2014). Es más, sigue inquietando aún la calidad y la seguridad de muchas de las fuentes de agua potable consideradas mejoradas, lo que hace pensar que la cantidad de personas sin acceso al agua potable segura podría ser incluso dos o tres veces superior a las estimaciones oficiales. De forma general, es preciso -y positivo- señalar que los valores porcentuales de precariedad se están reduciendo, aunque en valores absolutos, debido al crecimiento demográfico, las cifras sigan creciendo. Se puede por tanto afirmar -considerando sólo el último parámetro relativo a la falta de saneamiento mejorado en el mundo- que más del $35 \%$, una de cada tres personas en el mundo, vive en condiciones de habitabilidad precaria.

Y no se trata sólo de un problema urbano, la habitabilidad precaria rural es más numerosa -y severa- que la urbana. Ocho de cada diez personas sin acceso a fuente mejorada de agua vive en el ámbito rural, así como siete de cada diez que carece de saneamiento mejorado (UN, 2014). Sin olvidar la cifra récord alcanzada al final de 2013 de 51,2 millones de personas en todo el mundo desplazadas forzosamente como consecuencia de la persecución, de los conflictos, por la violencia generalizada y a causa de las violaciones de los derechos humanos que, en gran parte, se encuentran en campamentos "provisionales", fundamentalmente asistidos por ACNUR.

Afortunadamente, puedo decir que la Habitabilidad Básica se ha asentado en la ETSAM. Su incorporación a nuestra enseñanza universitaria ha brindado la oportunidad a los estudiantes de poder elegir una formación que, durante años, y pese a las necesidades que en el escenario internacional se hacían patentes, no se

habitación, con un mínimo de $4 \mathrm{~m}^{2}$ por habitación. Durabilidad de la vivienda, calidad estructural: Una vivienda se considera duradera si está construida en un emplazamiento no peligroso y tiene una estructura permanente y adecuada para proteger a sus habitantes de las inclemencias del tiempo tales como la lluvia, el calor, el frío y la humedad. Tenencia segura: Se considera que todos los individuos y grupos tienen derecho a contar con una protección eficaz del Estado contra los desalojos injustos forzados, considerándose que se cuenta con tenencia segura cuando existen pruebas documentales que se puedan utilizar para comprobar el derecho a la tenencia y cuando existe una protección de hecho o de derecho contra los desalojos forzados (UN-HABITAT, 2003). 
ofertaba. Nuestra formación universitaria sólo se preocupaba de preparar profesionales que atendiesen las demandas de poco más de un $20 \%$ de la población mundial -formación que, sin lugar a dudas, es necesaria-, pero que no aportaba las herramientas necesarias para trabajar en procesos que poco tienen que ver con los que nos enseñaban en las aulas. Debemos saber que en materia de vivienda, se estima que 7 de cada 10 viviendas que se hacen en el mundo son auto-construidas al margen del sector formal mercantil, porque el mercado formal no tiene capacidad de respuesta ante el crecimiento urbano en los países en vías de desarrollo, por lo que la gente -sin capacidad solvente- se construye sus viviendas o busca sus propias soluciones (DAVIS, 2007).

Este año se cumple la fecha meta de los ODM -que no procede analizar aquí-, dejando de manifiesto que aún hay trabajo por hacer y por ello, desde hace tres años se está preparando la Agenda de Desarrollo Post 2015 con un nuevo conjunto de objetivos -un total de 17-, esta vez denominados Objetivos de Desarrollo Sostenible (ODS). Sigue siendo necesaria, pues, la formación de profesionales de todas las disciplinas dispuestos a trabajar por intentar alcanzar estos nuevos Objetivos y luchar por hacer universal el acceso a la Habitabilidad Básica.

\section{REFERENCIAS BIBLIOGRÁFICAS:}

DAVIS, Ian (2007) Planeta de Ciudades Miseria. Madrid: Editorial FOCA

UN-United Nations (2014) Objetivos de Desarrollo del Milenio. Informe de 2014. Nueva York: Naciones Unidas

UN-HABITAT (2003) Slums of the World: The face of urban poverty in the new millenium?. Nairobi (Kenia): United Nations Human Settlements Programme

UN-HABITAT (2013) Planning and Design for Sustainable Urban Mobility: Global Report on Human Settlements 2013. Oxon (Reino Unido): Earthscan, Routledge 


\title{
QUE TREINTA AÑOS NO ES NADA...O SÍ: EL ABANDONO CONTINUADO DE LOS BARRIOS DE LA PERIFERIA HISTÓRICA
}

\author{
Isabel González (Dra. Arquitecta - Profesora asociada DUyOT)
}

Desde 1985 resulta difícil destacar un único evento o suceso urbano, máxime cuando este periodo de treinta años, coincide no sólo con la transición entre los dos siglos sino con la consolidación del modelo neoliberal más conocido como globalización, con importante repercusiones territoriales y urbanas y que realmente ha supuesto el declive de todo el modelo desarrollado en Europa desde finales de la Segunda Guerra Mundial, que parece haberse convertido en un espejismo, en la ilusión de una sociedad con cierto grado de prosperidad y con sistemas de regulación que si no pretendían la igualdad, al menos aspiraban a una cierta cohesión social con menor desigualdad (aunque fuese en pos de una paz social que evitase alternativas más revolucionarias que cuestionarán el sistema). A esta dificultad de partida se añade la propia experiencia profesional y académica que abarca un periodo menor del tratado y que me obliga a recurrir, más que a la experiencia a mi propio imaginario urbanístico para ese primer decenio 1985-1995. Esta reflexión, además, se centrará en el territorio que más conozco: la región madrileña. En cualquier caso, si me parece interesante destacar el comienzo de este periodo, que podría quedar representado por el tan mitificado Plan General del 85 de Madrid, pero también y sobre todo, por la consolidación del proceso de recualificación urbana centrado en la implementación de dotaciones urbanas (equipamientos, zonas verdes y servicios) y la mejora de los barrios iniciado con los primeros Ayuntamientos democráticos que representaría una cierta consolidación del incipiente Estado de Bienestar y tendría su ejemplo más paradigmático en el proceso de Remodelación de Barrios de Madrid (1979-1989). Un proceso que no ha sido suficientemente divulgado ni transmitido a los futuros urbanistas ni arquitectos en nuestras escuelas y que debería incorporarse por su carácter innovador en aspectos tan actuales como la gobernanza y la participación (conceptos también míticos de nuestro actual imaginario) donde se produjo esa tan deseada, por excepcional, convergencia de actores e intereses entre vecinos, técnicos y poderes públicos y donde las reivindicaciones legítimas de una mejor calidad de vida se tradujeron en propuestas concretas bastante exitosas en algunos aspectos (al menos desde el punto de vista de la calidad residencial y del reasentamiento de los vecinos en sus propios barrios). Este proceso, con sus luces y sombras, intentó intervenir y remodelar toda una periferia social y física que había crecido al albur de desarrollismo de los años 1960 y 1970 y que fue reconocido por Naciones Unidas en el Concurso de Buenas Prácticas en 1996.

Con objetivos y estrategias completamente diferentes nos encontramos las propuestas de la década posterior, ya en pleno "milagro económico" caracterizado por la tan conocida burbuja inmobiliaria y que, a mi entender, se apoya fundamentalmente en un desprecio absoluto por la ciudad existente como construcción colectiva y con un valor de uso en sí misma y se interesa exclusivamente por la ciudad y el territorio como valor de cambio e inversión dentro de un contexto económico global de escala planetaria. Así el modelo territorial se centra en un 
desarrollo inusitado de las infraestructuras de comunicación que a modo de red permita conectar los nuevos polos de concentración de capital e inversión. Los intersticios de este territorio red no interesan y así gran parte de la ciudad existente, fundamentalmente los barrios alejados de los centros de prestigio y representación, se abandonan a su suerte. Se apuesta por un desarrollo urbano incesante que alimente la máquina inmobiliaria con independencia de las necesidades reales. El resultado es un territorio invadido por innecesarias y costosas infraestructuras del que cuelgan piezas especializadas, "autistas", internamente homogéneas y simples que precisamente como carecen de las cualidades básicas para denominarse ciudad necesitan que se incluya en su denominación el apelativo de ciudad: Ciudad del $\mathrm{BSCH}$, Ciudad de la Justicia, Ciudad del BBVA, Ciudad Deportiva del Real Madrid, Ciudad Valdeluz. Todo ello apoyado en unos poderes públicos bien adiestrados que despliegan un aparato legislativo y unos instrumentos de planeamiento también adaptados a los objetivos perseguidos y donde su papel regulador se va difuminando hasta transmutarse en mero árbitro complaciente, en el mejor de los casos, o activo especulador, en otros (véase el caso de las famosas Cuatro Torres localizadas al norte de la Castellana en las antigua instalaciones Deportivas del Real Madrid).

El objetivo decían era posicionar la ciudad de Madrid dentro del ranking de ciudades, centros mundiales de capital, inversión y negocio. Evidentemente Madrid no podía aspirar a la liga de honor pero si creían que podían formar parte de una honrosa segunda división de ciudades europeas. Para ello, en línea con el modelo anteriormente descrito, era necesario recurrir al marketing urbano e ir colocando piezas de autor de reconocido prestigio internacional, desperdigadas por la ciudad pero conectadas a la red e incluso recurrir un gran acontecimiento como el gran espejismo de los Juegos Olímpicos, etc. En una reunión entre técnicos municipales y arquitectos en el Ayuntamiento de Madrid, fui testigo de una intervención de un insigne colega, que probablemente forme parte de alguno de los "think tanks" tan de moda ahora, que sin un ápice de rubor afirmó que en Londres, en París no se podía vivir ciertamente pero era donde ocurría todo y eso era a lo que tenía que aspirar la ciudad de Madrid. Para el escándalo de la mayoría de los técnicos municipales que lidian día a día con la gestión municipal, se estaba alardeando públicamente de un sinsentido no deseable pero además inalcanzable por irreal. En estos momentos es cuando cualquiera con cierto sentido común piensa "en que manos estamos". Hago aquí un inciso para afirmar que afortunadamente la Administración está llena de grandes profesionales que se mantienen firmes intentado aguantar la marea que les pretende arrastrar. Y como todo sueño o pesadilla llegó el momento de despertar y al hacerlo descubrimos la, por otro lado anunciada, crisis económica con el consabido pinchazo de la burbuja inmobiliaria y nos encontramos inmersos en un proceso sin precedente $y, a$ mi entender, sin posibilidad de remontada aunque algunos auguren la salida, porque se trata de una crisis sistémica que debería suponer el replanteamiento de todo el modelo. Desde el punto de vista territorial y urbano, las consecuencias de la crisis son evidentes y de todos conocidas y se resumen de forma fácil: la imposibilidad de mantener un modelo territorial y urbano del todo insostenible desde el punto de vista económico, social y ambiental cuya funcionalidad depende de una elevadísima movilidad que había podido funcionar gracias a un petróleo barato y que producía ciertas "externalidades" sociales y ambientales que el sistema creía poder soportar. Desde el momento en que las bases que sustentaban el modelo fallan, el modelo pasa de ineficiente a inviable. 
Y en medio de todo esto, nos encontramos con nuevos desarrollos residenciales fantasmas, suelos ocupados a medio urbanizar, infraestructuras infrautilizadas y de elevado coste de mantenimiento, viviendas vacías y familias sin vivienda, desahucios y... los barrios de la periferia histórica de Madrid y sus ciudadanos, resistiendo y adaptándose como han podido, echando mano de una cualidad, la resiliencia (otro término que ha comenzado a mitificarse) que está relacionado con algunas características de nuestros tejidos urbanos consolidados, la variedad articulada de sus elementos que favorece una alta complejidad en un área relativamente pequeña (elevada accesibilidad) y que facilita la diversidad de usos, población y actividades. Ahora bien, el modelo ineficaz y excluyente que hemos construido en las últimas décadas ha ido destruyendo la diversidad y debilitando la resiliencia de los barrios e incluso destruyendo los más vulnerables, los que no habían conseguido una suficiente complejidad que les permitiera sostenerse. Por tanto hay que empezar a articular un nuevo relato entre todos que permita reconstruir el modelo territorial y urbano e intentar volver a confluir actores (políticos, técnicos y ciudadanos) si es que realmente alguna vez se produjo esa convergencia. Con mucha frecuencia se habla de la crisis del planeamiento, de la ineficacia del instrumento para adecuarse a la nueva realidad, de la necesidad de instrumentos más ágiles y actuales, de la excesiva legislación urbanística y sectorial, etc... pero, a mi entender, el verdadero problema es la falta de interés real por la ciudad y por el territorio, por mucho que se hable continuamente de su profunda crisis. Por parte de los poderes públicos, reiteradamente ha hecho dejación de su función principal al olvidar algunos de sus objetivos fundamentales: el fin social del suelo (y por extensión del territorio y la ciudad) y el bienestar de la totalidad de sus ciudadanos.

Por parte de la población en general, existe una cada vez mayor porción que bastante tiene con sufrir las consecuencias del modelo y sobrevivir; otros menos, que se creían ganadores y que ven como todo era un espejismo, fruto del narcóticas promesas de clase media y que, día a día, pierden no sólo sus cada vez más exiguos emolumentos entre hipotecas y gasolina sino algo fundamental e irremplazable, su tiempo vital diario, en costosos desplazamientos por el territorio red para satisfacer las necesidades más básicas. Por parte de los agentes económicos, que siguen considerando la ciudad y el territorio como un bien exclusivamente económico donde campar sin restricciones como antiguos señores feudales. Por parte de los técnicos, arquitectos y urbanistas, que se debaten entre la reflexión improductiva desde los altares del Conocimiento y la Academia, el narcisismo del artista que se regocija en la maestría de su obra arquitectónica y la mera supervivencia de un oficio, en otros tiempos prestigioso y reconocido, y que ahora apenas permite sobrevivir a unos pocos. Evidentemente hay luces entre tanta sombra como las iniciativas desde debajo, de empoderamiento de la ciudadanía (más conceptos míticos), nuevos temas sobre los que se están trabajando como la regeneración urbana integrada, los planes de barrio, etc... pero siguen siendo propuestas muy locales, en ocasiones demasiado alternativas para su generalización. Se necesita una articulación y un impulso desde los poderes públicos.

En este punto, el planeamiento como instrumento "omnicompresivo" sigue siendo necesario, transformado, actualizado hacia la intervención en la ciudad y el territorio porque la visión integral es, más que nunca, imprescindible. Recuperar y rehabilitar los barrios desde la ciudad y la ciudad desde o barrios. 


\title{
EL PLANEAMIENTO COMO IMAGEN NECESARIA DE LA TRANSFORMACIÓN SOCIAL
}

\author{
Agustín Hernández Aja (Dr. Arquitecto - Profesor titular DUyOT)
}

Toda política con capacidad de transformación social tiene su correlato (consciente o inconsciente) en la escala física de la ciudad y el territorio. Es en esta escala en la que los ciudadanos encuentran satisfacción a sus necesidades y demandas o donde éstas se ven frustradas. No parece posible definir una nueva política que no tenga en cuenta el Espacio Urbano sobre el que tiene que desplegarse y que no busque su modificación de manera paralela a las transformaciones sociales que pretende acometer, necesitando por tanto un planeamiento urbano que visibilice su proyecto de transformación.

\section{CIUDAD Y TRANSFORMACIÓN SOCIAL}

No existe proyecto político o social que no vaya acompañado de un proyecto espacial propio y por tanto de un planeamiento urbano que lo signifique. La ciudad y el territorio se transforman acompasadamente con la sociedad que contienen. Lo anterior no significa que el espacio resultante sea producto exclusivo de una voluntad consciente, si no que será el resultado del reacomodo del espacio inicial a las necesidades explicitadas y a sus códigos de representación (que serán la "novedad" estilística que se usará como significante del cambio). Pero lejos de desaparecer, los códigos de la ciudad preexistente persistirán sin que sea totalmente ignorarlos, conviviendo los nuevos con los propios de otros proyectos coetáneos y otros significantes complementarios, antagonistas o independientes del nuevo proyecto político.

¿Cómo enfocar la reconstrucción física del espacio urbano, sabiendo que existen preexistencias y competencia con proyectos diferentes? De lo que aquí se trata no es hacer teoría de la ciudad, si no que apoyándonos en ella (como sustrato de nuestra acción), seamos capaces de determinar las líneas fundamentales de una intervención transformadora (temporalmente acotado), con los límites que nos imponen el espacio heredado, las capacidades administrativas, el marco económico y la necesidad de conciliarla con la herencia cultural y los múltiples proyectos (divergentes o complementarios) que conviven con el nuestro.

Necesitamos elevar la mirada de los problemas existentes aquí y ahora para contextualizarlos en un escenario futuro (limitado al tiempo de los plazos políticos y vitales de los ciudadanos) de crisis a medio y largo plazo, resultando fundamental considerar los escenarios de cambios económicos y sociales en el marco, de una crisis ecológica y de recursos global, que será más o menos grave para nuestras ciudades en función de las medidas de prevención que incluyan nuestras propuestas. Las líneas fundamentales que tiene que incluir el planeamiento son:

- La ciudad existente como espacio de trabajo.

- Un proyecto que sea capaz de reconocer la multiplicidad del hecho urbano 
- Un espacio en el que el ciudadano sea actor y no consumidor.

- Asunción de la diferencia entre territorio y ciudad, evitando el consumo del primero por la segunda.

- Un proyecto de ciudad para los ciudadanos, en la que se garantice su calidad de vida mediante la satisfacción de tres retos: Libertad individual. Responsabilidad social. Responsabilidad ecológica.

El desarrollo del nuevo Plan implica la incorporación del concepto de la calidad de vida, mediante la consideración de los aspectos ambientales en intersección con las necesidades humanas, implica el control, por el individuo, de su tiempo y de su espacio como base de la auténtica libertad. El tiempo porque es nuestro recurso menos renovable (el que disponemos los seres humanos para vivir aquí y ahora es irreproducible). Y el espacio porque, es sobre él en el que desarrollamos nuestro proyecto vital, decidiendo si abandonamos nuestro espacio de origen o nos reafirmamos en él.

Como consecuencia de la percepción de la quiebra de los límites ambientales y fruto del proceso de la globalización, los ciudadanos perciben la inseguridad de un sistema altamente volátil, donde bienes rentas y estructuras sociales se vuelven productos precederos. Es necesario desvelar la vida cotidiana que propone a sus ciudadanos y el modelo de gestión ambiental y social que contiene, preguntándonos:

- ¿Realiza una oferta medida y ponderada de dotaciones accesibles por los ciudadanos?

- ¿Propone centros de producción altamente concentrados y alejados de la residencia?

- ¿Oferta nuevas redes de transporte que aumenten la accesibilidad de los vehículos privados?

- ¿Concentra elementos de calidad en unas zonas y desabastece otras?

- ¿Plantea la vivienda como un problema independiente del resto de las necesidades humanas?

- ¿Qué índices de satisfacción y participación mide o se propone medir?

- ¿Cómo se mide el éxito del Proyecto Social propuesto?

- ¿Tiene en cuenta el consumo de recursos y energía?

Basta mirar a nuestro alrededor o escuchar las declaraciones de los responsables políticos y municipales, para deducir que las respuestas a estas preguntas implican un modelo incompatible con la Calidad de Vida Urbana. El modelo de ciudad propuesto, aleja cada vez más producción y residencia, invierte indiscriminadamente en redes viarias que nos mantienen horas y horas en nuestros vehículos o en tediosas líneas de transporte público. La vivienda hace mucho que ha dejado de ser un objeto para el disfrute de la vida, para convertirse en un medio de acumulación económica.

En los balances de las políticas urbanas, lo que se mide es la producción: de viviendas, de carreteras, de edificaciones públicas, en ningún caso se mide la calidad de vida, la integración de los ciudadanos en su entorno, la reducción de los desplazamientos, o la participación en las tareas sociales. Sin que aparezcan 
referencias no retóricas a los problemas ambientales globales. Frente a esta volatilidad del entorno, la revisión del modelo tendrá que basarse, antes o después, en la reducción del consumo y en la recuperación de la autonomía del ciudadano y su vida cotidiana. Es por tanto necesario un Plan que reordene las prioridades dando preferencia a las nuevas necesidades.

\section{DESMONETIZACIÓN, APROPIACIÓN, TERRITORIALIZACIÓN Y PLANEAMIENTO INTEGRAL}

Los principios antes enunciados pueden conseguirse mediante la realización de un conjunto de estrategias, que nos aproximen a la construcción del nuevo espacio urbano basado en la participación de los ciudadanos y la calidad de vida.

\section{Desmonetización y gestión compartida}

Si las poblaciones de amplias zonas urbanas, sobre todo en las periferias, comienzan a estar fuera de la economía formal, las intervenciones sobre estas poblaciones y territorios no pueden realizarse bajo la óptica de la rentabilidad, ni por la sustitución del servicio público por el mercado. La reducción de los fondos públicos, tiene que ser aprovechada por una acción colectiva que sustituya precio por participación, mediante una intervención activa que permita reconstruir las redes sociales, optimice los recursos existentes y pueda servir de base para el desarrollo de una economía local (basada en cooperativas y empresas de servicios locales), con objetivos sencillos, pero importantes, para la calidad de barrios y ciudadanos: el sostenimiento del empleo local, la participación en el diseño y gestión de los equipamientos y la cohesión social.

El equipamiento deberá de cumplir una misión de restaurador social, produciendo en su entorno un reequilibrio dotacional, suavizador de las diferencias económicas y sociales, creando en su entorno un área de influencia que produzca un efecto multiplicador de la intervención. Las cambios sociales demandan nuevos espacios y servicios, entre los sectores que amplían su peso específico en nuestras ciudades, se encuentran parados de larga duración, jubilados anticipados, obreros no especializados con contrataciones temporales e inmigrantes y jóvenes desarraigados, cuyo problema no es tan solo el de recibir una asistencia social que palie su situación económica, sino cubrir la necesidad, como individuos sanos, de intervenir en su entorno próximo colaborando en su transformación.

\section{Apropiación y territorialización}

Los ciudadanos necesitan actuar sobre espacios y tareas reales, dar salida a su necesidad de transformación del entorno, mediante equipamientos basados en la actuación sobre el medio como huertos de ocio o talleres. Generando territorios apropiables sobre los que sustentar una red social basada en el autoapoyo, la ecología y la solidaridad. No parece posible mejorar la gestión el control y mantenimiento de los equipamientos y zonas verdes, sin políticas que incrementen la participación en su diseño, ejecución y mantenimiento. Produciendo una simbiosis efectiva entre la actuación pública y la sociedad, que venga sustituir los aspectos más dudosos del 
estado asistencial, en el que el individuo puede ser sustituido por la actividad burocrática y convertido en un consumidor unidimensional que pierde la capacidad de transformación de la sociedad.

Si la unidad de intervención es el Barrio, es evidente que la gestión centralizada de los equipamientos no garantiza su utilidad u oportunidad. Es necesario que la gestión se aproxime al espacio al que se sirve, articulando la participación de las poblaciones afectadas, de forma que se garantice el éxito en la detección de las carencias reales y el de la oferta realizada. El modelo dominante nos presenta a un ciudadano que utiliza la metrópoli en su totalidad, que puede consumir servicios sofisticados ofertados en puntos diversos y distantes de su vivienda: Opera, Exposiciones, Centros Comerciales. Se determina que el usuario medio dispone de recursos económicos que le permiten completar e incluso sustituir la oferta pública de servicios públicos como la educación, la salud y la cultura. Pero la sociedad real está compuesta de grupos sociales que sólo pueden acceder teóricamente a los servicios de la metrópoli y que necesitan contar con los servicios clásicos del equipamiento básico, pero que al mismo tiempo necesitan de espacios de apropiación y de "restauración social" allí donde habitan.

\section{Planeamiento Integral}

El planeamiento no es una estructura autónoma capaz de generar por sí misma racionalidad. El planeamiento es una herramienta para la concreción de las propuestas políticas de los que detentan la representación social, y reflejan el orden de las relaciones existentes entre distintos poderes, reflejando un pacto más o menos explícito; por tanto el planeamiento reflejará aquellos pactos que se haya dado la sociedad que lo desarrolla. Aceptando el marco de políticas sectoriales de gran importancia, el planeamiento urbanístico puede no obstante en sus distintos escalones, reflexionar y en su caso proponer soluciones alternativas a las políticas sectoriales, de hecho es el único instrumento con capacidad para prever y describir en un documento único un conjunto de políticas sectoriales públicas o privadas, proponiendo las soluciones a los problemas detectados y alternativas a las propuestas.

Es necesario realizar una lectura nueva y matizada de la ciudad real en la que nos encontramos, para desarrollar "planes de intervención integral" que permitan la programación de inversiones públicas coordinadas que den un marco cierto y estable al objetivo de vertebración social. Es necesario definir cuáles son los espacios donde hay que actuar y con qué tipo de instrumentos. Deslindando en donde basta ofrecer un soporte, de donde haya que intervenir firmemente apoyando las iniciativas existentes. Se trata de crear espacios "convivenciales", espacios accesibles con usos múltiples, capaces de adecuarse a las necesidades cambiantes y múltiples de los ciudadanos, accesibles a estos y transparentes en su funcionamiento.

El planeamiento municipal es la concreción espacial de los objetivos de la unidad mínima de la articulación política. Debe por tanto reflejar los compromisos de esa colectividad con el medio ambiente, reflejar y desarrollar las políticas activas para la consecución de los compromisos políticos. El Plan General afina e interpreta las decisiones de los planes territoriales y de las políticas sectoriales, y en su caso las 
sustituye. Fija el modelo territorial, determinando las áreas de crecimiento en su caso y aquellas que hayan de ser preservadas de la urbanización por su interés medioambiental. Determina asimismo las áreas urbanas que deben ser reformadas y contiene en sus Normas Urbanísticas la definición concreta de las obligaciones de los usos y la edificación, no obstante sobre el planeamiento se podrán superponer ordenanzas, proyectos y formas de gestión independientes.

Por tanto el Plan General es la concreción física de las políticas municipales, en él deberán estar contenidas las determinaciones concretas para la mejora ambiental, fijando los objetivos para cada zona, ya sea de nuevo crecimiento o de reforma, y las condiciones generales que han de cumplir los usos y las edificaciones, el Plan tomará por tanto decisiones de estructura:

- Protección del territorio, conservación y mejora del capital natural.

- Determinación del modelo de gestión de residuos.

- Modelo de movilidad, asignando los espacios y las previsiones por tipo de desplazamientos.

- Distribución de usos, propiciando la diversidad y el equilibrio urbano.

- Determinación de la estructura de las dotaciones, definiendo los espacios para las nuevas dotaciones relacionadas con la conservación y mejora medio ambiental. 


\title{
BARRIOS SALUDABLES
}

\author{
Ester Higueras García (Dra. Arquitecta - Profesora titular DUyOT)
}

Desde finales del siglo anterior, el desarrollo sostenible se ha mostrado como el camino necesario para afrontar los grandes retos de las ciudades. Con más de veinte años transcurridos desde la emblemática Cumbre de Rio de Janeiro (1992), en 2015 se pueden evaluar las fortalezas y debilidades que se han abierto con este nuevo objetivo global para ser aplicado desde las escalas locales. Un nuevo camino aparece con fuerza, el de los barrios saludables, entendiéndolos como una célula básica de sostenibilidad donde se pueden resolver satisfactoriamente gran cantidad de problemáticas sociales y ambientales ${ }^{23}$, como son la contaminación ambiental, el ruido urbano, la reducción del $\mathrm{CO}_{2}$, el aumento de las zonas verdes, el control microclimático de los espacios urbanos, el uso adecuado del espacio público y la reducción del stress urbano también necesario para la salud mental de todos los residentes. ${ }^{24}$

Aparece ahora como una línea de investigación prioritaria la transformación de los barrios de la ciudad consolidada en barrios saludables, y de esta forma afrontar algunos de los retos de sostenibilidad ambiental que debe resolver la ciudad del siglo $\mathrm{XXI}^{25}$. Por su peso cuantitativo en las ciudades actuales, las barriadas configuradas con las tipologías de la ciudad del movimiento moderno, se presentan como un gran espacio de oportunidad debido a su combinación de una alta densidad (en torres o edificaciones lineales), con alta proporción de espacios verdes, y con unas buenas condiciones teóricas de soleamiento y ventilación de todas la viviendas, pero que en la realidad necesitan un nuevo proyecto integrado y estructurado de sus espacios libres y zonas verdes. Esta tipología merece una reflexión detallada por diversas razones: en primer lugar, se trata de una tipología universal, es decir, se encuentra en las periferias de muchísimas ciudades europeas y americanas, debido a la adopción de una solución única en un momento en el que era necesaria la construcción masiva de viviendas para resolver la inmigración del campo a la ciudad; en segundo lugar los inmuebles son muy poco eficientes energéticamente hablando, debido a la falta casi unánime de sistemas de aislamiento y eficiencia en sus instalaciones, en este sentido han sido numerosos y sobresalientes los avances técnicos y constructivos para mejorar las condiciones de confort térmico de los inmuebles que se han producido desde los años 1970 hasta la actualidad y por tanto parece necesario y urgente introducir estos avances en esta tipología edificatoria para resolver los problemas de

\footnotetext{
23 http://www.euro.who.int/en/health-topics/environment-and-health/urban-health/activities/healthycities/who-european-healthy-cities-network/what-is-a-healthy-city. (Consultado dic 2014)

${ }^{24}$ Destacan los proyectos de investigación financiados por fondos de la UE, en particular, INTARESE, HEIMTSA y PAREST, los tres de ellos proponen el Modelado de Evaluación Integrada para apoyar el Medio Ambiente de la UE y el Plan de Acción de Salud; el primero modela el riesgo de los factores de estrés ambiental, el segundo investiga sobre la salud y el impacto ambiental de los escenarios de las políticas urbanas, y el tercero, evalúa el impacto de la concentración de partículas contaminantes en suspensión (PM 10 y PM 2.5). También el proyecto INEQ-CITIES, cartografía las desigualdades socioeconómicas de la salud de las ciudades de la UE.

25 Acioly, C. (2000) 'Can Urban Management Deliver the Sustainable City?' en Compact Cities: Sustainable Urban Forms for Developing Countries, (eds.M.Jenks and R.Burgess), Spon Press, London.
} 
calidad del aire interior y confort térmico; en tercer lugar, en esta tipología se apuesta por soluciones constructivas universales ignorando completamente las consideraciones del lugar, o las lecciones aprendidas a lo largo del tiempo por edificaciones anteriores, con las aportaciones del urbanismo y la arquitectura bioclimática donde ya existe un amplio abanico de soluciones con muchas aplicaciones y mejoras para resolver los problemas específicos de estas edificaciones ${ }^{26}$; y por último aparece la oportunidad de mejorar las condiciones del microclima exterior y circundante a los edificios, con el convencimiento que si se mejoran la temperatura, humedad, viento y permeabilidad de los espacios exteriores urbanos, esto traerá una mejora en las condiciones del microclima exterior, atenuará los efectos negativos provocados por la isla térmica de calor urbano y mejorará las condiciones de los espacios exteriores para múltiples actividades.

En este sentido, la existencia de bajas ocupaciones de suelo con altas densidades edificatorias, resulta completamente oportuno para resolver algunas de las disfucionalidades térmicas y ambientales tanto de los espacios abiertos como de las edificaciones ${ }^{27}$. Este camino, se vislumbra como necesario y oportuno, y una vez adaptado a las condiciones generales del clima de cada ciudad ${ }^{28}$, puede seguirse para resolver este problema en numerosas ciudades americanas o europeas, y sin duda abre un cauce de acción necesario para afrontar la sostenibilidad de la ciudad consolidada, a través de acciones propositivas locales.

\section{Barrios saludables para una ciudad sostenible.}

Los barrios saludables, se entienden como la unidad desde la cual es posible afrontar y resolver algunos de los problemas de eficiencia y sostenibilidad ambiental que hoy día tienen planteadas la mayor parte de las ciudades del planeta, con un alcance desde la arquitectura y el urbanismo realista y propositivo. Las ciudades nunca fueron pensadas para que fueran eficientes. Es por esto, que desde 1980 donde los problemas ambientales empiezan a aparecer y a relacionarse tanto con la industrialización como con la densidad y la existencia de grandes conurbaciones, ${ }^{29}$ todos los indicadores de sostenibilidad aplicados a las zonas urbanas, dan un resultado alarmante.

Sin embargo, y ya son muchos autores que manifiestan ${ }^{30}$, que la ciudad no es el problema de sostenibilidad, sino que hay que entenderla como la gran solución . La existencia de concentración de personas, actividades y funciones, debe ser ahora abordada desde otra perspectiva nueva, desde la óptica de la sostenibilidad, y desde este marco es desde donde hay que empezar a actuar de otra forma para detener primero las tendencias negativas y reconducirlas después, hacia los nuevos objetivos

\footnotetext{
${ }^{26}$ Higueras, E. (2012) Manuales de urbanismo bioclimático para Vitoria-Gasteiz http://www.vitoriagasteiz.org/we001/was/we001Action.do?idioma=es\&aplicacion=wb021\&tabla=contenido\&uid=u6fa2fe e7 14273f1b7eb 7fb5

27 Fariña , (2014) "Los edificios de gran altura afectan particularmente al bienestar mental de madres con niños pequeños y, posiblemente, al de los propios niños" El blog de Jose Fariña.

28 FARIÑA TOJO, J. (1998) La ciudad y el medio natural. Akal. Madrid

${ }^{29}$ El consumo de energía en los edificios residenciales y comerciales representa aproximadamente el $40 \%$ del consumo total de energía final y el 36\% de las emisiones totales de $\mathrm{CO}_{2}$ de la Unión Europea (2008). Fuente UE.
} 
consensuados internacionalmente, Jenks \& Jones (2012) afirman: "Overall, research indicates that there are unlikely to be single spatial or physical solutions, rather that there may be many forms that can achieve sustainability, depending on the context in which they are applied (e.g. Guy and Marvin, 2000; Jenks and Dempsey, 2005). ${ }^{31}$

\begin{tabular}{|c|c|c|c|c|c|c|}
\hline & $\begin{array}{l}\text { VARIABLES A } \\
\text { (SPATIAL PLA }\end{array}$ & $\begin{array}{l}\text { JNSIDERAR EN LA } \\
\text { ING AND URBAN }\end{array}$ & $\begin{array}{l}\text { PLANIFICIAC } \\
\text { ESIGN) }\end{array}$ & Y EL DISEÑO & RBANO & \\
\hline $\begin{array}{l}\text { ENFEMEDADES } \\
\text { URBANAS } \\
\text { (CITY } \\
\text { DISEASES) }\end{array}$ & $\begin{array}{l}\text { Alta densidad } \\
\text { (High density) }\end{array}$ & \begin{tabular}{|l} 
Estructura \\
urbana \\
(Urban Structure)
\end{tabular} & $\begin{array}{l}\text { Isla urbana de } \\
\text { calor } \\
\text { (Urban Heat } \\
\text { Island) }\end{array}$ & \begin{tabular}{|l} 
Escasez de \\
zonas verdes \\
(Few green \\
areas)
\end{tabular} & \begin{tabular}{|l} 
Distribución de \\
los usos del \\
suelo \\
(Land use \\
pattern)
\end{tabular} & $\begin{array}{l}\text { Acabados } \\
\text { superficiales } \\
\text { (Pavements) }\end{array}$ \\
\hline $\begin{array}{l}1^{\circ} \text {.- Obesidad y } \\
\text { enfermedades } \\
\text { cardiovasculares } \\
\text { (Obesity and } \\
\text { cardiovascular } \\
\text { diseases) }\end{array}$ & & & & & & \\
\hline $\begin{array}{l}2^{\circ} .- \\
\text { Enfermedades } \\
\text { respiratorias } \\
\text { (Respiratory } \\
\text { diseases) }\end{array}$ & & & & & & \\
\hline $\begin{array}{l}3^{\circ} \text {.- Stress } \\
\text { térmico por frio o } \\
\text { calor } \\
\text { (Excess winter } \\
\text { and summer } \\
\text { mortality) }\end{array}$ & & & & & & \\
\hline $\begin{array}{l}4^{0} \text { - } \\
\text { Enfermedades } \\
\text { especificas de la } \\
\text { infancia y } \\
\text { ancianidad } \\
\text { (Children and } \\
\text { eldery risks) }\end{array}$ & & & & & & \\
\hline
\end{tabular}

Fig. 1. Sombreada la relación entre las principales variables de la planificación y el diseño urbano con las enfermedades, ordenadas por importancia.

Fuente: Adaptación de Delivering Healthier Communities in London 2007.

El reto es grande, debido principalmente a que no nos sirven ni las herramientas ni las soluciones del siglo XX para resolver el problema de la sostenibilidad urbana. La necesidad de establecer acciones transversales, integradas, multidisciplinares, sintéticas y ecosistémicas establece unas nuevas reglas de juego en el que hasta ahora, estaba todo fragmentado, aislado y autónomo ${ }^{32}$. Es por esto que la aportación del barrio saludable, puede convertirse en una nueva vía de transformación de lo

31 Mike Jenks · Colin Jones, Editors Dimensions of the Sustainable City. ISBN 978-1-4020-8646-5(HB) e-ISBN 978-1-4020-8647-2; ISBN 978-1-4020-8645-8(PB)- DOI 10.1007/978-1-4020-8647-2 .Springer Dordrecht Heidelberg London New York

32 Fariña Tojo, J. Merino Merino, B. Cuadernos del OSE sobre políticas de salud en la UE. Número 7: Urbanismo y Salud Pública. Granada: Observatorio de Salud en Europa de la Escuela Andaluza de Salud Pública; García-Sánchez, I. Editora. Diciembre 2012 
existente en un nuevo barrio con soluciones reales y oportunas. La escala del barrio es lo suficientemente compleja para abordar soluciones urbanas, pero a su vez es lo suficientemente limitada para establecer planteamientos eficaces y sencillos. Ya son numerosas las guías en las que se ha manifestado la relación entre el diseño de un barrio y la salud de sus residentes ${ }^{33}$ En el conocimiento de estas influencias y el planteamiento de las nuevas soluciones, no debe olvidar que deben combinarse con otras estrategias institucionales, sociales, económicas y urbanas para que la ciudad se transforme verdaderamente en algo sostenible en este siglo XXI y mejore las condiciones de salud urbana de los ciudadanos. ${ }^{34}$

\section{¿Qué es un barrio saludable?}

Se define barrio saludable, aquel perteneciente a la ciudad consolidada existente, y por lo tanto con importantes deficiencias en cuestiones de eficiencia energética, y con gran contaminación ambiental, que se transformará mediante la adopción de medidas urbanas y arquitectónicas en una nueva realidad, que reduzca su consumo de energías contaminantes y sea capaz de presentar un balance mas equilibrado o incluso positivo de generación de energía limpia para sus actividades y usos, y donde la mayor parte de sus residentes reduzcan las patologías relacionadas con la ciudad industrializada: enfermedades cardiovasculares, respiratorias, de estress térmico o de estrés psicológico (Figura 1). ${ }^{35}$

En las últimas décadas del siglo XX, han aparecido los ecobarrios, como el paradigma del desarrollo sostenible. Sin quitar importancia a estas propuestas, es necesario hacer las siguientes consideraciones. En primer lugar, los ecobarrios representan extraordinarios ejemplos de una nueva forma de hacer tanto arquitectura como urbanismo desde los criterios de sostenibilidad, pero son solo una "gota en el océano"; es decir, representan acciones aisladas, de pequeña escala y en casi todos los casos conocidos, se muestran autónomos e independientes de la ciudad existente 36. No se pueden ver como la solución al problema de sostenibilidad del planeta ${ }^{37}$, ni tampoco servirán para mejorar las condiciones de salud urbana; pero sí se puede extraer de ellos algunas líneas de acción y estrategias que se pueden aplicar en otros contextos y escalas. Creo que es desde esta reflexión, donde aparece la oportunidad de los ecobarrios que merecen un estudio pormenorizado de sus soluciones para buscar la replica en la ciudad consolidada que es donde verdaderamente debemos resolver los problemas actuales. En segundo lugar, la eficiencia de los ecobarrios se

33 Delivering Healthier Communities in London (2007). NHS London Health Urban Development Unit Land Use Consultants and CREH, Capitulo 3 "Health and Planning"

34 Sandin-Vazquez y Sarria-Santamera: "Evaluación de impacto en salud: valorando la efectividad de las políticas en la salud de las poblaciones. " Junio 2008, Revista Española de Salud Pública, no 3. Y Observatorio de salud y Medio Ambiente de Andalucía: Urbanismo, Medio ambiente y salud, ISBN-97884-694-5935-5, Capitulo 5

35 Thomson H, Thomas S, Sellstrom E, Petticrew M, (2013) "Housing improvements for health and associated socio-economic outcomes". 2013 The Cochrane Database of Systematic Reviews. Issue 2 . Collaboration Published by John Wiley \&sons, Ltd. Su objetivo es: "to assess the health and social impacts on residents following improvements to the physical fabric of housing"

36 Bolund, P. \& Hunhammar, S. (1999) 'Ecosystem services in urban areas'. Ecological Economics, 29, pp.293-301.

37 HOUGH, M. (1998). Naturaleza y ciudad. Planificación urbana y procesos ecológicos. Editorial Gustavo Gili. Barcelona 
basa en la mayor parte de los casos en sistemas con infraestructuras de alta tecnología con elementos de generación de calor distrital, centrales de co-generación o tri-generación, etc. ${ }^{38}$ Estas soluciones están alejadas de la realidad de un barrio convencional a corto o medio plazo, por lo que las acciones deben ir en otras direcciones.

Un Barrio saludable es aquel que tiene las siguientes características básicas:

1. Tiene una concienciación de la población en el ahorro energético de combustibles contaminantes, por lo tanto aparece un consumo responsable para todas sus actividades, y desplazamientos

2. Tiene medidas de acondicionamiento pasivo en los espacios exteriores ${ }^{39}$ con una doble finalidad: por un lado reducir la demanda energética de los inmuebles (en invierno o verano); y por otro lado fomentar las actividades en el espacio público que favorecen la relación social y la cohesión del barrio ${ }^{40}$

3. Tiene medidas de acondicionamiento pasivo en las edificaciones. Aparece una diferenciación del diseño de las fachadas según cada orientación ${ }^{41}$ : aparece un diseño de huecos acorde con las necesidades de captación solar o iluminación de cada estancia; tiene un diseño especifico de elementos volados del inmueble según la cantidad de radiación solar que recibe: aparece una diferenciación entre las plantas altas y las bajas del inmueble, etc.

4. Genera una fracción de energía renovable solar limpia para los consumos de los residentes, bien individualmente o bien en una red común para el abastecimiento de servicios comunitarios (ascensores, bombas, alumbrado general, etc) ${ }^{42}$

5. Los residentes reducen sus riesgos frente a enfermedades cardiovasculares, ya que se mueven andando por la proximidad de actividades y servicios del barrio; usan la bicicleta para sus desplazamientos cotidianos ya que existe una red de carriles bici adecuada y segura. ${ }^{43}$

6. Los residentes reducen sus riesgos frente a enfermedades respiratorias, ya que se ha reducido la presencia de contaminantes atmosféricos, especialmente el dióxido de carbono, el plomo, el oxido de nitrógeno y las partículas en suspensión.

\footnotetext{
38 Stritzky, J. von y Cabrerizo, C (2011): Ideas para las ciudades inteligentes del futuro.

39 ERELL, Evyatar; PEARLMUTTER, David; WILLIAMSON, Terry. (2010) Urban microclimate : designing the spaces between buildings. London, etc.: Earthscan

40 HIGUERAS, E. Urbanismo bioclimático. (2006) Editorial Gustavo Gili. $1^{a}$ edición. ISBN-13: 978-84252-2071-5

41 IDAE (Instituto para la Diversificación y el Ahorro de la Energía) (2010): "Prestaciones medias estacionales de equipos y sistemas de producción de frío y calor en edificios de viviendas"

42 AAVV. 2004. RUROS, Designing Open Spaces in the Urban Environment: A Bioclimatic Approach. (2009) Director Marianela Nikolopoulou, Center for Renewable Energy Sources, Department of Buildings. Athens. Greece. ISBN- 960-86907-2-2

43 HIGUERAS , E. El reto de la ciudad habitable y sostenible. (2009) Editorial DAPP.ISBN-978-84-9250719-1
} 
Especialmente las poblaciones más vulnerables, los niños y los ancianos. ${ }^{44}$ Gracias a la distribución de usos del suelo, densidad, movilidad sostenible, control de contaminantes e incremento de las zonas verdes del barrio (tanto en espacios libres, públicos o privados, como en la edificación, cubiertas y fachadas)

7. Los residentes reducen sus riesgos frente a enfermedades mentales ${ }^{45}$ ya que el barrio está equilibrado, es dinámico, está cohesionado y aparece una comunidad estable para afrontar retos y plantear soluciones ante cualquier eventualidad. ${ }^{46}$

Establecidos los retos de la sostenibilidad de los barrios como primer paso para la sostenibilidad urbana, cabe preguntarse si estamos realmente resolviendo los problemas detectados. Las últimas décadas del siglo XX y primera del siglo XXI, se han caracterizado por la existencia de una gran cantidad de diagnósticos, mediante nuevas herramientas como son los indicadores (entre las más innovadoras), que han estructurado los cambios necesarios en los ámbitos medioambiental, social y económico.

Ahora desde la perspectiva de la salud de los residentes de la ciudad, es necesario incorporar las acciones sobre la distribución de los usos del suelo, la movilidad, la reducción del consumo de agua, energía y suelo, la reducción de la demanda energética mediante técnicas adecuadas de acondicionamiento pasivo de las estructuras urbanas y arquitectónicas, y desde luego mediante una eficaz red del sistema verde local y metropolitano, que mitigue las enfermedades de las ciudades, sobre todo hacia las poblaciones de mayor riesgo como son los niños y los ancianos. De esta forma se conseguirán barrios con población más sana y con menores riesgos de salud procedentes de su entorno.

\footnotetext{
44 Declaración de la OMS Parma 2010 sobre Medio Ambiente y Salud: el proyecto aborda las recomendaciones sobre cuestiones ambientales y de salud que afectan el estado de salud de los niños. 45 Wolf, S., Bruhn, JG. The power of clan. The influence of human relationships on heart disease. (1993) New Bruswick, NJ: Transaction Publishers.

46 Bonaiuto, M., Aiello, A., Perugini, M., Bonnes, M., and Ercolani, A.P. (1999) 'Multidimensional Perception of Residential Environment Quality and Neighbourhood Attachment in the Urban Environment'. Journal of Environmental Psychology, 19, pp.331-352
} 


\title{
EL PLANEAMIENTO URBANÍSTICO, DE LA SEGURIDAD A LA INCERTIDUMBRE
}

\author{
Marian Leboreiro Amaro (Dra. Arquitecta - Profesora titular DUyOT)
}

Al iniciar mi vida profesional, nada más lejos de mí que dedicarme al planeamiento, a la ciudad sí. Desde que naces formas parte de ella y en ella te mueves y moldea tus intereses como un medio más de los que te rodean y al que el arquitecto se incorpora en su construcción. Por otra parte de caer en la tentación, no había más que un texto con el que trabajar, la Ley del Suelo de 1975, a la que Larrodera nos había introducido con su natural competencia y unos reglamentos que aprender, nada que un curso en la Escuela de Práctica Jurídica no pudiese resolver. Textos claros y contundentes, jurídicamente comprensibles y de fácil aplicación. Un Estado centralizado y unas competencias claras.

Dicho esto habrá que explicar e intentar comprender que es lo que ha ocurrido. Cuando apenas habían pasado unos años de actividad profesional, con planeamiento en ejecución, de repente nos vimos sumidos en la mayor incertidumbre y aún no había empezado la judicialización de unos documentos que, en principio y ateniéndose a las reglas no podían presentar mayor complicación. Una buena cartografía, no siempre era así, un buen conocimiento del lugar a través de un trabajo de campo en profundidad, unos criterios y objetivos bien definidos por los políticos, tampoco era siempre así, pero a los técnicos aún se les escuchaba.

El trabajo en conjunto iba surgiendo y se matizaba con el contacto con los vecinos y sus aportaciones; ellos eran y siguen siendo los auténticos conocedores de sus problemas y necesidades, aún cuando casi siempre vigilando su propio interés, pero escuchaban y permitían aprender juntos. Rápidamente los contactos se fueron perdiendo, la clase política fue teniendo constancia de sus prerrogativas y la participación reglada, formal, prevista en la ley se consideró suficiente.

Un análisis y un diagnóstico, un modelo definido y consensuado y la utilización de las herramientas legales, la panoplia de instrumentos de la que hablaba Eduardo Mangada, y en las que todos, en mayor o menor media confiábamos, bastaban para que el documento tomase forma, en un momento en el que el planeamiento científico ya se ponía en duda ante la complejidad de un mundo que comenzaba a cambiar rápidamente y en el que sucesivas crisis obligaban a repensarlo todo.

No se puede decir que la llegada de las autonomías y la transferencia de competencias en materia urbanística, tuviese consecuencias en el método de trabajo ni en la defensa de la seguridad jurídica, se asumía un marco aceptado para el desarrollo de la actividad urbanística. Por otra parte, no era difícil entender que cada territorio tenía sus peculiaridades propias y que acercarse a ellas y asumirlas suponía una oportunidad para el territorio y para nuestras ciudades.

Puede decirse que, al menos de mi experiencia personal, hasta que la Sentencia del Tribunal Constitucional, 61/1997 que trastoca el orden establecido, todo discurría dentro de la normalidad, las legislaciones se habían ido adaptado en las distintas comunidades y eran pocas las legislaciones propias, continuaba la inercia, que aún 
continua, al aceptar la validez de los Reglamentos de Planeamiento, Gestión y Disciplina del 1978, siempre y cuando no contradigan las nuevas leyes.

La Sentencia supuso un punto de inflexión y abrió la espita que condujo a una legislación propia en cada Comunidad, aún cuando más de una asumió la legislación contestada.

La entrada en la Unión Europea, en principio sin consecuencias al no tener ésta competencias en materia de territorio ni urbanística, fue poco a poco incidiendo y exigiendo adaptaciones, a veces de fuerte calado como la trasposición de la Directiva 2001/42/CE.

Para entonces el panorama había cambiado con España ya incorporada a los países plenamente desarrollados. En el país la competitividad económica empieza a adquirir relevancia y pronto se traslada, al igual que en otros países de su entorno, a la competitividad entre ciudades, a la necesidad de su posicionamiento y desarrollo. Una plena incorporación al estado del bienestar, un mayor nivel de renta y una mayor formación de sus ciudadanos, conlleva nuevos hábitos, formas de comportamiento y nuevas demandas ya sea en equipamientos y servicios o nuevas tipologías de vivienda.

Todo ello, junto con cambios en el sistema financiero, terminará conduciendo a una alteración o alza del precio del suelo y de la vivienda que en su momento lleva a la redacción de la Ley estatal 6/1998, de 13 de abril, sobre régimen del suelo y valoraciones y el Real Decreto Ley 4/2000, de medidas urgentes de liberalización en el sector inmobiliario y de transportes, en la pretensión de que una mayor cantidad de suelo conduciría a la bajada de los precios. Pronto se demostró que eso no era así, pero no obstante se desencadenó la adaptación de la legislación autonómica. Se había producido un primer cambio, que no tardaría en convertirse en una catarata legislativa, que nos ha conducido a que en el momento presente, a la espera de nuevas modificaciones manejemos textos consolidados en sucesivas ediciones de la legislación urbanística, véanse los caso de Madrid y Galicia, caso este último sobre el que me gustaría incidir.

Ambas comunidades parten de dos leyes con idéntica numeración con un año de diferencia la 9/2001 de Madrid y la 9/2002 en Galicia. Desde el 2002 ambas han sufrido múltiples modificaciones, algunas de gran calado y de difícil justificación más allá de razones coyunturales. En el caso de Madrid se acumulan 12 modificaciones con una prevalencia de las realizadas a través de las Leyes de medidas fiscales y administrativas, que han de entenderse ajenas a cuestiones urbanísticas y vinculadas a situaciones de otra índole, básicamente económicas. En Galicia son 11, en este caso se trata de leyes en paralelo utilizándose solo una Ley de Medidas Fiscales y Administrativas en el 2010. No es un fenómeno que no se tenga en cuenta y no preocupe, así la exposición de motivos del Texto Refundido de la Ley sobre Régimen del Suelo de 2008, ya se hace eco de lo preocupante de la situación.

En el caso de Galicia, y con anterioridad a la legislación urbanística vigente, apareció la Ley 10/1995, de 23 de noviembre, de ordenación del territorio de Galicia, escasamente utilizada excepción hecha de los planes sectoriales nacidos para resolver conflictos puntuales de incidencia supramunicipal o atender a políticas de vivienda 0 de previsión de parques empresariales. 
Los documentos producidos de mayor relieve son las Directrices de Ordenación del Territorio, su larga tramitación desvirtuó su contenido y alcance. Se trata de un documento indicativo, sin determinaciones estructurantes para influir en el territorio, más allá de una jerarquización del mismo, incluye unas normas orientativas y excluyentes, lo que obliga a acudir a ellas en la elaboración del planeamiento urbanístico.

El otro documento es el Plan de Ordenación del Litoral, tiene más el carácter de un documento de investigación de lo ocurrido y control para los planeamientos urbanísticos sobre los que se impone, con un escaso valor normativo y más dirigido a un reconocimiento paisajístico conducente a la elaboración de una estrategia de paisaje en marcha. El POL no será de aplicación en los suelos urbanos y de núcleo rural reconocidos por el planeamiento, en la línea de la Ley de Costas.

La ley 9/2002 de Ordenación Urbanística y Protección del Medio Rural de Galicia (en adelante LOUG), hoy vigente con modificaciones sucesivas, se aprueba como modificación de la de 1997, justificándose su necesidad en la aprobación de la Ley estatal 6/1998, de 13 de abril, sobre régimen del suelo y valoraciones y el Real Decreto Ley 4/2000, de medidas urgentes de liberalización del sector inmobiliario y de transportes, que suponen un cambio sustancial en el régimen del suelo no urbanizable, que pasa a tener la consideración de protegido y el urbanizable, que adquiere un carácter residual, al ser el que no queda protegido, en contra de ser un elemento de definición del modelo, como venía siendo antes.

Su aprobación se produce cuando ya un número importante de ayuntamientos han iniciado la adaptación, la revisión o nueva redacción de su planeamiento general a la ley 1997. Se inicia así un camino, en apariencia irreversible, si antes la tramitación de los planes se realizaba en dos años, ahora se pueden superar los diez y cuando nacen son totalmente inadecuados a la realidad que pretenden ordenar. La LOUG, como ya lo había hecho la de 1997, obligaba a adaptar el planeamiento en el plazo de dos años, sin discriminar municipios con nula complejidad urbanística o aquellos que la dinámica anterior a la crisis estaba transformando rápidamente, principalmente en relación con la vivienda y las tipologías demandadas.

La LOUG plantea una estructura similar a la de todas las leyes urbanísticas españolas, una clasificación del suelo ajustada a las clases tradicionales, incorporando el suelo urbano no consolidado y la ya reconocida clase de núcleo rural y las denominadas áreas de expansión, con la clara intención de reconducir el proceso edificatorio en los bordes de núcleo y la herencia dejada por el mal uso del suelo no urbanizable común. Se modificaba así el tratamiento del suelo de núcleo de la Ley de 1997 que permitía delimitaciones muy amplias. Se iba tomando conciencia de la necesidad de controlar la ocupación del suelo en un territorio especialmente valioso donde el planeamiento general suele proteger más del $70 \%$ de la superficie municipal, como suelo rústico, ya recuperado el término en la Ley de 1997, frente a no urbanizable. Básicamente esto es así dada la gran cantidad de superficie de montes en mano común, el gran número de cursos de agua, que otorgan una calidad paisajística importante, suponen un soporte de vida y garantizan el potencial de la explotación agrícola, que también se protege.

La LOUG no modifica de manera importante el régimen de suelo, a excepción del de núcleo para el que las determinaciones pasan a ser normativas, planteando casi 
unas ordenanzas vinculantes. A título de ejemplo se establecen condiciones de parcelación con carácter general sin tener en cuenta las grandes diferencias del tamaño de parcela entre unas zonas y otras. Además también insiste en las normas estéticas sin tener en cuenta la riqueza de la diversidad del patrimonio arquitectónico gallego.

Otro tanto ocurre con el suelo rústico para el que plantea un régimen de usos pormenorizado y una regulación para las reclasificaciones en el caso de incendios y la aparición del art. 206 en el que se restringe de manera notable la parcelación, sin duda con el objeto de evitar la reproducción histórica del minifundio. Más tarde se incorporará la posibilidad de la división de parcelas sin edificar, por razón de herencias, con la condición de no edificar los lotes resultantes y estos tengan más de $15.000 \mathrm{~m}^{2}$.

Siendo quizás el tema más relevantes desde le punto de vista de la ordenación la incorporación de los arts. 46. Límites de Sostenibilidad, 47. Calidad de Vida y Cohesión social y 48. Normas de Calidad Urbana. El 46 con un criterio limitado de lo que es la sostenibilidad, en un momento en que la Estrategia Territorial Europea (1999) ya planteaba la sostenibilidad como dependiente de tres factores: cohesión social, desarrollo económico y medio ambiente. Este artículo habla solo de edificabilidades a asignar para el suelo urbano no consolidado y urbanizable en función exclusivamente del número de habitantes, generalizando para toda Galicia, con independencia de la evolución urbanística histórica del municipio. Plantea la necesidad de mantener la trama urbana y que las nuevas edificaciones sean coherentes con la tipología arquitectónica característica.

En lo relativo a la gestión se introduce la permuta forzosa junto con los sistemas tradicionales, la ocupación directa ya había quedado incluida anteriormente. Como novedad introduce el Sistema de Concesión de Obra Urbanizadora, que pese a las sucesivas sentencias en relación con la Comunidad Valenciana y lo leonino de su condiciones sigue aún vigente, cabiendo esperar que no se ponga en marcha, dado lo injusto e inadecuado de su planteamiento en relación con el sistema de propiedad, en el que el número de propiedades impide acuerdos rápidos tanto en la gestión por sistemas convencionales como de reacción ante la iniciación de un sistema de este tipo. Madrid lo suprimió en su día.

En cuanto a la documentación la LOUG exige, como novedad, para los Planes Generales la realización de un Estudio de Sostenibilidad Ambiental, Territorial y Paisajística (ESATP). La trasposición de la directiva 42 y la entrada en vigor de la Ley 9/2006, de 28 de abril, de evaluación de determinados planes y programas en el medio ambiente, provoca la aparición de la Ley 6/2007, de 11 de mayo, de medidas urgentes en materia de ordenación del territorio y del litoral de Galicia que incorpora, a través de una artículo denominado Integración de Procedimientos, la necesidad de la Evaluación Ambiental Estratégica (EAE) y su tramitación conjunta con el planeamiento. Como no podía ser de otra manera, el ESATP desaparece en el Texto consolidado del 2012, no así su exigencia en el planeamiento de desarrollo cuando se ha declarado no necesaria la EAE, pero vaciado de contenido al desaparecer de la Ley.

Dos años después de la LOUG entra en vigor la Ley 15/2004, de 29 de diciembre de modificación de la LOUG, en su aprobación tiene mucho que ver, sin duda, la entrada en vigor de la Ley 10/2003, de 20 de mayo, de medidas urgentes de 
liberalización del sector inmobiliario y de transportes. La ley se aprueba con el objetivo de perfeccionar la LOUG: "con la finalidad de garantizar el acceso de la población a la vivienda, garantizar la sostenibilidad de los usos del territorio y fortalecer el sistema urbano y de asentamientos surales tradicionales procurando evitar la dispersión de la urbanización y la edificación sobre el territorio".

Modifica sustancialmente el régimen del suelo rústico y la definición de sus categorías, por ejemplo en el caso del protegido forestal en la LOUG, los "montes públicos y los montes en mano común" quedan incluidos en esa categoría y en la 15/2004 "los montes en mano común podrían ser calificados como suelo rústico de protección forestal". Para concluir con la desprotección de estos monte en la Ley $15 / 2010$, de 28 de diciembre, de medidas fiscales y administrativas, en la que en la nueva redacción no se mencionan, dando carta de naturaleza para su ocupación por diversos usos, ya sean industriales, infraestructuras o equipamientos como, de hecho, ya se venía permitiendo.

También la Ley 15/2004, introduce la posibilidad de "excluir de esa categoría las áreas sin masas arboladas merecedoras de protección, colindantes sin solución de continuidad con el suelo urbano o los núcleos rurales, que resulten necesarias para el desarrollo urbanístico racional", lo que se mantiene ignorando lo previsto en la Ley $3 / 2007$, de 9 de abril, de prevención y defensa de los incendios forestales. De nuevo aquí se modifican las condiciones generales de edificaciones en suelo de núcleo rural y rústico volviendo a incidir en temas normativos propios del carácter del planeamiento municipal.

Se mantiene el art.50. Normas Técnicas de Planeamiento, realmente necesarias en función de la dispersión de la calidad de las cartografías, la introducción de las técnicas digitales o la diversidad de interpretación de determinados términos de carácter general. Servirían para garantizar la calidad de los documentos y la coordinación entre municipio. Once años después siguen sin ponerse en marcha.

La irrupción de la crisis en el año 2007 y la entrada en vigor de la Ley Estatal, $8 / 2007$, de 28 de mayo, del suelo y su posterior texto refundido y la creación de la Consellería de Vivienda tiene mucho que ver con la aparición de la Ley 6/2008, de 19 de junio, de Medidas Urgentes en Materia de Vivienda y Suelo, por la que de nuevo se modifica la LOUG. En este momento se aprovecha para incorporar como cesión obligatoria "terrenos destinados a la dotación autonómica" para la construcción de viviendas de promoción y titularidad pública y establece una cuantía de $2,5 \mathrm{~m}^{2}$ de suelo por cada $100 \mathrm{~m}^{2}$ de edificación residencial, en el suelo urbanizable", norma que al igual que en Madrid ha quedado derogada, perdiéndose una oportunidad efectiva de intervención pública en materia de vivienda.

La Ley plantea, poniéndola en el artículo 47 como un factor de cohesión social, la exigencia de una reserva del $40 \%$ de la edificabilidad residencial en municipios de más de 20.000 habs., que como novedad', afecta no solo al suelo urbanizable sino también al suelo urbano no consolidado y será como mínimo el 30\% en los restantes municipios, ajustándose al mínimo establecido en la legislación estatal. La distribución de estos porcentajes se hará en función de unas reglas que la propia ley establece, amén de precisiones en los municipios de menos de 20.000 habs. La LOUG ya había establecido la necesidad de la reserva del $20 \%$ para el suelo no urbanizable. 
Dichas viviendas "se deberán localizar evitando la concentración excesiva de viviendas de dicho tipo, para favorecer la cohesión social y evitar la segregación territorial de los ciudadanos por su nivel de renta". En un intento de evitar al "guetificación" de épocas anteriores. Más adelante, en el Texto consolidado de 2012 se reduce, a un mínimo, el porcentaje al 30\% de la edificabilidad residencial del suelo que vaya a ser incluido en actuaciones de urbanización. Se plantean también unas reglas matemáticas para la estimación de la demanda potencial de vivienda protegida en función de distintos factores, entre los que figuran el estar inscrito como solicitante en el registro de demandantes, como es lógico, por la dificultad de su parametrización, no se tiene en cuenta la realidad social de cada municipio.

La ley incide en el destino y la constitución de los patrimonios públicos de suelo, señalando que no se pueden enajenar o permutar bienes del patrimonio público, en tanto no se haya constituido el patrimonio público y el registro de solares, se entiende que para atajar las prácticas anteriores, en las que el patrimonio público de suelo estaba muy lejos de ser utilizado para los fines de su constitución.

Tan solo dos años más tarde se aprueba la Ley 2/2010, de 25 de marzo, de Medidas Urgentes de Modificación de la LOUG, en esta ocasión con un primer objetivo de partida, atender a los ayuntamientos en sus inquietudes ante la imposibilidad de tramitación del planeamiento en unos plazos prudenciales y aprovecha para insistir en el perfeccionamiento del suelo de núcleo rural y del suelo rústico complejizándolo innecesariamente y vaciando de contenido una vez más al Plan General, común a todos los municipios una vez desaparecidas las Normas Subsidiarias Municipales, por las sucesivas vinculaciones del planeamiento a las determinaciones pormenorizadas de la ley.

Esta Ley afecta básicamente en la delimitación de los núcleos rurales, estableciendo tres categorías: histórico tradicionales, comunes y complejos, estos últimos como conjunto de los anteriores, con unas condiciones mucho más restrictivas en relación con las leyes anteriores, dejando fuera de ordenación viviendas construidas con licencia, lo que ha dificultado enormemente la adaptación de los planes aprobados anteriormente o aquellos que estaban tramitándose con la LOUG. Posteriormente se aprueba una instrucción, con el carácter limitado que ésta tiene pero asumida con generalidad, en la que la delimitación se convierte en una simple fórmula matemática que ignora la realidad de los asentamientos y su desarrollo tradicional.

A lo largo de la redacción de la legislación urbanística gallega se había manifestado una clara preocupación por la ordenación de los núcleos y así aquí aparecen los Planes Especiales de Ordenación del Núcleo Rural, en sustitución de los antes denominados Planes Especiales de Protección, Rehabilitación y Mejora del Medio Rural, a su vez herederos de los Planes Especiales de Mejora del Medio Rural de la Ley de 1997. Se considera un documento de ordenación urbanística pormenorizada del núcleo que se aproxima, cada vez más, a las características del suelo urbano, en cuanto a deberes y derechos, sin atender a las grandes diferencias económicas y sociales de los distintos municipios.

Se incorpora la memoria de sostenibilidad económica a la que obliga la ley estatal, pero no se aprovecha para adaptar los convenios a la misma o eliminarlos como si haría la legislación madrileña, en un momento en el que los temas de corrupción 
urbanística empiezan a ocupar los titulares de los periódicos. En ese mismo año aún habrá otra modificación importante aprovechando el cierre del año económico, la Ley 15/2010, de 28 de diciembre, de medidas fiscales y administrativas, sirve de nuevo para modificar el suelo rústico, y tratar de algunos temas relativos a la expropiación y parcelaciones.

El 26/09/2012 se publica el texto consolidado de la LOUG, estando en el 2015 pendiente de aprobación la nueva Ley. Es posible que el presente artículo no parezca más que una enumeración sucesiva de leyes, con el tratamiento parcial de algunos temas, pero entiendo que es suficiente para entender la incertidumbre en la que se mueve el planificador, al carecer de un marco legal estable, la situación no es diferente en Galicia de otras Comunidades Autónomas, donde el planeamiento se tramita y aprueba igualmente de forma limitada.

El planificador ha dejado de ser un profesional que se dedica a la ordenación urbanística a partir de una realidad existente en aplicación de unos criterios y objetivos establecidos previamente para pasar a moverse en el proceloso mar de la legislación urbanística y de la legislación sectorial que a modo de catarata se ha ido emitiendo, tanto desde el Estado como de las Comunidades Autónomas y receloso de meter la pata u olvidar alguna norma por el camino. Sin olvidar la complejidad de interpretación de todas las disposiciones adicionales y transitorias que la modificación de las leyes exigen y por tanto, acompañan a cada nueva norma.

No hay que olvidar que seguimos en Galicia, donde municipios con una escasa o nula complejidad urbanística se ven obligados a redactar un Plan General, en ausencia de unas Normas Subsidiarias Provinciales adaptadas, las últimas son de 1.991 y documento más que suficiente, utilizando recursos que serían mejor empleados en otras áreas. En su normativa de obligado cumplimiento incorporan un listado de 104 leyes, decretos, etc., de imposible seguimiento con los medios técnicos que disponen. O donde municipios más dinámicos costeros, con puerto, aeropuerto, ferrocarril y autopista como elementos añadidos requieren para su aprobación 36 informes sectoriales, caso de Redondela, que hay que coordinar entre sí y pueden ser favorables o no, pero vinculan, y por los que hay que esperar, no los plazos administrativos legales, sino hasta dos años, lo que conlleva la proliferación de modificaciones frente a la adaptación, revisión o redacción de nuevo planeamiento.

La inseguridad jurídica de una actividad con un alto contenido económico ha llevado a su judicialización, por las imprecisiones y los cambios sobrevenidos, las dudas en cuanto a la vinculación de las nuevas determinaciones al planeamiento vigente. Los contratos se rescinden por imposibilidad manifiesta de concluir los trabajos, trabajos sin aprovechamiento posible por la obsolescencia de los mismos dado el tiempo transcurrido, el incumplimiento generalizado de los plazos en los informes sectoriales y la posibilidad de la espada de Damocles de olvidar algo por el camino o un informe que no llega a tiempo. Todo ello ha convertido una profesión necesaria en un calvario, al parecer sin retorno, salvo que en algún momento alguien decida refundar el sistema adaptándolo a los nuevos tiempos llenos de retos, la sostenibilidad bien entendida, la globalización, la gobernanza... y se garantice la seguridad jurídica con normas claras y tramitaciones ajustadas. 


\section{LA CIUDAD FALLIDA}

Juan Miguel Morell y Fuentes (Arquitecto - Profesor asociado DUyOT)

Uno de los temas que han surgido en estos años y que serán objeto de multitud de disquisiciones en este siglo, han sido las ampliaciones fallidas de ciudades.

Con mayor o menor intensidad, con mayor o menor desarrollo en multitud de poblaciones, se han producido ocupaciones de suelo con urbanizaciones, pavimentaciones, estructuras incompletas y toda suerte de elementos constructivos, que han modificado suelo, paisaje y las economías municipales y de los ciudadanos. Los planteamientos especulativos en todos los órdenes, propiedad del suelo, gestión, urbanizadores, promotores, constructores, técnicos.... han llevado a planificar desarrollos ilusorios de crecimiento de las poblaciones, bien por incrementos poblacionales que superaban valores imposibles, bien por futuros industriales que iban a eclipsar los de poblaciones vecinas, bien por una riqueza que iba a alcanzar para todo.

Al final, todas las expectativas chocaron con la realidad y la economía y, tras los oportunos esfuerzos de toda índole ha acabado en agua de borrajas y han llevado a los municipios a un fracaso en sus pretensiones de ampliación. Uno de los casos que, por haber visto su desarrollo y la situación que actualmente presenta, es el de la ciudad de Mérida, capital administrativa de Extremadura.

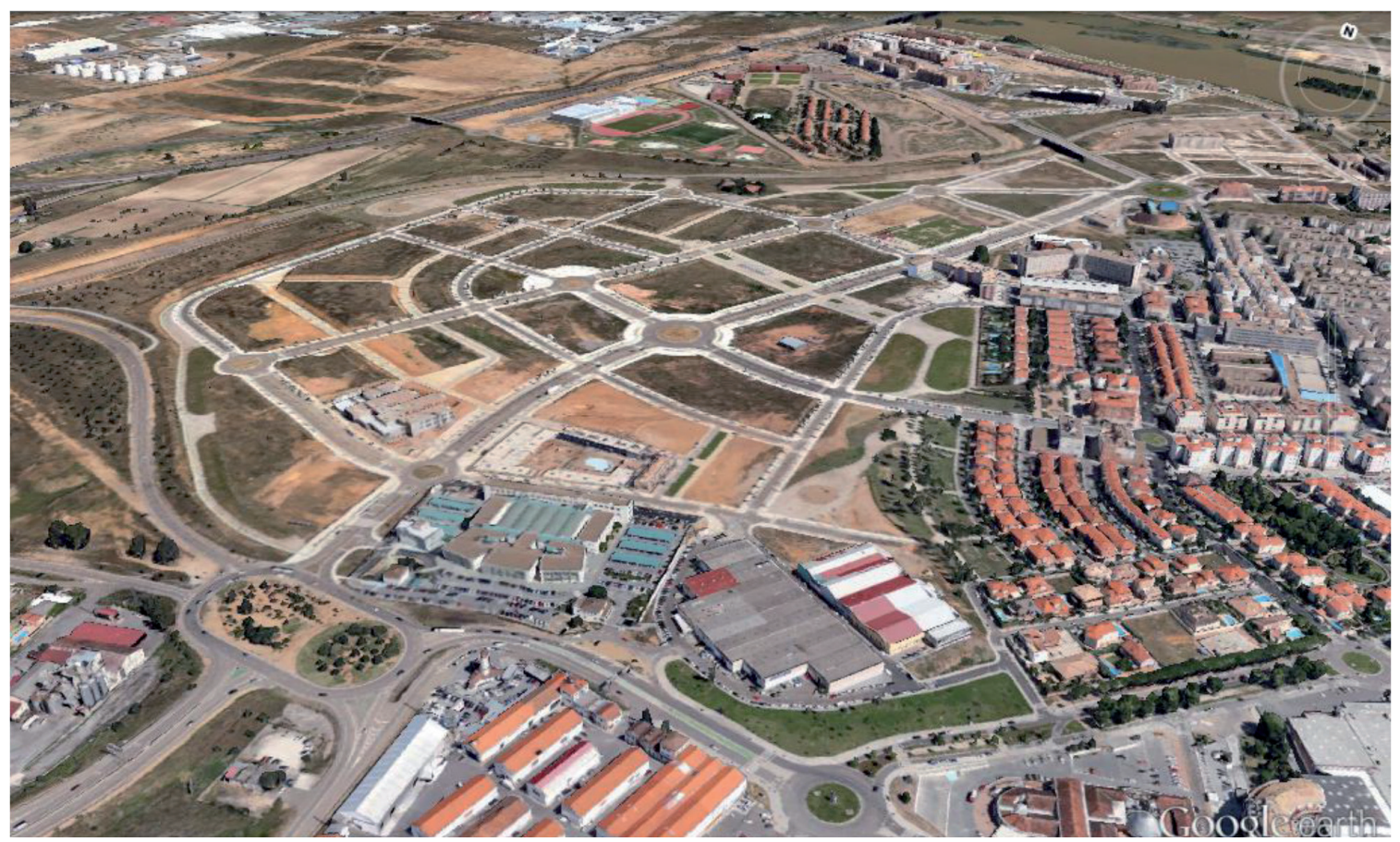

Figura 2. Estado actual de los nuevos ensanches urbanos en la ciudad de Mérida (España)

Fuente: Google Earth 
No voy a hacer una historia de su desarrollo, pero sí señalar lo ocurrido en los últimos diez años. Desde que se formó su nombramiento como sede del Gobierno Autónomo, las expectativas de crecimiento tuvieron su fundamento y se acomodaron a esta realidad, pero, una vez alcanzado el nivel que semejante titularidad podría generar, los desarrollos fueron desproporcionados al tamaño que se podría lograr. Hectáreas de suelo, con un valor natural de más o menos valía agrícola, medioambientalmente propicios como entorno de la ciudad, han sido "adecuados" al desarrollo urbano, moviendo tierras, pavimentando, organizando redes de desagües, eléctricas y todo lo preciso para que pudieran ocuparse (construirse) las parcelas resultantes.

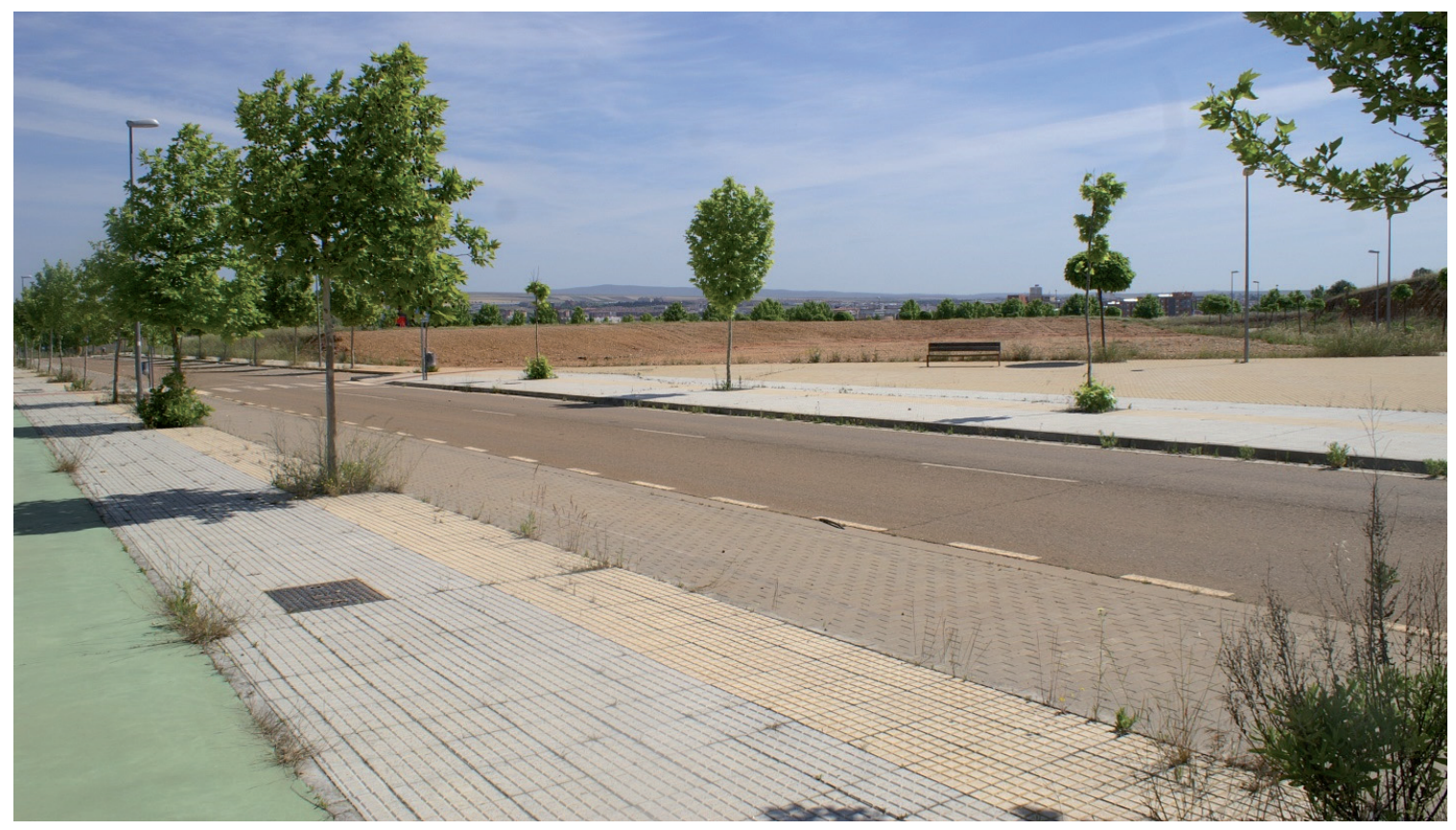

Figura 3. Vista de una de las calles de los nuevos ensanches urbanos en la ciudad de Mérida (España) Fuente: Archivo del autor

Pero las escasas intervenciones (algunas viviendas VPO, centros médicos y estructuras en "stand by") no han llegado a ocupar un $5 \%$ de todo lo modificado. Las impolutas calles, con sus carriles bici-acerados, arbolados, alumbrados, mobiliario urbano, sólo sirven para atajar la comunicación entre áreas de la ciudad (algunas de ellas) y, el resto, para paseo esporádicos de practicantes de footing y cientos de ciempiés, sus usuarios casi exclusivos al haberles "robado" parte de su hábitat; son los dueños materiales de este espacio. Los recintos para construcción (solares) son la manifestación de los movimientos de tierras, acumuladores de residuos y la degradación del suelo natural, toda una exhibición tras la simple torsión. Las zonas pavimentadas, fruto de una ejecución cuidada, soportan honrosamente el abandono de su futuro que ha hecho que carezcan del mantenimiento propio, al no ser generadoras de recursos. Las redes de alumbrado y sus equipos, el riego, arquetas y mobiliario, poco a poco se "vampirizan" y, en este vacío, sólo destacan las instalaciones infantiles que languidecen, esperando a unos usuarios que tardarán muchos años en disfrutarlas. 


\title{
LOS ANTECEDENTES FRANQUISTAS DE LA POLÍTICA DE LA VIVIENDA SOCIAL
}

\author{
Luis Moya González (Dr. Arquitecto - Catedrático DUyOT)
}

Además de otras razones conocidas y publicadas para explicar la "burbuja inmobiliaria" y su consecuente crisis posterior que se produce en España con el cambio de siglo, no se ha reparado suficientemente que el problema de la vivienda no es coyuntural sino que es el resultado de una estructura inmobiliaria, que si no tiene su origen estrictamente después de la Guerra Civil, sí es el momento de su sistematización y puesta en práctica, sin interrupción hasta nuestros días. En efecto el proceso no sufre cambios sustanciales con la nueva democracia, y solo cabría destacar algún intento de nueva legislación sobre el alquiler, la fiscalidad y el control de las viviendas vacías, en el Gobierno de Rodriguez Zapatero de alrededor de 2005; lo cual, sin embargo, ha quedado en suspenso con el advenimiento de la crisis económica.

En una sociedad como la nuestra con insuficientes años de democracia, seguimos confiando, en gran parte, en el providencialismo que provoca la falta de transparencia y la auténtica representatividad, o falta de participación, con la que actúa la Administración Pública. En el problema de la vivienda se traduce en la fe del efecto benéfico de nuevas leyes y retoques en la organización administrativa. En varios países europeos, que nos llevan bastante delantera, han desarrollado desde hace un siglo medidas para que la vivienda social no sea un objeto de especulación, que revisan cada año para ajustarlas a los cambios de la economía. En España no se ha incluido la vivienda social entre las medidas básicas del estado del bienestar, junto a la sanidad, la educación y las pensiones, y ni se ha dado el paso trascendente de excluirla de las actividades lucrativas; por el contrario desde 1940 se ha potenciado el negocio inmobiliario, perdiendo profesionalidad técnica y ganando en arribistas y aficionados, constituyendo el sector básico del "pelotazo". Así ocurre que empresas como los Bancos, compañías de seguros y otras, ajenas al objeto de producción, forman parte espuriamente del tejido productivo de la vivienda social. Un índice del cambio estructural que se ha producido en los últimos 45 años, es que el $89 \%$ de las viviendas están bajo el régimen de propiedad, invirtiendo casi exactamente lo que ocurría en 1940 (en 1950 88\% en alquiler, 6\% en propiedad, y 6\% otros, según Foessa) $)^{47}$, y que de ellas solo un $1 \%$ son propiedad de la Administración, mientras que en Francia es el $44 \%$, Países Bajos 47\% y en Alemania el 57\% (23\%, 35\% y 6\% propiedad de la Administración respectivamente), sobre viviendas principales ${ }^{48}$. Otro dato significativo son las 3,5 MM de viviendas vacías que existen en España ${ }^{49}$, sin contar las de $2^{a}$ residencia, sobre un total de 25 MM, y simultáneamente una fuerte demanda (no calculada estratégicamente por los organismos correspondientes,

\footnotetext{
47 Véase L. Moya Barrios de promoción oficial: Madrid 1939-1975, Ed. COAM, 1983

48 Véase La Vivienda Social en Europa: Alemania, Francia y Países Bajos, Coord. L. Moya, Ed. Mairea 2008

${ }^{49}$ Véase Julio Vinuesa La vivienda vacía en España: un despilfarro social y territorial insostenible, Ed. Scripta Nova, 2008
} 
únicos con suficientes fuentes de información) que provoca una de las tasas de emancipación más tardía de Europa, y conflictos graves en separaciones y divorcios.

Analizando las leyes franquistas se llega a la conclusión que el Estado no construye viviendas sociales realmente hasta la Ley de Viviendas de Renta Reducida y Limitada de 1954. Por tanto en la inmediata posguerra sus dos finalidades principales son ya fomentar la construcción para incentivar la economía y subsidiariamente dotar de vivienda a familias del Régimen, empleados, profesiones liberales y pensionistas. Para apoyar la política de la vivienda se crea el INV (Instituto Nacional de la Vivienda) en 1939, y se aprueba la Ley de Viviendas Protegidas y en 1944 la de Viviendas Bonificables. Debemos entender que la protección y la bonificación tienen como principales destinatarios los organismos oficiales con los objetivos mencionados, apoyando la iniciativa privada para desarrollar la economía. Pero los entes privados no tenían entonces capacidad económica para promover, ni estaban integrados en la nueva estructura económica. Por tanto, excepto algunas excepciones (URBIS y Banús) no se ponen en funcionamiento hasta los años 60, y mientras tanto las actuaciones en vivienda social se concentran en la propia Administración. El paso definitivo se producirá a partir de 1957 con la Ley de Viviendas Subvencionadas, debido a las mayores facilidades que se dan a promotores, y sobre todo a la salida de la autarquía, en relación con los acuerdos militares con EEUU y sus consecuencias de apertura económica al exterior. En este momento cambian sustancialmente los gobiernos de la Falange (era la fracción del Régimen encargada de esta política como parte de su ideología de contenido social, con el refuerzo de la Iglesia por su labor en las parroquias de los barrios de infravivienda) y fuerzas tradicionales de Régimen, para ser sustituidos por la corriente del Opus Dei, la cual, entre otras cosas, pone en marcha los sucesivos Planes de Desarrollo. En este contexto el impulso legislativo y las mayores facilidades que proporciona la Ley de Viviendas Subvencionadas de 1957, con superficies comprendidas entre 35 y $150 \mathrm{~m}^{2}$, cubren un arco grande de demanda que serán absorbidas principalmente por la promoción privada protegida de viviendas para las clases medias, cuya inversión supera el $207 \%$ de la Programada y sin embargo el sector público desciende al $45 \%$ (en el Plan Nacional de Viviendas Protegidas 1944-54 se programan 315.000, en total se construyen 150.000 protegidas y bonificadas; en el Plan 1955-60 se programan 550.000 de tipo social y se construyen la mitad pues la otra mitad están protegidas pero de categoría superior; entre 1961-1971 se programan 2,1 MM y se construyen 1,4 MM, de las cuales son de carácter social un 10\%).

Por otra parte, si observamos detenidamente la estructura organizativa de la promoción oficial de viviendas hasta los años 1960, podemos reconocer que bajo los organismos públicos como la Obra Sindical del Hogar, el INV, los patronatos militares, el Patronato Municipal de la Vivienda, etc. existe una incipiente organización de empresa privada, aunque sus fines no sean económicos sino políticos, con ciertos rasgos en cuanto que sus competencias y campos de aplicación son muy parecidos, compiten entre ellas y tienen un cierto grado de autonomía.

Abundando en la idea de la política de privatización de la vivienda social, observamos que las diferentes denominaciones que han recibido las viviendas protegidas por la Administración en las sucesivas legislaciones, corresponden al tamaño de las mismas, directamente relacionado con su precio, y no con su programa. El tamaño marca el estrato de población al que van dirigidas, es decir 
pocas tienen una finalidad social, excepto las construidas en la década de $1950^{50}$. En 1954 se crea la llamada Vivienda Social a la que se fija el tamaño de $42 \mathrm{~m}^{2}$ útiles, bastante menor a la de leyes anteriores (que aunque no se fija la superficie se construyen mayores de la indicada). También en este año se crea la Vivienda Mínima de 35-58 m², la de Renta Reducida de 74-100 m², la de Renta Limitada de 56-68 m² en su $3^{a}$ categoría y de $65-150 \mathrm{~m}^{2}$ en su $2^{a}$ categoría,. Al ser aprobadas estas últimas se suprimen las Protegidas y Bonificables pues las ayudas se sistematizan dentro de las primeras.

Es decir, la superficie de la vivienda, no responde a programas diferentes de hogares; las viviendas de superficie mínima tienen un programa completo de salacomedor-cocina, tres dormitorios y aseo, y se conciben para familias de 4 a 8 miembros; a medida que aumenta el número de estos, el incremento de $\mathrm{m}^{2}$ es desproporcionadamente pequeño con un dormitorio más, pero la solución realmente consiste en sustituir camas por literas. Desde los años 1940 mejora el cuarto de baño que pasa de una cabina para el retrete y utilización del fregadero como lavabo, a colocar un lavabo en el aseo, y más tarde una ducha, que se convertirá en bañera a lo largo de los años 1960. Tanto las superficies de las viviendas e incluso el desdoblamiento de cuarto de baño completo y aseo, solo se producirá en la Operación de Remodelación y Realojamiento de Barrios en Madrid de los años 1980.

El problema de la vivienda social persiste hasta nuestros días porque hay razones de base que permanecen en la democracia, y no han surgido verdaderas políticas que hayan tratado de encauzarlas. La inmigración del franquismo fue una auténtica oleada, difícil de asimilar en poco tiempo. Entonces eran nacionales procedentes de un medio rural empobrecido como corresponde a un sistema de propiedad de la tierra y su explotación, de tiempos arcaicos. La irrupción de inmigrantes extranjeros a partir de los años 1990, ha sido igualmente rápida pero podemos decir que no tan marginada como la primera. La mayoría de la inmigración de la etapa franquista se situó en infraviviendas en la periferia madrileña, en este caso, considerada como "un cinturón rojo" por la burguesía vencedora de la Guerra. Una y otra lo forman una mano de obra poco cualificada cuyo refugio laboral es la construcción, pero pagada con salarios bajos (en el año 2007 el precio de la construcción en España era 2/3 partes de la Alemana ${ }^{51}$ ), que por una parte hace más rentable el negocio de la construcción y por otro contribuye al poco desarrollo de su industrialización.

Los esfuerzos del Instituto Torroja, que funciona desde el año 1934, no tiene más que un pálido reflejo en algunos materiales y técnicas constructivas que no son mayoritarias. Situación que nos despega de otros países europeos como Alemania, Suiza, Francia o Inglaterra que iniciaron en décadas anteriores su camino hacia la producción en serie de elementos desde su previa normalización en 1937, y en algunos casos redujeron los costes reales hasta un $30 \%$ frente a la construcción

\footnotetext{
50 Según demuestra el trabajo de investigación que realiza el Grupo de "Vivienda Social", titulado "Análisis urbanístico de conjuntos con vivienda pública [VP] en la ciudad de Madrid, 1940-2010" dirigido por L. Moya y coordinado por C. Fernandez Salgado, explotando la base de datos del catastro, la vivienda pública madrileña, en este período solo es más pequeña que la privada en los años 1950 (pendiente de publicación).

51 Véase La Vivienda Social en Europa: Alemania, Francia y Países Bajos, Coord. L. Moya, Ed. Mairea 2008
} 
artesanal $^{52}$. En realidad Walter Gropius venía propugnando lo mismo desde la primera década del S XX con el argumento de inscribir la arquitectura en el sistema de producción industrial. En España hubiera hecho falta una auténtica política en este sentido para homogeneizar el dimensionado, favorecer los componentes reconocidos y premiar de alguna manera a los que utilizaran el sistema industrial. De esta forma se hubiera conseguido, a medio y largo plazo abaratar la construcción mejorando su calidad, cualificar la mano de obra haciéndola más segura con un trabajo en mejores condiciones ambientales y al mismo tiempo fomentar el sector industrial, hoy en franca decadencia. Por otra parte la construcción industrializada por componentes en otros países nos demuestra que la seriación produce más variación y belleza que la construcción con métodos anticuados ${ }^{53}$. En 1956 el recién estrenado Ministerio de la Vivienda convocó un concurso que tenía prácticamente las mismas intenciones que se han puesto aquí de manifiesto y en paralelo con la Interbau de Berlín 1957, pero no prosperó por la fuerza de la tendencia contraria y predominante.

Con todo ello hemos sido testigos de una Dictadura que prometía miles de viviendas pero que no era capaz de construir, y ahora una democracia que promete empleos que no puede generar. Tanto en un régimen como en el otro aumenta progresivamente el déficit de viviendas y empleos en las grandes ciudades. Ambas variables son la base de una buena administración pero ambas son irresolubles cuando están sometidas al mercado libre. Su relación además es directa y ya planteaba en el S XIX en Europa, un conflicto entre industriales e inmobiliarios, a pesar de los esfuerzos hechos por la Administración, y en algunos casos por los propios industriales construyendo sus poblados junto a las fábricas. En un sistema como el español, es incompatible favorecer la tenencia en propiedad de la vivienda, y al mismo tiempo la llamada flexibilidad, o mejor precariedad en el empleo, pues sin una cierta estabilidad laboral los jóvenes no pueden emanciparse y adquirir una vivienda. Además el escaso todavía mercado del alquiler y su carestía, empeora la situación, por tres razones fundamentales: el apoyo fiscal a la vivienda en venta, la inseguridad jurídica y la falta de flexibilidad en la gestión.

En conclusión para mejorar el acceso a la vivienda con condiciones suficientes de habitabilidad para todo el mundo en España, se necesita comenzar inmediatamente una reestructuración del sector con el objetivo de su utilización y no de su comercialización, al tiempo que se mejora la construcción mediante su industrialización. Implica cambios en legislaciones fundamentales como la fiscalidad, la propiedad horizontal, el alquiler, el patrimonio, etc. y también nueva organización administrativa que apoye a los usuarios y no a los promotores. Este proceso no puede estar sometido a las vicisitudes políticas con sus discursos habituales repletos de promesas imposibles, porque como todo cambio de base, necesita tiempo y estabilidad.

\footnotetext{
52 Pepa Casinello La vivienda experimental: concurso de viviendas experimentales de 1956, coord. José M. Fernández Isla, Ed. COAM 1997.

53 Julián Salas et alt. Estrategias para incentivar la industrialización de la Construcción Ed. Ministerio de Fomento 2011
} 


\title{
UN EPISODIO RELEVANTE: LA BURBUJA ESPECULATIVA Y LA CRISIS INMOBILIARIA EN PERSPECTIVA
}

\author{
José Manuel Naredo (Dr. Economista - Profesor Ad Honorem DUyOT)
}

\section{CONTEXTO}

A mi juicio, el episodio más relevante y condicionante para el territorio y el urbanismo de finales del siglo pasado y principios del actual, ha sido la enorme burbuja especulativa y la posterior crisis inmobiliaria que ha vivido el país. El pinchazo de esta burbuja ha forzado la crisis económica y también la del modelo inmobiliario que la posibilitó, invitando a reflexionar sobre él.

El modelo económico-inmobiliario condiciona el modelo territorial y urbano: en la medida en la que impera el modelo económico que trata el suelo y la vivienda, no como bienes de uso, sino como activos patrimoniales en los que invertir para obtener plusvalías, se impone también un mismo modelo de orden territorial, urbano y constructivo. Pues, como he venido subrayando, la globalización de ese modelo económico genera por todas partes, sin decirlo, la polarización territorial, la dispersión urbana y la uniformidad constructiva, en ausencia de otras orientaciones y frenos.

\section{EL MODELO INMOBILIARIO ESPAÑOL, SU CULMINACIÓN Y CRISIS}

El actual modelo inmobiliario no ha resultado de aplicar ningún plan teórico premeditado, sino de la configuración histórica de un marco institucional en el que se solapan aspectos e instrumentos (políticos, económicos, jurídicos, ...) orientados por el poder de determinados intereses oligárquicos. Es este poder oligárquico el que se impone y da unidad al modelo en toda nuestra geografía, trascendiendo la casuística de las legislaciones autonómicas.

Durante el franquismo se instalaron dos características esenciales del modelo: $1^{\circ}$ ) Los empeños especulativos de algunos se impusieron sobre otros posibles criterios de ordenación urbana y territorial más acordes con los intereses generales de la ciudadanía. Se extendió la cultura del "pelotazo" y el virus de la especulación por todo el cuerpo social. $2^{\circ}$ ) La vivienda libre y en propiedad se acabó imponiendo sobre la vivienda en alquiler $y$ en alquiler social.

Tres condiciones permitieron la culminación del modelo: $1^{a}$ ) La refundación oligárquica del poder que resultó de la metamorfosis democrática del franquismo, engendró una especie de neocaciquismo en el que los más poderosos continuaron tomando las grandes decisiones de espaldas a la ciudadanía. $2^{a}$ ) La crisis de la planificación territorial y urbana, permitió instalar un laissez faire de los poderosos. Es decir que se instaló, no el laissez faire igualitario y democrático que predica el liberalismo, sino un laissez faire elitista que permitió a los nuevos caciques desarrollar sin trabas sus lucrativas "operaciones" inmobiliarias en el conjunto del territorio. La propia palabra "operaciones", tomada del lenguaje militar, denota la intervención directa del poder en la toma de decisiones, por caminos que ajenos a ese mercado libre, transparente e igualitario cuyas propiedades benéficas ensalzan los manuales 
de economía. 3a) La adhesión de España a la Unión Europea y la entrada en el euro facilitó la financiación barata y abundante que alimentó los procesos especulativos hasta niveles sin precedentes.

\section{CONSECUENCIAS}

La confluencia de esas tres condiciones hizo un cocktail explosivo para el urbanismo y el territorio: desencadenó una burbuja inmobiliario-especulativa sin precedentes, que provocó una sobredosis constructiva que hizo de España el país europeo con más viviendas, kilómetros de autopista, de AVE, puertos y aeropuertos por habitante. Pero el estancamiento demográfico y la ausencia de vivienda social, hizo también de España líder europea en viviendas vacías o infrautilizadas, manteniendo a la vez personas sin vivienda o hacinadas en infraviviendas.

Se acentuó también una extrema polarización territorial: España cuenta con grandes aglomeraciones de población, pero a la vez con grandes territorios vacíos, con menos de un habitante por kilómetro cuadrado. En Europa no se encuentran zonas de tan baja densidad poblacional, como no sea en las proximidades del Círculo Polar Ártico, o en el desierto lapón. España es también líder europeo en pueblos abandonados y en patrimonio inmobiliario rural en ruina.

Se impuso el urbanismo disperso: hay varias tesis doctorales en la Escuela de Arquitectura de Madrid, que muestran que las "operaciones" inmobiliarias han desarrollado en la metrópoli un urbanismo disperso, guiado por los grandes ejes del viario y por el poder de los propietarios de terrenos, ajeno a las previsiones del planeamiento.

Finalmente, el intenso proceso de destrucción de edificios antiguos, por demolición o ruina, y de construcción nueva repetitiva, orientada a obtener plusvalías de la reclasificación y recalificación de suelo, originó la monotonía y mala calidad del entorno urbano.

Podríamos poner como ejemplo de "operaciones" la que modificó la utilización de la antigua ciudad deportiva del Real Madrid, para meter allí un gran volumen de construcción en altura que cambió el skyline de la ciudad y arrojó enormes plusvalías. O, en las proximidades de Madrid, los casos de la "Ciudad Valdeluz" en Yebes, o de "Residencial el Quiñón" en Seseña, con unas diez mil viviendas proyectadas cada uno, pero con sólo unos cientos de habitantes residiendo, lo que indujo a llamarlas "ciudades fantasma". Debe de quedar claro que el objetivo de las "operaciones", no es hacer ciudad, sino maximizar las plusvalías de los propietarios de suelo añadiendo varios ceros a su valor por el mero hecho de ampliar su edificabilidad. Estos trozos de ciudad no siguen ninguna racionalidad de planeamiento, sino que ilustran esa especie de urbanismo a la carta de los especuladores más poderosos. Según mis cálculos, en los años centrales del boom inmobiliario, estas plusvalías han superado ampliamente los ingresos ordinarios de la población.

Esta avalancha de "operaciones" además de extender por toda la geografía española el modelo urbano disperso, invirtió en las zonas más densas el modelo originario de ocupación del territorio: transformó un mar de ruralidad con islotes urbanos en un mar metropolitano con islotes de naturaleza o ruralidad degradada que 
ahora se trata de proteger. El nuevo modelo consume mucho más suelo y recursos que el anterior: por ejemplo, la Comunidad de Madrid ha más que duplicado la ocupación del suelo por habitante, al disparase las servidumbres indirectas que el dicho modelo exige en forma de actividades extractivas y de vertido, embalses, viario, suelo en promoción, etc.

El nuevo modelo de urbanismo disperso no ha tendido a mejorar, sino a destruir los asentamientos anteriores. Ha destruido los asentamientos lejanos, al vaciarlos de población y actividades, sometiéndolos al abandono y la ruina. Y engullido los próximos al arrojar sobre ellos tal contenido de edificaciones e infraestructuras, dejando las muestras de lo que había como algo testimonial o sin sentido.

El nuevo modelo constructivo, industrializado, homogéneo, repetitivo, genera una especie de "estilo universal" que, lejos de mejorar, destruye los edificios de la ciudad clásica o histórica. Basta con que se pueda aumentar el volumen construido de las parcelas, para que se condene a la demolición los edificios antiguos y se imponga el nuevo "estilo universal" multiplicando la superficie construida. Más de la mitad de las viviendas registradas en el Censo de 1950 han desaparecido hoy por demolición o ruina.

Al ser la construcción nueva de edificios e infraestructuras, colaboradora necesaria del negocio inmobiliario, ésta se ha disparado hasta límites que parecían impensables. España vino construyendo, en los años centrales del pasado boom inmobiliario, más del doble de viviendas que Francia y Alemania juntas, cuando estos dos países triplican a España en población y la duplican en superficie. Tomando el consumo anual de cemento como indicador sintético de la actividad constructiva, nos encontramos con que se acercó en los años centrales del boom a los sesenta millones de toneladas, cayendo sobre el territorio más de una tonelada de cemento por hectárea y cerca de diez toneladas de cemento mezclado ya con grava, arena etc. Lo cual hace que la palabra tsunami inmobiliario deje de ser una simple metáfora para cargarse de materialidad.

Este proceso de ocupación efectiva del suelo por construcciones e infraestructuras (conocida como "sellado" de suelos) originó una destrucción territorial mucho más amplia, no solo por servidumbres de extracciones, vertidos, embalses,...sino también por suelo en promoción o en "barbecho urbano". Las desmesuradas expectativas de urbanización han generado muchos miles de hectáreas de sistemas agrarios abandonados y sometidos a deterioros diversos. La burbuja inmobiliaria nos ha legado así, un sobredimensionado y dantesco espacio periurbano degradado.

El pinchazo de la burbuja inmobiliaria ha acentuado la depresión de la economía española recordando con dramatismo que los movimientos especulativos son juegos de suma cero, en los que algunos ganan porque a la postre otros pierden o se endeudan para seguir sufragando las plusvalías que cobraron los ganadores. Muchos tendrán que seguir pagando, porque la financiación de la burbuja inmobiliaria y sus megaproyectos asociados, devoró el ahorro financiero del país, tornándolo negativo en los últimos años del boom, e induciendo a la banca a seguirlo financiando hasta el final con dinero de fuera. Finalmente, cuando las suspensiones de pagos de las inmobiliarias y empresas asociadas extendieron la desconfianza, desapareció la liquidez barata y abundante que el país venía recibiendo de fuera, colapsó el sistema 
financiero, acarreando la consabida "sequía de créditos", las operaciones de salvamento del Estado y las inyecciones de liquidez del BCE.

El andamio especulativo inmobiliario-financiero instalado durante el auge acabó situando el endeudamiento hipotecario de la economía española respecto a la renta por encima del de todos los países de nuestro entorno, incluido EEUU, cuando antes de la burbuja se situaba por debajo. El hecho de que el grueso de la deuda hipotecaria de los hogares recaiga sobre los escalones más bajos de renta, aumenta sus dificultades de pago convirtiendo la crisis económica en crisis social (por ejemplo, en 2011, el $20 \%$ de los hogares endeudados con menos renta tuvo que destinar al pago de la deuda más del 46 \% de sus ingresos, según la EFF del Banco de España).

Por otra parte, el monocultivo inmobiliario imperante trajo consigo tasas de paro muy superiores a las de los otros países de la UE (que no pudo corregir ninguna "reforma laboral", cuando el grueso del paro provino de actividades directa o indirectamente afectadas por el desplome de la construcción y la promoción inmobiliaria).

Cabe preguntarse qué ha cambiado para hacer tan gravosas unas deudas que durante el auge parecían soportables. El principal cambio viene de la diferente naturaleza de los activos y pasivos que componen el balance de hogares y empresas. Mientras que el valor de los inmuebles y terrenos cae, junto con los ingresos, el valor de las deudas permanece invariable o puede aumentar si lo hace el tipo de interés. En este contexto asistimos en España a un forcejeo para ocultar o maquillar la caída de los precios que se observa en el mercado inmobiliario. Al principio de la crisis, las empresas de tasación, mayoritariamente dependientes de bancos y cajas de ahorros, retrasaron más de un año la caída de precios de la vivienda registrada en los precios de los anuncios, cuya caída total superó a la de los precios de tasación (y recordemos que en momentos de crisis los precios de mercado caen bien por debajo de los de los anuncios, pero no salen en la foto de nuestras precarias estadísticas). Si al principio los precios de tasación trataron de ilustrar un "aterrizaje suave", ahora se apresuran a anticipar "el repunte", mientras que los de los precios anuncios siguen cayendo. Así, la opacidad estadística sobre la evolución de los verdaderos precios de mercado retrasa los ajustes en el mercado inmobiliario, manteniendo un patrimonio inmobiliario sobredimensionado y en buena parte desocupado, que enfrenta viviendas desocupadas a necesidades de vivienda insatisfechas, agravadas por ola de desahucios en curso, haciendo más penosa la crisis.

El actual neocaciquismo ha promovido, más que la producción, la adquisición de riqueza a través de operaciones y megaproyectos especulativos sin interés social, ni viabilidad económica. La dimensión que alcanzaron estos procesos hizo que el beneficio empresarial y el crecimiento económico no redundaran en mejoras de la calidad de vida del conjunto de la población, que tiene que pagar ahora los platos rotos del aquelarre de plusvalías, comisiones y obras sin sentido, de las que se beneficiaron algunos.

Más preocupante que los daños ecológicos y los endeudamientos económicos que han dejado las prácticas especulativas, resulta la herencia de stress psicológico, de crispación social y de bancarrota moral. 


\section{PERSPECTIVAS Y ALTERNATIVAS}

Hay que asumir que estamos sufriendo las consecuencias de un modelo inmobiliario agotado, que no resuelve los problemas que tiene planteados el país en estos momentos, lo que pide a gritos su reconversión.

Hay que diagnosticar el panorama "post burbuja" subrayando que se ha desplazado el problema desde la supuesta escasez originaria de suelo urbanizable, infraestructuras y viviendas, hacia un desmesurado exceso de los mismos... unido al enorme endeudamiento antes mencionado.

Los principales objetivos que se desprenden de ese diagnóstico son, reconvertir, sanear y/o hacer habitables, los excesivos stocks de suelo, infraestructuras y viviendas y paliar la carga del excesivo endeudamiento.

La definición de los problemas y objetivos señala la configuración del marco institucional y la elección de políticas e instrumentos. Las instituciones, políticas e instrumentos alternativos propuestos tendrían que ser, en la mayoría de los casos, justo los contrarios de los que han venido operando hasta el momento. Pues justo habría que situarlos en las antípodas de los actuales para orientar el metabolismo económico hacia la habitabilidad y el uso eficiente del patrimonio inmobiliario pasando de la vivienda como inversión, hacia la vivienda como bien de uso; desde la realización de plusvalías hacia el cobro de rentas; desde la vivienda libre hacia la vivienda social; desde la construcción nueva hacia el saneamiento, la reutilización, rehabilitación, y ocupación del suelo y el patrimonio inmobiliario construido...

Cambiar el modelo inmobiliario actual no exige descubrir la pólvora, ni hacer la revolución, sino mirar más allá de los Pirineos y fijarnos en otros países de capitalismo maduro (como Alemania o Suiza, en los que predomina el alquiler como régimen de tenencia mayoritario del stock de viviendas) que gestionan de forma más razonable su patrimonio inmobiliario... o seguir las orientaciones que marcan documentos que van desde el Libro verde del medio ambiente urbano, publicado por la UE en 1995... hasta Libro blanco de la sostenibilidad en el planeamiento urbano, publicado por el antiguo Ministerio de Vivienda en 2010 y el Libro verde de la sostenibilidad urbana y local, Ministerio de Agricultura, Alimentación y Medio Ambiente, 2012.

Las exigencias contempladas en estos documentos de una "nueva visión integrada" y un de "cambio de lógica" respecto a los enfoques parcelarios y pecuniarios habituales, se resumirían en la consideración de la ciudad como proyecto, con todas sus piezas. Y las exigencias habituales de "compromiso público institucional" tendrían que concretarse apoyando el proyecto urbano-territorial sobre la interacción de estas tres patas: un núcleo administrativo responsable capaz de gestionar con esa visión integrada, un sistema de información capaz describir el comportamiento y la evolución del sistema urbano-territorial (con especial referencias a los dos stocks fundamentales a gestionar en régimen de escasez: el territorio y el patrimonio construido); y un proceso que incentive y facilite la participación informada de los ciudadanos en la toma de decisiones.

El objetivo de paliar a la vez las necesidades de vivienda insatisfechas y el excesivo endeudamiento y falta de liquidez de hogares y empresas bancarias e inmobiliarias, pasa por gestionar más eficientemente el infrautilizado stock 
inmobiliario. Para ello hay que disponer de buena información sobre el stock inmobiliario en suelo e inmuebles y sobre las minusvalías, reconociendo el panorama y no ocultándolo. Además, la reconversión propuesta exige la entrada de nuevos actores en el monocorde panorama inmobiliario, gobernado por la vivienda libre y en propiedad. Debería facilitarse a la vez la desinversión inmobiliaria de las empresas bancarias e inmobiliarias y los hogares más endeudados, con la entrada de nuevas entidades mayoristas especializadas en gestionar viviendas en alquiler, libre y social, capaces de financiar sus inversiones recurriendo a los mercados financieros, como ocurre en los países antes mencionados. Esta doble diversificación inmobiliaria y financiera, permitiría paliar el absurdo panorama actual que enfrenta "casas sin gente a gente sin casa".

A la vista de lo anterior, la reconversión propuesta pasa obligadamente por reforzar la democracia participativa en el escalón local, para paliar el caciquismo que ha venido hundiendo el país. Hace falta un verdadero rearme democrático, unido a un rearme moral, para que la ciudadanía perciba a los especuladores como una vergonzosa plaga social y no como personas a imitar.

\section{REFERENCIAS BIBLIOGRÁFICAS:}

NAREDO y MONTIEL (2011) El modelo inmobiliario español y su culminación en el caso valenciano, Barcelona: Icaria.

NAREDO, J.M. (2015a) Raíces económicas del deterioro ecológico y social. Más allá de los dogmas, Madrid: Siglo XXI

NAREDO, J.M. (2015b). Economía, poder y política. Crisis y cambio de paradigma, Madrid: Díaz\&Pons . 


\title{
LA CULTURA Y LAS POLÍTICAS DE REHABILITACIÓN Y VALORIZACIÓN DE LOS CENTROS HISTÓRICOS
}

\author{
Francisco Pol Méndez (Arquitecto - Profesor asociado DUyOT)
}

\section{1.}

Lo que se nos pide: esbozar en un par de páginas lo que consideremos la aportación más importante de la reflexión y las prácticas de la urbanística en los últimos cincuenta años. iAhí es nada! Pero no es tan mal formato. Más difícil lo tenía Julian Barnes, para mí el más interesante escritor británico de ese arco de tiempo, cuando tituló una de sus mejores obras, compuesta de breves relatos, Historia del mundo en diez capítulos y medio... Desde mi perspectiva: la conformación de la cultura y las políticas de recuperación de los centros históricos en la primera mitad de los 70 en Italia, Francia y otros países europeos, que se extendería a España a principios de los 80 , y se desarrollaría hasta hoy, influenciando, a través de "ampliaciones de campo" y de "incorporaciones de temas", buena parte de los planteamientos y prácticas urbanísticas recientes (valorización de los paisajes urbanos, regeneración de barrios, diseño de nuevos crecimientos desde reelaboraciones actuales de los modelos de la ciudad clásica europea etc.)

Esa conformación se produjo a través de procesos complejos -de algún modo similares a los que dieron lugar, en anteriores etapas, a otros cambios de paradigmas culturales- mediante dinámicas e inesperadas agregaciones, intersecciones, adentramientos y confluencias de muy diversas líneas de pensamiento y de elaboraciones propositivas, con un campo de referencia material y a la vez ideal e "ideado", la ciudad antigua ... En el escenario de todos esos procesos concurrieron muy diversos "malestares": la desazón de las corrientes más vivaces y críticas de la cultura urbanística ante los resultados de los nuevos crecimientos orientados por la vulgata de las doctrinas funcionalistas (las informes "periferias de masas", y no las prometidas cités radieuses). Las indagaciones de sociólogos, geógrafos, psicólogos urbanos... pero también de "observadores/activistas", sobre las erosiones y escisiones que en la vida social generaban esos esquemas de crecimiento. La paulatina germinación en la cultura arquitectónica de atenciones hacia la "inserción" en la historia, en buena parte asentadas en la apreciación de la "segunda tradición" del Movimiento Moderno... Más otros aspectos, derivados de inesperados acontecimientos económicos y de cambios de climas políticos y sociales: las nuevas sensibilidades y comportamientos derivados del mayo 68, las inquietudes y reflexiones inducidas por la brusca crisis económica de 1973, provocada por la desmesurada alza de los costes del petróleo, que generaron nuevas actitudes sobre los "límites del crecimiento" y los "equilibrios ambientales", abriendo crecientes debates que, con otras muchas aportaciones, configurarían la actual cultura de la sostenibilidad. Más los impactos políticos y sociales provocados por el reconocimiento de los extensos y graves problemas de deterioro y de habitabilidad de la edificación antigua (en algunos países, como Francia y Reino Unido, como resultado de surveys específicos, en España como resultado de estudios sobre ciudades concretas). Más la difusión proteica de movimientos sociales y luchas vecinales en oposición a operaciones de renovación 
urbana con objetivos especulativos, en defensa del patrimonio histórico, en reivindicación de medidas para la mejora de las condiciones de vivienda...

Todas esas atenciones e intenciones, de contornos difusos, encontraron un "campo de condensación" en la idea de salvaguardia y recuperación de los centros antiguos como modelo de una nueva cultura y de la política de la ciudad: otorgando así un inesperado protagonismo a unos ámbitos hasta entonces casi marginales en las políticas públicas y en el pensamiento urbanístico dominante. En efecto, como es bien sabido, en las ideologías del planeamiento funcionalista, codificadas institucionalmente, esos tejidos habían sido considerados como rémoras de unos pasados urbanos "ineficientes", "desajustados", "insalubres", y por tanto como objetos de necesarias reformas, de alcance a veces extremo, más allá de la casi rutinaria aceptación de la preservación de los grandes episodios monumentales. Las corrientes que reivindicaban la conservación de los cascos antiguos, por sus valores propios o contextuales, que se expresaron en la Carta de Atenas de 1939 (curiosamente simultánea a la alentada por Le Corbusier y otras personalidades de los CIAM como cuadro de referencia de las estrategias urbanísticas del Movimiento Moderno) se encontraron reducidas en las primeras décadas de la postguerra a círculos académicos, o vinculadas a minoritarias asociaciones en la mayoría de los casos de incidencia local, o limitadas a denodadas "campañas de opinión" de algunas personalidades culturales, teñidas casi siempre de actitudes nostálgicas... y ajenas, en gran medida, a las nuevas condiciones urbanas y sociales.

Por supuesto, todos los Estados de la Europa occidental disponían, desde el XIX, de soportes administrativos para la tutela y restauración del patrimonio histórico, pero con fuertes limitaciones: en sus prioridades (arquitecturas o lugares de valores "monumentales"), en sus capacidades inversoras y en su propia "situación" en las maquinarias estatales, al encuadrarse en los ministerios encargados de la "instrucción pública" o la "cultura", sin conexión alguna con los departamentos de gran carga económica y protagonismo político, responsables de la vivienda, las obras públicas y los equipamientos, centrados en los nuevos crecimientos. Por ello, sus atenciones hacia los cascos antiguos sólo llegaron a manifestarse en normas de "conservación pasiva", a través de la declaración de conjuntos histórico-artísticos -por emplear la terminología italiana y española- que implicaban muy esquemáticos procedimientos de tutela (aunque con algunas exploraciones de políticas activas, como las impulsadas en los 1960 por la Ley Malraux en Francia).

\section{2.}

¿Cuáles fueron los procesos que trasmutaron en todos los países europeos occidentales esos anquilosados e inoperativos marcos, dando lugar a la nueva política y cultura y política de la recuperación? De un modo muy sintético, diríamos que consistieron en "integraciones sinérgicas" de argumentaciones culturales, urbanas, sociales, económicas, que muy pronto se coagularon en potentes decisiones políticas: en la planificación urbanística, en el establecimiento de nuevos marcos legislativos y amplios recursos financieros públicos, en la disposición de estructuras específicas de gestión... En los aspectos relacionados con la cultura urbanística y arquitectónica deberíamos destacar las sustanciales "ampliaciones de campo" desarrolladas desde los 70, que se expresarían, por ejemplo, en la superación de las anteriores visiones 
sobre los tejidos antiguos, en gran medida epidérmicas, para considerar los sustratos morfológicos y tipológicos de la ciudad; en la incorporación de atenciones a la conservación y rehabilitación de las edificaciones populares, las arquitecturas de los eclecticismos historicistas, las construcciones industriales, etc.; en la articulación con otras líneas del planeamiento y del proyecto urbano (infraestructuras, movilidad, ambiente, espacios libres...); y, en fin, en la extensión de las "escalas" de actuación, antes limitadas a los viejos cascos, para incluir en sus horizontes operativos los ensanches de mediados del XIX, las agregaciones de finales de ese siglo y de las primeras décadas del XX... En los aspectos relacionados con la sociedad y la vida urbana, las atenciones e intenciones fundamentales se centraron en la defensa de los "usos tradicionales", con especial atención a la vivienda; el compromiso social con los vecindarios, sobre todo en los barrios populares degradados; la activación funcional y la inserción de dotaciones de distintos tipos, preferentemente mediante la reutilización de edificaciones antiguas; la incentivación de las interacciones sociales, confiando sobre todo en la cualificación de los espacios libres públicos...todo ello con propósitos estratégicos de valorización de los significados de los centros antiguos como lugares decisivos en la imagen y la identidad de la ciudad. Deberíamos añadir además, por sus relaciones con la actual situación de crisis, que todos esos entramados propositivos se reforzaron además con razonamientos de índole políticoeconómica, defendiendo la "reutilización" frente al "despilfarro inmobiliario" de las renovaciones y los crecimientos indiscriminados.

Esas magmáticas argumentaciones se condensaron, con mayor o menor acierto y capacidad operativa, en una reformulación, a lo largo de los 1970, de las políticas urbanas en todos los países cercanos. Nuestro país se incorporó a esa estrategia con cierto retraso, por sus circunstancias políticas, pero con un fuerte ímpetu, en coherente respuesta a las dimensiones de los problemas heredados del franquismo, con el acrecentamiento del deterioro y de la decadencia social de los antiguos cascos desde los 50 y los brutales procesos de depredación especulativa de los 1960 y 1970. En la compleja y veloz configuración de esas nuevas políticas tendrían fundamental importancia los episodios siguientes: el establecimiento, desde los primeros pasos de los Ayuntamientos democráticos en 1979, de nuevos planes, generales y especiales, que constituirían las indispensables urdimbres de esas estrategias; la creación, en 1983 , de amplios y adecuados marcos y medios de financiación pública con el $R D L$ sobre Rehabilitación del Patrimonio Residencial y Urbano, cuyos mecanismos se han mantenido básicamente hasta hoy en los sucesivos planes estatales y de las CCAA, con los procedimientos de ágiles correcciones y adiciones que proporcionaba su estructuración; los desarrollos operativos de los previsiones de los planes, apoyados en la disponibilidad de préstamos cualificados y significativas subvenciones para la "rehabilitación dispersa" y, con incidencia aún más considerable, para programas especiales de "rehabilitación integrada"; la simultánea disposición de estructuras de gestión (con los modelos de agencias especializadas de las experiencias francesas o británicas, a las que se incorporaron mecanismos de activa participación vecinal); y, en fin, la articulación con otras políticas sectoriales, integrando actuaciones sobre infraestructuras urbanas y espacios libres públicos, promoviendo la rehabilitación de edificaciones antiguas, y en algunos casos nuevas arquitecturas, para la implantación de dotaciones sociales y culturales o sedes administrativas, aprovechando dinámicamente las capacidades de las CCAA... 


\section{3.}

Unos sucintos comentarios sobre los resultados de los procesos y las nuevas tareas

- Los procesos de rehabilitación de los centros históricos, desarrollados en nuestro país desde los primeros 1980, constituyen, sin duda, una de las experiencias más valiosas de la urbanística europea en ese amplio arco temporal: por su generalizada difusión, desde las ciudades singulares a los cascos "menores"; por la articulación de estrategias de revitalización residencial y de valorización funcional y simbólica; por la variedad y aportaciones innovadoras de la proyectualidad arquitectónica desplegada en las muy numerosas actuaciones públicas "focalizadoras"... Teniendo en cuenta además que la evaluación de esos resultados se acrecienta si se consideran las lamentables condiciones de partida, cuando esos denominados "centros" eran en gran medida lugares marginales.

- En toda la exposición hemos ido apuntando la incidencia de "cuestiones políticas", pero sin precisarlas en detalle, relegándolas a connotaciones de lectura. Pero quizá para concluir sería útil algún comentario. La conformación de la cultura y de la política de rehabilitación tuvo en España una inequívoca caracterización "de izquierda" (como también en Italia, pero no en Francia ni en el Reino Unido y otros países del entorno, donde se situó en esferas con más difusos contornos... probablemente de modo más congruente con la complejidad y diversidad de los problemas). Las motivaciones de ese sesgo político e ideológico en nuestro país son fáciles de explicar: bastaría un esquemático diagnóstico DAFO sobre las condiciones que tuvieron que afrontar los gobiernos de los primeros 1980. Pero lo importante, en estos comentarios, es que esos planteamientos pronto se extenderían a otras orientaciones políticas, en un proceso que muy bien caracterizó Gramsci: la progresiva trasmutación de una ideología "de parte" en sentido común difundido en el conjunto de la sociedad...

- Para terminar: en ese desarrollo globalmente positivo de las políticas de rehabilitación ya habían comenzado a manifestarse ciertas incoherencias desde comienzos de siglo, relacionadas con el "enquistamiento" de antiguos problemas junto a la emergencia de nuevas cuestiones, pero que apenas tuvieron reconocimiento en los poderes públicos, en la exuberancia de los años de la "burbuja". El desencadenamiento de la crisis, que entre otras muchas consecuencias ha supuesto la inevitable reducción de las políticas de gasto público, exige por ello nuevas atenciones y proposiciones, en el horizonte general de una redefinición de los modelos económicos y sociales de nuestro país. En esta perspectiva, no son escasas ni fáciles, pero sí extremadamente estimulantes, las tareas que debemos afrontar los profesionales, los investigadores, los colectivos culturales y sociales, los organismos públicos, las instituciones universitarias... En lo que nos concierne como profesionales, porque en mi opinión parte importante de los nuevos planteamientos sobre los centros de nuestras ciudades deberá asentarse en "inteligencias proyectuales"... por supuesto en el planeamiento, pero también -y quizá sobre todoen la programación y la gestión urbana, económica y social. 


\title{
RASGOS URBANÍSTICOS DEL CRECIMIENTO RESIDENCIAL ASOCIADO A LA BURBUJA INMOBILIARIA, 1995-2006
}

\author{
Julio Pozueta Echávarri (Dr. Ingeniero de Caminos - Catedrático DUyOT)
}

Posiblemente, el fenómeno urbanístico más sorprendente de los últimos 22 años ${ }^{54}$, ha sido lo que se ha venido en llamar la "burbuja inmobiliaria", el amplio ciclo inmobiliario expansivo que se desarrolla en España, entre 1995 y 2006, durante el cual se triplica el número de licencias de viviendas concedidas en España, que pasan de una media de 217.863 durante el quinquenio $1990-94$ a las 737.186 que se alcanzan en 2006, una cifra más de tres veces superior a la anterior.

La "burbuja inmobiliaria" o "tsunami urbanístico", como también se ha llamado55, ha dado lugar a una ingente cantidad de publicaciones, noticias y opiniones y ha sido un tema recurrente en la prensa española durante sus años finales y los primeros de la crisis que le siguiós6. Sin embargo, aparte de su mera dimensión cuantitativa global, en realidad, los rasgos del crecimiento urbano asociado a la publicitada y debatida "burbuja" son poco conocidos, mucho menos que la evolución de los precios y las ventas, que han centrado la atención pública, y una de las principales razones de este desconocimiento es seguramente la dificultad de contar con datos precisos de un fenómeno cuyo modelado y control es una competencia básicamente municipal, lo que significa que los datos detallados de este proceso están repartidos entre las 8.123 corporaciones municipales que, de acuerdo con el MINHA, componen España57.

De hecho, aparte de la información que pueden proporcionar los Ayuntamientos sobre la construcción de viviendas en el período, las dos fuentes principales que ofrecen datos agregados sobre la construcción de viviendas son las de las Estadísticas de la Construcción del Ministerio de Fomento, recogidas, entre otros, en los Atlas de la Construcción en España de 2005 y 2008 y provenientes de los datos que le facilitan los Colegios de Aparejadores (visados) o los Ayuntamientos (licencias) y las del Consejo General de Colegios de Arquitectos de España, basadas en los visados de proyectos de ejecución, que facilitan datos por trimestres ${ }^{58}$.

\footnotetext{
54 El primero de los 100 números de los Cuadernos de Investigación Urbanística, CIUr que conmemoramos con éste se publicó en 1993, hace ahora 22 años.

55 Ver: Gaja i Díaz, F (2008). "El "tsunami urbanizador" en el litoral mediterráneo. El ciclo de hiperproducción inmobiliaria 1996-2006. Scripta Nova. Revista Electrónica de Geografía y Ciencias Sociales. Barcelona: Universidad de Barcelona, 1 de agosto de 2008, vol. XII, núm. 270 (66), http://www.ub.es/geocrit/sn/sn-270/sn-270-66.htm.

56 Google da 562.000 resultados cuando se le consulta sobre "burbuja inmobiliaria en España" y 8.130 si la búsqueda se realiza en Google Académico, www.google.scholar.com.

57 Ver Ministerio de Hacienda y Administraciones Públicas, MINHAP, 2014: http://ssweb.seap.minhap.es/REL/frontend/inicio/municipios/all/all

58 Los Informes de la Construcción del Ministerio de Fomento están disponibles en: http://www.fomento.gob.es/MFOM/LANG CASTELLANO/ATENCION CIUDADANO/INFORMACION ESTA DISTICA/EstadisticaSintesis/AtlasConstruccion/default.htm. Por su parte los Informes de Coyuntura del Consejo General de Colegios de Arquitectos de España pueden descargarse en: http://www.cscae.com/index.php/es/servicios58/estadistica/informes36.
} 
Complementariamente, pueden usarse también los datos del proyecto Corine Land Cover, que ofrece mapas y cifras de ocupación del suelo por distintos usos, urbanos y no urbanos (44 en total), a través de cartografía a escala 1:100.000 de determinados años $(1990,2000,2006,2012)^{59}$. Sin embargo, como dice José Luis Campos en su libro sobre La burbuja inmobiliaria española, "las estadísticas que se muestran hay que tomarlas como acercamientos limitados a la realidad"60.

$Y$, en efecto, muchos de los datos ofrecidos están basados en fuentes indirectas y no contrastadas, como encuestas y agregaciones de información que envían los ayuntamientos o los colegios profesionales al Ministerio de Fomento, en relación a licencias o visados, o proceden de las sociedades de tasación, caso de los precios, sin que en ninguno de los casos, se haya procedido a comprobar si se han construido las viviendas para las que se ha concedido licencia o visados o si se han vendido aquellas para las que se ha realizado la tasación.

Debe además tenerse en cuenta, por ejemplo, que en las estadísticas de visado de proyectos no se incluyen las de las Administraciones, que no están obligadas a ello, y que no todos los ayuntamientos envían la información al Ministerio de Fomento, tal como se indica en los propios Atlas de la Construcción. Esta circunstancia puede ser la base de las discordancias que se dan entre los datos de las dos fuentes principales sobre el tema.

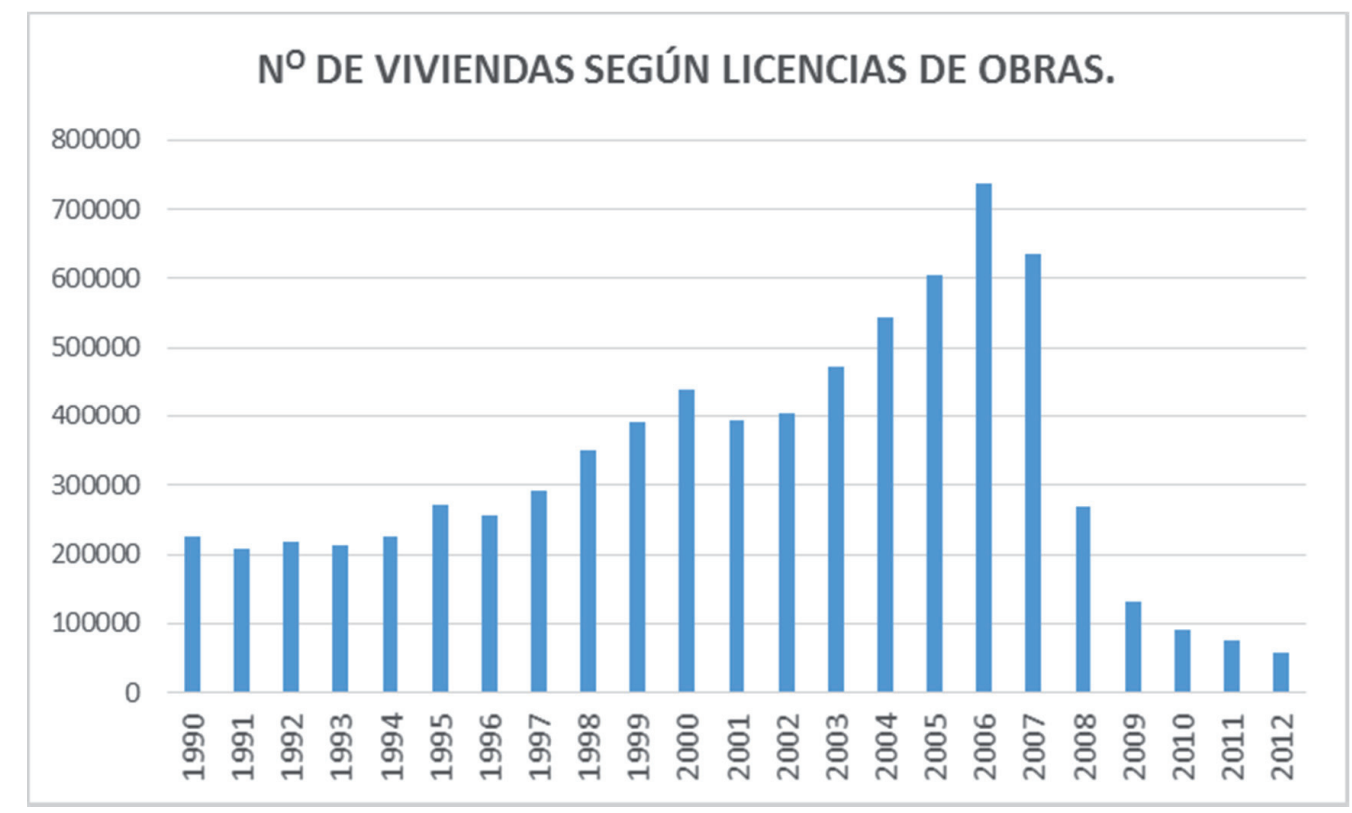

Figura 4. Número de viviendas según licencias de obras entre los años 1990 y 2012 Fuente: Viviendas nuevas. Información Estadística del Ministerio de Fomento.

59 El Programa Corine, 'Coordination of Information on the Environment', lo inició la Unión Europea en 1985 y está a cargo de la European Environment Agency (EEA): http://www.eea.europa.eu/publications/COR0-landcover/page001.html

60 Campos, J.L. (2008): La burbuja inmobiliaria española, Marcial Pons, página 25. 
Si se toman como referencia las cifras del Ministerio de Fomento sobre el número de viviendas para las que se dio licencia municipal, en el gráfico puede verse cómo a partir de 1995 o 1996 comienza una clara tendencia al alza de su cuantía anual, que tras dos años de estancamiento a principios del nuevo siglo, se acelera considerablemente hasta $2006^{61}$, año que marca el máximo histórico y a partir del cual se produce una brusca caída de las cifras, reduciéndose a menos de la quinta parte para 2009 (130.546) y a menos de una décima para 2012 (57.543), lo que supone una cuarta parte de la cifra de 1990. En total, en los doce años de "burbuja", se conceden en España licencias de obra para más de 5 millones de viviendas (5.159.350), según datos del INE (Estadísticas de la Construcción 2015, sobre datos del MF).

Aunque, a la fecha, los datos de que se dispone para analizar las características urbanísticas del crecimiento asociado a la masiva construcción de viviendas que se desarrolla en los años de la burbuja son escasos y sufren limitaciones importantes, los grandes rasgos que dibuja la información disponible resultan en cierta medida sorprendentes, si se tiene en cuenta el rápido proceso de expansión y el aparente cambio que ha experimentado el tipo de edificios residenciales mayoritarios. Así:

- En relación al uso, entre el año 2000 y 2006, se construyeron en España $132.922 .000 \mathrm{~m}^{2}$ de edificación no residencial, frente a $700.183 .000 \mathrm{~m}^{2}$ de edificación residencial. Esta última supuso, por tanto, más del $84 \%$ del total edificado en el período.

- En relación a la compacidad, y de acuerdo con los datos del Observatorio de la Sostenibilidad, tomados del Proyecto Corine Land Cover, entre 1997 y 2005, el tejido urbano continuo en España aumentó de 253.136 a $293.446 \mathrm{Ha}$, un 15,9\%, mientras que el tejido urbano discontinuo pasó en el mismo período de 230.505 a $338.996 \mathrm{Ha}$, lo que supuso un aumento del 47\%. Y lo que tal vez es más sorprendente, las zonas industriales o comerciales pasaron de ocupar una superficie de 76.624 a $146.580 \mathrm{Ha}$, es decir que experimentaron un crecimiento del $91,3 \%{ }^{62}$.

- En relación al tipo de promoción y tal como muestra Bernardos con datos del Consejo Superior de Arquitectos de España, mientras la cantidad de viviendas libres visadas se multiplicaba por dos entre 1998 y 2005, la de viviendas de protección oficial se mantenía prácticamente constante, en su opinión debido a "su escasa rentabilidad económica, el elevado ritmo de ventas observado en el

\footnotetext{
61 Debe siempre tenerse en cuenta que la cronología de las licencias va, normalmente, adelantada en relación a la cronología de la construcción y puesta en servicio de los edificios y viviendas, que puede retrasarse fácilmente hasta dos años o más. Ello significa que el proceso de crecimiento urbano ligado a las nuevas construcciones puede haberse prolongado según las zonas hasta 2008 o 2009, generando a menudo urbanizaciones sin vender que se han convertido en "ruinas modernas" (ver: Julia SchulzDornburg, "Ruinas modernas", Edit. S.A Ambit Serveis, 2013).

62 Observatorio de la Sostenibilidad, Sostenibilidad en España 2014, p.92, http://www.observatoriosostenibilidad.com/sostenibilidad-en-espana-2014/
} 
mercado libre y la reducida disponibilidad de suelo público dedicado a su construcción" ${ }^{\prime 63}$.

- En relación a la densidad, entre 2000 y 2006, según fuentes del Ministerio de Fomento, la superficie de suelo afecta a la edificación de viviendas nuevas fue de $711 \mathrm{Km}^{2}$, lo que significaría una densidad neta de unas $50 \mathrm{viv} / \mathrm{ha}$ que, extendida al conjunto urbanizado, podría situarse en torno a las $33 \mathrm{viv} / \mathrm{ha}^{64}$, una densidad considerablemente inferior a la que tienen actualmente la mayoría de los de los ensanches del XIX y a la de los polígonos de los años 1960-80, aunque no llega todavía a las bajas densidades que caracterizan las áreas de residencia unifamiliar que conforman a menudo las áreas suburbanas típicas de la dispersión urbana de las dos últimas décadas.

- En relación a la altura, si se cruzan los datos de superficie total de edificación residencial $\left(597.394 .000 \mathrm{~m}^{2}\right.$ ) con los de la superficie total ocupada en planta $\left(127.902 .000 \mathrm{~m}^{2}\right)$, se llega a la conclusión que la altura media de la edificación residencial del período 2000-2006 ha sido de 4,67 plantas, algo que, al igual que la densidad, no parece corresponder a la imagen que se tiene de las nuevas áreas residenciales, tal vez porque proporcionalmente las de baja altura ocupan mayores extensiones en las áreas suburbanas más recientes y marcan con su impronta el paisaje general de éstas.

- Finalmente, y en congruencia con los datos anteriores, el porcentaje de viviendas en edificios colectivos se mantiene muy alto globalmente, con un 74,9 $\%$ del total, mientras las unifamiliares alcanzan una significativa proporción del total, con un 25,1\%, para el conjunto del período 200-2006.

Todo parece indicar por tanto que, en buena medida, el crecimiento urbano durante los años centrales de la "burbuja" se ha basado fundamentalmente en la construcción de edificios colectivos de vivienda, con un número importante de plantas, lo que apunta a una cierta continuidad de los tipos edificatorios respecto a periodos precedentes, mientras que sí se ha producido un cambio significativo en lo relativo a las densidades, donde la media ha bajado sustancialmente, situándose muy probablemente por debajo de las 35 viv/ha y en el porcentaje de viviendas libres. También con los datos disponibles pueden avanzarse algunas consideraciones sobre la distribución territorial del crecimiento residencial en los años de la burbuja.

En el cuadro siguiente puede observarse, cómo el crecimiento residencial durante la burbuja, tal como lo reflejan las licencias se concentró básicamente en cuatro

\footnotetext{
63 Bernardos, G. (2009): "Creación y destrucción de la burbuja inmobiliaria en España". En Información Comercial Española. Revista de Economía ICE, 2009, num. 850. http://diposit.ub.edu/dspace/bitstream/2445/53144/1/637799.pdf

${ }^{64} \mathrm{~A}$ los $711 \mathrm{Km}^{2}$ de solares y parcelas habrían de añadirse la que ocupan las infraestructuras (viales, aparcamientos,...) y los equipamientos (espacios libres públicos, colegios,...), además de las parcelas destinadas a otros usos dentro de las áreas residenciales, para referir las viviendas a la superficie total urbanizada. Para aproximar esa densidad global se ha estimado que los solares y parcelas residenciales constituyen en torno al $65 \%$ de la superficie total de un sector urbanizable residencial.
} 
regiones españolas, Andalucía $(19,36 \%)$, Cataluña $(14,64 \%)^{65}$, Región Valenciana $(14,37 \%)$ y Madrid $(11,03 \%)$, que acogieron conjuntamente casi el $60 \%$ del total.

No obstante, es importante subrayar que regiones mucho menos pobladas que las anteriores, como Canarias, las dos Castillas, Galicia o Murcia albergaron cada una en torno al $5 \%$ del total, una proporción muy elevada si se tiene en cuenta la población de algunas de ellas.

\begin{tabular}{|l|r|r|}
\hline \multicolumn{3}{|c|}{ DISTRIBUCIÓN DEL CRECIMIENTO } \\
RESIDENCIAL \\
Viviendas nuevas 1995-2006 \\
\hline CCAA & $\begin{array}{r}N^{0} \text { de } \\
\text { viviendas }\end{array}$ & $\begin{array}{r}\text { \% sobre el } \\
\text { total }\end{array}$ \\
\hline Andalucia & 1229793 & 19,36 \\
\hline Aragon & 149572 & 2,35 \\
\hline Asturias & 122751 & 1,93 \\
\hline Baleares & 141049 & 2,22 \\
\hline Canarias & 311900 & 4,91 \\
\hline Cantabria & 98477 & 1,55 \\
\hline Castilla La Mancha & 355292 & 5,59 \\
\hline Castilla y León & 362256 & 5,70 \\
\hline Cataluña & 929785 & 14,64 \\
\hline C. Valenciana & 912551 & 14,37 \\
\hline Extremadura & 116311 & 1,83 \\
\hline Galicia & 337148 & 5,31 \\
\hline Madrid & 700418 & 11,03 \\
\hline Murcia & 286880 & 4,52 \\
\hline Navarra & 71974 & 1,13 \\
\hline Pais Vasco & 168609 & 2,65 \\
\hline La Rioja & 57260 & 0,90 \\
\hline Total España & 6352026 & 100,00 \\
\hline
\end{tabular}

Figura 5. Distribución del crecimiento residencial entre los años 1995 y 2006

Fuente: Ministerio de Fomento: http://www.fomento.gob.es/BE/?nivel=2\&orden=09000000 y elaboración propia.

En la siguiente tabla, en la que se comparan el crecimiento residencial de cada región con su parque total de viviendas, puede evaluarse con más detalle el significado del crecimiento en cada región.

65 La provincia de Barcelona acogió, por sí sola, el 8,30\% del total del crecimiento nacional, algo menos que Madrid, mientras Alicante es la siguiente provincia en participación sobre el total, el 6,67 \%, según datos de la misma fuente. 


\begin{tabular}{|c|c|c|c|}
\hline \multicolumn{4}{|c|}{$\begin{array}{l}\text { COMPARACIÓN DEL CRECIMIENTO (1995-2006) } \\
\text { CON EL PARQUE RESIDENCIAL DE } 2001\end{array}$} \\
\hline CCAA & $\begin{array}{l}\text { Crecimiento } \\
1995-2006\end{array}$ & $\begin{array}{l}\text { Parque } \\
\text { residencial } \\
2001\end{array}$ & $\begin{array}{l}\text { Crecimiento/ parque, en } \\
\%\end{array}$ \\
\hline Andalucia & 1229793 & 3554198 & 34,60 \\
\hline Aragon & 149572 & 657555 & 22,75 \\
\hline Asturias & 122751 & 524336 & 23,41 \\
\hline Baleares & 141049 & 504041 & 27,98 \\
\hline Canarias & 311900 & 855022 & 36,48 \\
\hline Cantabria & 98477 & 286901 & 34,32 \\
\hline Castilla La Mancha & 355292 & 988555 & 35,94 \\
\hline Castilla y León & 362256 & 1455050 & 24,90 \\
\hline Cataluña & 929785 & 3328120 & 27,94 \\
\hline C. Valenciana & 912551 & 2558691 & 35,66 \\
\hline Extremadura & 116311 & 575284 & 20,22 \\
\hline Galicia & 337148 & 1312496 & 25,69 \\
\hline Madrid & 700418 & 2482885 & 28,21 \\
\hline Murcia & 286880 & 595319 & 48,19 \\
\hline Navarra & 71974 & 261147 & 27,56 \\
\hline Pais Vasco & 168609 & 892009 & 18,90 \\
\hline La Rioja & 57260 & 156769 & 36,53 \\
\hline Total & 6352026 & 20988378 & 30,26 \\
\hline
\end{tabular}

Figura 6. Comparación del crecimiento entre 1995 y 2006 con el parque residencial de 2001 Fuente: Ministerio de Fomento: http://www.fomento.gob.es/BE/?nivel=2\&orden=09000000 y elaboración propia.

Del cuadro anterior pueden avanzarse algunas conclusiones interesantes sobre el carácter del crecimiento urbano asociado a la burbuja inmobiliaria:

- En primer lugar, que el mayor crecimiento residencial relativo no corresponde cómo tal vez podría esperarse a las grandes áreas metropolitanas, como Madrid $(28,21 \%)$ o Cataluña $(27,94 \%)$, ambas claramente por debajo de la media nacional $(30,26 \%)$, y que las regiones que experimentaron un menor crecimiento han sido el País Vasco $(18,9 \%)$, Extremadura $(20,22 \%)$, Aragón $(22,75 \%)$ y Asturias $(23,41)$.

- En segundo lugar, que los mayores crecimientos relativos se produjeron en Murcia (48,19\%), La Rioja (36,53\%), Canarias (36,48\%), Castilla la Mancha $(35,66 \%)$, Comunidad Valenciana $(35,55 \%)$, Andalucía $(34,60 \%)$ y Cantabria $(34,32 \%)$, una mezcla aparentemente incongruente de regiones muy diversas, turísticas y no turísticas, costeras e interiores, con bases económicas muy diferentes y entre las que se incluyen las de mayor y menor parque residencial (Andalucía y La Rioja). 
Resulta asimismo interesante, analizar cómo varía regionalmente la componente unifamiliar del crecimiento residencial en el período, que aparece en la tabla siguiente.

\begin{tabular}{|c|c|c|c|}
\hline \multicolumn{4}{|c|}{$\begin{array}{l}\text { COMPONENTE UNIFAMILIAR DEL CRECIMIENTO RESIDENCIAL } \\
1995-2006\end{array}$} \\
\hline \multirow[b]{2}{*}{ CCAA } & \multirow{2}{*}{ Total viviendas } & \multicolumn{2}{|c|}{ Viviendas unifamiliares } \\
\hline & & En número & \% sobre total \\
\hline Andalucia & 1229793 & 399978 & 32,52 \\
\hline Aragon & 149572 & 40530 & 27,10 \\
\hline Asturias & 122751 & 18503 & 15,07 \\
\hline Baleares & 141049 & 40501 & 28,71 \\
\hline Canarias & 311900 & 77200 & 24,75 \\
\hline Cantabria & 98477 & 31349 & 31,83 \\
\hline Castilla La Mancha & 355292 & 170035 & 47,86 \\
\hline Castilla y León & 362256 & 121449 & 33,53 \\
\hline Cataluña & 929785 & 216225 & 23,26 \\
\hline C. Valenciana & 912551 & 233485 & 25,59 \\
\hline Extremadura & 116311 & 52090 & 44,79 \\
\hline Galicia & 337148 & 59224 & 17,57 \\
\hline Madrid & 700418 & 159024 & 22,70 \\
\hline Murcia & 286880 & 89950 & 31,35 \\
\hline Navarra & 71974 & 24037 & 33,40 \\
\hline Pais Vasco & 168609 & 22039 & 13,07 \\
\hline La Rioja & 57260 & 9148 & 15,98 \\
\hline Total & 6352026 & 1764767 & 27,78 \\
\hline
\end{tabular}

Figura 7. Componente familiar del crecimiento residencial entre los años 1995 y 2006 Fuente: Ministerio de Fomento: http://www.fomento.gob.es/BE/?nivel=2\&orden=09000000 y elaboración propia.

En esta tabla, sorprende también el diferente grado de importancia que la componente unifamiliar tiene en el crecimiento urbano en las distintas regiones. En efecto:

- En relación a la media nacional del período, un 27,78 \% de las viviendas eran de carácter unifamiliar (aisladas o adosadas), destaca que los mayores porcentajes, cercanos al 50\% correspondan a regiones como Castilla La Mancha $(47,86 \%)$ o Extremadura (44,79\%), con 170.035 y 52.090 viviendas unifamiliares aprobadas respectivamente en el período. De hecho, las cifras de unifamiliares de Castilla La Mancha superan a las de Madrid y ocupan la cuarta posición entre las regiones en números absolutos, además de la primera en números relativos. ¿Debe animar esto a suponer que el precio del suelo pueda ser determinante en esta cuestión? 
- Los datos de las regiones de menor componente unifamiliar en el crecimiento residencial no despejan la incógnita, ya que si bien vienen encabezados por el País Vasco $(13,07 \%)$, lo que corroboraría por su escasez de suelo y altos precios del mismo la hipótesis de su importancia, les siguen a continuación tres regiones como Asturias, La Rioja y Galicia, todas ellas con un porcentaje de unifamiliares muy por debajo de la media nacional, pero que no destacan por los altos precios del suelo. Las regiones de las grandes ciudades, como Cataluña o Madrid ofrecen porcentajes de unifamiliares netamente por debajo de la media nacional ${ }^{66}$.

Todas estas cifras, que más que aclarar parecen velar, encubrir, la lógica de la distribución geográfica del crecimiento residencial en el período, muestran la complejidad del fenómeno y animan a plantear hipótesis que consideren sobre todo las oportunidades concretas de cada región y las estrategias de los agentes, públicos y privados, como las variables principales que la han determinado ${ }^{67}$. Posiblemente, también induzcan a pensar que el territorio asociado a la "burbuja" inmobiliaria no está compartimentado regionalmente, sino que es, cuando menos, de alcance nacional, tanto a nivel de los productores inmobiliarios, que han crecido en dimensión y alcance probablemente al ritmo de la "burbuja", como de los propios compradores, cada vez con un mayor campo de juego para invertir, que en ocasiones ha desbordado incluso los límites nacionales extendiéndose a otros países europeos.

Concluyamos subrayando las dificultades que, con los datos agregados disponibles, plantea el análisis de los rasgos inmobiliarios del crecimiento urbano asociado a la "burbuja inmobiliaria", y la necesidad de investigaciones más profundas que los definan con mayor precisión y desvelen su lógica, en aras a estar preparados para ordenar el nuevo ciclo expansivo inmobiliario que, aunque ahora se niegue con rotundidad desde tantas instancias, casi todos sospechamos que puede presentarse, casi, en cualquier momento y nos acucia la necesidad profesional de afrontarla con el conocimiento de los instrumentos y criterios urbanísticos más adecuados a sus rasgos.

\footnotetext{
66 La provincia de Barcelona tiene un componente unifamiliar en el período del 20,79, mientras la de Alicante lo tiene superior a la media nacional, el 30,79\%.

67 Para Romero, "Construcción residencial y gobierno del territorio en España. De la burbuja especulativa a la recesión. Causas y consecuencias", Cuadernos Geográficos de la Universidad de Granada, $2010 ; 47$ (2), www.ugr.es/ cuadgeo/docs/articulos/047/047-002.pdf , "La clave ha estado, básicamente, en la actitud permisiva de gobiernos regionales que han dimitido voluntariamente de sus obligaciones de control y coherencia a la hora de aprobar propuestas insensatas remitidas desde diferentes municipios y de sus capacidades de coordinación y de elaboración de Planes Territoriales de Ámbito Supramunicipal", pag. 35.
} 


\title{
EXPANDIRSE CUANDO SE ENCOGE. LA CATASTRÓFICA PARADOJA DEL URBANISMO MADRILEÑO
}

\author{
Fernando Roch Peña (Dr. Arquitecto - Catedrático DUyOT)
}

Apenas se había aprobado el Plan General de Madrid de 1985 que proponía un "estado de la materia y de la forma urbanas" decididamente inspirado en el bienestar social y en el empleo moderado de los recursos, cuando el hoy casi olvidado decreto Boyer de 30 de abril del mismo año, pone la semilla de un nuevo orden, un nivel de energía tan exigente como quimérico, que negaba radicalmente la armonía social del lugar, la posibilidad misma de la vida cotidiana para entregarse al vértigo de la supervivencia en la alta competición de la economía mundo, según los postulados Thatcher-Reagan.

El difícil equilibrio entre la vida de los ciudadanos y los mandatos de la gran economía, se decantarían enseguida hacia las medidas de liberalización del crédito que abrían de par en par las economías familiares al crédito hipotecario, y con él a una sorda lucha competitiva por la posición exclusiva: en sociedades donde sólo sobreviven los más aptos nadie está conforme con el lugar que la fortuna le ha deparado. Se inauguraba una nueva era, una especie de esquizofrenia social y urbana que iba a alterar profundamente las leyes que habían regido la formación de la ciudad durante la industrialización asociada al bienestar: una especie de nuevo estado de la materia de propiedades imprevisibles impulsado por una abrumadora liquidez de capital dispuesto a financiar la sustitución del agotado cuerpo industrial que se abandonaba, por la construcción de una escenografía, un teatro en el que el drama laboral de la industria fordista, se sustituía por la tragicomedia de escalar la cumbre social por los medios que fueran. La propia producción de esa distopía imaginaria se convertía en producto y mercancía, que sustituía a la vieja producción industrial en desmantelamiento. El argumento central de esta parodia del éxito, sería el imperio de los valores monetarios sobre las condiciones de uso, sobre lo funcional, sobre la vida misma.

Por fin se había encontrado la peor salida posible a una década (1975-1985) de ensayos fallidos de fórmulas productivas diversas, destinadas a paliar el hundimiento de aquella sociedad industrial que había dirigido el crecimiento de la ciudad desde finales de la Segunda Guerra Mundial, modelando su morfología social y espacial. Y la salida no consistía en recuperar el deteriorado aparato industrial, en reinventarlo, sino en una huida hacia adelante: una expansión en plena recesión, un crecimiento material que contrapesara la recesión demográfica y económica, y el deterioro evidente de las condiciones materiales de existencia de la población. Un gran banquete financiero que conmemoraba el final de la sociedad salarial, y que ha dejado profundos efectos colaterales en nuestras ciudades $y$, sobre todo, en nuestros ciudadanos y su imaginario colectivo, cuya representación de lo urbano ha sufrido alteraciones irreparables.

Baste una constatación para hacernos una idea del sustancial cambio sobrevenido: desde principios de los años 90 hasta 2008 se han construido más viviendas que durante el periodo de formación de los sistemas metropolitanos que culminaron el desarrollo industrial y alcanzaron las cotas de bienestar más altas, 
materializando el tránsito de una sociedad rural a una sociedad urbana. Y este despropósito se ha acompañado contradictoriamente con salarios decrecientes o camino de la precarización, con aumento progresivo del paro, con el desmantelamiento del aparato fabril y sus relaciones laborales, con una demografía en disminución y más vulnerable. También con una asimetría creciente en el reparto de la riqueza que coincidía con el deterioro progresivo de los equilibrios que proporcionaba la vieja fórmula. En esta desolación, sólo una magnitud "positiva": crédito disponible en cantidades inagotables y poco discriminatorio, dispuesto a implicar a toda la formación social en una competición por posicionarse en el nuevo orden social que ya sólo respondía a criterios de jerarquía expresada (representada) en términos monetarios. Una suerte de determinismo posicional que actuaba como un talismán sobre el porvenir y la propia supervivencia, y cuya principal representación se desarrollaría en los viejos escenarios urbanos fuertemente intervenidos para desplegar ese nuevo espacio social sin otro principio ordenador que la renta, sin otro criterio que la exclusión. Y una nueva paradoja, pues la generalización social del crédito, su expansión sin límites, coincide con una vuelta masiva a la incertidumbre que condena su futuro.

La contradictoria orgía inmobiliaria que hemos vivido ocultaba, así, una refundación del orden urbano, de su física más íntima. Es la sociedad familiar y su patrimonio en un contexto jerarquizado (gradiente de exclusión) la verdadera protagonista, no las relaciones laborales, la utilidad, la eficiencia o la funcionalidad de una sociedad industrial en extinción. Mucho menos la justicia. Las representaciones del mundo industrial en declive se sustituyen por el imaginario colectivo de la expansión: el teatro del éxito, para compensar ilusoriamente el vanishing point de la actividad industrial y su mundo de equilibrios asistidos que tanto había costado construir. Adiós a los valores colectivos, y renovado impulso al individualismo del prestigio social, que junto al nuevo reparto de papeles alteran la economía política del espacio social y sus significantes.

El problema es que construir un teatro imaginario como éste bajo creciente incertidumbre material (laboral, salarial, institucional), puede representar una salida para los excesos de liquidez de capital, pero conduce a una catástrofe. Y no precisamente para las corporaciones financieras, expertas en convertir desastres semejantes en nuevas oportunidades para incrementar su soberanía sobre Estados, regiones y familias: les ha bastado añadir la ingente deuda privada que ha generado la construcción de esta ficción, a la propia deuda pública. Nuestras ciudades en débito son el resultado de una especie de pacto inmobiliario - sustituto del viejo pacto por la industrialización - bajo el bloque dirigido por la banca y las grandes constructoras y corporaciones inmobiliarias (algunas de rango planetario), lanzadas a la sobreproducción de espacio urbano: grandes infraestructuras y equipamientos monumentales -despilfarro y arquitectura de pasarela- con sus propiedades "mágicas" para recualificar el escenario, es decir, para remodelar el espacio social según un gradiente de prestigio, ajustándolo a los descarnados principios neoliberales que, por fin, encuentran el camino de expresión que les negó la delicada fisiología equilibrada de la sociedad industrial fordista.

El urbanismo pinta poco en esta impostura salvo para legitimar el desafuero urbanizador. El comedido Plan de 1985 es sustituido apenas aplicado por el desenfreno del Plan de 1997 que "agota" el suelo disponible en el municipio madrileño 
y lo convierte en un cúmulo de operaciones imposibles, como esa Operación Chamartín que lleva 20 años arrastrando su inviabilidad, y que necesita más de 3.000 millones de euros de inversión que las arruinadas administraciones públicas no pueden regalarle. Había que competir en el escenario internacional, sacando "pecho inmobiliario" a falta de otros argumentos. En realidad la disciplina había nacido para dar forma a la sociedad industrial y sus equilibrios reales o aparentes, como herramienta de intervención pública en un mundo construido conjuntamente con las empresas privadas, para darle racionalidad y oportunidades de existencia al interés público, colectivo, ciudadano si se quiere. Nada revolucionario: moderadamente reformista si acaso, pero imprescindible porque aquella mano invisible, que según la vulgata liberal ordenaba las divergencias del capital privado hacia el bien común de forma natural, no era más que una quimera que conduce al caos, a la ineficiencia radical.

Con la sociedad "industriosa" en liquidación, la Ley del Suelo madrileña que inaugura el siglo se entrega al banquete inmobiliario dispensando al territorio de toda cautela, dando rienda suelta a la promoción desenfrenada y sus agentes: el bloque ya mencionado y los responsables públicos asiduos de los tribunales de justicia. No cabe tanto fenómeno contradictorio sin corrupción. Hemos visto quiebras históricas como la de Martinsa-Fadesa que ha superado a la mítica quiebra de la Olympia en los docks londinenses, más de veinte años atrás. Y es sólo un ejemplo. Lo que en el planeamiento urbanístico había de búsqueda de equilibrios ha sido presentado como un obstáculo o como irrelevante en el reino de las coyunturas del mercado, mientras la población y sus condiciones de vida, el interés público, es decir, lo estructural, se ha sacrificado o sometido a toda clase de coacciones, a repetidos expolios, convirtiendo a la población en rehén de su propia credulidad, o de un desarraigo propiciado por ese marco de representaciones tan manipulado. El producto de esta monumental discrepancia entre representación y realidad, que se pudre como activo inmobiliario irrealizable en los asientos bancarios, ha constituido el objeto central del rescate público.

Así que estas ciudades escenario, como Madrid, jerarquizadas, desproporcionadas y rescatadas, teatro de toda suerte de mistificaciones, privadas de elementos de equilibrio y cargadas de viviendas vacías, que pesan como una losa sobre los recursos de los ciudadanos, son el "ecosistema" perfecto para el ejercicio de la supremacía, un campo de batalla donde las asimetrías incentivan los comportamientos. Un ecosistema del que se ha borrado todo mecanismo de colaboración, toda solidaridad. Mientras las inversiones privilegian los espacios de la gran economía con sus centralidades y lugares de alto rango generando nuevas coyunturas para la especulación, los fracasos sociales de todo tipo se vuelven estructurales como el drama de los desahucios: otra inaceptable paradoja en un mundo de viviendas vacías que muestra hasta qué punto se han monetarizado los propios derechos constitucionales. La modesta y reformista utopía del bienestar se va transformando en la insolidaria distopía neoliberal del "sálvese quien pueda a costa de quien sea", mientras se habla de ciudades inteligentes destinadas a confundir a los necios, a enredar más aún la sofisticada telaraña de las representaciones colectivas y consolidar la dependencia tecnológica que ya es una patología, o se celebra el advenimiento de nuevas "especies exitosas", como hipsters, yuccies, etc., que 
alientan los procesos de elitización en curso, nutriendo la mitología de la innovación y la creatividad banal.

Seguimos en una disyuntiva. Una opción es ceder ante el viejo bloque que persiste en sus proyectos expansivos sin salida (Chamartín, Vicente Calderón, Campamento, etc.) reforzado por los nuevos "visitantes nocturnos" - como diría Braudel- de la economía mundo que prefieren especular en los lugares emblemáticos (una lucha entre liquidez y posición). A cambio ofrecen empleo basura, expolio de los bienes comunes e incremento de la deuda ciudadana, así como paro a medio y largo plazo. Es un suicidio para necios. La otra opción, la única salida de progreso, es recuperar la soberanía ciudadana, poner fin al expolio de las condiciones materiales de vida y activar todo el potencial creativo y productivo de una sociedad tan diversa y socialmente plural como la madrileña. Los cambios en el gobierno de la ciudad central sugieren esa posibilidad, pero no parece que vaya a ser fácil variar el curso de las cosas en una ciudad en quiebra y sin proyecto. Son muy fuertes los vínculos con el pasado. La deuda del Ayuntamiento de Madrid es también histórica y está muy arraigada la idea de sacrificar la metrópoli con sus habitantes para salvar la gran economía, porque de ese éxito dependerá nuestra propia salvación. De poco sirve que la historia haya demostrado sistemáticamente su falsedad, pero justifica malvender patrimonio -edificios públicos y paquetes de vivienda social a fondos buitre-, entregar las conquistas sociales (sanidad, educación) al negocio mercantil, ceder ante inversores que imponen sus condiciones más allá de los límites constitucionales. Nos libramos por puro azar de Eurovegas, pero no de otros especuladores que exigen alteraciones profundas de las garantías asumidas colectivamente, y fuertes inversiones públicas. No caben nuevas grandes operaciones sin renegociar su coste, lo que la ciudad aporta, porque no cabe más endeudamiento.

Todo esto dibuja una ciudad vulnerable, presa fácil; que ha perdido la iniciativa, que viaja a la deriva mientras se deteriora la vida cotidiana, las conquistas ciudadanas. Madrid es una gigantesca superchería envuelta en burbujas sucesivas, como ésta de naturaleza monetaria que se vende ahora como una recuperación. Secuestrada bajo ese envoltorio mistificado, bajo esa claudicación, frenada por la economía parasitaria dominante, palpita sin embargo una sociedad compleja con capacidades y saberes inagotables, con posibilidades de reinventar una cultura de lo útil y lo necesario y su cuerpo productivo de proximidad con la autonomía suficiente, lo contrario de ese trivial teatro de consumo en el que cada cual intenta representar el papel que le permita olvidar cual es su verdadera posición en esta baratija. Sólo hay que atreverse colectivamente a romper las ataduras. Se llama emancipación y es un sublime y creativo gesto romántico irrenunciable. ¿Acaso tenemos otra alternativa? 


\title{
MODELO URBANO Y LITORAL: UNA ASIGNATURA PENDIENTE
}

\author{
Raquel Rodríguez Alonso (Arquitecta - Profesora asociada DUyOT)
}

Como sistema vivo y en constante equilibrio, el litoral se va acomodando a los embates del mar y dicho proceso permite la salvaguarda de los usos y actividades antrópicas y de los ecosistemas situados tierra adentro. Como fuente de recursos naturales y económicos, la explotación, ocupación y transformación del litoral ha sido muy intensa en España desde los años 60, y uno de los objetivos clave del reciente boom inmobiliario.

El valor ambiental del litoral se recoge por primera vez en el marco jurídico durante los años 1980. La nueva estructura trata de poner solución a los problemas heredados: a través de herramientas de protección que salvaguarden el territorio de nuevas presiones; poniendo fecha de caducidad a construcciones y actividades inadecuadas; ampliando el conocimiento sobre la forma de funcionamiento del sistema físico; o interviniendo en la regeneración de los tramos de costa más afectados, normalmente urbanos. La coyuntura económica y social derivada de la crisis del petróleo ayudará a avanzar en la visión compleja del territorio, pero también pesará en las decisiones sobre el modelo económico y el reparto de inversiones. El marco legal funcionará no como una bisagra entre el medio físico y los intereses lucrativos sino como un muro de contención que pretende frenar la deriva ambiental pero también económica. Así, el litoral heredado por el reciente boom inmobiliario se caracteriza por un marco legal y jurídico donde se acumulan las restricciones en el papel y los agentes en la gestión del territorio se han multiplicado; un sistema físico en el que las numerosas actuaciones públicas han estado destinadas a salvaguardar los intereses económicos pero no han sido suficientes para paralizar su degradación ni las nuevas amenazas y riesgos; y un modelo económico donde el único destino posible para el litoral es la coalición turismo-producción inmobiliaria.

El boom inmobiliario se traduce en un importante incremento de la presión sobre un espacio altamente antropizado y ambientalmente degradado. La demanda sobre los recursos litorales parte desde todas las políticas sectoriales sin que el marco legal sobre costas pueda detener muchos de los procesos. Las políticas de protección del territorio desarrolladas durante la década anterior ponen freno en parte a este crecimiento, pero no son suficientes ni homogéneas en el territorio. Además, entra en carga el complejo sistema administrativo y competencial, y la STC de 1991 sienta un precedente fundamental en la gestión de la costa. Dentro del ámbito regulado por la Ley de 1988, la Administración General del Estado gestionará el Dominio Público Marítimo Terrestre, mientras que todas las decisiones a tomar en el área de propiedad privada, servidumbres de tránsito y protección y zona de influencia, quedan reguladas por las determinaciones derivadas de las políticas urbanísticas y de ordenación del territorio. La STC de 1997, que anula gran parte de la Ley de Suelo de 1992, reducirá aún más la posibilidad de una visión conjunta sobre el litoral, enfrentando formas de hacer en un espacio continuo. Las decisiones sobre el modelo urbanístico y territorial, origen de la mayoría de las presiones sobre el medio físico, se independizan del 
equilibrio ambiental de la costa. La mayoría del planeamiento urbanístico de los municipios litorales revisa el modelo anterior con incrementos desmedidos en la clasificación del suelo y en el número de nuevas viviendas. A esta situación hay que sumar las consecuencias del estallido de la burbuja, con miles de viviendas construidas y sin vender, una importante superficie de solares sin edificar, y promociones inmobiliarias paralizadas a mitad del proceso de urbanización o construcción.

Las consecuencias visibles de la crisis son todavía mayores que a finales de los años 1970: por el volumen del crecimiento inmobiliario, por la acumulación de presiones y problemas sobre el sistema físico y por el sobredimensionamiento de la demanda estimada que afectó tanto a los productos inmobiliarios como a las infraestructuras: incremento en los kilómetros de autovías y autopistas; nuevos aeropuertos construidos y sin uso como en el caso de Castellón o Murcia; y expansión de todas las instalaciones portuarias, destacando el aumento del número de atraques deportivos y la ampliación exterior de los puertos de interés general sobre nuevos tramos de costa, con el agravante de que el vínculo entre interés general, desarrollo económico y sistema portuario hace que las afecciones que su actividad provoca en el entorno se entiendan como un mal asumible. El estallido de la burbuja inmobiliaria en 2007 paraliza el desarrollo de muchas de esas propuestas, pero no las cancela. Así, el litoral a gestionar en el futuro parte de un marco jurídico en el que la protección del litoral se ha reducido, un modelo urbano y territorial que ha consolidado físicamente o jurídicamente un desarrollo residencial e infraestructural diseñado para una demanda que no existe, y un sistema físico cada vez más degradado y amenazado por el cambio climático.

Mientras desde la política urbanística y territorial se aumentaba sin control la presión sobre el litoral, el papel de la Dirección General de Costas quedaba reducido a plantear nuevos proyectos y alternativas en las que se procurara mantener la estabilidad del frente costero y, por tanto, la defensa física de los intereses ubicados tierra adentro, dedicando así una importante parte del presupuesto público a garantizar la seguridad material y futura de los intereses económicos. Además, los riesgos inherentes al funcionamiento del sistema litoral, como la erosión costera, los temporales, las inundaciones por lluvias torrenciales o la inestabilidad de los acantilados, provocan todos los años nuevas inversiones públicas que, con carácter de urgencia, van destinadas a reconstruir lo que la inercia del sistema se ha llevado por delante.

La descoordinación entre las distintas administraciones reabre la polémica social sobre la forma de actuar en la costa, llegando en muchas ocasiones a situaciones paradigmáticas. El programa estatal de adquisición de fincas rústicas para su incorporación al Dominio Público Marítimo Terrestre tiene mucho que ver con la desconfianza entre los distintos niveles de la administración. A pesar de los esfuerzos que la comunidad científica y los poderes públicos están realizando para la evaluación de los efectos del cambio climático en la costa, en muchos casos los resultados llevan a un callejón sin salida: ya sea por la búsqueda de yacimientos de áridos para procurar la estabilidad de las playas, o por el impacto sobre las actividades económicas, el desarrollo urbano y los ecosistemas. Entre 2006 y 2008 la Dirección General de Costas redactó la Estrategia de Sostenibilidad de la Costa y el Mar, segundo intento de hacer un documento para la gestión completa del litoral español. Entre 2004 y 2008, se 
remata la revisión de los deslindes, no sin polémica, y los criterios de intervención pública en la costa se modifican parcialmente a partir de 2006, incrementando las inversiones en la regeneración y accesibilidad de áreas vírgenes, en la recuperación del patrimonio etnográfico y cultural, y condicionando las intervenciones en áreas urbanas a la liberación de los frentes situados en servidumbre de tránsito y protección. La vuelta de tuerca en la política de costas y la llegada inminente de la fecha de caducidad de las concesiones (2018) generarán bastante inquietud en los sectores económicos y en la población. La regulación de la Ley de 1988 y su aplicación se ponen en tela de juicio, y el conflicto entre los intereses privados y el valor ambiental del litoral se vuelve a hacer evidente.

A día de hoy, se puede afirmar con rotundidad que las respuestas a la pugna entre la inestabilidad del sistema litoral y la persistencia de los intereses económicos y sociales no han sido todo lo eficaces que se podría esperar. La ilusión de que las innovaciones técnicas son capaces de dar solución a los problemas y riesgos no ha dejado nunca de estar presente en la transformación del litoral. La primera reacción siempre es un nuevo intento de dominar el territorio. En el mejor de los casos, la respuesta ha sido la búsqueda de soluciones intermedias, que parten de la comprensión total o parcial de los procesos naturales, y cuyo objetivo es mantener la rentabilidad económica o social de los usos y actividades existentes, aunque muchos de ellos estén en el origen de lo que se pretende solucionar. La superposición de nuevas obras de defensa no ha conseguido parar la inercia del sistema. Como nuevos parches a los problemas, evitaban además la confrontación de los riesgos y amenazas que permanecían sobre la mesa. En el peor de los casos, la solución ha pasado por negar lo evidente, como en el caso de la reciente reforma de la Ley de Costas: se podrán relajar las reglas de actuación, reconocer todos los derechos que demandan los propietarios airados, eliminar todas las restricciones existentes, pero no se puede detener el mar.

Las consecuencias del cambio climático sobre el litoral, con incrementos de los fenómenos climáticos extremos, la subida del nivel del mar, o los cambios en la orientación local del oleaje, incorporan nuevas incógnitas al futuro de un espacio ya de por sí complejo. La desaparición de ecosistemas y hábitats que contribuyen a la regulación de los procesos costeros, a la defensa de los usos y actividades situados tierra adentro, y al mantenimiento de la vitalidad económica del litoral puede poner en tela de juicio la propia construcción social del litoral. La visión compleja e integral de los procesos económicos, sociales, jurídicos y ambientales que se superponen en la costa, reivindicada desde la década de los 1980, ha dejado de ser, si alguna vez lo fue, una alternativa dentro de las distintas formas de gestión posibles. La respuesta al futuro del litoral pasa necesariamente por la coordinación real y efectiva de todas las políticas disponibles para la gestión del territorio, pero también de todos los agentes y los intereses implicados. Sea cual sea el problema a solucionar, la toma de decisiones pasa siempre por actuar sobre los procesos litorales con el fin de permitir la continuidad de la actividad afectada, o bien, eliminar la actividad permitiendo el desarrollo de los procesos del sistema físico litoral.

En este sentido y a pesar del reparto competencial, las actuaciones en la costa y la política urbanística están condenadas a coordinarse y entenderse; partiendo de un modelo pactado, las herramientas urbanísticas pueden proporcionar una solución definitiva y más barata para la protección de los suelos situados en primera línea, 
incluso para la reubicación a corto, medio o largo plazo de los usos afectados por la subida del nivel del mar. Las tres estrategias básicas planteadas por la Agencia Europea del Medio Ambiente para procurar la adaptación de las poblaciones y áreas urbanas al cambio climático, proteger, adaptar y retirar ${ }^{68}$, pasarán necesariamente por la utilización de las herramientas de ordenación en la futura gestión del litoral.

Otro de los grandes retos será la revisión del modelo urbano heredado, adecuándolo a las necesidades reales de la población y a la capacidad de carga del propio sistema físico, entendido en su sentido amplio: la autorización del nuevo trasvase desde el Tajo al Segura y las protestas que se han generado entre los municipios situados en la cabecera ${ }^{69}$ vuelven a abrir la polémica pública sobre la gestión de un bien escaso en la confrontación entre el desarrollo económico y la protección ecológica. El litoral no puede subsistir a costa de la destrucción de parte de su sistema físico, sean cuales sean los derechos adquiridos sobre el papel.

68 Proteger o reducir el riesgo disminuyendo la probabilidad de que ocurra el suceso; Adaptar, o aumentar la capacidad de la sociedad para hacer frente a los efectos del suceso, y Retirar o reducir el riesgo limitando el potencial del suceso,

69 http://politica.elpais.com/politica/2015/08/28/actualidad/1440752893_805663.html 


\title{
LA EVOLUCIÓN CONCEPTUAL DEL PLANEAMIENTO Y LA LEGISLACIÓN URBANÍSTICA ACTUAL
}

\author{
Luis Rodríguez-Avial Llardent (Dr. Arquitecto - Profesor Ad Honorem DUyOT)
}

\section{INTRODUCCIÓN: EVOLUCIÓN CONCEPTUAL DEL PLANEAMIENTO EN LAS ÚLTIMAS DÉCADAS}

Para intentar definir la evolución posible, previsible y deseable del Planeamiento y la Gestión Urbanística en España, conviene comenzar por dar un repaso a como son las "coordenadas" representativas de la ciudad actual en los países desarrollados de Europa, en la época correspondiente al cambio de siglo, ya que nuestra nación pertenece a este ámbito geográfico.

Si bien la Revolución Industrial indujo una importante necesidad de suelo urbano, en el momento actual, con tasas de urbanización (población que vive en ciudades) del orden del $90 \%$ en los países europeos desarrollados, podría parecer que se necesita menos suelo de aquella clase. Por ello en estos países, durante las décadas de los setenta y ochenta del pasado siglo se volvió la mirada, en sus ciudades, hacia el centro de las mismas. La primera consideración que se hizo, como consecuencia de esta vuelta al centro, fue la de la necesidad de poder usarlo. Para ello se intentó hacerlo más vividero con operaciones de prestigio (por ejemplo en Madrid la transformación de la glorieta de Carlos $\mathrm{V}$ o de Atocha con el desmontaje del "scalextric" que allí existía).

Sin embargo con este tipo de actuaciones en lugar de hacerlo más vividero lo que se consiguió fue hacerlo más representativo, incrementándose los usos terciarios, ya que las grandes operaciones residenciales en el centro de las ciudades tropezaban con muchos problemas, de los que quizás los más importantes eran los de la circulación y la contaminación ambiental y acústica.

Además la necesidad de contacto con la Naturaleza, propiciada por el movimiento ecológico, que, paradójicamente, aumentaba la necesidad de "consumo" de aquella, se oponía a esta tendencia centrípeta de volver al centro de las ciudades. En consecuencia no se desarrollaron grandes operaciones residenciales en este, pero en cambio sí tuvieron éxito las de rehabilitación y renovación urbana; el problema es que estas requerían, en general, la puesta en valor del centro, lo que chocaba con los criterios de protección de la edificación, puramente conservacionistas, en los años de arranque del movimiento de preservación del Patrimonio heredado.

Ahora bien, ¿cómo hacer para conservar viva una ciudad inadecuada?. La respuesta en los años noventa fue: Rehabilitando, conservando las esencias y modificando lo accidental; esto en teoría, aunque en la práctica resultó complicado por los costes económicos y los problemas sociales inherentes a la necesidad de desalojar población residente aunque fuera temporalmente. Por estas circunstancias, manteniendo en lo posible la vuelta al centro, siempre buscando la mejora de su calidad urbana, en los años noventa vuelve a entrar en carga la ordenación de las 
periferias de las ciudades europeas, escenario al que no son ajenas las ciudades españolas.

Fernando de Terán, arquitecto urbanista, Catedrático Emérito de la ETSAM, describe la realidad urbana de finales de siglo - descripción con la que nos identificamos plenamente - de la siguiente forma: Se había ido formando, fundamentalmente en las grandes ciudades, una especie de "territorio urbanizado" en el que se diluye la idea de forma estable tradicional en un continuo y heterogéneo magma, en el que las grandes infraestructuras, los grandes contenedores edificados (los nuevos monumentos) y los elementos singulares del medio natural que permanecen visibles, constituyen los nuevos hitos diferenciadores, caracterizadores y referenciales de un nuevo paisaje ( ¿"posturbano" como se pregunta Terán?) ${ }^{1}$.

En el mismo se pueden distinguir: Áreas residenciales dispersas, industrias, centros comerciales, hospitales, locales de exposición de productos industriales, estaciones de servicio, moteles, parques de atracciones, salas de juegos, terrenos deportivos, estadios, palacios de congresos y de convenciones, grandes discotecas ..... que son los nuevos espacios del tiempo colectivo, nuevos polos intermitentes de agrupamiento e intercambio social, nuevas manifestaciones del espacio público y representativo, enhebrado en secuencias espaciales dinámicas, a través de los incesantes desplazamientos canalizados por la red viaria; este es el espacio infraestructural en el que se desarrolla una parte fundamental de la vida de una ciudad, que es experiencia en movimiento. (Esta parece ser la "postcity" que puede venírsenos encima) ${ }^{2}$.

Sin embargo, esta realidad nueva estimula, también, la necesidad de una forma nueva y diferente de entender el planeamiento general.

En nuestra opinión, este planeamiento general debería haberse definido, de acuerdo con la opinión de Fernando de Terán, partiendo de la nueva realidad urbana y territorial de nuestras ciudades. Para él: "Es evidente que el tratamiento de esta nueva realidad, y el establecimiento para ella de alguna clase de estrategia ordenadora previa, no se puede identificar con la planificación territorial. En sus más avanzadas formulaciones la organización de ese variado territorio es pensada en términos solo de estructura, extendida sobre amplios espacios, dentro de la cual sea posible una gran libertad de movimiento, de localización y de comunicación". Con este planteamiento Terán entiende que se puede superar la disyuntiva entre planeamiento global y actuaciones "fragmentarias", tanto a nivel urbano como territorial'.

Ahora bien, cabe preguntarse: ¿Es posible hoy en España este tipo de planeamiento?, pregunta a la que debemos responder con un no rotundo en el marco de nuestra actual legislación urbanística.

El planeamiento general que hemos venido elaborando desde 1956 siempre ha sido "hijo" de la legislación vigente en cada momento. La realidad es que la evolución de la legislación urbanística en España, a partir de la Ley del Suelo de 1956 siempre se ha producido en la dirección de hacer más complejo, determinista $y$, en consecuencia, más rígido y omnicomprensivo el Planeamiento. La legislación actual no responde, en nuestra opinión, a la evolución conceptual de este, ni tampoco, entendemos, a lo que demanda la sociedad. Por ello hoy es imposible elaborar un planeamiento general del tipo que acaba de proponerse, especialmente sobre grandes 
ciudades. El planeamiento general debe ser, por tanto, mucho más abierto y flexible. Lo mismo entendemos que ocurre con la Gestión Urbanística que también se ha ido volviendo cada vez más compleja de definir y tramitar. Este es el panorama a partir del que debemos escudriñar la evolución posible del Planeamiento y de la Gestión Urbanísticas en España, difícil siempre de prever y fácilmente confundible con lo que sería, en nuestra opinión, deseable. Con esta advertencia previa intentaremos abordar una propuesta razonable.

\section{EVOLUCIÓN DESEABLE DEL PLANEAMIENTO, LA LEGISLACIÓN Y LA GESTIÓN URBANÍSTICA}

\section{A) En relación con el planeamiento}

Siguiendo el pensamiento de Fernando de Terán, especialmente a la escala territorial, pero también a escala municipal, para aquellos suelos que no sean ciudad (suelo urbano), ni deban ser protegidos por sus valores intrínsecos o por legislación sectorial, es indispensable, no lo que venimos haciendo - un planeamiento determinista - sino sólo la definición de alguna clase de estrategia ordenadora, planteada mediante un esquema global de referencia, aunque sea de carácter genérico y en buena medida indicativo, que defina una organización estructural del territorio extendida sobre amplios espacios, dentro de la cual sea posible una gran libertad de movimiento en la localización de actuaciones y en la ubicación de las correspondientes infraestructuras de desarrollo.

En este marco será posible contemplar a posteriori propuestas de creación de ciudad, fragmento a fragmento, que deberán demostrar el respeto a las coordenadas generales de la estrategia ordenadora global, así como a la previsión de las infraestructuras básicas que dicha estrategia contemple, y en las que asuma un papel protagonista el diseño del espacio público a través de la redacción de proyectos urbanos.

Será por tanto necesario hacer algunas apuestas voluntaristas de obligada realización, las menos posibles, que aseguren esa organización estructural, que sirvan como marco de referencia y compatibilidad, para asegurar la coherencia de las decisiones imprevisibles que vayan a ir adoptándose sobre la marcha y vengan a insertarse en el territorio. Papel fundamental habrán de tener los programas de inversiones para la realización de las infraestructuras básicas vinculantes, entendidas estas como apuestas vertebradoras claramente definidas; igual rango deberán asumir los espacios que hayan de ser protegidos del desarrollo urbano. A ambas herramientas se deberá confiar la definición de la estructura y por tanto de la estrategia ordenadora.

Las actuaciones para el desarrollo posterior de dicha estrategia quedarían liberadas, en mayor o menor grado según las regulaciones que aquella incluya, de la contingencia de un ajuste constante, en una situación evolutiva a manejar con discrecionalidad.

Entrando en un mayor detalle, comenzaríamos por decir que vamos hacia un planeamiento general de evolución continua, que pueda adaptarse, día a día, a los 
cambios en las demandas que se producen en el seno de la sociedad, y que, en consecuencia, no esté concebido de forma que resulte obsoleto en buena parte de sus planteamientos en cuanto aquellos se produzcan, que en definitiva esté preparado para poderlos asimilar y dar la adecuada respuesta.

Un planeamiento general que permita su evolución continua requiere que su elaboración se realice desde dos premisas de partida:

- La búsqueda de la flexibilidad frente a la rigidez

- El protagonismo de la participación de la sociedad en todo el proceso a fin de conseguir para el mismo el máximo respaldo social.

La flexibilidad en el planeamiento se debería conseguir diferenciando el conjunto de sus determinaciones en dos rangos o niveles a partir de los siguientes criterios:

- Determinaciones fundamentales: Pocas, concretas y rígidas, cuya modificación siempre tendría en cuenta el protagonismo de la sociedad.

- Determinaciones secundarias: Constituirían el paquete fundamental en cuantía, que no en importancia; su alteración habría de ser fácil y rápida pues no cambiarían los elementos básicos que definen la concepción global de la ciudad para el futuro.

Por otra parte, y desde el punto de vista de la concepción urbanística actual, el planeamiento general conviene que persiga la obtención del equilibrio entre la componente estructural y el protagonismo del diseño urbano. Debe por tanto mantenerse el énfasis en las propuestas sobre la ciudad existente para conseguir la permanente mejora de su calidad urbana, así como de la protección de su patrimonio, siempre desde una visión positiva - la mera protección no sirve - que se plantee una verdadera recuperación y revitalización de las áreas históricas, haciendo que la vida en las mismas vuelva a ser atractiva.

Hemos de superar la desagregación por usos de la ciudad (el zoning), recuperando una mezcla equilibrada de usos, actividades y funciones ("centralidad") en el centro de la ciudad y en las periferias zonificadas en su día, y difundiendo esta característica hacia los nuevos desarrollos que se planteen. (Al reflexionar sobre una ciudad hay que hacerlo pensando en el ayer, el hoy y el mañana de la misma). Solo de esta forma recuperaremos el equilibrio territorial en cada una de las partes de la ciudad y entre estas y la totalidad de la misma.

Y finalmente la elaboración del planeamiento ha de plantearse desde la búsqueda de la sostenibilidad ambiental.

B) En relación con la actual legislación urbanística

La actual legislación urbanística no preconiza, como se ha expuesto anteriormente, este tipo de planeamiento de estructura, abierto y flexible y por eso pensamos que no sirve a lo que hoy demanda nuestra sociedad y en consecuencia sería deseable su revisión. Esta tendría que permitir la elaboración de ese tipo de planeamiento, 
fácilmente adaptable a los cambios de criterio de la sociedad, y facilitar todos los aspectos de detalle que acabamos de comentar en el punto anterior.

Sin embargo, algunos aspectos de la misma, como la adquisición gradual de derechos por los propietarios del suelo urbanizable - legislación estatal de 1990-92 o del suelo en situación rural con posibilidad de paso a la situación de suelo urbanizado - vigente ley estatal - según se fueran produciendo, en ambos casos, iniciativas realistas y creíbles de ejecución de actuaciones de urbanización, en muchos casos mediante proyectos urbanos, pensamos que encajarían mejor con los criterios que se acaban de exponer. (Sería también conveniente que la legislación urbanística reconociera el papel ordenador de estos Proyectos Urbanos).

En paralelo sería igualmente muy necesario introducir, en la legislación medioambiental, criterios de mayor racionalidad para la elaboración de Informes Ambientales y de Evaluación de Impacto Ambiental, así como en el análisis, por parte de las Administraciones competentes, de las propuestas urbanísticas que se sometan a su consideración.

\section{C) En relación con la Gestión Urbanística}

También es imprescindible, en nuestra opinión, revisar y simplificar los procedimientos de gestión urbanística, fundamentalmente agilizando la tramitación del planeamiento de desarrollo y definiendo nuevos sistemas de actuación o flexibilizando los actuales. Es necesario también volver más sencilla la tramitación de aquellos, reducir los plazos legales de cada paso de la misma, y conseguir unos tiempos de aprobación razonables - no como los actuales - acordes con las demandas sociales de la promoción y desarrollo de todo tipo de actuaciones urbanísticas.

1, 2 y 3 Fernando de Terán "El pasado activo. Del uso interesado de la historia para el entendimiento y la construcción de la ciudad" (Editorial Akal 2009) 


\title{
LA TORRE DE BABEL
}

\author{
María José Rodríguez Tarduchi (Arquitecta - Profesora Ad Honorem DUyOT)
}

Este no es un comentario a un hecho urbanístico del que se hayan derivado consecuencias catastróficas para nuestras ciudades; por no ser, ni siquiera, "sensu stricto", es un hecho. Tomando la palabra a algo que se nos sugería en la convocatoria, este es un comentario a un "no hecho". Un "no hecho" que se viene arrastrando y acrecentando desde que la COPLACO desapareció como responsable de la coordinación de las acciones que se producían en el área metropolitana de Madrid. En ese momento de exaltación democrática de los ayuntamientos, el rescate de la autonomía municipal se exhibía como una conquista irrenunciable, y así afortunadamente fue.

La canalización de las aspiraciones municipales y la armonización intermunicipal en aras de un bien común superior se trasladaron de la COPLACO a la Comunidad Autónoma de Madrid. Pero este hecho no se tradujo en esa efectiva "coordinación" que aparecía en el propio nombre del organismo primitivo. Y los planes de los municipios del área metropolitana se empezaron a tramitar y aprobar con un somero control ante la mirada inhibida de un organismo lastrado por la herencia autoritaria de la dictadura.

Los planes generales se redactaban por arquitectos designados por los ayuntamientos, ávidos de incorporar visiones nuevas o enfoques propios -acertados o no, fundamentados o no- muy poco contestados por la recién estrenada Comunidad Autónoma. Y en menos de dos decenios se había ya detectado la necesidad de compensar la autonomía municipal con una cierta armonización de los intereses locales desde objetivos territoriales comunes.

Pero las ordenanzas reguladoras de la edificación eran otra cosa. Nunca se han significado en el interés de los arquitectos, y en los municipios ni se sabía lo que eran ni se planteaban como un objetivo ambicioso que pudiera generar réditos. De forma que los organismos superiores de control hacían algunas sugerencias en relación con los desarrollos futuros de la ciudad que, esos sí, despertaban apasionamientos inesperados, y las normas urbanísticas se fueron produciendo sin apenas atención. Sin apenas atención y sin control, según la subjetiva decisión de los equipos encargados de la redacción de los planes, con un sinfín de conceptos interpretados a su libre albedrío, resultado de esa loabilísima voluntad de estilo que todo arquitecto tiene a la hora de enfrentarse a un plan. De nuevo esa voluntad de ser diferente, esa vena creativa del arquitecto que todo urbanista lleva dentro. Semejante actitud, nunca contestada, dio lugar a decenas de definiciones distintas -conscientes o inconscientes, innovadoras o consabidas- de vocablos que hasta ese momento se habían interpretado en una única dirección.

Probablemente en el origen, algunas de ellas respondían a disfunciones ciertas dictadas por la experiencia, pero pronto el panorama fue tan amplio que cada cual se aplicó a aportar su propia interpretación. Sin duda este texto se plantea como un registro critico de esta situación, y la propuesta que en él se contiene, como el 
empeño de ser racional en el significado de los conceptos urbanísticos y de mirarlos como si estuviéramos empezando a descubrirlos.

En todo caso, es un error entender que el enunciado de los conceptos urbanísticos es inocente o meramente descriptivo. Y constituye una prueba más, si necesaria resultara alguna, la reiterada negativa de los poderes locales que he detectado cuantas veces he intentado introducir la idea de homogeneización terminológica en algún foro político o municipal. Detrás de la definición de cada uno de esos conceptos hay una voluntad inequívoca de incrementar la edificabilidad, de aumentar los beneficios, de primar lo individual frente a lo que nos concierne a todos, lo privado frente a lo público, frente a lo social. No son inocentes la definición de una planta en un determinado nivel como semisótano o planta baja, la ocupación del área de retranqueo por determinadas edificaciones, en principio auxiliares, o naturalmente, el cómputo de la ocupación o de la edificabilidad.

Nada en el urbanismo es inocente. Resignificar esos conceptos urbanísticos, otorgarles un nuevo y común significado, no es sino una forma más de regeneración que podría enmarcarse en esa otra que los ciudadanos han reclamado a sus dirigentes muy recientemente en el ámbito más general de la política. Porque también detrás de esta variedad de definiciones se ha deslizado una sociedad que se ha permitido sancionar el delito, creándolo y alimentándolo al mismo tiempo.

Y sin embargo, Neufert había publicado por vez primera vez su "Arte de proyectar en arquitectura" en 1936, con el objetivo de crear un cierto orden en torno a todo lo que surgía alrededor de la nueva arquitectura, desde los formatos del papel, su plegado en los proyectos y su simbología, hasta la métrica de los distintos elementos y fábricas constructivas, de las instalaciones, de las viviendas, de los edificios de usos diversos y de la urbanización.

Han transcurrido desde entonces casi ochenta años, y las ordenanzas reguladoras de la edificación de nuestros planes contienen decenas de formas distintas de computar la superficie edificable en un proyecto de edificación y otros tantos criterios para medir la altura en calles con pendiente acusada o para determinar por qué una planta se considera sótano y no semisótano o al revés, por no hablar de la diversidad de códigos de color, símbolos y leyendas que pueblan nuestros planes y proyectos y que están reclamando con urgencia una imprescindible normalización.

Se podría ir más lejos. Porque no es razonable que existan diez y siete leyes del suelo para satisfacer las aspiraciones megalómanas de los representantes de las diez y siete comunidades autónomas en las que está dividido el país. Y todos los profesionales lo sabemos y nos lo decimos (ni qué hablar de lo que comentan nuestros colegas extranjeros cuando se lo explicamos) ¿Las leyes son realmente distintas? ¿Las leyes son exactamente iguales? A partir de un tronco básico y conceptual común se han generado desigualdades, excepcionalmente sustanciales, pero con frecuencia irrelevantes y coyunturales, que hacen esas leyes iguales y distintas.

Pero no es ese el objetivo de este texto. Carezco de esa inusual aunque admirable capacidad de revisión de lo tenido por supuesto. Las competencias territoriales han sido hace tiempo transferidas. Aceptemos, contra toda razón, que no conviene instalarse en la contra corriente, imaginemos que esta situación es producto de un inapelable determinismo genético, o de esa idea griega de un destino con el que se 
nace y al que es imposible escapar. Sea. Aceptemos pues, las diez y siete leyes del suelo. El objetivo es mucho más modesto. Madrid. Solo Madrid.

Item más, ni siquiera se trata de acometer una armonización general de todos los Planes de Ordenación Urbana, objetivo deseable y diferido a una etapa posterior. Para empezar la propuesta es mucho más simple. Hay cuatrocientos cincuenta millones de personas que llaman al sol, sol, a la luna, luna y a la muerte, muerte. Y sin embargo no se entiende lo mismo "semisótano" en Fuenlabrada que en Móstoles que en Alcorcón, por poner un ejemplo. Pero, ¿sería posible la comunicación si la interpretación de los signos/palabras no fuera una convención acordada? ¿Podríamos entendernos si el contenido que las asignamos no fuera igual para todos? ¿No es la semántica independiente del contexto? ¿No sería posible, entonces, empezar por acordar solo algunos conceptos, solo algunas definiciones? Si las respuestas a todas estas preguntas retóricas son las que se presumen ¿No sería razonable crear un cuerpo común de definiciones en todos los planes de la Comunidad de Madrid?

Es algo muy menor pero muy básico: homogeneizar el contenido de los conceptos fundamentales utilizados en todos los planes que desarrollan el crecimiento de la ciudad, de dar a esos términos un contenido común imprescindible para el entendimiento compartido de los documentos que rigen en último término la forma de nuestras ciudades, de acordar la interpretación generalizada de una docena de definiciones y conceptos que aparecen en cualquier documento de planeamiento. Una labor sencilla, de manual, un acuerdo de mínimos para establecer una única clasificación de usos del suelo, para regular los criterios para el cómputo de la superficie edificable, de la superficie de ocupación y la determinación de las construcciones admisibles dentro de la zona de retranqueos, para unificar las definiciones de conceptos tales como cota de origen y referencia, sótano, semisótano, planta baja o bajo cubierta. Un objetivo humilde, nada brillante, nada revolucionario, muy elemental, pero nunca consumado.

Esta hipotética y simple puesta en común ofrecería a todos los agentes implicados en el hecho constructivo unas garantías y una seguridad jurídicas de las que hoy carecen y permitiría superar la situación de indefensión en la que a menudo se desenvuelven todos ellos en sus relaciones con la administración.

Reconocer las mismas definiciones, los mismos conceptos y las mismas interpretaciones en algunos aspectos claves para la elaboración de un proyecto no sólo favorecería a los profesionales libres, los propietarios de suelo y edificaciones, los usuarios, los promotores y las empresas constructoras, sino también a los equipos redactores del planeamiento, los arquitectos y aparejadores municipales, los funcionarios públicos en general, los ayuntamientos y las comunidades autónomas, que experimentarían una simplificación considerable en su labor y se beneficiarían de una notable economía en tiempo y recursos.

Es imprescindible superar las disfunciones, la precariedad y la incertidumbre con que los profesionales se enfrentan a unos sistemas reguladores complejos y oscuros que quiebran las garantías jurídicas y favorecen las lecturas arbitrarias de un lado, ventajistas de otro, de unos textos con sobreabundancia de normas en los que nunca puede darse una interpretación como implícita, a pesar de que existen algunas, históricamente consagradas por la validez de sus resultados y convenciones, que no sería difícil acordar. 
Más complejo resultaría homogeneizar la normativa completa de los Planes Generales $y$, sin embargo, son muchas las leyes y normas que comparten todos los municipios de una misma Comunidad Autónoma y no habría ninguna razón para que no pudiera redactarse un documento base común a todos ellos. Así, la Ley del Suelo estatal y la autonómica, el Código Técnico de la Edificación, la Ley de Ordenación de la Edificación, la Normativa sobre Accesibilidad y Supresión de Barreras Arquitectónicas, la Normativa Contra Incendios, la Normativa Sectorial de los Usos y Actividades, son compartidas por todos los municipios del área metropolitana de Madrid. Aún más, las soluciones constructivas de las infraestructuras y los servicios urbanos, el propio formato de los planes y la estructura de su contenido, las fichas de ordenación y las de gestión, los códigos de colores y la simbología podrían conformar un documento base que bastaría completar con las normas estéticas, las normas particulares de los usos y algunas otras que satisficieran las necesidades específicas de cada municipio.

Se podría llegar muy lejos sin menoscabo de la autonomía municipal. En nada la afectaría el hecho de disponer de un cuerpo normativo común que facilitara la redacción de los planes y acotara los ámbitos de diferenciación entre unos y otros. El urbanismo municipal puede enfrentarse a los intereses locales y orientar su gestión en la forma que resulte más beneficiosa para los ciudadanos, se disponga o no del cuerpo doctrinal que aquí se propugna. Ninguna de las capacidades interventoras de los ayuntamientos se vería afectada por ello. La antigua reivindicación de la política urbana bajo criterios y objetivos fijados por los ayuntamientos es una conquista ya cumplida e irreversible.

Pero no se propone esto ahora. Se trata de posponer lo mejor por conseguir lo bueno. Todo se andará. De momento solo hablamos de léxico, de terminología. Aparquemos las ficciones, que son solo el otro nombre de los deseos. 


\title{
PAISAJES DE LA CRISIS: PROBLEMAS Y OPORTUNIDADES
}

\author{
Emilia Román (Dr. Arquitecta - Profesora asociada DUyOT)
}

\section{PAISAJES DE LA BURBUJA INMOBILIARIA}

En los últimos lustros el paisaje de nuestro país ha sido invadido por numerosas urbanizaciones deshabitadas, con edificios terminados o a medio construir, solares en el interior de las ciudades, terrenos urbanizados vacíos, infraestructuras y equipamientos sin uso, operaciones ruinosas consecuencia de la burbuja inmobiliaria y la crisis económico-financiera.

Estas urbanizaciones y edificios fantasma están presentes en gran diversidad de paisajes de la Península, sobre todo en áreas del litoral pero también en el interior, ubicadas generalmente en terrenos próximos a pueblos y ciudades de nuestra geografía, e incluso en parques y parajes naturales que gozaban de protecciones de escala nacional e internacional.

Un ejemplo de esta última circunstancia es lo ocurrido en el Embalse de Valdecañas (Cáceres) donde, a pesar de ser un humedal de gran importancia a nivel internacional por sus valores naturales ${ }^{70}$, se aprobó con el apoyo del Gobierno de Extremadura la construcción de un resort con dos hoteles y 200 viviendas de lujo, club social, campo de golf y puerto deportivo. Todo bajo su declaración en el año 2007 como Proyecto de Interés Regional (PIR) ${ }^{71}$, es decir, por su utilidad pública, incidencia socio-económica e interés social...

Actualmente el proyecto se encuentra ejecutado al $60 \%$ debido a la crisis económica, pero también a una Sentencia del Tribunal Supremo del año 2014, que confirmaba la ya emitida por el Tribunal Superior de Justicia de Extremadura en 2011, en la que declaraba nulo el PIR. En la sentencia el Tribunal Supremo recuerda la importancia de la legislación sectorial (en este caso ambiental) como condicionante de la ordenación territorial y urbanística: "cuando unos terrenos están sujetos a algún régimen especial de protección sectorial, lo mismo que cuando concurren en ellos valores de los que la legislación urbanística considera merecedores de protección, resulta preceptiva su exclusión del desarrollo urbano y su clasificación como suelo no urbanizable de especial protección" y ordena el derribo del complejo turístico y la reposición y restitución de los terrenos a su estado anterior.

Sin embargo, la Junta de Extremadura se resiste a ejecutar la sentencia asegurando que demoler lo construido conllevaría un gasto de más de 34 millones de euros, a los que habría que añadir los gastos correspondientes a la indemnización del promotor. Además, alega que es menos perjudicial para el medio ambiente dejarlo como está que retornarlo a su situación inicial (se talaron 7.000 eucaliptos y se han plantado unos 8.000 árboles y 100.000 matorrales autóctonos). A día de hoy el resort

\footnotetext{
70 Estaba clasificado como suelo no urbanizable especialmente protegido y pertenecen a la red ecológica europea Red Natura 2000.

71 Información obtenida de Ecologistas en Acción : http://www.ecologistasenaccion.es/article27375.html [Fecha de consulta: 21 de julio de 2015]
} 
continua activo... Ante esta disyuntiva surge una primera cuestión ¿demoler o aprovechar lo construido? ¿Qué es más beneficioso y tiene menos costes para el medio ambiente y para la sociedad?
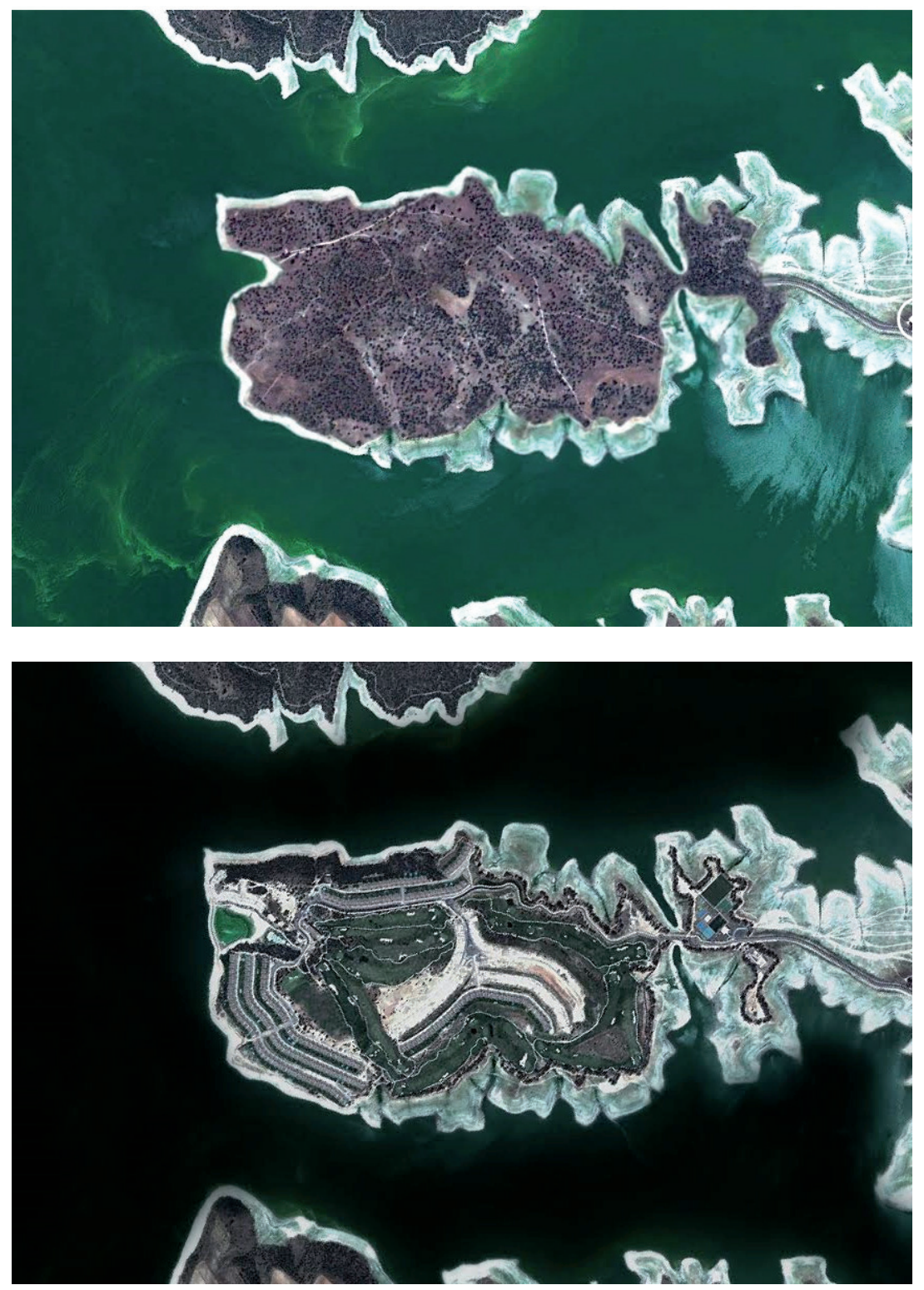

Figura 8. Evolución de Isla de Valdecañas a Campo de Golf Valdecañas , 2002-2013 Fuente: Nación Rotonda

A los problemas ambientales y paisajísticos generados por estas actuaciones se añaden otros de índole socioeconómica, como las familias que, en su día y animadas por el boom inmobiliario, invirtieron sus ahorros en estas viviendas y que actualmente se enfrentan a grandes dificultades no sólo para habitarlas sino también para venderlas o alquilarlas. 
Otros propietarios conviven diariamente con cientos de edificios e infraestructuras abandonadas, espacios libres sin mantenimiento, sin vida social y sin una solución a corto plazo.

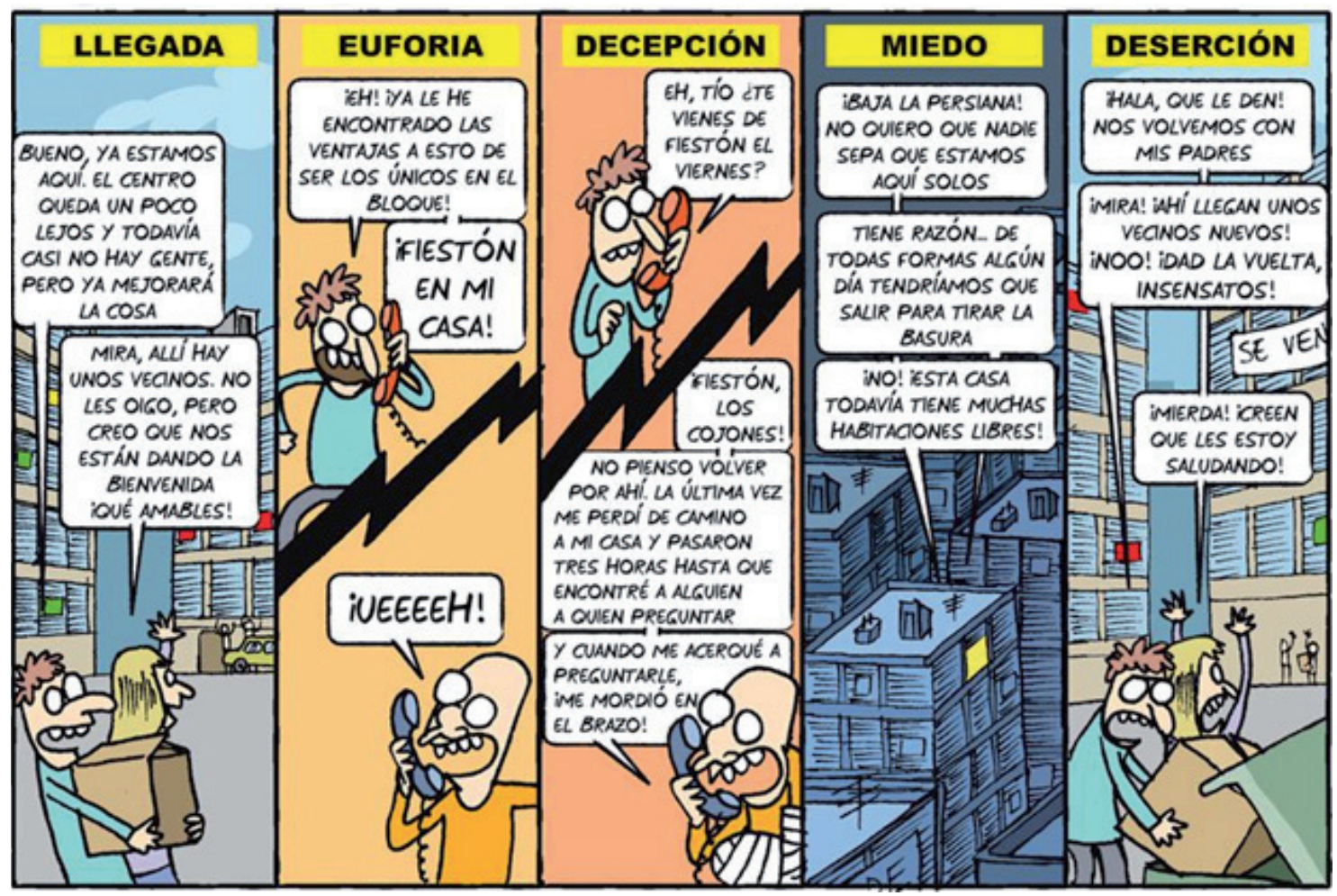

Figura 9. ¿Cómo es la vida en una urbanización fantasma?

Fuente: revista $\mathrm{El}$ jueves ${ }^{72}$

También existen casos de "okupación" por familias con escasos recursos o que han sido desahuciadas y que han encontrado una alternativa en estos lugares, que carecen de los servicios básicos para alcanzar una calidad de vida digna. A este estado de precariedad vital se suma el deterioro y desmantelamiento que han sufrido gran parte de estas zonas debido al paso del tiempo, pero también a hurtos y actos vandálicos. Estos "cadáveres inmobiliarios"73 representan la peor cara de nuestra sociedad, cuyo principal modelo de desarrollo se ha basado en la consideración de la vivienda como un producto, objeto de negocio, y no como un derecho fundamental para los ciudadanos. Se da la paradoja de que en nuestro país existen casi 3,5 millones de viviendas vacías ${ }^{74}$, mientras diariamente escuchamos las dificultades de acceso de la población más joven o historias de familias que no tienen dónde ir. Además España es un país con una de las tasas de natalidad más bajas del mundo: en el año 2014 alcanzó la cifra de 9,14\%o, con un Índice de fecundidad de 1,3275

\footnotetext{
72 http://www.eljueves.es/2013/11/01/como vida una urbanizacion fantasma.html

73 Término utilizado por proyecto colectivo "Cadáveres Inmobiliarios": http://cadaveresinmobiliarios.org/

74 Cifra que no contempla datos de edificios y urbanizaciones a medio terminar.

75 Datos obtenidos de Expansión: http://www.datosmacro.com/demografia/natalidad/espana [Fecha de consulta: 17 de julio de 2015]
} 


\section{ALTERNATIVAS Y OPORTUNIDADES}

Ante este desolador panorama surgen cuestiones relacionadas con nuestras competencias profesionales como ¿Qué hacer con estos nuevos paisajes? ¿Presentan entre sí las mismas características? ¿Cómo afrontar su intervención?. Para resolver estas cuestiones es esencial conocer el número y variedad de casos que existe y, por ello, es preciso su identificación y caracterización. En función de las particularidades de cada ámbito, su localización, estado de desarrollo y de conservación, uso previsto, ocupación, régimen de propiedad, etc. los objetivos de actuación e intervención variarán notablemente. A continuación se exponen algunas alternativas para afrontar este vasto problema.

\section{Inventariado y caracterización}

Leyenda: 6000km (Basurama) Especulación (Ecologistas en Acción) Me-

\section{dit Urban Nación Rotonda Neoruinas (Tenerife) Ruinas modernas}

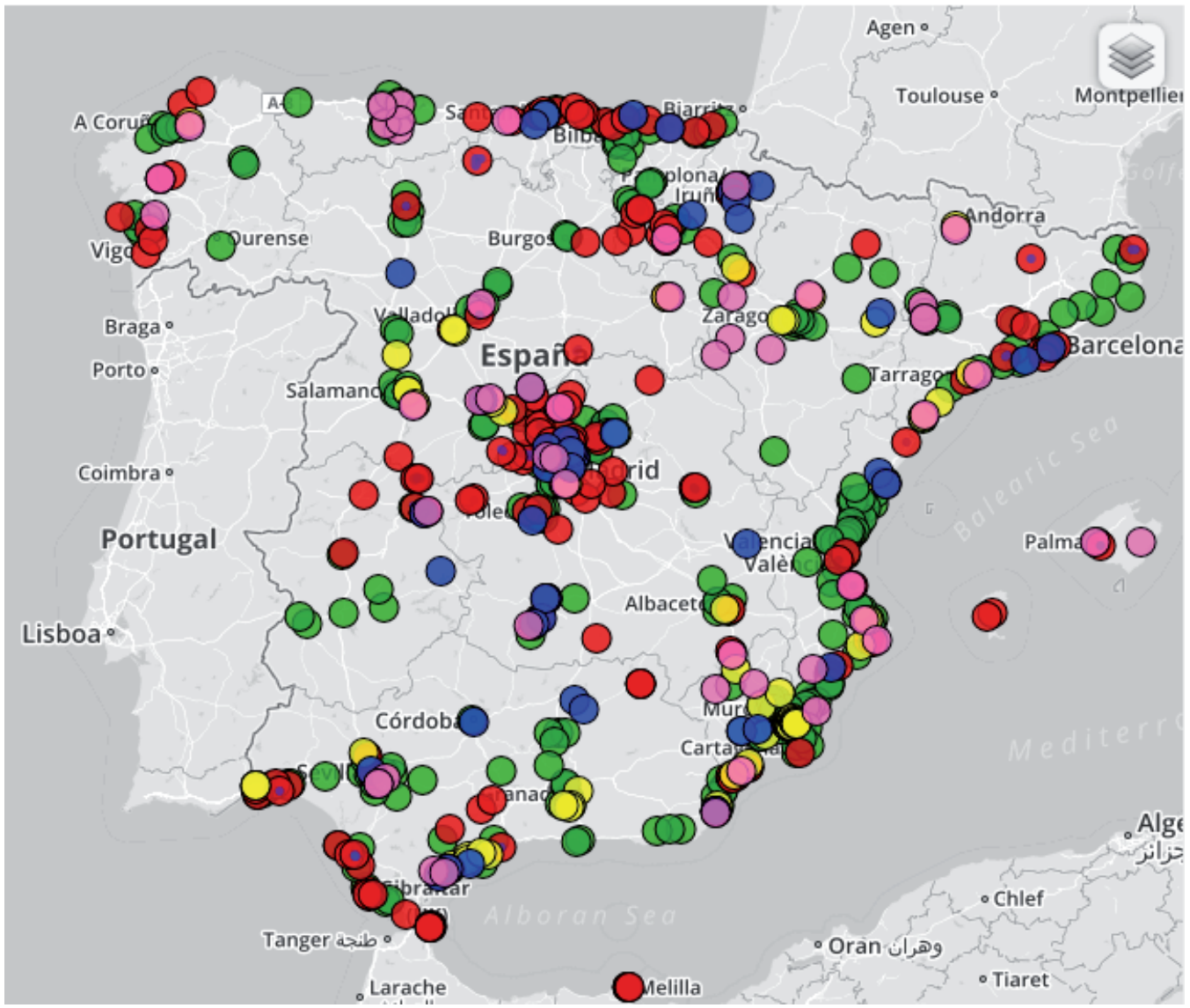

Figura 10. Base de datos post-burbuja

Fuente: Cadáveres Inmobiliarios http://cadaveresinmobiliarios.org/ 
Existen iniciativas cuyo objetivo es comprender y cartografiar la dimensión de la burbuja inmobiliaria española como, por ejemplo, la elaboración de un inventario denominado "Cadáveres Inmobiliarios: Base de datos post-burbuja". Mediante este Sistema de Información Geográfica se ofrecen datos sobre los numerosos casos existentes distribuidos por toda la geografía española. Esta base de datos es completada y mantenida por diversas asociaciones, grupos de investigación y colectivos como Basurama, Ecologistas en Acción, Nación Rotonda, el Grupo de Investigación Medit_Urban, Neoruinas, etc. y también está abierta a la colaboración del público interesado.

\section{Demolición y reposición}

Otra alternativa son las políticas que algunos países aplican a sus ciudades en contracción o menguantes ("Shrinking cities"). Por ejemplo, los planes de demolición de la administración estadounidense para combatir extensas áreas en declive y abandono del noreste del país. La gran diferencia con los crecimientos urbanos de nuestro país es que se abandonaron lugares que nunca fueron habitados, ni siquiera concluidos. Por ello "deberíamos intentar incluir en los planes de nuestras ciudades y en los proyectos de urbanización, la forma de deshacer lo que se propone construir y sus costes ecológicos, ambientales y sociales"76. Existen actuaciones de ámbito local como la de Ses Covetes, al sur de Mallorca, en la que, por resolución del Tribunal Supremo de Justicia de Baleares, el ayuntamiento demolió una urbanización ilegal y actualmente se está finalizando la restauración vegetal de los terrenos. Otro ejemplo, todavía sin ejecutar, es la sentencia del Tribunal Supremo de Justicia de Andalucía, que ordenó la demolición del polémico hotel "Algarrobico", ubicado en Carboneras (Almería) y cuyas obras están paralizadas desde el año 2006. El edificio permanece actualmente en pie y con un coste estimado de demolición de unos 7 millones de euros.

\section{Reactivación}

A día de hoy esta alternativa está siendo liderada por las entidades bancarias, actuales propietarios de urbanizaciones y edificios cuyos dueños iniciales no pudieron hacer frente al pago de hipotecas. También por promotores y grandes inmobiliarias, que han retomado la finalización de conjuntos residenciales paralizados desde hace años. Esta reactivación debería realizarse mediante procesos de gestión que faciliten el acceso de los sectores de la población más débiles, dando prioridad a estas áreas a medio desarrollar antes que plantear nuevos crecimientos urbanos. Aunque la situación periférica de estos lugares, combinada con la falta de vida y servicios, provoca que los bajos precios ofrecidos no sean un aliciente lo suficientemente atractivo para su adquisición.

\footnotetext{
${ }^{76}$ Ciudades Menguantes, El Blog de Fariña: http://elblogdefarina.blogspot.com.es/2015/02/ciudadesmenguantes.html [Fecha de consulta: 22 de julio de 2015]
} 


\section{Reutilización y reciclaje}

Otras actuaciones están dirigidas al aprovechamiento de recursos y energía ya consumida, de cara a la sostenibilidad global del planeta. La idea principal es reciclar y transformar edificios y espacios abandonados en lugares habitables, con nuevos usos. En este sentido existen experiencias que nos pueden servir de referencia, como el caso de la ciudad de Detroit, donde dos emprendedores pretenden aprovechar los terrenos abandonados para crear uno de los huertos urbanos más grandes del mundo. Otra iniciativa en la misma ciudad es la de una empresa que está realizando un "experimento agrícola" introduciendo ganado mediante la compra de varias propiedades para que pueda pastar entre los jardines y edificios abandonados. La gestión y parte de los beneficios repercutirán en personas desempleadas de la localidad 77 . Curiosamente este es el destino al que han sido abocados gran parte de los terrenos urbanizados vacíos de nuestro país.

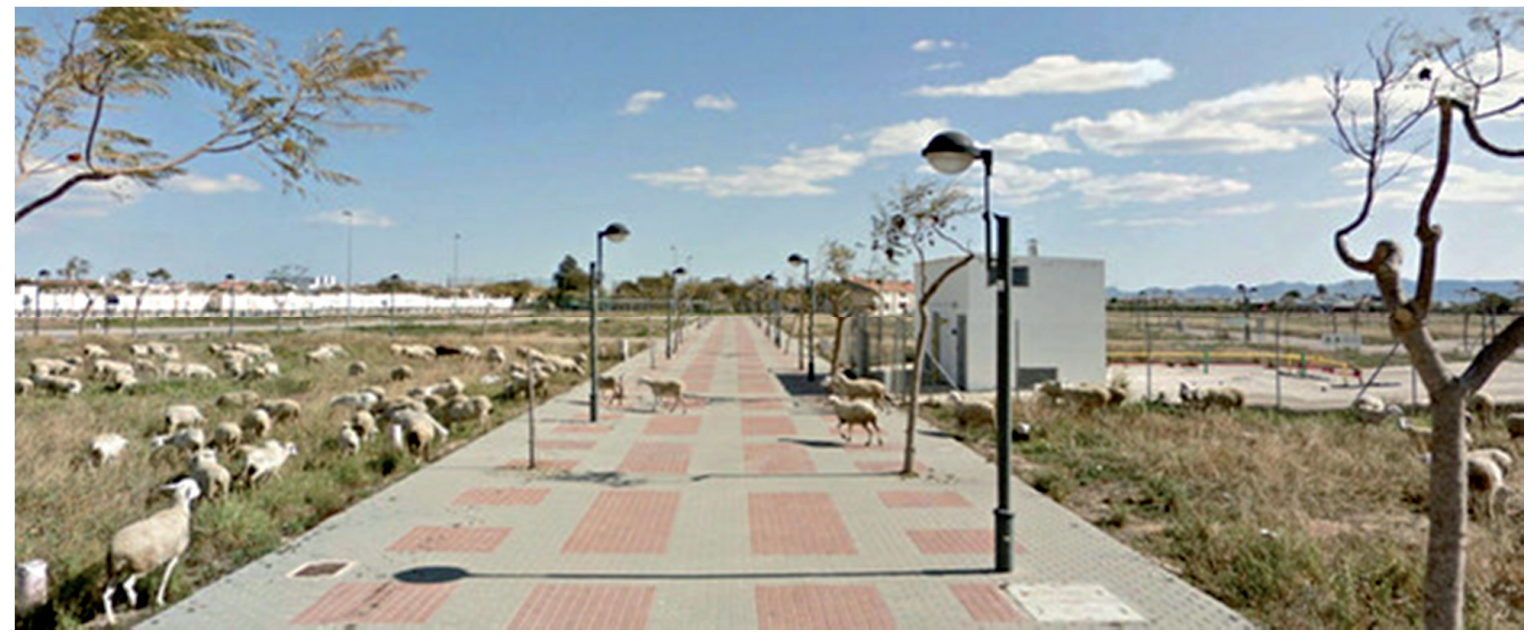

Figura 11. Ganado pastando en terrenos urbanizados vacíos en algún lugar de España Fuente: Nacion Rotonda, http://www.nacionrotonda.com

En España el colectivo Recetas Urbanas ${ }^{78}$ recurre al reciclaje y la reutilización de suelos y edificios vacíos para construir espacios y edificios autogestionados. Otras iniciativas interesantes son las realizadas por el proyecto Esto no es un solar, que se dedica a la recuperación, mantenimiento y reactivación de espacios urbanos abandonados dentro de las ciudades o la promovida por la Red Internacional de Colectivos: Arquitecturas Colectivas, que acaba de publicar una colección de guías para la activación de espacios de estas características: Activar un inmueble en desuso / Protocolo para la activación de vacíos urbanos autogestionados / Guía para la activación del espacio público. ${ }^{79}$

\footnotetext{
77 El Mundo: http://www.elmundo.es/economia/2014/06/09/53920114e2704e5e6f8b4575.html [Fecha de consulta: 10 de julio de 2015]

78 Recetas Urbanas: http://www.recetasurbanas.net

79 Arquitecturas Colectivas:

http://arquitecturascolectivas.net/herramientas/grupos/guias-para-la-activacion-de-espacios-de-aaccversion-para-imprimir
} 
En Madrid, estudiantes de postgrado de la ETSAM han desarrollado una propuesta denominada Splash\#Madrid para la reutilización de un edificio en fase de estructura que fue construido como Centro Acuático para el sueño del "Madrid Olímpico". Las obras se iniciaron en el año 2004 y se paralizaron en 2010, cuando el ayuntamiento ya había invertido 89 millones de euros. Los alumnos proponen un espacio de ocio para los vecinos del Barrio de San Blas, como cines de verano, festivales al aire libre, terrazas, etc., utilizando las parcelas aledañas para jardines y huertos urbanos ${ }^{80}$

La puesta en marcha de actuaciones imaginativas a pequeña escala en este tipo de espacios, podría ser el motor de acciones y sinergias de carácter mucho más amplio.

\section{Reflexiones para el debate}

Los procesos de declive, abandono y transformación de áreas urbanas no son nuevos. La historia de la humanidad ofrece numerosos ejemplos, como el abandono de castillos y ciudades debido a invasiones, epidemias, desastres naturales, etc. Restos urbanos contenidos que fueron procesados por el medio ambiente a lo largo de los años, e incluso incorporados de nuevo al ciclo constructivo mediante su reutilización en nuevos edificios y espacios urbanos. La gran diferencia con los procesos urbanizadores de la última década, es la voracidad y velocidad con la que estos se han producido, provocando que el soporte territorial y la sociedad que lo habita tengan grandes dificultades para asimilarlos, dejando un panorama desolador, con una extensión de notable presencia.

Estos desarrollos urbanísticos se ofrecieron a las comunidades locales como motores de generación de empleo, desarrollo y bienestar, pero se paralizaron bruscamente debido, entre otras causas, a su inviabilidad y a una crisis que dura ya varios años, tiempo que no ha servido para la reflexión sobre lo ocurrido, puesto que la gran mayoría de casos están en barbecho, esperando que vuelvan tiempos "mejores".

De cara al futuro, la formulación de actuaciones para la reactivación y/o recuperación de estos lugares debería tener en cuenta el nuevo panorama socioeconómico generado tras la crisis, así como las múltiples situaciones geográficas y culturales de cada uno de los territorios donde se han generado. Todo ello acompañado por una revisión crítica de los procesos e instrumentos legales, económicos, sociales, etc. que permitieron la creación de estos paisajes de la vergüenza.

${ }^{80}$ Departamento de Proyectos: http://dpa-etsam.com/tag/splashmadrid/ 


\title{
UNA JOYA POCO CONOCIDA (O ELOGIO DE LA INTUICIÓN): LA COLONIA LUKIŠKĖS EN VILNIUS (1911-13)
}

\author{
Javier Ruiz (Dr. Arquitecto - Profesor titular DUyOT)
}

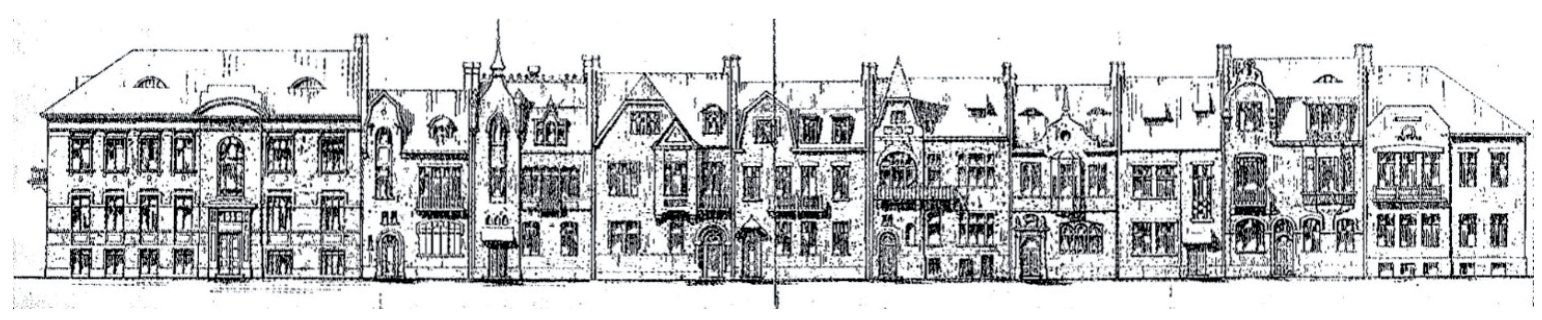

Este modesto texto no pretende ser más que un breve apunte, una reivindicación de una de esas pequeñas joyas urbanas apenas conocida y reconocida, generalmente debido a su condición periférica (lejanía geográfica o del centro del debate urbanístico imperante) o a su sólo aparente falta de pretensión culta, sobrepasada en cualquier caso por sus alcances y logros reales. También pretende, y de ahí el subtítulo "elogio de la intuición", servir de agradecimiento, y nada mejor que para ser incluido en el número con que se alcanza el primer centenar de Ci[ur], al marco que me ha permitido durante todos estos años entrenar la intuición que me permite, entre otras cosas, disfrutar del placer de la experiencia y la práctica del urbanismo. Porque mi descubrimiento de la pequeña joya que aquí presento se produjo, sin mayor expectativa previa, durante un solitario y distraído paseo por la capital lituana entre los dos hoteles que alojaban a los participantes en una conferencia.

La colonia Lukiškès ocupa una pequeña manzana triangular próxima al final de la Gedimino prospektas, la avenida más notable de la Vilnius moderna que parte de su centro histórico. Se trata de un conjunto formado por tres hileras de edificios adosados de manera que casi encierran un pequeño jardín común. Cada edificio ha sido proyectado de manera individualizada, algunos comparten patrones estilísticos en mayor o menor medida, otros presentan formas y funciones más singularizadas. Pese a una media de altura aproximadamente homogénea (tres alturas, a veces construcciones por encima de la cornisa, a veces semisótanos) el conjunto presenta una fascinante heterogeneidad, cabría pensar que más producto del tiempo (diversidad de fechas y autores, diversidad de programas y clientes) que de una voluntad más o menos unívoca.

La pequeña colonia es la mejor conservada de las promovidas por el financiero Juzef Montwill (Juozapas Montvila, en lituano) a principios del siglo XX, insertas en la doble tradición colonia obrera/ciudad jardín. El arquitecto del conjunto ( $y$ de la mayoría de los edificios) es August Klein, de origen germano, sólo algunos edificios proyectados por Wladislaw Stipulowski. Las instrucciones del promotor eran crear vivienda para clases medias y obreras, entremezcladas en un conjunto urbano con espacios libre compartidos. 

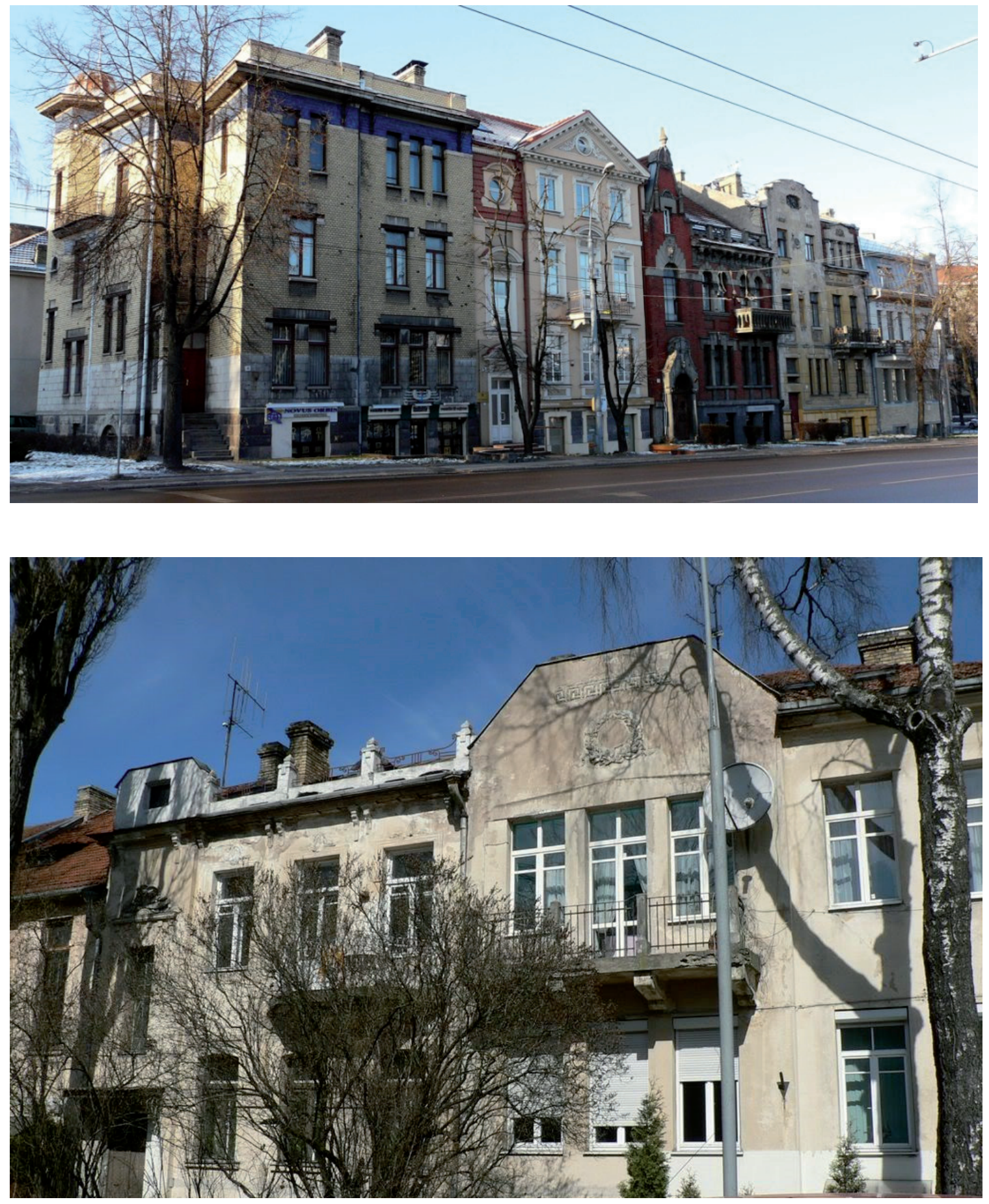

Figura 12. Dos vistas parciales de la colonia lukiškès Fuente: Archivo del autor 
Incluso las construcciones más singulares (el edificio en esquina proyectado por el arquitecto Waclaw Michniewicz para sí mismo) son coproyectadas o supervisado su diseño por Klein, de manera que se salvaguarda la armonía del conjunto en la diversidad pretendida.

Enfoscados rojos, blancos y terrosos, ladrillos vistos de color amarillo, toques de azulejo azul, o verde, cubiertas planas, frontones clásicos, formas románticas y modernistas, torreones, composiciones simétricas y muy complejas, modestia constructiva y ornamento pueden ser rastreados en cada uno de los edificios. El conjunto es, sin duda, magnífico, en su conjunto una lección de un cierto urbanismo que apuesta por la calidad urbana por encima de la rentabilidad económica y simplicidad proyectual/de gestión que por desgracia es ahora norma.

(Fotografías de Javier Ruiz y Silvia Fernández, a quien agradezco el paseo y la panorámica)
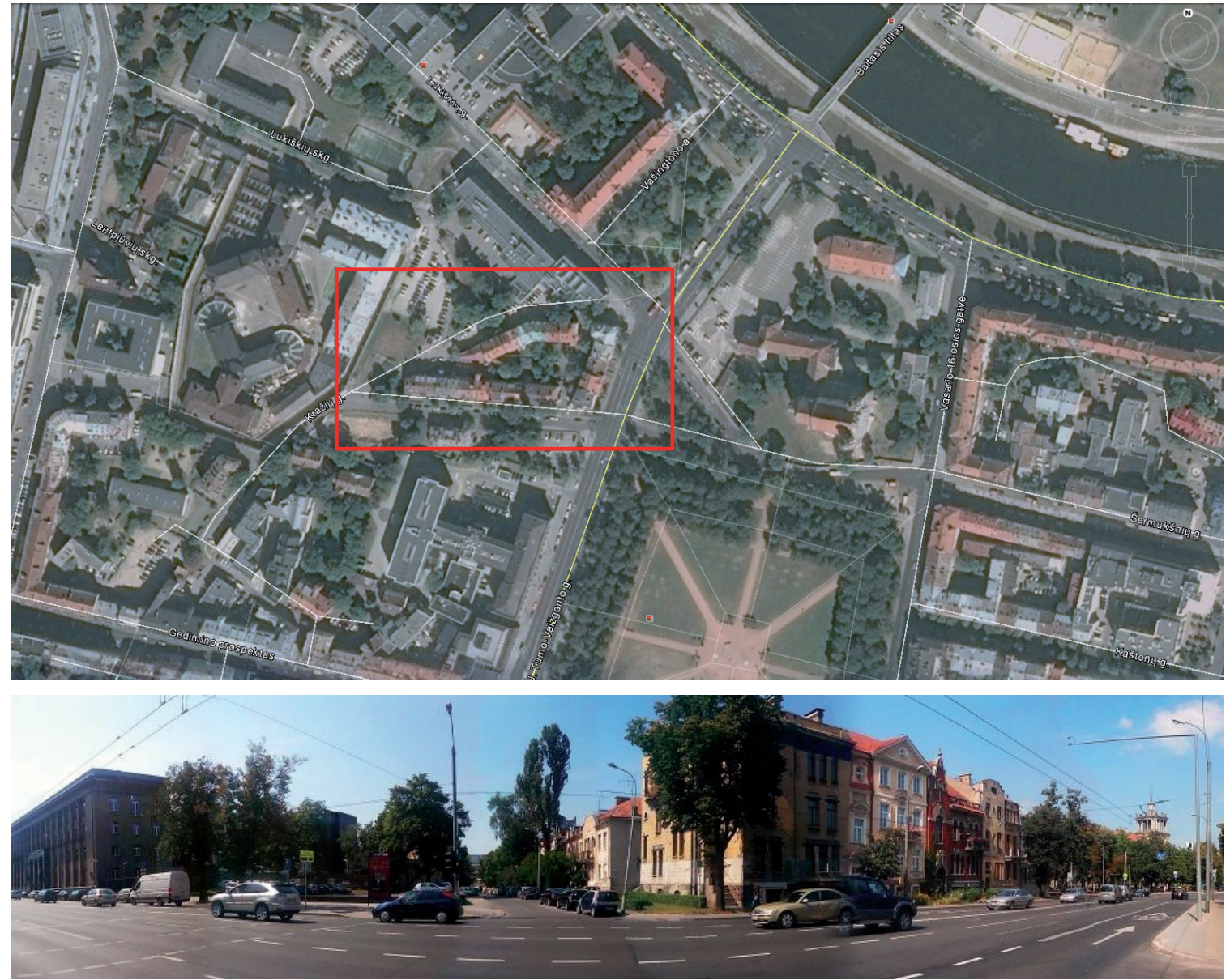

Figura 13. Planta y panorámica del conjunto Fuente: Google Earth y Archivo del autor 


\title{
A LAS PUERTAS DE HÁBITAT III
}

\author{
Julián Salas (Dr. Ingeniero Industrial - Profesor Ad Honorem DUyOT)
}

Nos invita el Dr. Fariña a reflexionar desde nuestras ópticas académicas sobre los veinte años transcurridos desde la creación de Ci[ur], afirmando que: '...desde entonces, han ocurrido cambios muy importantes y acelerados en la forma en la que los ciudadanos vivien sus ciudades como en los rerquisitos que estas deben de cumplir'. Esta es la intención de este trabajo que pretende cubrir cuatro décadas: desde la participación del autor en Hábitat I (Vacouver, 1976), hasta la que pretende que sea su meta profesional: participar en Hábitat III (Quito, 2016).

Lo que hoy conocemos como 'Programa de las Naciones Unidas para los Asentamientos Humanos', comenzó al início se los 1970 como 'Fundación Hábitat', órgano vinculado entonces al Programa de las Naciones Unidas para el Medio Ambiente (PNUMA). En 1976 se llevó a cabo, en Vancouver, Canadá, la Conferencia de las Naciones Unidas sobre Asentamientos Humanos (Hábitat I). En dicho evento, la Fundación Hábitat cambió de nombre y se transformó en 'Centro de las Naciones Unidas para los Asentamientos Humanos' (CNUAH), con sede en Nairobi, Kenia.

Veinte años después, se realizó la segunda Conferencia de las Naciones Unidas para los Asentamientos Humanos (Hábitat II), en Estambul, Turquía y hoy nos convocan a Hábitat III en octubre de 2016 en Quito, Ecuador.

La Declaración de Vancouver comenzaba con un Preámbulo en el que se denunciaba: "...la inaceptable situación de los asentamientos humanos, en circunstancias que son previsibles que puedan agravarse con el crecimiento de la inequidad económica y la actual urbanización descontrolada, a menos que se tomen medidas positivas y concretas a nivel nacional e internacional". La primera acción que debería ponerse en práctica, en opinión de Hábitat I, debería ser: "adoptar políticas de asentamientos humanos audaces, significativas $y$ eficaces $y$ estrategias de ordenación del territorio (...) que tengan en cuenta los asentamientos humanos como instrumento y objeto del desarrollo". Entre los principios generales, la mencionada Conferencia abogó en 1976 por mejorar la calidad de vida a través de una distribución más equitativa de los beneficios del desarrollo, la planificación y regulación del uso del suelo, la protección del medio ambiente, la integración de las mujeres y los jóvenes, y la rehabilitación de las personas desplazadas por catástrofes naturales y de origen humano.

La Declaración de 1976 establecía, que vivienda y servicios adecuados son un derecho humano básico y que los gobiernos deben ayudar a las autoridades locales para que participen en mayor medida en el desarrollo nacional. La Declaración hacía especial hincapié en que "el uso y tenencia de la tierra deben estar sujetos a control público". Veinte años después, 1996, con la participación de la práctica totalidad de jefes de estados y de gobiernos del mundo, con más de diez mil participantes y la abrumadora y activa presencia del 'tercer sector's1 se convocó la segunda Conferencia

81 Ver J. Salas, 'HÁBITAT: El implacable desarrollo del subdesarrollo', Rev. Urban no 3, ETSAM 1999, páginas 53 a 66 
de las Naciones Unidas sobre los Asentamientos Humanos (Hábitat II), en Estambul, Turquía:

'Nosotros, los Jefes de Estado y de Gobierno... aprovechamos la oportunidad de hacer nuestros los objetivos universales de garantizar una vivienda adecuada para todos y de lograr que los asentamientos humanos sean más seguros, salubres, habitables, equitativos, sostenibles y productivos'.

Hoy, al revisar la ingente documentación distribuída 'in situ' en dicha Conferencia, teniendo muy presentes algunas de las nuevas políticas puestas en práctica y analizando realizaciones inspiradas en los principios básicos que allí, en Estambul se discutieron, incluso apasionadamente, nos permitimos recordar algunos de los aportes conceptuales, que puede que para algunos suenen a superados, lo que no nos lo parece. Apuntemos algunos:

- El desarrollo rural y el desarrollo urbano son interdependientes. Debemos ampliar adecuadamente las infraestructuras, los servicios públicos y las oportunidades de empleo en las zonas rurales, a fin de hacerlas más atractivas.

- Se enfatizó el notabilísimo papel encomendado a los municipios y a las autoridades municipales como dinamizadores de la lucha contra el déficit ${ }^{82}$ de viviendas.

- Se reafirmó la voluntad para lograr progresivamente el derecho pleno en favor de la mejora de los asentamientos humanos degradados y la lucha contra la tugurización. En este aspecto, hemos de rememorar el protagonismo de las autoridades municipales participantes, y de forma muy especial, la del entonces Alcalde de Barcelona, Pasqual Maragall en su Discurso de la Apertura de la Conferencia.

- Federico Mayor, en su calidad de Secretario General de UNESCO, defendió en un discurso magistral el derecho universal a una vivienda digna, asequible y adecuada, convocando la activa participación de los sectores públicos y privados y a las organizaciones no gubernamentales, a todos los niveles.

- Defendimos, en nombre del Programa Latinoamericano CYTED ${ }^{83}$, el derecho a un techo, como una condición para el ejercicio de la ciudadanía, ya que, sin un cobijo digno, la familia está más cerca de la condición de sobrevivientes que de la de ciudadanos. La inmensa mayoría de los habitantes del Tercer Mundo nacen y mueren en una vivienda 'no terminada', en algo que no es una vivienda a la usanza del Norte, sino el soporte de un proceso de mutación y mejora continua.

- En Hábitat II, los gobiernos locales fueron reconocidos como uno de los principales socios de ONU Hábitat para la ejecución de las Agendas Hábitat I y Hábitat II: El Programa facilitará el fortalecimiento de las capacidades y

82 'Hambre de Vivienda' fue la expresión que acuñada por el autor, se abría camino entre los 'viviendistas' latinoamericanos. J. Salas: Contra el hambre de vivienda: Soluciones tecnológicas iberoamericanas. Edt. Escala, Bogota. Colombia. 1992.

83 J. Salas, '1987 Año Internacional de las Vivienda para las Personas sin Hogar', EL PAÍS, 12.11.1984. y J. Salas, 'De aquí a 20 años', EL PAÍS, 8.06.1996. 
promoverá la transferencia de tecnologías y conocimientos especializados apropiados.

Estambul finalizó con la siguiente reafirmación de esperanza en el futuro del sector: 'Con esta Conferencia se inicia una nueva era de cooperación, la era de una filosofía de solidaridad. Al acercarnos al siglo XXI, ofrecemos una visión positiva del desarrollo de asentamientos humanos sostenibles, la esperanza de un futuro común y una exhortación a participar en una empresa de indudable valor e interés, la de construir mancomunadamente un mundo en el que todos vivan en un hogar seguro con la promesa de una vida decorosa en condiciones de dignidad, buena salud, seguridad, felicidad y esperanza".

\section{CUARENTA AÑOS DESPUÉS DE HÁBITAT I}

Hábitat I y II se centraron en lo que debería hacerse, como puede comprobarse en las respectivas Declaraciones de Vancouver y de Estambul. Si Hábitat III sigue esta ruta, habrá mucho debate de por qué las ciudades están en el eje de la nueva agenda global, pero también habrá, muchos replanteamientos de cuestiones planteadas en documentos anteriores, ya que 'nuevos' temas como la gobernanza urbana, el papel de los entornos urbanos en el crecimiento económico, la cohesión social, y la adaptación al cambio climático y su mitigación, que hoy necesitan aún más atención.

Hábitat III también tiene que aclarar, por qué el compromiso de los gobiernos con los objetivos de las conferencias anteriores, no consiguieron las respuestas necesarias. Todavía, por ejemplo, hay muchos países en los que más de la mitad de su población urbana carecen de agua corriente.

Los gobiernos locales y regionales sugieren en las reuniones preparatorias de Hábitat III, que hay que centrarlo en quién debe actuar para aplicar las recomendaciones pertinentes de Hábitat I y II y de los próximos 'Objetivos para el Desarrollo Sostenible, 2015-2030'84 y qué apoyo necesitan para poder llevarlos a cabo. Los países que mejor están consiguiendo el cumplimiento de estos objetivos y recomendaciones, son los que cuentan con gobiernos locales más competentes, responsables y con mayores recursos.

84 El 13 de Enero de 2015, Jeffrey Sachs, Director de la SDSN de Naciones Unidas, y Miguel Ángel Moratinos, Presidente del Consejo Asesor de la Española REDS, presentaron en Madrid REDS: su misión, sus objetivos y su perspectiva de futuro: «enredar» a las generaciones futuras para construir un mundo más sostenible.

De los 17 objetivos del SDSN, nos permitimos mencionar, por las múltiples conexiones con la temática de este trabajo, los tres siguientes:

5. Alcanzar la igualdad entre los géneros y empoderar a todas las mujeres y niñas.

6. Garantizar la disponibilidad y la gestión sostenible del agua y el saneamiento para todos.

11. Conseguir que las ciudades y los asentamientos humanos sean inclusivos, seguros, resilientes y sostenibles.

De los 17 objetivos identificados hasta ahora en las negociaciones que están teniendo lugar en Naciones Unidas, la SDSN ha asignado a España la coordinación de tres ámbitos sumamente importantes: 'Energía', 'Género' y 'Agua'. 


\section{ASUNTOS CLAVES EN LA PREPARACIÓN DE HÁBITAT III}

Entre las actividades previas y preparatorias de Hábitat III, a la vista de los documentos editados, aparecen en nuestra opinión, cuatro áreas clave que inciden en la vivienda y en el logro de objetivos de desarrollo sostenible en las zonas urbanas:

a) La gestión de un mundo en constante proceso de urbanización, reforzando la gobernanza local y mejorando la colaboración entre los diferentes niveles de gobierno (nacional, regional, local).

b) Apoyo a los esfuerzos de las ciudades para innovar, construir soluciones creativas para desarrollar el potencial económico de las ciudades, con un efecto multiplicador en toda la nación de mejores condiciones de vida, especialmente para las ciudades con pocos ingresos.

c) Hacer frente a la urgente necesidad de abordar cuestiones de medio ambiente: cambio climático y riesgos de desastres.

d) Fortalecimiento de mecanismos que permitan una verdadera participación de la población en la toma de decisiones y garantizar la rendición de cuentas de los gobiernos a todos los niveles.

Al objeto de vislumbrar los posibles contenidos de Hábitat III, nada nos parece más pertinente que reproducir en la Tabla 1 las 'Áreas, Informes temáticos y Unidades de política' en los que trabaja el Equipo de Soporte Técnico Interinstitucional de las Naciones Unidas sobre los Objetivos de Desarrollo Sostenible.

\begin{tabular}{|c|c|c|}
\hline Áreas & Informes Temáticos & Unidades de Política \\
\hline $\begin{array}{l}\text { 1. Cohesión Social y Equidad } \\
\text { - Ciudades Habitables }\end{array}$ & $\begin{array}{l}\text { 1. Ciudades inclusivas (Género, } \\
\text { Juventud, Envejecimiento) } \\
\text { 2. Migración y refugiados en zonas } \\
\text { urbanas } \\
\text { 3. Ciudades Más Seguras } \\
\text { 4. Cultura Urbana y Patrimonio }\end{array}$ & $\begin{array}{l}\text { 1. Derecho a la Ciudad y Ciudades } \\
\text { para Todos } \\
\text { 2. Marco Urbano Sociocultural }\end{array}$ \\
\hline 2. Entorno Urbano & $\begin{array}{l}\text { 5. Normas Urbanas y Legislación } \\
\text { 6. Gobernanza Urbana } \\
\text { 7. Hacienda Municipal }\end{array}$ & $\begin{array}{l}\text { 3. Políticas Nacionales Urbanas } \\
\text { 4. Gobernanza r Urbana, } \\
\text { Capacidad y } \\
\text { Institucional } \\
\text { 5. Sistema Fiscal Local y Finanzas } \\
\text { Municipales }\end{array}$ \\
\hline 3.Desarrollo del Espacio & $\begin{array}{l}\text { 8. Urbanismo, Ordenación del } \\
\text { Territorio y Diseño } \\
\text { 9.- Áreas, Informes temáticos y } \\
\text { unidades de política Suelo Urbano } \\
\text { 10.- Vínculos urbano-rurales } \\
\text { 11.- Espacio Público }\end{array}$ & $\begin{array}{l}\text { 6- Estrategias urbano-espaciales: } \\
\text { tierras de mercado y segregación }\end{array}$ \\
\hline 4.- Economía Urbana & $\begin{array}{l}\text { 12. Desarrollo Económico Local } \\
\text { 13. Empleo y medios de vida } \\
\text { 14. Sector Informal }\end{array}$ & $\begin{array}{l}\text { 7. Estrategias Urbanas de } \\
\text { Desarrollo Económico }\end{array}$ \\
\hline
\end{tabular}




\begin{tabular}{|l|l|l|}
\hline $\begin{array}{l}\text { 5. Ecología Urbana y Medio } \\
\text { Ambiente }\end{array}$ & $\begin{array}{l}\text { 15. Resiliencia Urbana } \\
\text { 16. Ecosistemas Urbanos y Gestión } \\
\text { de Recursos } \\
\text { 17. Ciudades, Cambio Climático y } \\
\text { Gestión del Riesgos de Desastres }\end{array}$ & 8. Ecología Urbana. Resiliencia \\
\hline $\begin{array}{l}\text { 6. Infraestructura Urbana y } \\
\text { Servicios Básicos }\end{array}$ & $\begin{array}{l}\text { servicios básicos, incluida la } \\
\text { energía } \\
\text { 19. Transporte y Movilidad } \\
\text { 20. Vivienda } \\
\text { 21. Ciudades Inteligentes } \\
\text { 22. Asentamientos Informales }\end{array}$ & 9. Servicios Urbanos y Tecnología \\
\end{tabular}

Figura 14. Áreas, informes temáticos y unidades de política ${ }^{85}$

Fuente: autor

\section{El implacable desarrollo del subdesarrollo: probable contexto HÁBITAT III}

Se prepara Hábitat III en un contexto cosmopolita de necesidades abrumadoras en materia de hábitat. Sin ánimo catastrofista y tratando en la medida de lo posible de basarnos en valores cuantitativos fiables, recogeremos seguidamente algunos hechos de contexto que estimamos destacables. La desigualdad desarrollo-subdesarrollo en materia de asentamientos humanos, cuantificada a nivel planetario con motivo de Hábitat I, ocasionó una extrema perplejidad cosmopolita y propició que se evaluasen con mayor detalle y continuidad, especialmente en los Informes del PNUD, la evolución de los resultados en materia de Habitabilidad Básica ${ }^{86}$. Súbitamente, sin más fundamento que la constatación de que no se habían cumplido las previsiones catastrofistas para las grandes urbes emanadas hace cuarenta años de Hábitat I (Vancouver, 1976), se abrió camino una nueva forma de ver lo urbano, de valorar la ciudad, incluso las ciudades millonarias en ciudadanos. Durante las últimas décadas del pasado siglo la urbanización creciente y las migraciones internas merecieron diagnósticos sumamente perniciosos. Con posterioridad, los planificadores urbanos trataron $^{87}$ de comprender en vano las razones por las que decenas de millones de habitantes optaban decididamente por hacinarse en México D. F., Sao Paulo, Shangai, Calcuta, Buenos Aires, Bombay... Coincidimos con la insistente recomendación, en la preparación de Hábitat III por corregir el público meta de sus trabajos y conclusiones. Si bien es cierto que sus destinatarios oficiales siguen siendo los gobiernos nacionales, se reconoce que la principal causa de algunos de los fracasos de Hábitat II (1996) fue el no percatarse de la necesidad de establecer alianzas más sólidas con el poder local y con las ONGs, fortaleciendo la capacidad de actuación de las organizaciones comunales y grupos vecinales para dirigir estos problemas globalmente. Recomendación que emana con fuerza de las conclusiones de Hábitat II.

\footnotetext{
85 Toward Habitat III World cities at a Crossroads; $\neq$ Cities WeWant $\neq$ HABITAT III

${ }^{86} \mathrm{El}$ sintagma 'Habitabilidad Básica' lo acuñaron y definieron, Colavidas y Salas en 1993 como:'... es la que colma las necesidades esenciales de cobijo que tenemos todas las personas. Su satisfacción requiere, pues, que se cubran las urgencias residenciales del vivir: no sólo las que conciernen al mero cobijo individual, sino también a los espacios públicos, las infraestructuras y los servicios elementales que constituyen, en conjunto, un asentamiento propicio para la reproducción vital'.

87 United Nations Centre for Human Settlements (HABITAT): Informe Mundial sobre los Asentamientos Humanos. ISBN 92-1-331015-3.
} 


\begin{tabular}{|c|c|c|c|}
\hline & HABITAT I & HABITAT II & HABITAT III \\
\hline Año de celebración & 1976 & 1996 & 2016 \\
\hline Lugar de celebración & Vancouver (Canadá) & Estambul (Turquía) & Quito (Ecuador) \\
\hline Población Mundial & 4.068 millones & 5.674 millones & (2015) 7.376 millones \\
\hline $\begin{array}{l}\text { Población urbana } \\
\text { porcentual mundial }\end{array}$ & $37.9 \%$ & $45.1 \%$ & $54.5 \%$ \\
\hline $\begin{array}{l}\text { Población viviendo en } \\
\text { tugurios }\end{array}$ & (Sin datos fiables) & (año 2000): 776,7 millones & (año 2014): 1.125 millones \\
\hline $\begin{array}{l}\text { Inequidad: } 20 \% \text { de } \\
\text { población más rica / } \\
20 \% \text { de población más } \\
\text { pobre }\end{array}$ & $\begin{array}{l}\text { (1960) 30,5 veces más } \\
\text { ricos }\end{array}$ & $\begin{array}{l}\text { (1989) 59,1 veces más } \\
\text { ricos }\end{array}$ & $\begin{array}{l}\text { (2000) 78, } 2 \text { veces más ricos. } \\
\text { NOTA: El } 1 \% \text { ( } 7,2 \text { Millones) } \\
\text { de los habitantes más ricos } \\
\text { del mundo acaparan una } \\
\text { riqueza igual al } 99 \% \text { de } \\
\text { población restante. }\end{array}$ \\
\hline
\end{tabular}

Figura 15. Datos del 'contexto' previsible en el que se desarrollará Hábitat III

Fuente: el autor, en base a información del PNUD, OXFAM - Intermón; Programa CYTED ${ }^{88}$

La situación universal del hábitat hoy, 2015, en modo alguno podría calificarse de aceptable ni tampoco de esperanzadora, puede que ese pesimismo realista fuese la principal causa de la convocatoria de HÁBITAT I. Seguidamente analizaremos algunos hechos y datos, pero las perspectivas para HABITAT III no son halagüeñas, aunque en nuestra opinión se siguen ensalzando algunos datos 'menos malos' (fundamentalmente expresados en valores porcentuales) y silenciando otros realmente más que preocupantes (generalmente expresados en valores absolutos), puede que con la intención de inyectar ánimo positivo.

\section{Hechos de extraordinaria importancia acaecidos en el sector entre 2000- 2015:}

\section{- 2007}

La población urbana mundial sobrepasó a la población rural. La humanidad ha sido testigo de uno de los eventos más significativos de su historia: El Homo Sapiens se ha convertido en un Homo Urbanus. El que la ciudad haya vencido cuantitativamente al mundo rural es un hecho remarcable, si se tiene en cuenta que tan solo hace 200 años la existencia humana era fundamentalmente rural, con tan solo un $3 \%$ de la población del planeta residiendo en áreas urbanas ${ }^{89}$. El presente es urbano y el futuro lo será cada vez más. Incluso las sociedades menos avanzadas de África y Asia se urbanizan rápidamente y se espera que para el año 2030 no haya un solo continente cuya población sea predominantemente rural.

88 CEPAL: Alojar el Desarrollo: Una tarea para los asentamientos humanos. Documento LC / L906. CONF.85 / 3 . Ver Actas de la Reunión CYTED: Iberoamérica ante HABITAT Il. Ministerio de Vivienda de España.

89 Eduardo López Moreno Ciudad ONU-Hábitat. Desanimo o Esperanza en un Mundo de Realidades Contrastadas. CIUDAD SOSTENIBLE: LOS RETOS DE LA POBREZA URBANA. II Congreso Internacional de Desarrollo Humano. Madrid - 22 y 23 de abril de 2009 
Para el año 2050, seis de cada diez habitantes del orbe serán urbanos. Como puede verse en la Tabla 2, la población urbana crece de forma muy notable.

\section{- 2011}

El Programa del PNUD anunció oficialmente que el mundo acababa de superar los 7.000 millones de habitantes, información nada baladí si se tienen presentes algunos datos de contexto como: que hasta 1814 el mundo no alcanzó los 1.000 primeros millones de habitantes, y que cada día, alrededor de 193 mil personas se agregan a la población urbana del mundo, un poco más de dos por segundo, del orden de 72 millones de crecimiento 'neto' anual. Sin catastrofísmo, pero sí preocupado por lo que la reciente noticia bien documentada representa ${ }^{90}$, hemos de señalar que previsiones científicamente justificadas con un $95 \%$ de probabilidad anuncian que la población en el 2050 será de 9.000 millones de habitantes y que, contra todos los pronosticos fiables 'hasta el momento', la población mundial oscilará entre 9.000 y 13.200 millones de habitantes en el año 2100.

\section{- 2015}

El 1\% de los habitantes más ricos del mundo (7, 2 millones) acaparan una cantidad de riqueza igual a la del $99 \%$ de la población restante $(7.128 \text { millones })^{91}$. En opinión de Joseph Stiglitz ${ }^{92}$ "La extrema desigualdad en términos de renta y riqueza que existe actualmente en gran parte del mundo es perjudicial para nuestra economía y nuestra sociedad, y socava nuestra política. Si bien esta situación debería preocuparnos a todos, lo cierto es que son las personas más pobres quienes más la sufren: no solo sus vidas se ven afectadas por una gran inequidad, sino que también carecen, en gran medida, de igualdad de oportunidades. El informe de Oxfam nos recuerda, en un momento muy oportuno, que cualquier iniciativa que realmente pretenda erradicar la pobreza debe hacer frente a las decisiones sobre políticas públicas que generan y perpetúan la desigualdad."

\section{- 2000-2015}

El numero de habitantes viviendo en tugurios era en el año 2000 muy superior a los 923 millones que contabilizó y difundió los 'Objetivos del Milenio', ya que sólo se refería a la población urbana. Hoy, pese al éxito cierto que anuncia NNUU asegurando que las previsiones de la Meta 11 de los Objetivos del Milenio se han superado en un $220 \%$, hoy, hay más de 2.000 millones de personas (urbanas y rurales) viven en tugurios ${ }^{93}$. ONU-Hábitat en su informe bienal para 2010: 'Estado de las Ciudades del Mundo 2010/2011: Reducir la Brecha Urbana', dice que los 22 millones de personas de países en desarrollo que han dejado de vivir en barrios de tugurios cada año entre 2000 y 2010 lo hicieron gracias al mejoramiento de estos barrios. Aunque sea una buena nueva, todavía es necesario un mayor esfuerzo para la reducción general de la brecha urbana mundial, ya que en realidad el "número absoluto" de habitantes urbanos en tugurios tugurios ha aumentado: de 776,7 millones en 2000 a unos 827,6 millones en 2010.' Parece necesario insistir,

\footnotetext{
90 Sarah C. P. Williams, Univ. Univ. Washington, UW Seattle, Rev. Science 19.09.2014

${ }^{91}$ Informe Mundial OXFAM-INTERMÓN sobre Inequida, 13.01.2015.

92 Joseph Stiglitz, professor de la Universidad de Columbia y premio nobel de Economía

93 J. Salas, ponencia: 'The Informal Habitat Sector: the most important absentee at World SB14', Barcelona 'SB14', 29.10.2014.
} 
que esta cita, cierta, se refiere únicamente a tugurios urbanos, y que nuestro trabajo detalla el total de personas tugurizadas en el mundo.

\section{- 2000-2015}

El deterioro global de la 'Habitabilidad Básica' en valores absolutos sigue creciendo paulatinamente en lo que ha transcurrido del siglo presente. El concepto de 'Habitabilidad Básica' hace su camino, y resulta más que nunca necesario denunciar que cada vez son más los que no tienen 'vivienda' ni tan siquiera 'Habitabilidad Básica'. Intentemos acercarnos a 'contar' cuantos son los habitantes que no tienen Habitabilidad Básica, en el supuesto que estimamos plausible que lo son gran parte de los que viven en tugurios (urbanos y rurales) y los alojados o acogidos en campamentos de refugiados.

- El suministro de agua. El número de habitantes que hoy cuentan con suministro de agua, ciertamente ha crecido extraordinariamente desde el 2000, pero los problemas debidos al agua han aumentado. Según Ban Ki-Moon, Secretario General de Naciones Unidas: 'Es inaceptable que cerca de la mitad de la población de los países en desarrollo tenga problemas de salud provocados por deficiencias en materia de agua o que los habitantes de los barrios marginales paguen cinco e incluso diez veces más por el agua que consumen que los residentes ricos de las grandes ciudades'. Es más que evidente, que el abastecimiento sostenible de agua potable, junto con un alcantarillado e higiene adecuados, conforman la línea de vanguardia en el combate contra las enfermedades y la muerte vinculadas al agua.

- Letrinas y saneamiento. Aunque es cierto que según datos de NNUU que entre 2000 y 2011, unos 1.900 millones de personas tuvieron acceso a nuevas letrinas, inodoros u otras instalaciones de saneamiento mejoradas, resulta inadmisible que más de 1.000 millones de personas residentes en comunidades rurales carezcan de retretes y tengan que defecar al aire libre.

- Cocinas y fogones. 'El 39\% de la población mundial utiliza la biomasa como fuente de energía para cocinar y calentarse ${ }^{\prime 94}$. Por otra parte, la exposición al humo de la cocina es el cuarto riesgo para la salud en el mundo, causando más de cuatro millones de muertes al año.

- Techos y suelos. El uso de mosquiteras y lonas, así como la no utilización en cubiertas de elementos con asbesto, son precauciones claramente recomendables para eliminar la malaria y la asbestosis. Los pavimentos a base de tierra compactada resultan altamente peligrosos.

Coincidimos con Jeffrey Sachs cuando afirma en su libro 'El Fin de la Pobreza' que: "Cada año sucumben a la malaria más de un millón de niños africanos, quizá hasta tres millones. Esa catástrofe espantosa sucede a pesar de que la enfermedad se puede prevenir en parte por medio del uso de mosquiteras, lonas plásticas impermeables $y$ otros controles ambientales...no existe ninguna excusa que justifique que esa enfermedad se cobre millones de vidas todos los años."

94 Global Alliance for Clean Cookstoves, 2013. 


\title{
LO COMÚN Y SU DESMANTELAMIENTO
}

\author{
Álvaro Sevilla Buitrago (Dr. Arquitecto - Profesor contratado Doctor DUyOT)
}

Los cambios recientes en la producción del espacio deben entenderse en el marco de la reestructuración económico-política post-1989/1991; a su vez, el sentido de ambos procesos se revela más nítidamente si los contextualizamos en ciclos históricos más amplios (Harvey, 2005). En esa perspectiva tanto la crisis actual como la etapa de "apogeo" precedente, con todas sus implicaciones territoriales y espaciales, pueden concebirse como una fase avanzada de la agenda de políticas neoliberales inaugurada en la década de 1970 - en particular, en relación a las políticas urbanas, en el episodio fundacional de la crisis fiscal de la ciudad de Nueva York (Tabb, 1982). Se abre aquí un nuevo régimen de gobernanza local sustentando en los principios de austeridad fiscal, desmantelamiento de los acuerdos regulatorios del fordismokeynesianismo y ampliación de las prerrogativas de actores corporativos en la administración y la actividad urbanística (Harvey, 1989). Junto a la progresiva globalización de las cadenas productivas, la expansión de las telecomunicaciones y redes logísticas, y la financiarización de volúmenes crecientes de actividad económica, esta reestructuración de la gobernanza y la economía locales constituye uno de los pilares básicos de un orden que sigue vigente hoy día. Motor proteico de esa nueva economía política, las ciudades y ciudades-región -y por tanto las políticas y programas urbanísticos - han cobrado un papel protagonista, a medida que las agendas económicas nacionales se re-escalaban para aprovechar las ventajas competitivas de sus activos territoriales más estratégicos en un nuevo mapa de lucha global por la localización de capitales (Brenner, 2004; Brenner \& Theodore, 2002).

Pero, según ciertos observadores críticos, esta fase se ha caracterizado además por un elemento menos obvio pero aún más inquietante (Harvey, 2006; Negri \& Hardt, 2009). Enfrentado al agotamiento de sus estrategias de expansión tradicionales, el nuevo capitalismo global -y su expresión urbana- estaría sosteniendo su necesidad estructural de ampliación constante gracias a la reactivación del viejo mecanismo de 'acumulación por desposesión' - una acumulación de capital realizada no a través del ciclo productivo convencional, sino directamente por extracción, esquilmación o apropiación forzosa de riquezas comunes, bien presentes en la naturaleza, bien creadas colectivamente y al margen del mercado. En realidad este procedimiento de depredación de los comunes para su mercantilización es inherente al sistema, como muestran las clásicas campañas de eliminación de tierras y derechos comunales en sucesivos contextos y episodios históricos (Sevilla-Buitrago, 2012a). Pero el régimen neoliberal agudiza esta dinámica, trastocando el enfoque relativamente apaciguador de los equilibrios fordistas-keynesianos durante los Treinta Gloriosos. Junto a la creciente preeminencia de lo urbano y sus políticas en el nuevo marco regulatorio, este aspecto interpela directamente a nuestra disciplina - efectivamente, como en episodios pretéritos de 'cercamiento' (enclosure) y expolio de los comunes, la propia producción del espacio y las políticas de reestructuración urbana y territorial sirven de vehículo clave en estos procesos (Sevilla-Buitrago, 2015a). 
El común tiene una base espacial fundamental que implica a las técnicas espaciales en su desmantelamiento. Sus formas más rudimentarias aparecen en torno al aprovechamiento colectivo de recursos naturales, a través de ensamblajes sociomateriales - de la comunidad primitiva al asentamiento rural-que desarrollan instituciones y formas jurídicas para organizar espacialmente el uso de los recursos de forma que sean sostenibles en el tiempo (Ostrom, 1990). La organización comunal del cultivo, el usufructo de bosques, baldíos, reservas hídricas y acuíferos, etc. han constituido históricamente ejercicios de micro-ordenación del territorio a escala local que terminaban generando paisajes y patrones de asentamiento específicos. Como en estas formas "simples" de común, encontramos también producciones particulares de nuevos espacios sociales en las formas más complejas de creación de riqueza colectiva características de los entornos urbanos (Hardt, 2010). Las expresiones culturales que vemos nacer en estos contextos tienen a menudo un origen ajeno 0 , incluso, antagónico respecto a las leyes de mercado. Se trata de un arco amplio de manifestaciones que van de la cultura cotidiana del barrio popular -tejida históricamente de tácticas colectivas de subsistencia y apoyo mutuo- a las nuevas formas de organización cooperativa del trabajo y el consumo, a las vanguardias artísticas alternativas o los centros sociales autogestionados.

El nexo espacial es aún más obvio en los procesos de destrucción de las formas de organización comunal. He defendido desde hace tiempo la necesidad de revisar la historia de la planificación espacial desde esta perspectiva, leyendo a contrapelo el pasado de nuestras técnicas para mostrar su papel central en los procesos de desposesión que han apuntalado sucesivas formaciones territoriales del capitalismo (Sevilla-Buitrago, 2012b): desde la eliminación de tierras comunales en sociedades preindustriales a las reestructuraciones de centros urbanos y los programas de reforma del XIX, a los nuevos imaginarios de un urbanismo capaz de refigurar integralmente el hábitat cotidiano en el siglo XX. La labor de desposesión ha atravesado todo tipo de declinaciones: del desplazamiento crudo al disciplinamiento travestido de servicio asistencial, o la seducción material y simbólica a través de nuevos mundos urbanos sustentados en el consumo de masas. Es común a todas ellas la movilización de herramientas de diseño y regulación espacial para un ejercicio de erosión y desmantelamiento paulatino de arreglos socioespaciales que generaban formas de riqueza y bienestar colectivo organizados de forma autónoma y al margen del mercado; arreglos, hay que añadir, que otorgaban grados de libertad e independencia relativa respecto a las formas de relación social y uso del espacio dominantes bajo el capitalismo.

En las décadas de 1970 y 1980 esta tendencia se manifiesta a diversas escalas de la práctica urbanística. Entre lo local y lo nacional se forja un nuevo régimen de empresarialismo urbano y desmantelamiento de activos públicos que inaugura la cadena de privatizaciones y mercantilizaciones de servicios e infraestructuras vertebradores en la ordenación del territorio fordista. En distintos contextos nacionales y a distintos ritmos la vivienda social, el equipamiento energético, los servicios de comunicaciones, el abastecimiento de agua y depuración de residuos, la seguridad ciudadana, etc., son presa de un proceso que produce el aumento de las desigualdades socioespaciales conforme se abandonan las viejas estrategias keynesianas de reequilibrio territorial (Brenner, 2004; Harvey, 2005). Más recientemente, la esquilmación de los recursos naturales y el deterioro del medio han 
sido refigurados en la matriz neoliberal, mercantilizando su gestión y protección, por ejemplo, en el nuevo marco de los servicios de los ecosistemas. En la escala infralocal la mayor expresión de los procesos de desposesión y desplazamiento tras la década de 1970 son las dinámicas de gentrificación que comienzan a proliferar en áreas deprimidas de la ciudad consolidada (Smith, 1996). Desde la perspectiva aquí propuesta, estos procesos deben entenderse como actos de apropiación corporativa de valor creado en común, a medida que los operadores inmobiliarios descubren las ventajas diferenciales de una inversión en espacios recualificados espontáneamente por otros agentes sociales y dotados de un atractivo intrínseco y hasta ese momento extra-mercantil en razón de su posición de centralidad, sus valores históricos, su dinamismo sociocultural, etc. Si en la década de los 1980 encontramos generalmente iniciativas privadas apoyadas por la administración pública y articuladas en formas urbanísticas "blandas", a partir de los 90 dicha estrategia es promovida activamente por instituciones estatales a distintas escalas - de lo local a lo nacional e, incluso, supranacional, como en el caso de la UE- a través de una nueva generación de planes y programas integrales para un mal entendido renacimiento o regeneración urbana. Mezclado con el particular elogio del "emprendimiento" y la "innovación", esta pauta ha cristalizado en la última década en acciones concertadas de estímulo a la llamada "clase creativa" para la dinamización económica y cultural de barrios degradados, a menudo espacios residenciales de una languideciente clase trabajadora industrial (Peck, 2005).

Junto a la mercantilización de la capacidad de los ciudadanos para reimaginar la ciudad encontramos otros fenómenos que redundan en esta apropiación aparentemente exhaustiva de riquezas colectivas: el patrimonio -desustanciado de su espesor histórico y depurado como reclamo turístico- o la participación -cooptada por la administración pública en un tono celebratorio/festivo en beneficio de operadores inmobiliarios y dinamizadores culturales- avanzan como nuevas fronteras en la articulación de un urbanismo que parece movilizarse íntegramente para ofrecer nuevos nichos de acumulación. Finalmente el espacio público, símbolo central de la diversidad social y el derecho a la ciudad, aparece cercado y asediado desde multitud de flancos, desde la comercialización esporádica a la privatización cruda, pasando por distintos mecanismos de bloqueo y vigilancia de su potencial democrático (Mitchell, 2003). Es aquí, sin embargo, donde encontramos un ejemplo claro de los movimientos que intentan contrarrestar estos procesos de acumulación por desposesión de base espacial. La oleada de movilizaciones sociales desde 20101 ha girado de forma doble en torno a la posibilidad de una alternativa que conserve lo común como aglutinador social (Sevilla-Buitrago, 2015b). Por un lado, por supuesto, estas protestas han reivindicado la protección de derechos sociales que, bajo la tormenta de la austeridad, aparecen como plataformas mínimas de bienestar colectivo. Pero por otra parte las ocupaciones del espacio público expresan lo común de un modo que revela de nuevo su inescindible sustrato espacial: en su prefiguración del nuevo orden que aspiran a alcanzar, las tomas del espacio público, acampadas y concentraciones, materializan ya esa alternativa a través de una producción espontánea pero regulada de un espacio autónomo autogestionado. Un urbanismo que pretenda romper su vinculación histórica con el desmantelamiento de los comunes para involucrarse en un posible cambio de régimen debe aprender de estas micro-ordenaciones del espacio y concentrar sus energías en idear técnicas capaces de reforzarlas, popularizarlas y generalizarlas. 


\section{REFERENCIAS BIBLIOGRÁFICAS}

Brenner, N. (2004) New State Spaces: Urban Governance and the Rescaling of Statehood. New York: Oxford University Press.

Brenner, N. \& Theodore, N. (2002) "Cities and the geographies of 'actually existing neoliberalism'", Antipode 34, pp. 349-379.

Hardt, M. (2010) "The common in communism", en C. Douzinas and S. Žižek (eds.) The Idea of Communism, New York: Verso, pp. 131-144.

Harvey, D. (1989) "From managerialism to entrepreneurialism: the transformation in urban governance in late capitalism", Geografiska Annaler, Series B, Human Geography 71, pp. 3-17.

Harvey, D. (2005) A Brief History of Neoliberalism. New York: Oxford University Press.

Harvey, D. (2006) "Neo-liberalism as creative destruction", Geografiska Annaler. Series B, Human Geography 88, pp. 145-158.

Mitchell, D. (2003) The Right to the City: Social Justice and the Fight for Public Space. New York: Guilford Press.

Ostrom, E. (1990) Governing the commons: the evolution of institutions for collective action. Cambridge: Cambridge University Press.

Peck, J. (2005) "Struggling with the creative class", International Journal of Urban and Regional Research 29, pp. 740-770.

Sevilla-Buitrago, A. (2012a) "Territory and the governmentalisation of social reproduction: parliamentary enclosure and spatial rationalities in the transition from feudalism to capitalism", Journal of Historical Geography 38, pp. 209-219.

Sevilla Buitrago, A. (2012b) "Urbanismo y reproducción social. Una introducción a su historia", Cuadernos de investigación urbanística 80.

Sevilla-Buitrago, A. (2015a) "Capitalist formations of enclosure: space and the extinction of the commons", Antipode, doi: 10.1111/anti.12143.

Sevilla-Buitrago, A. (2015) "Outraged spatialities: the production of public space in the \#spanishrevolution", ACME: An International E-Journal for Critical Geographies 14. Online: http://ojs.unbc.ca/index.php/acme/article/view/1141/909.

Smith, N. (1996) The New Urban Frontier: Gentrification and the Revanchist City. London: Routledge.

Tabb, W. (1982) The Long Default. New York City and the Urban Fiscal Crisis. New York: Monthly Review. 


\title{
LA CONSOLIDACIÓN DEL PROCESO DE GENERACIÓN DE DESIGUALDAD SOCIAL EN LOS SISTEMAS URBANOS CONTEMPORÁNEOS. LA CIUDAD NEGOCIO.
}

\author{
Alejandro Tamayo Palacios (Dr. Arquitecto - Profesor asociado DUyOT)
}

La observación del espacio social de las periferias construidas durante las últimas décadas en las ciudades occidentales muestra importantes diferencias entre éstos ámbitos y la ciudad tradicional en cuanto a la segregación social del territorio. Frente a unos tejidos donde convivían, incluso en los mismos edificios, población de muy diferente condición, las periferias actuales muestran una gran diferenciación entre las clases de barrios. Esta constatación nos indica que el desarrollo de los sistemas urbanos postfordistas contiene un proceso de segregación social del territorio de una dimensión sin precedentes. La cuestión no es nueva, desde el siglo XIX es comúnmente aceptado que las transformaciones urbanas han ido de la mano, generalmente, de una reordenación espacial de la población, pero la escala de este proceso en las últimas décadas si es algo destacable. Para abordar esta cuestión se plantea en este artículo que el fenómeno descrito tiene que ver con la natural deriva de las ciudades de un sistema capitalista que se desarrolla sobre el territorio a través de un modelo inmobiliario que, para poder funcionar, necesita reproducir la estructura social existente mediante una oferta muy jerarquizada y ordenada que debe ser percibida en estos términos.

\section{EL MODELO INMOBILIARIO Y LA REPRODUCCIÓN SOCIAL}

En cuanto a la natural deriva de los sistemas urbanos contemporáneos hacia la clasificación y ordenación de la población en el territorio habría que señalar dos aspectos muy importantes que se encuentran estrechamente vinculados: el modelo inmobiliario y la estructura social. No se pretende plantear en este artículo que quien determina el proceso descrito sea el modelo inmobiliario, sino que la materialización a través de éste, condicionada por sus mecanismos de funcionamiento, consolida físicamente un fenómeno que tiene sus raíces en la reproducción de la estructura social. Se trataría de un fenómeno de materialización espacial de la estructura de clases que conforma la población. Dentro de este proceso de reproducción social la necesidad actual de que la población se sitúe sobre el territorio de forma clara y ordenada tiene mucho que ver con los mecanismos de funcionamiento de un sistema capitalista sustentado en el sector financiero. En este sentido, la única forma de garantizar a medio plazo las inversiones inmobiliarias encargadas de materializar el desarrollo de las ciudades, es a través de una ordenación espacial de las promociones muy precisa. Así, el desarrollo inmobiliario "culpable" de la forma en que han crecido los sistemas urbanos contemporáneos se encuentra condicionado por un sector financiero que obliga a la clasificación del territorio ${ }^{95}$. Por otro lado la reproducción de la estructura social en un dibujo que incorpore todos los niveles de las jerarquías

\footnotetext{
95 Respecto a la vinculación entre el modelo inmobiliario y el sector financiero es importante señalar como la legislación española incorporó entre 1956 y 1966 leyes que permitieron financiar operaciones inmobiliarias y facilitaron la venta de pisos individuales en edificios aún sin construir y regularon la inscripción de estos procesos.
} 
existentes tiene que ver con otro requisito de los desarrollos inmobiliarios. En un contexto de promoción residencial basado en la venta financiada de viviendas sólo es posible asegurar el negocio inmobiliario si existe una clara correspondencia entre la capacidad de endeudamiento de la población, traducidos en un entorno de cierta estabilidad en sus niveles de renta, y los precios de la vivienda. No obstante, habría que volver a incidir en que sólo se entiende el papel desempeñado por los sectores financiero e inmobiliario y la dimensión del fenómeno considerando la evolución de la estructura social durante el periodo señalado, ya que éstos simplemente son los encargados de reproducir esa estructura.

En este sentido hay que destacar un aspecto que diferencia a la sociedad postfordista de su predecesora: el surgimiento de una proporción importante de población asalariada con capacidad de endeudamiento. Una vez que se ha planteado el papel del modelo inmobiliario como un mero constructor de un dibujo preestablecido por dinámicas de largo recorrido, habría que señalar cómo éste, a su vez, también interviene en la necesidad de que la reproducción social se materialice sobre el territorio de una forma clara y ordenada. El modelo inmobiliario no determina a su antojo el mosaico apreciado en el territorio, lógicamente no puede alterar por sí mismo la estructura de clases existentes, pero la forma en que "construye" ese mosaico si tiene que ver con sus mecanismos de funcionamiento. Podríamos decir que se trata de un fenómeno doble de producción inmobiliaria y reproducción social donde el modelo inmobiliario está determinado pero a su vez acaba siendo determinante. En cuanto a los mecanismos del modelo inmobiliario éstos no dejan de ser instrumentos que le permiten funcionar de forma eficiente. ¿Qué hace falta para alcanzar esa eficiencia? Fundamentalmente dos cuestiones: reproducir con fidelidad la jerarquía social y ordenarla en el territorio. Por un lado la reproducción de la jerarquía social es necesaria para establecer el puente entre las capacidades de la población dispuesta a adquirir una vivienda y la oferta residencial y, por otro, el orden garantiza que la inversión financiera se mantenga. La necesidad de garantizar la inversión financiera lleva a clasificar los precios sobre el territorio de forma que haya el mínimo error en su percepción. El modelo inmobiliario se dotó para ello de una regulación que introducía la valoración a través de las áreas de valor ${ }^{96}$. Así obtenemos, que el modelo inmobiliario actuaba de la mano del sistema financiero y requería construir un parque residencial de una diversidad jerarquizada muy ordenada sobre el territorio.

Si contemplamos que el modelo operaba principalmente bajo un régimen de venta de viviendas y consideramos que sus compradores podían acceder a un sistema financiero que convertiría toda su capacidad de endeudamiento futuro en una localización que se correspondiera con el máximo estatus al que podían acceder podemos llegar a la conclusión de que el resultado iba a ser un espacio de acumulación y exclusión sin precedentes. La vinculación total entre pertenencia a un determinado rango de capacidad económica y dirección postal se convirtieron en una seña de identidad de los sistemas urbanos actuales. Respecto al papel del sector inmobiliario como transmisor de este proceso es muy interesante observar como hay una relación absoluta entre el precio de las viviendas en relación a la media anual y el espacio

\footnotetext{
96 En España se establecieron las áreas de valor mediante el Reglamento Hipotecario de 1960.
} 
social resultante décadas después ${ }^{97}$. A partir de esta constatación se puede llegar a considerar que durante el doble fenómeno de transformación inmobiliaria y social que vivieron los sistemas urbanos en el siglo XX se produjo un cambio de fase en el modelo de configuración de la ciudad. Estaríamos ante la transformación del modelo de ciudad fordista en un nuevo modelo que hemos denominado "Ciudad Negocio". En este nuevo modelo el sector inmobiliario, olvidándose del antiguo sistema basado en el alquiler, conseguiría producir viviendas para vender a largo plazo a un ritmo desconocido hasta la fecha mediante mecanismos que facilitaban promocionar y vender viviendas sin ni siquiera haber puesto un ladrillo. ${ }^{98}$

\section{EL MODELO DE CIUDAD NEGOCIO}

En el nuevo modelo de ciudad, la concepción, construcción, venta y financiación de su propio crecimiento son el negocio central. No se trata de que la ciudad facilite el negocio inmobiliario, su razón de ser, el motivo por el que se configura de una forma y no de otra, es el negocio en sí. Podríamos afirmar, que la ciudad se convierte en una suerte de gran y diversificada operación financiera. Como ya se ha visto la búsqueda de beneficios del sector inmobiliario y los mecanismos de funcionamiento del sector financiero obligan a que el mapa de precios de las viviendas coincida en todos los aspectos con el mapa de rentas que refleja el espacio social de la ciudad. La utilización del precio de la vivienda, y con ella de la capacidad de endeudamiento de la población, como filtro de exclusión social llevaría, más adelante, a que los costes se acercaran al límite de capacidad de cada estrato social, es decir, al ahorro de toda su vida laboral. El espacio social se acabaría convirtiendo en un espacio de acumulación y exclusión (sistémica) excesivamente dependiente del sistema financiero. El nuevo modelo de ciudad confirma la vocación del sistema capitalista por producir y reproducir desigualad y la obligación de que esa desigualdad se perciba con claridad por la población. Por otro lado el aumento de la capacidad de endeudamiento, la imagen de riqueza que trasmitía una propiedad en constante revalorización, el alargamiento de los plazos, la incorporación masiva de suelo al que se le añadían grandes expectativas y las grandes infraestructuras realizadas por la administración, acabaron de impulsar un crecimiento acelerado de los sectores financiero e inmobiliario que generó una peligrosa asociación entre el desarrollo inmobiliario y el crecimiento de la economía y el empleo. Llegados a este punto, habría que señalar que las condiciones de entorno en las que se produjo la transformación del modelo urbano descrito fueron, entre otras, la escasez de viviendas, un aumento constante de la población asalariada, el desmantelamiento del modelo de alquiler, ayudas públicas a la compra de vivienda, un contexto económico internacional de bonanza económica, facilidades de financiación, energía relativamente barata y patrones de consumo en aumento. El escenario actual de freno en seco de la financiación, acumulación de viviendas vacías, y disminución de la masa de población asalariada pone sobre la mesa importantes incógnitas sobre la evolución actual del modelo descrito.

\footnotetext{
97 Esta cuestión se puede comprobar en los datos recogidos por la Tesis doctoral del autor de este artículo Tamayo, A. (2015) Desigualdad social en la Ciudad Negocio. El modelo inmobiliario en la construcción social de Madrid durante el desarrollismo (inédita)

98 En el caso de España la Ley de Propiedad Horizontal, la Ley Hipotecaria y el Reglamento Hipotecario, entre otras, fueron las culpables de la transformación de un modelo basado en el alquiler a otro condicionado totalmente por la venta y financiación de viviendas.
} 


\title{
EL SUEÑO DE LOS PESCADORES DE PERLAS. EL NUEVO DUBAI.
}

\author{
Lucila Urda Peña (Dra. Arquitecta - Profesora asociada DUyOT)
}

La evolución de las ciudades está cada vez más relacionada con la situación económica del país donde se ubican, no solamente desde un punto de vista local sino también desde su trascendencia como metrópolis de relevancia a nivel internacional. La macroeconomía mundial como motor de cambio urbano ha sido uno de los factores más determinantes en la transformación de las ciudades desde mediados del siglo $X X$. Sin embargo, en la mayoría de los casos, las metrópolis eran ciudades con una importante tradición industrial o comercial desde su origen (Londres o Nueva York). El crecimiento impulsado por el progreso económico continuaba una evolución natural de las propias polis que se transformaban en metrópolis. El desarrollo y evolución de ciudades históricas y su transformación en metrópolis, contrasta con la aparición de macrociudades exnovo desde el comienzo del siglo XXI. Un fenómeno que ha comenzado a producirse en lugares sin tradición urbana y sin las condiciones mínimas de habitabilidad. Hay numerosos ejemplos de pequeños asentamientos localizados en lugares de climatología adversa (con temperaturas de $50^{\circ} \mathrm{C}$ la mayor parte del año) que se están convirtiendo en territorios de referencia mundial para el intercambio comercial y el negocio internacional. Las "macrociudades artificiales" han proliferado en varios lugares del mundo (en China, Turquía y en Emiratos Árabes se encuentran las ciudades del mundo que más han crecido en el año 2014) ${ }^{99}$. Entre ellas se encuentran las nuevas metrópolis de oriente próximo que vieron cómo se multiplicaba el producto interior bruto de sus países de forma exponencial gracias a la exportación del llamado "oro negro".
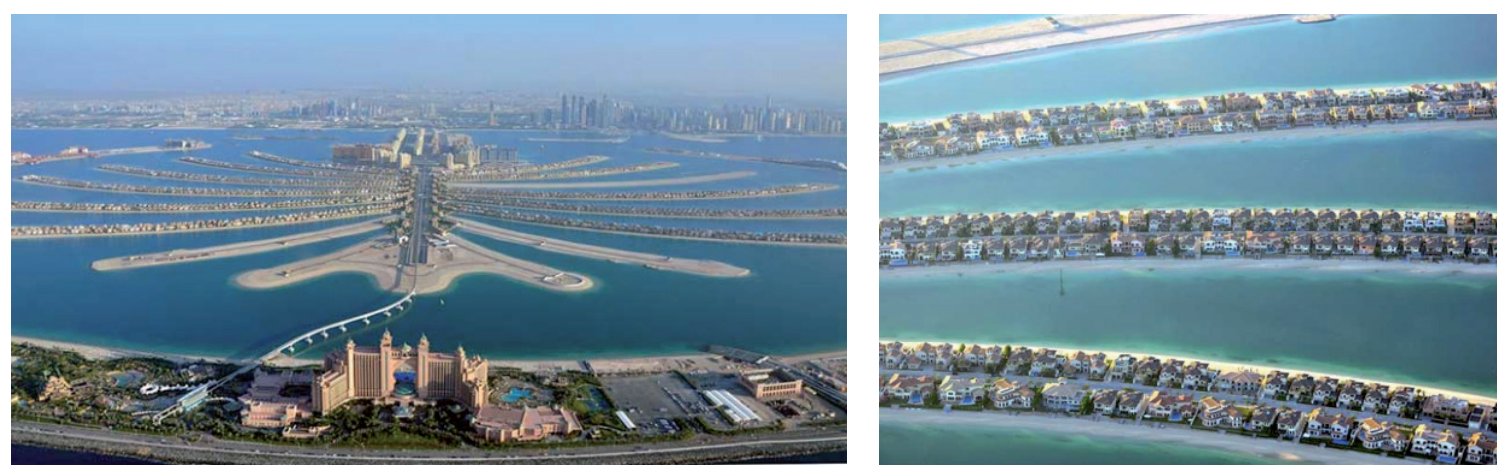

Figura 16. Vista de las últimas construcciones turísticas en el complejo "The Palm" en Dubái Fuente: Archivo de la autora (2015)

El caso de los Emiratos Árabes Unidos es especialmente llamativo, un país que ha pasado de la subsistencia básica a un nivel de renta per cápita en el año 2013 de casi $50.000 \$ 100$, siendo el octavo país del mundo con mayor renta después de Estados

\footnotetext{
99 http://www.bbc.com/mundo/noticias/2015/02/150212_economia_ciudades_crecimiento_mj

100 http://www.elcaptor.com/2014/01/top-mundial-pib-per-capita-por-paises.html
} 
Unidos, con una población de 9.500.000 habitantes a principios de 2015. La beneficiosa situación económica del país durante las tres últimas décadas del siglo XX permitió a los gobernantes emiratíes, elaborar una estrategia de diversificación comercial ante la inminente desaparición del petróleo durante los años venideros. El emirato de Dubái ha sido el que más ha crecido tanto a nivel poblacional como a nivel físico. Su población se ha multiplicado por diez en los últimos 45 años, pasando de tener 265.702 habitantes en 1970 a tener casi 3.000.000 de habitantes en 2015.
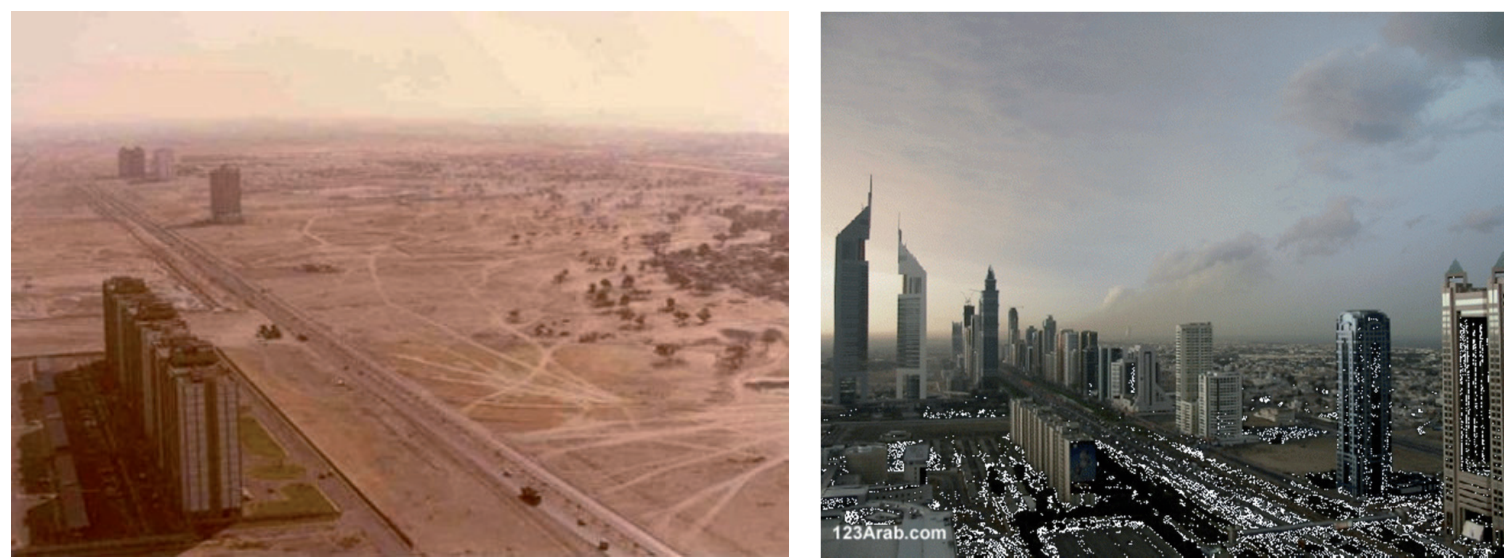

Figura 17. La misma vista de Dubái en 1990 y en 2003. Todavía no colmatada

Fuente: https://miradasporeldesarrollo.wordpress.com/2013/04/22/modelos-de-desarrollo-insostenible-dubai/

El crecimiento físico de la ciudad de Dubái se ha asociado a la búsqueda de modelos sorprendentes y novedosos, en los que el reto de la construcción se asociaba a un desafío de los límites físicos y económicos que limitaban los crecimientos de las ciudades tradicionales. En Dubái se encuentra el rascacielos más alto de mundo (el Burj Khalifa, con $828 \mathrm{~m}$. de altura) y las islas artificiales más sofisticadas y exclusivas (The Palm Jumeirah y The Palm Jebel Ali). Dubái es el paradigma de la ciudad del siglo XXI, entre sus aspiraciones se encuentran la de ser la ciudad representativa de la prosperidad, el consumismo y el turismo de lujo. Estos objetivos no pueden conseguirse a cualquier precio, sobre todo teniendo en cuenta las peculiares condiciones de partida de la ciudad de finales del siglo XX. Si analizamos el caso de Dubái desde un punto de vista urbanístico, atendiendo a aspectos físicos, sociales y económicos entenderemos las dificultades a las que se han enfrentado los emiratíes para poder conseguir sus objetivos.

El Emirato de Dubái está asentado en un territorio horizontal sin ninguna alteración topográfica relevante, las montañas más cercanas se encuentran a unos $80 \mathrm{~km}$ hacia el este. Su situación de costa ha favorecido el asentamiento junto al mar del Golfo Pérsico, cuya actividad pesquera mantuvo, junto con el comercio de perlas preciosas, a los habitantes del lugar en sus orígenes. Su clima es uno de los aspectos más críticos para la adecuación de unas condiciones mínimas de habitabilidad, ya que más de $1 / 3$ del año tiene temperaturas superiores a los $40^{\circ} \mathrm{C}$ y su precipitación media anual es inferior a los $120 \mathrm{~mm}$. La ausencia de vegetación autóctona también es llamativa y uno de los motivos de existencia de las temperaturas tan extremas, ya que, en el origen, la mayoría del territorio del emirato era un desierto. Sin embargo, el clima extremo del Golfo Pérsico forjó la identidad de sus habitantes históricos, que 
estaban acostumbrados a sobrevivir en el desierto y explotar los pocos recursos de que disponían. Los pescadores de perlas, famosos por su método de pesca por apnea tenían una relación íntima con el mar, al que agradecían sus tesoros que les daban de comer.

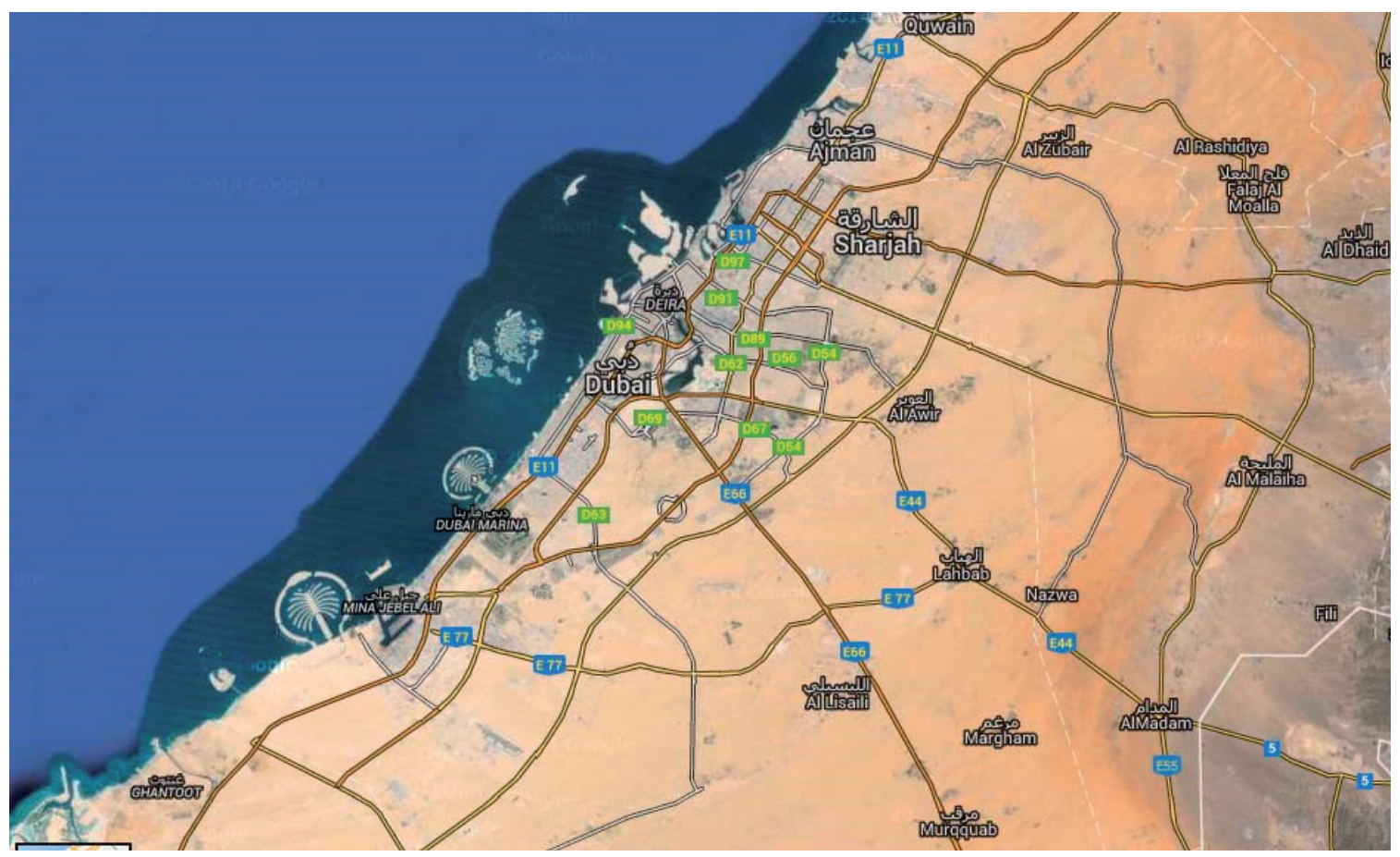

Figura 18. Fotografía de satélite de Julio de 2015

Fuente: Google Maps

Desde el punto de vista social, la composición de la población original del emirato se dividía en dos tipos de pobladores, los que vivían en el desierto y los que vivían en la costa. Los pobladores de la costa eran conocidos por su piratería que sembraba el terror en una de las rutas comerciales más frecuentadas de los siglos XIX y XX. Para solventar este problema el Reino Unido negoció con los jeques de las tribus nómadas una tregua marítima perpetua (en 1853) a cambio de un protectorado que perduró hasta 1971. El sistema de gobierno tradicional se basaba en el consenso y la participación, cada comunidad transmitía a su jeque las necesidades y los asuntos más relevantes que afectaban a sus habitantes, era una democracia directa, un sistema factible con una población muy escasa y dividida. Los recursos del país se apoyaban en una economía de subsistencia basada en el comercio de perlas y la pesca. La población interior era una población nómada del desierto que vivía sin patrimonio propio y en unas condiciones extremas. Con estas condiciones de partida resulta difícil creer que, en este momento, Dubái sea una de las ciudades paradigma del progreso económico y centro mundial de negocios e intercambio comercial.

¿Cómo ha sido posible una transformación tan extrema en tan poco tiempo? La visión de futuro y la ambición de un país moderno de Zayed bin Sultan Al Nahyan, el jeque que ha gobernado los Emiratos Arabes desde su constitución en 1971 hasta 
2004 desencadenó todos los cambios. El descubrimiento del petróleo y la constitución de la federación de los Emiratos Arabes como estado independiente del protectorado inglés fueron el comienzo de la transformación del país y del modo de vida de sus habitantes. El alto nivel de beneficios que aportaba la exportación de petróleo desencadenó toda una serie de ayudas a la población que se tradujo en subvenciones, la incorporación de equipamientos básicos (colegios, hospitales y universidades gratuitas) y, en consecuencia, un crecimiento muy significativo del nivel de vida.

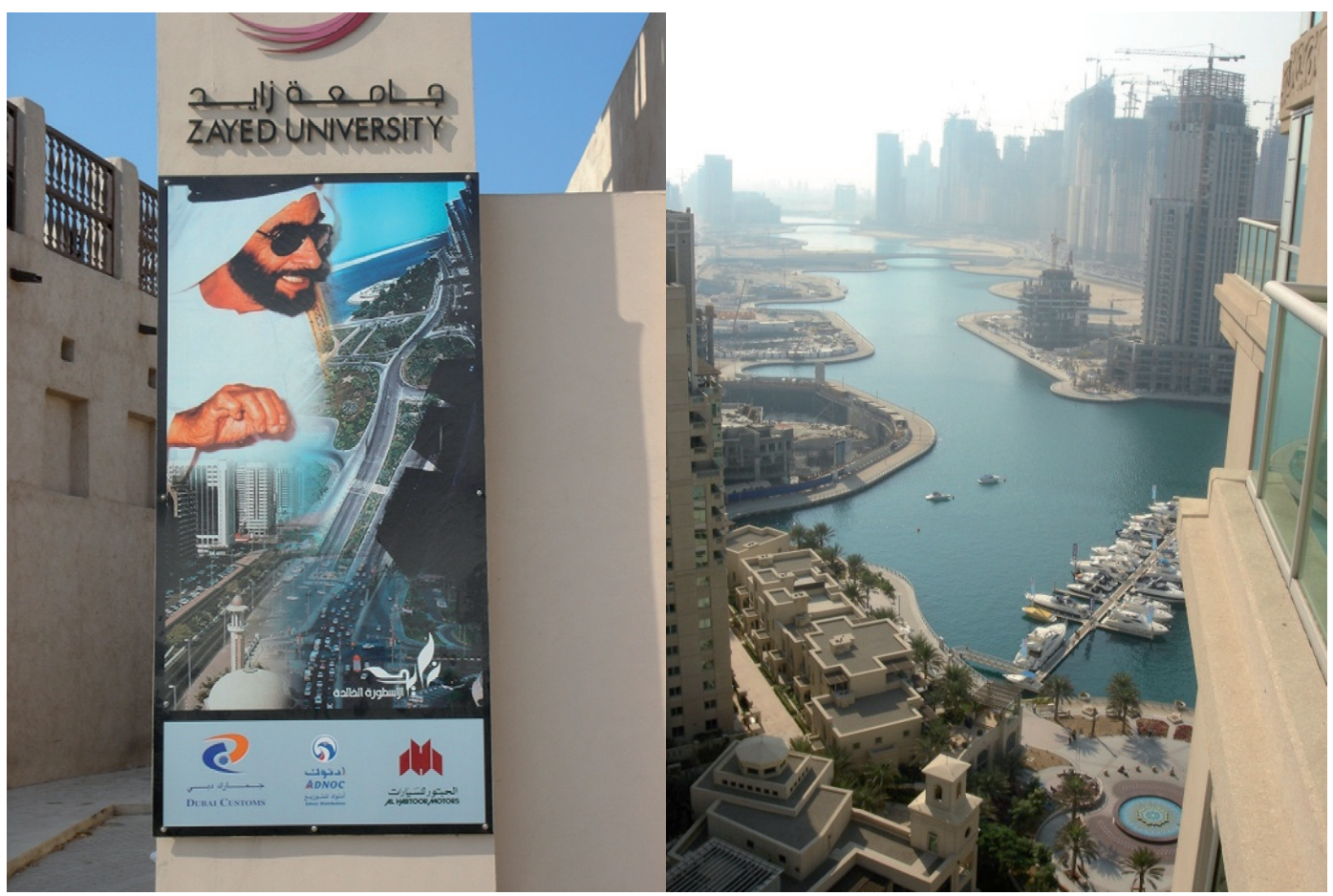

Figura 19. Universidad de Zayed Dubái Construcción de la urbanización Marina Towers Fuente: Jorge Ribadeneira

Esta situación provocó una planificación del futuro del país, que veía que sus recursos peligraban con la escasez de petróleo. La transformación del desierto en un lugar de turismo de lujo también ha sucedido a gran velocidad. La única forma de atraer turismo a un área sin ningún atractivo natural ha sido la invención de un producto turístico exclusivo en hoteles o apartamentos de superlujo. La urgencia de desarrollar nuevos recursos basados en los servicios provocó un crecimiento desmesurado desde el año 2000 hasta la actualidad donde la variedad de oferta turística se diseñaba a cualquier precio. Esta situación no hubiera sido posible sin la importación de los "nuevos esclavos" de la construcción. Se trajo población india y pakistaní que se hacinaban en barracones de obra y a los que se les sustraía el pasaporte nada más llegar al país. Las condiciones de trabajo en un lugar de temperaturas tan extremas eran penosas. Los antiguos pescadores de perlas vendieron sus terrenos para hacer promociones turísticas. Olvidaron su austera vida para rendirse a los brazos del consumismo más atroz violando los principios básicos de los derechos humanos. 
El futuro de los emiratíes está ahora asegurado. En este momento representan tan solo el $20 \%$ de la población de su país, formada en su mayor parte por "expatriados" de países europeos, asiáticos, americanos o australianos. Las grandes marcas y las empresas más importantes del mundo tienen una sede en los Emiratos Árabes. Para poder ofrecer condiciones excelentes a sus turistas se han climatizado de forma artificial todas las edificaciones nuevas. La construcción de este nuevo babel tiene un elevado coste energético, con consecuencias más allá de sus fronteras. ${ }^{101}$

"(...) Cada habitante de Dubái emite 44 toneladas de $\mathrm{CO}_{2}$ al año (para hacernos una idea, en España esta cifra baja a unas 8,17 toneladas según datos de Eurostat, 2013)."

Haciendo un repaso a las nuevas condiciones físicas, políticas y económicas actuales del país lo que medimos en dólares como un progreso objetivo de un país, está teniendo un elevado coste medioambiental y social. El derroche energético y la fórmula de la "nueva esclavitud" son sólo algunas de las graves consecuencias.

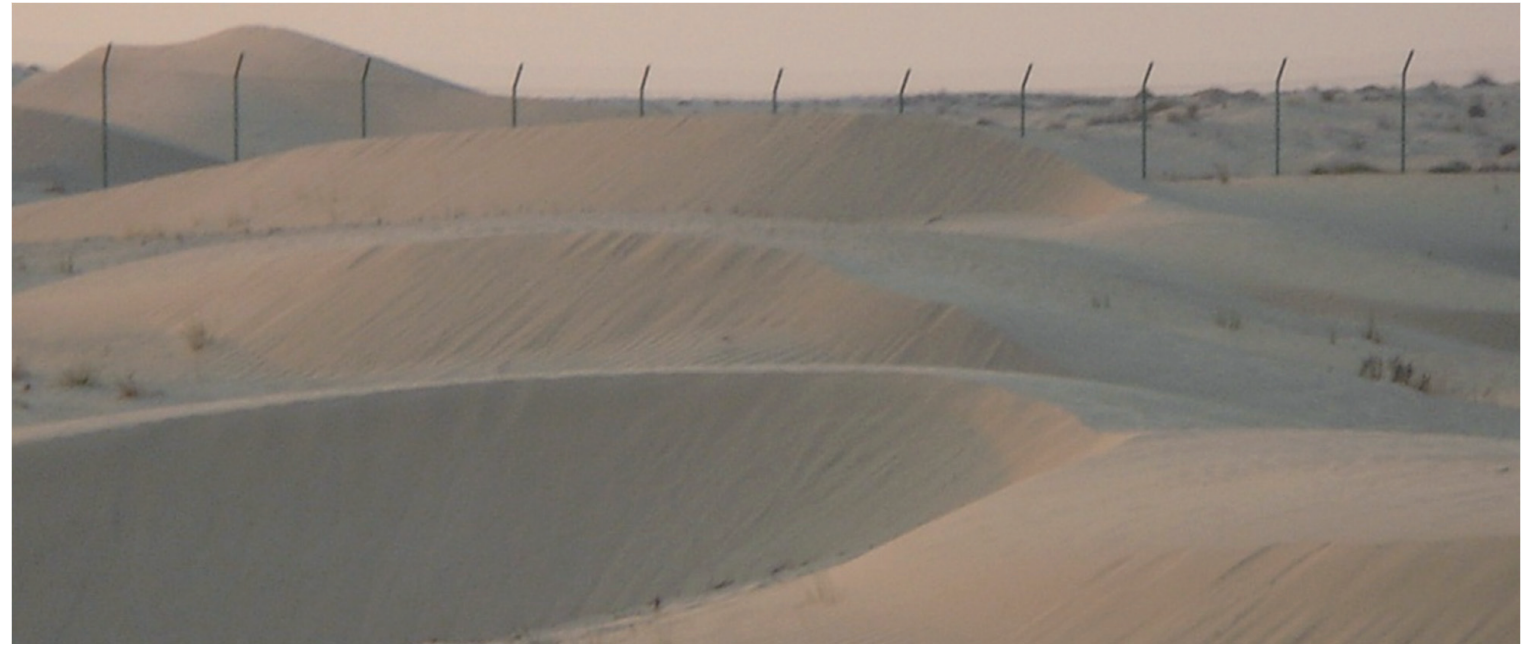

Figura 20. Desierto de Dubai

Fuente: Archivo de la autora (2005)

Las secuelas de esta lucha contra-natura las sufren también los pobladores originales que han perdido sus referencias y los valores que les había transmitido un territorio tan singular, un lugar que los hacía únicos y diferentes, unos supervivientes de lo extremo. La ambición económica es ahora el sueño de los antiguos beduinos y pescadores de perlas, un sueño ya hecho realidad a costa de las pesadillas de otros muchos. 102

\footnotetext{
101 https://miradasporeldesarrollo.wordpress.com/2013/04/22/modelos-de-desarrollo-insostenibledubai/

102 https://eltoque.com/slideshow/trabajadores-inmigrantes-en-dubai-nos-chupan-la-sangre
} 


\title{
CONOCIMIENTO CIUDADANO E INVESTIGACIÓN URBANÍSTICA.
}

\author{
Carlos Verdaguer Viana-Cárdenas (Arquitecto - Profesor asociado DUyOT)
}

"No hay otro conocer urbano que la acción de la ciudadanía". Casi bastaría con replicar el contundente título que Mariano Vázquez Espí le puso a su magnífica ponencia del año $2002^{103}$ para sintetizar el contenido de la siguiente reflexión, pues dicho título constituye en sí mismo un programa y una declaración de intenciones que suscribo en su totalidad.

En su comunicación, Vázquez Espí partía de una reflexión epistemológica ("queremos conocer cómo es que conocemos") para pasar a plantearse los "límites de la técnica" ante el dilema de la toma de decisiones en el marco de una realidad intrínsecamente multidimensional en la que la obtención de soluciones "viables" es matemáticamente posible (mediante optimación vectorial), pero no lo es la selección entre todas las soluciones obtenidas, pues, como él planteaba: "¿quién escoge? ¿el técnico? ¿el azar? ¿hay diferencia?". Tras abordar el carácter "polivalente" del "sujeto de la ciudad", y hacer hincapié en la necesidad de "perder el miedo al conflicto", la exposición culminaba con un alegato a favor de una democracia participativa que ayudase a "que los nuevos sujetos sociales acaben por construir su decisión colectiva".

Siguiendo el hilo de esta argumentación, que sitúa sin paliativos el "conocer ciudadano" en el centro de la construcción de la ciudad y el territorio, y que corresponde plenamente a un cambio de paradigma basado en la ecología como ciencia de las relaciones, cabría preguntarse cuál puede ser el papel asignado a los "expertos" y, por ende, cuál puede ser el papel de la investigación urbanística dentro de un nuevo urbanismo que podríamos calificar de "autopoiético", es decir, en proceso permanente de retroalimentación dinámica desde arriba y desde abajo.

En relación con el papel de los denominados expertos, en este caso los urbanistas, arquitectos y otros profesionales de la planificación socio-espacial, este cambio de paradigma en el ámbito de la intervención es frecuentemente contemplado como una amenaza, como un despojamiento de funciones considerados ineludibles o como un espejismo irrealizable, o como ambas cosas al mismo tiempo, y en cualquier caso, como una intolerable restricción que viene a sumarse a la que supone el sometimiento a los "dictados" de la ecología104.

Al margen de los aspectos reaccionarios que indudablemente comparten como mera defensa de privilegios, estas posturas convergen en una visión unidimensional de la realidad que menosprecia, en primer lugar, la riqueza de posibilidades que existe para todos y cada uno de los agentes, sin excepción, implicados en el proceso de

103 Vázque Espí, Mariano (2002), No hay otro conocer urbano que la acción de la ciudadanía, en Los derechos humanos y la ciudad. Informe 2002. Valladolid: Universidad de Valladolid, ISBN 94-688-11734. PP. $127-130$

104Verdaguer, Carlos (2002) Algunas aportaciones al debate de la sostenibilidad (http://www.gea21.com/equipo/cv/2002_debate_sostenibilidad.pdf) 
construcción colectiva de la ciudad y en la adecuada comprensión de los factores limitantes que ofrece la biosfera, y en segundo lugar, desprecia igualmente el enorme caudal de conocimiento holístico y literalmente experto que acumula el colectivo social y que, en sí mismo, puede ser considerado un verdadero filón inagotable.

Por otra parte, además de negarse a asumir la profunda crisis que aqueja al urbanismo como disciplina, estas actitudes reactivas no son capaces de entender que "en un mundo fundamentalmente urbano, el urbanismo, entendido como capacidad de describir, articular y configurar lo urbano, está abocado a convertirse en un lenguaje de uso común". ${ }^{105}$

Entendiendo lo ineludible de este fenómeno, y al contrario de lo que suponen las mencionadas posturas, desde el punto de vista de los técnicos y profesionales, la asunción de este nuevo paradigma supone un conjunto de retos apasionantes asociados a las nuevas funciones posibles en el ámbito de la intervención y al amplio abanico de nuevas áreas de conocimiento que implica una visión sistémica de la ciudad y el territorio.

Como sujeto clave de la intervención, al técnico, cuando es capaz de renunciar al papel exclusivo y engañosamente cómodo de demiurgo, se le ofrecen nuevos papeles mucho más apasionantes como el de traductor de deseos y necesidades, mediador y facilitador de procesos, catalizador de situaciones y conector entre sujetos e intereses diversos, del mismo modo que al usuario se le plantea el reto de abandonar su actitud pasiva inducida para hacer efectivo su conocimiento experto como aborigen de esas segunda naturaleza que es lo urbano. ${ }^{106}$

Por lo que respecta al conocimiento propiamente experto, aquel que requiere necesariamente el recurso a técnicas y disciplinas especializadas, al técnico dispuesto a aceptar estos retos le compete dilucidar cuáles son en cada caso los abanicos de opciones verdaderamente viables para satisfacer los deseos y necesidades identificados colectivamente, exponiendo con claridad las cadenas de impactos y los flujos de recursos energéticos y materiales asociados a las diversas soluciones consideradas como posibles satisfactores, manteniendo siempre como objetivo el de facilitar la toma de decisiones por parte del conjunto de actores en su totalidad ${ }^{107}$.

¿Cuál puede ser, pues, el papel de la investigación urbanística en relación con este marco? La respuesta exige contemplar de cerca las diversas dimensiones del conocimiento a las que acabamos de hacer referencia y, al mismo tiempo, tratar de dilucidar cuáles pueden ser las articulaciones entre estas dimensiones del conocimiento y las funciones de intervención, sin olvidar en ningún caso que el objetivo final, al menos desde la perspectiva aquí adoptada, no puede ser otro que el de facilitar la creación colectiva de un entorno espacial global más habitable para los

\footnotetext{
${ }^{105}$ Verdaguer, Carlos (2003) Por un urbanismo de los ciudadanos en: Ecología y ciudad : raíces de nuestros males y modos de tratarlos. El Viejo Topo, Madrid, pp. 175-196. ISBN 84-95776-57-X. También en $\mathrm{CF}+\mathrm{S}$ Textos sobre sostenibilidad

106 Verdaguer, Carlos (2006) Urbanismo Participativo: Evolución, conceptos básicos y experiencias. Fundación COAM Curso de diseño urbano / Perspectiva de sostenibilidad .Presentación en powerpoint 107 Verdaguer, Carlos (2014) Vías para la sostenibilidad urbana en los inicios del siglo XXI Informe marco para la revisión de la Agenda 21 de Málaga. OMAU (Observatorio del Medio Ambiente Urbano), Ayuntamiento de Málaga
} 
seres humanos dentro de las pautas y limitaciones ineludible que impone la biosfera como sistema.

Así considerada la cuestión, en relación con la dimensión del conocimiento que hemos denominado especializado, el problema al que se enfrenta el urbanismo es exactamente el mismo que el de las demás ciencias y disciplinas: ¿quién elige lo que se investiga? ¿quién y cómo se establecen las prioridades? ¿cómo se distribuyen los recursos? Naturalmente, la cuestión de quién detenta el poder es aquí la clave y el problema es qué mecanismos de control deben crearse para que las líneas de investigación no vengan impuestas, como es frecuente en los ámbitos más directamente relacionados con la acumulación de capital (industrias farmacéutica, del transporte, nuevas tecnologías, etc) por los intereses de mercado y políticos de los grandes operadores globales. En el ámbito de lo urbano, el énfasis en las smart cities, los big data o la domótica, presentados como panaceas tecnológicas, responden claramente a este fenómeno.

Sin embargo, lo cierto es que, en el caso del urbanismo y, en general, de la planificación del espacio, desde la perspectiva aquí adoptada podría decirse que este conocimiento especializado ocupa y debe ocupar un lugar verdaderamente secundario en relación con ese conocimiento holístico y complejo que emana del propio fenómeno urbano como resultado emergente de la interacción dinámica entre todos los actores que lo forman, es decir, de todo el cuerpo social en su conjunto. Y es precisamente este carácter subsidiario el que, en el caso del urbanismo, puede ayudar a afrontar de forma más fructífera el problema que plantea la existencia de presiones en el campo de la investigación "especializada".

En efecto, planteada en estos términos, la investigación urbanística debería centrar todos sus esfuerzos y recursos en la identificación del conjunto de deseo y necesidades del cuerpo social en su conjunto y en relación con su hábitat, y en el descubrimiento y el desarrollo de aquellos satisfactores multidimensionales más sostenibles. Tal como se deduce de todo lo expuesto, esta orientación exige, por una parte, la presencia y el contacto con todos los actores durante el proceso mismo de investigación, de modo que los intereses diversos del estado, el mercado y la sociedad estén presentes de forma equilibrada en todo momento en dicho proceso para la adecuada identificación de las divergencias, los solapamientos, hibridaciones y sinergias entre estos intereses en relación con la producción / transformación del espacio. La idea del conflicto como oportunidad de creación de lo nuevo debe ser una de las directrices de esta forma de investigación.

Y, por otra parte, esta apuesta por una investigación firmemente anclada en la realidad debe asegurar la creación y articulación de mecanismos ágiles de retroalimentación que permitan una rápida aplicación de los resultados de la investigación en los propios escenarios urbanos $\mathrm{y}$, sobre todo, una evaluación colectiva y continua de las hipótesis implícitas en la misma con el objeto de reconducirlas o revalidarlas.

Aceptando la idea de que, en un planeta urbano, el urbanismo puede y debe convertirse en un lenguaje común, puede decirse, de hecho, que la investigación urbanística es un ámbito privilegiado para avanzar en el sentido de convertir la propia investigación en un esfuerzo colectivo y contribuir a borrar las fronteras entre las diversas formas de conocimiento, haciendo realidad un anhelo que ha estado presente 
de una forma u otra en todas las propuestas filosóficas transformadoras que se han producido a lo largo de la historia humana.

Cabría preguntarse, a modo de reflexión final, hasta qué punto lo que se entiende actualmente por investigación urbanística corresponde a esta visión de una investigación anclada en la realidad y volcada hacia el conocimiento holístico colectivo, la participación y la re-evaluación continua con el objetivo de generar un nuevo urbanismo autopoiético.

Para una respuesta adecuada, cabría hacer mención en primer lugar a todos los procesos de transformación urbana que se están produciendo en la escala planetaria y que, gracias a la creación continua de redes horizontales trasversales de intercomunicación y difusión, se convierten en sí mismos en ejemplos de investigación viva y activa, en ocasiones gracias a iniciativas originadas en ámbitos institucionales y académicos especialmente activos y atentos al pulso de una realidad en perpetua mutación, como es el caso de esta revista y otras plataformas académicas de difusión, pero en la mayoría de las ocasiones como fruto emergente y exclusivo de la propia dinámica urbana, al margen o incluso en contra de la academia y las instituciones. Desde esta perspectiva, cabría hacer mención a la historia del urbanismo para recordar que muchas de las propuestas más transformadoras que constituyen actualmente el ADN de la teoría y la práctica de la disciplina, desde Howard y Jacobs hasta los Provos y los situacionistas, entre otros muchos, surgieron realmente de entornos muy ajenos o directamente beligerantes con la lógica institucional o académica.

Pero sobre todo, desde la perspectiva de la academia que representa esta revista, habría que reflexionar sobre la esterilización o la falta de repercusión que muchas de estas iniciativas y esfuerzos corren el riesgo de sufrir cuando, convertidas en simple material de trabajo académico, caen en los pozos sin fondo del conocimiento infinitamente fragmentado que se generan cuando lo que domina es un concepto endogámico de la investigación en el que es prioritaria una lógica perversa de acumulación de méritos académicos basada en la simple réplica de métodos que pueden tener sentido tal vez en otros ámbitos disciplinares o científicos, pero que, en un campo vivo, dinámico e intrínsecamente político como es del urbanismo, no contribuyen sino a retrasar su inevitable transformación. 
LOS CUADERNOS DE INVESTIGACIÓN URBANÍSTICA publicados por el Departamento de Urbanística y Ordenación del Territorio desde el año 1993, difunden bimensualmente aquellos trabajos de investigación realizados en el área del Urbanismo, la Ordenación Territorial, el Medio Ambiente, la Planificación Sostenible y el Paisaje, que por sus características, muchas veces de investigación básica, tienen difícil salida en las revistas profesionales. Su objetivo es la difusión de estos trabajos, en el convencimiento de que es necesario potenciar el uso de este idioma entre el mundo científico para conseguir alcanzar ámbitos de difusión a los que, de otra forma, no se podría acceder.

Su formato no es el convencional de una revista de este tipo, con artículos de diferentes autores que, en realidad, abordan aspectos parciales de cada trabajo, muy adecuados para la difusión y el conocimiento rápido de los mismos, pero que no pueden profundizar demasiado debido a su limitada extensión, sino que se trata de amplios informes de la investigación realizada que ocupan la totalidad de cada número. Esto permite, sobre todo a aquellos investigadores que se inician, el tener accesibles los aspectos más relevantes del trabajo y conocer con bastante precisión el proceso de elaboración de los mismos.

La realización material de los Cuadernos de Investigación Urbanística está a cargo del Departamento de Urbanística y Ordenación del Territorio de la Escuela Técnica Superior de Arquitectura de Madrid, garantizándose el respeto de la propiedad intelectual, pues el registro es siempre en su totalidad propiedad del autor. Está permitida su reproducción parcial en las condiciones establecidas por la legislación sobre propiedad intelectual citando autor, previa petición de permiso al mismo.

\section{NORMAS DE PUBLICACIÓN}

Las condiciones para el envío de originales se pueden consultar en la página web:

http://www.aq.upm.es/Departamentos/Urbanismo/publicaciones/ciurpublicar.html

\section{FORMATO DE LAS REFERENCIAS}

Monografías: APELLIDOS (S), Nombre (Año de edición). Título del libro (No de edición). Ciudad de edición: Editorial [Traducción castellano, (Año de edición), Título de la traducción, No de la edición. Ciudad de edición: editorial].

Partes de monografías: APELLIDOS (S), Nombre (Año de edición). "Título de capítulo". En: Responsabilidad de la obra completa, Título de la obra (No de edición). Ciudad de edición: Editorial.

Artículos de publicaciones en serie: APELLIDOS(S), Nombre (Año de publicación). "Título del artículo", Título de la publicación, Localización en el documento fuente: volumen, número, páginas.

Asimismo, se recuerda que el autor tendrá derecho a tres ejemplares gratuitos.

\section{CONSULTA DE NÚMEROS ANTERIORES/ACCESS TO PREVIOUS WORKS}

La colección completa se puede consultar en color y en formato pdf en siguiente página web:

The entire publication is available in pdf format and full colour in the following web page:

http://www.aq.upm.es/Departamentos/Urbanismo/publicaciones/ciurnumeros.html

\section{ÚLTIMOS NÚMEROS PUBLICADOS:}

99 María Teresa Broseta Palanca: "La catalogación del patrimonio arquitectónico de la ciudad de Valencia ", 94 páginas, Marzo 2015.

98 Sonia de Gregorio Hurtado: "Políticas urbanas de la Unión Europea desde la perspectiva de la planificación colaborativa", 74 páginas, Enero 2015.

97 Juan Ramón Selva Royo: "Antecedentes y formación del Plan General de Valencia de 1966 ", 68 páginas, Noviembre 2014.

96 Irina Tumini: "The urban microclimate in open space. Case studies in Madrid", 78 páginas, Septiembre 2014.

95 Luz Elena Cornejo Ganga: "Categorías de análisis de un modelo de planificación turística sustentable", 96 páginas, Julio 2014. 


\author{
PREINSCRIPCIÓN DEL 15 DE MARZO AL 27 DE JUNIO DE 2014 \\ COORDINADORA DEL MÁSTER: Ester Higueras García \\ PERIODO DE DOCENCIA: Septiembre 2014 -Junio 2015 \\ MODALIDAD: Presencial y tiempo completo \\ NUMERO DE PLAZAS: 40 plazas \\ CREDITOS: 60 ECTS
}

\begin{abstract}
El Máster se centra en la comprensión, análisis, diagnóstico y solución de los problemas y la identificación de las dinámicas urbanas y territoriales en curso, atendiendo a las dos dimensiones fundamentales del fenómeno urbano actual: por un lado, el proceso de globalización y, por otro lado, las exigencias que impone la sostenibilidad territorial, económica y social. Estos objetivos obligan a insistir en aspectos relacionados con las nuevas actividades económicas, el medio físico y natural, el compromiso con la producción de un espacio social caracterizado por la vida cívica y la relación entre ecología y ciudad, sin olvidar los problemas recurrentes del suelo, la vivienda, el transporte y la calidad de vida. Estos fines se resumen en la construcción de un espacio social y económico eficiente, equilibrado y sostenible. En ese sentido la viabilidad económica de los grandes despliegues urbanos y su metabolismo se confrontan con modelos más maduros, de forma que al estudio de las técnicas habituales de planificación y gestión se añaden otras nuevas orientaciones que tratan de responder a las demandas de complejidad y sostenibilidad en el ámbito urbano.
\end{abstract}

El programa propuesto consta de un Máster con dos especialidades:

- Especialidad de Planeamiento Urbanístico (Profesional)

- Especialidad de Estudios Urbanos (Investigación Académica)

Se trata de 31 asignaturas agrupadas en tres módulos:

MÓDULO A. Formación en Urbanismo.

MÓDULO B. Formación en Estudios Urbanos e Investigación.

MÓDULO C. Formación en Planeamiento.

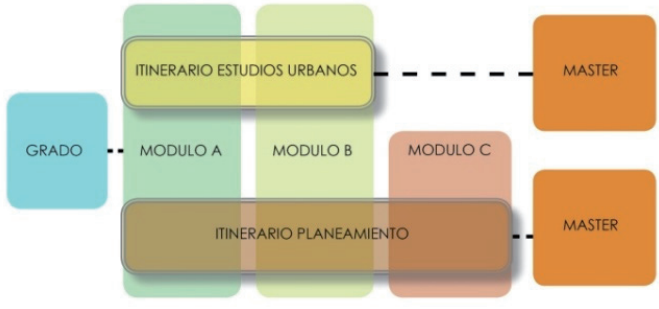

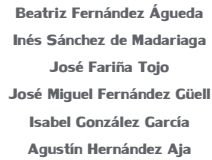

PROFESORADO:

$$
\begin{gathered}
\text { Ester Higueras García } \\
\text { Francisco José Lamiquiz } \\
\text { Julio Pozueta } \\
\text { Fernando Roch Peña } \\
\text { Felipe Colavidas } \\
\text { Luis Moya } \\
\text { José María Ezquiaga }
\end{gathered}
$$

Llanos Masiá avier Ruiz Sánche Carlos Verdaguer Enrique Villa Polo Carmen Andrés Mateo Álvaro Sevilla

ENTIDADES COLABORADORAS: Q Cilur] =urban

CONTACTO: masterplaneamiento.arquitectura@upm.es www.aq.upm.es/Departamentos/Urbanismo/masters/index.html 


\section{ALGUNAS DE LAS ACTIVIDADES REALIZADAS DURANTE EL CURSO 2014/15...}
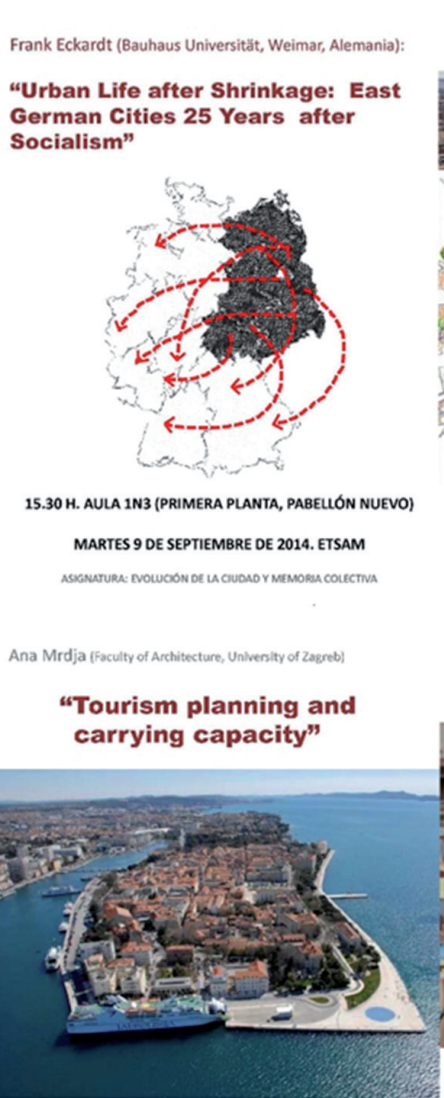

11.30 H. SALA DE GRADOS B (PABELLÓN ANTIGUO) JUEVES 18 DE SEPTIEMBRE DE 2014. ETSAM

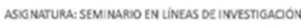

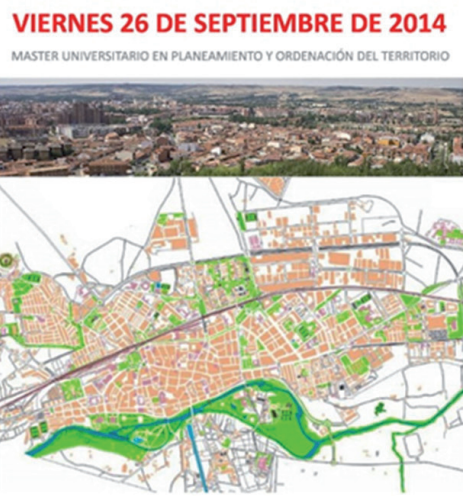

"Visita a la ciudad de Palencia"

RECEPCION EN LL AYUNTAMIENTO Y PASEO POR LA CIUDAO Y SUS BARRIOS

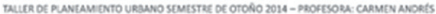

MIÉRCOLES 11 DE FEBRERO DE 2015. ETSAM MASTER UNVERSTIARIO EN PLANEAM ENIO Y OROERACÓN OEL TERRIORIO

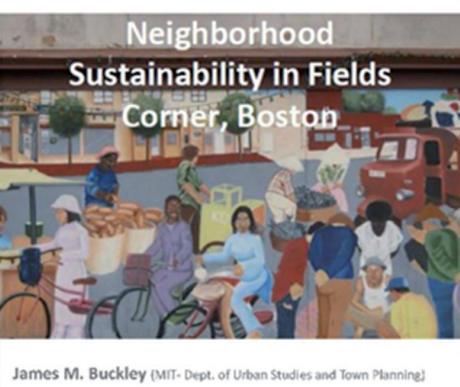

"Urban regeneration in USA" 11.30 H. AULA 1N3 (AULA MÁSTER) MRUGURACON ACCOEMICA DEL SEGUNDO SEMESTRE DEL MESTSR
José Fariña Tojo (Costedratico UPM, Duvor) Luis Felipe Alonso Teixidor (Catedratico "Ad Honorem" UPM, Dupon Ramón López de Luclo (Cotodrático "Ad Honorem" upM, DU,or)

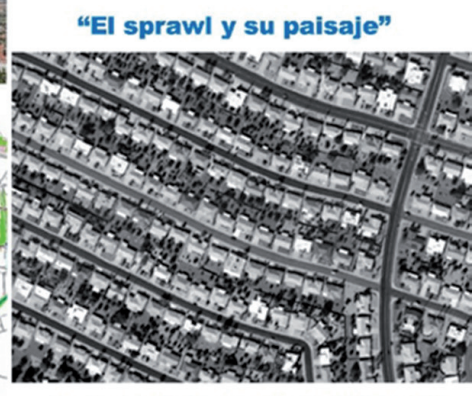

11.30 H. SALA DE GRADOS B (PABELOÓN ANTIGUO) JUEVES 9 DE OCTUBRE DE 2014. ETSAM

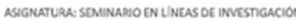
NASTER UN NERSTARO IN D ANFAMEFTO Y OROFNACDN OEL TTRRTORO

MIÉRCOLES 5 DE NOVIEMBRE DE 2014. ETSAM MUSTER UNVERSTINRO EN PLANEAMIENTO Y ORDERMCON DEL TERR TORIO

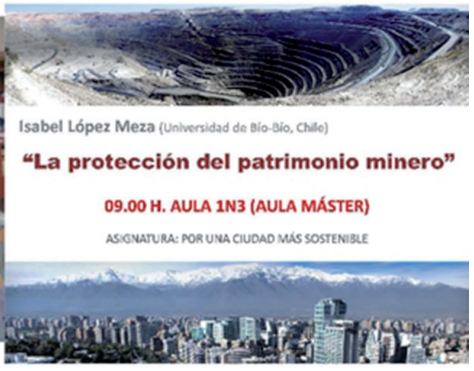

Mario Torres Jofré \{Univensidad de Chile)

"La ciudad contemporánea. Una perspectiva crítica"

16.00 H. AULA 1N3 (AULA MASTER)

VIERNES 27 DE FEBRERO DE 2015 JUEVES 19 DE MARZO DE 2015 MIÉRCOLES 25 DE MARZO DE 2015

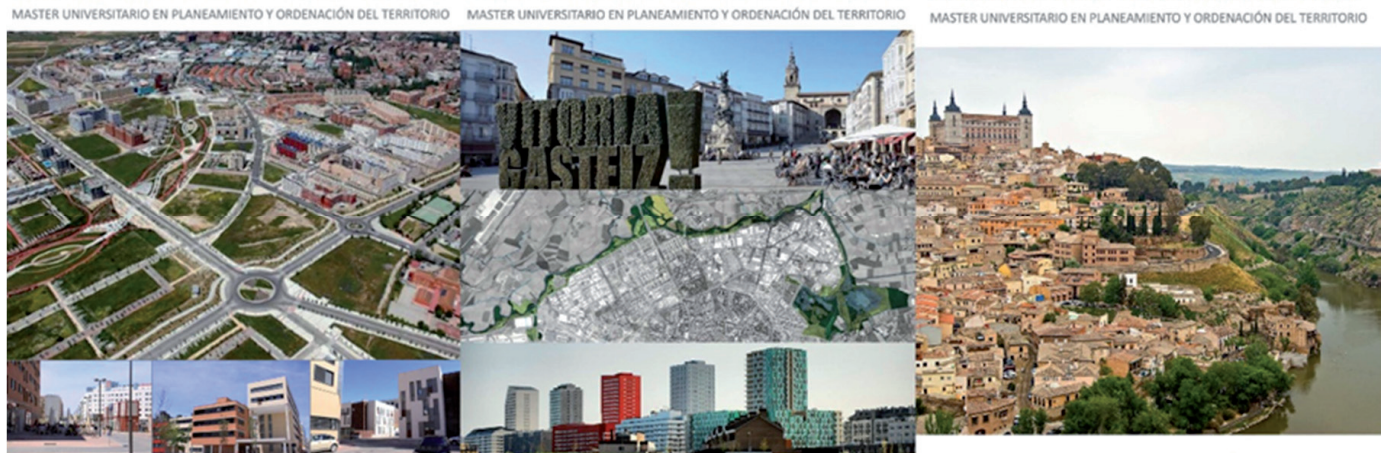

"Visita a Móstoles Sur (Madrid)"

15.30 H. METRO MANUELA MALASAÑA (METROSUR)
"Visita a Vitoria-Gasteiz"

12.00 H. PLAZA DE LA VIRGEN BLANCA (CENTRO)
"Visita a Toledo"

16.00 H. PLAZA DE ZOCODOVER (CENTRO)

JOINT WORKSHOP - SPRING 2015 - EVOLVING CTIIES

(1) (1) DUyOT 
Otros medios divulgativos del Departamento de Urbanística y Ordenación del Territorio:

\section{urbain}

ReVISTA del Departamento de URBanística y ORDENACIÓN del TERRITORIO ESCUELA TÉCNICA SUPERIOR DE ARQUITECTURA

\section{PRESENTACión SEGUNDA ÉPOCA}

DESDE el año 1997, URBAN ha sido vehículo de expresión de la reflexión urbanística más innovadora en España y lugar de encuentro entre profesionales y académicos de todo el mundo. Durante su primera época la revista ha combinado el interés por los resultados de la investigación con la atención a la práctica profesional, especialmente en el ámbito español y la región madrileña. Sin abandonar dicha vocación de saber aplicado y localizado, la segunda época se centra en el progreso de las políticas urbanas y territoriales y la investigación científica a nivel internacional. Ayer y hoy, nuestro objetivo es contribuir al desarrollo de las técnicas y modelos de ciudad y territorio, desde una perspectiva crítica y conjugando las ventajas de nuestra posición en la encrucijada entre el Norte y el Sur globales, entre Europa, el Mediterráneo y Latinoamérica.

Apoyándose en cuatro vectores de interés -carácter generalista y transversal, espíritu crítico, visión regional de los procesos globales y recuperación de la memoria de la disciplina- la nueva URBAN se propone servir de espacio para un debate en el que la planificación se juegue sus condiciones de posibilidad. Frente a la deriva disciplinar de las últimas décadas, frente al desplazamiento paulatino del lugar social de la planificación urbana y territorial en los modos de gobierno, nos parece urgente replantear el papel que ésta merece en las economías políticas de la producción de espacio.

\section{CONVOCATORIA PARA LA RECEPCIÓN DE ARTÍCULOS: nº8- Teoría urbana. Estados del arte}

Sin una teoría urbana consistente nunca habrá buen urbanismo. Este problemático aforismo podría servir para abrir el debate que la revista Urban se propone albergar en un próximo número especial. La teoría urbana (teoría de la ciudad, teoría del proceso urbanizador) ha presentado una relación histórica compleja con la práctica de la planificación y las políticas de la ciudad y el territorio: anticipación de mundos más o menos felices, re-conocimiento pericial de fenómenos urbanos ya materializados, interpretación crítica que re-imagina el pasado y el presente de la ciudad y el territorio, abriéndolos a un nuevo horizonte... El trabajo teórico es, qué duda cabe, un indicador efectivo de la salud y orientación de la disciplina urbanística pero ¿es también un arma cargada de futuro? ¿Cabe aún idear teorías capaces de cambiar los hechos de un mundo urbano que se presenta cada vez más complejo, abigarrado y ajeno a cualquier indicio de racionalidad? ¿Debe la teoría conformarse, por el contrario, con adoptar una actitud de 'testigo modesto', buscar producciones de sentido en los intersticios de los discursos urbanos dominantes? ¿Qué perspectivas teóricas debemos perseguir, con qué herramientas conceptuales y en qué marcos intelectuales? ¿Cómo debe la teoría pensar su articulación con la práctica? ¿Qué tipo de teoría demanda nuestro mundo urbano en un contexto de crisis global? ¿En qué medida los ensayos por comprender la crisis pueden contribuir a ensanchar el campo teórico del fenómeno urbano?

Este número especial de la revista Urban pretende albergar aportaciones internacionales que exploren sistemática y críticamente los estados del arte en los distintos campos de la teoría urbana y los conecten a las tendencias más amplias de la teoría social contemporánea - de la planificación a la geografía, de la sociología a la historia y más allá, en el horizonte general del conocimiento técnico, las ciencias sociales y las humanidades. Serán especialmente bienvenidas las contribuciones que analicen corrientes actuales de reflexión sobre las intersecciones de ciudad, economía, sociedad, política, cultura, tecnología, naturaleza, medio ambiente, diseño, instituciones... Asimismo se espera que los autores consideren y problematicen la articulación entre teoría y práctica urbanística, recordando que 'la experiencia sin teoría es ciega, pero también que la teoría sin experiencia es un mero juego intelectual'. En definitiva ¿cómo puede contribuir la teoría urbana a cambiar no sólo el conocimiento y discurso sobre la ciudad, sino también los propios procesos que la sostienen y transforman? ¿Enfrenta el urbanismo un horizonte de 'miseria de la teoría' o, por el contrario, cabe imaginar un futuro floreciente y un lugar propio para la teoría urbana en el campo más amplio de la teoría social? 
Urban mantiene abierta una convocatoria permanente para la remisión de artículos de temática relacionada con los objetivos de la revista: Para más información:

http://www2.aq.upm.es/Departamentos/Urbanismo/institucional/publicaciones/urban/ns/instrucciones-para-autores/

Por último, se recuerda que, aunque La revista URBAN organiza sus números de manera monográfica mediante convocatorias temáticas, simultáneamente, mantiene siempre abierta de forma contínua una convocatoria para artículos de temática libre.

\section{DATOS DE CONTACTO}

Envío de manuscritos y originales a la atención de Javier Ruiz Sánchez: urban.arquitectura@upm.es Página web: http://www.aq.upm.es/Departamentos/Urbanismo/public/urban/info.html

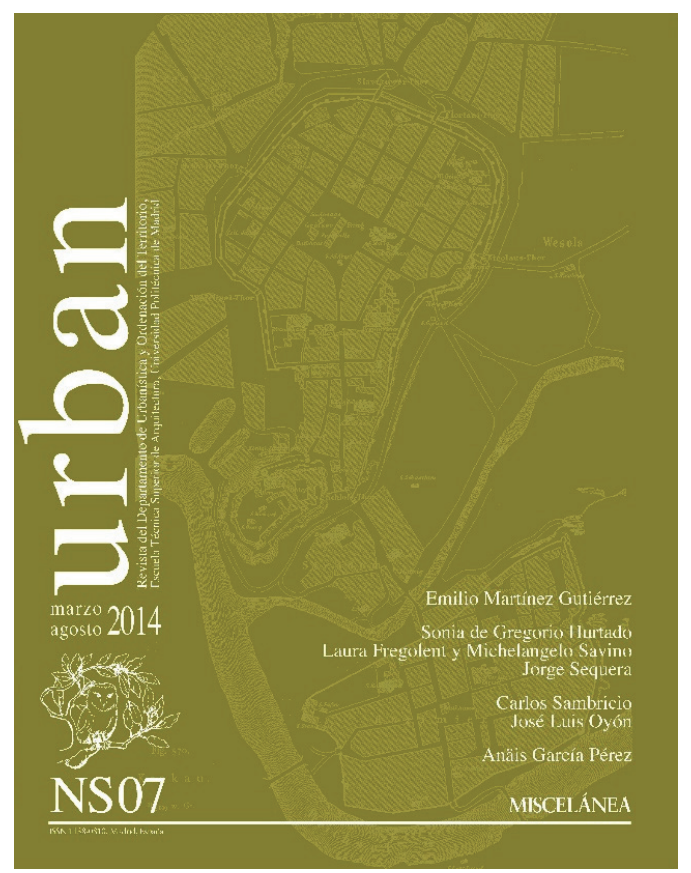

Consulta y pedido de ejemplares: ciur.urbanismo.arquitectura@upm.es

Web del Departamento de Urbanística y ordenación del Territorio: http://www.aq.upm.es/Departamentos/Urbanismo

Donde figuran todas las actividades docentes, divulgativas y de investigación que se realizan en el Departamento con una actualización permanente de sus contenidos. 